\title{
Reference Samples in Geology And Geochemistry
}

\section{U.S. GEOLOGICAL SURVEY BULLETIN 1582}





\section{Reference Samples in Geology And Geochemistry}

By F. J. FLANAGAN

The report discusses some history of analytical problems that resulted in early standards. Geologic samples of economic interest and general information are discussed by country of origin, whereas geochemical samples are mentioned by samples types and by their intended use. Numerous topics and problems for reference samples and their data are discussed. 


\title{
DEPARTMENT OF THE INTERIOR DONALD PAUL HODEL, Secretary
}

\section{U.S. GEOLOGICAL SURVEY}

\author{
Dallas L. Peck, Director
}

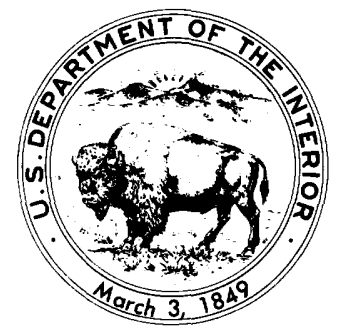

For sale by the Distribution Branch, U.S. Geological Survey, 604 South Pickett Street, Alexandria, VA 22304

Library of Congress Cataloging-in-Publication Data

Flanagan, F.J. (Francis James), 1915-

Reference samples in geology and geochemistry.

(U.S. Geological Survey bulletin ; 1582)

Bibliography: p. 56

Supt. of Docs. no.: I 19.3:1582

1. Rocks-Composition. 2. Mineralogy, Determina-

tive. 3. Sediments (Geology)-Composition.

I. Title. II. Series.

QE75.B9 no. 1582 [QE438] $\begin{array}{cc}557.3 \mathrm{~s} & 85-600274 \\ {\left[552^{\prime} .06\right]} & \end{array}$ 


\section{CONTENTS}

Abstract 1

Introduction and historical review $\mathbf{1}$

Analysis of natural materials and mixtures 2

Zinc ores 4

Products made from ores 4

1901 and precursors of geochemical standards 5

Uniformity in rock analysis 6

Plant pest control regulations 6

Sources of information on reference samples 7

Samples for geology and geochemistry 8

Artificial samples $\mathbf{8}$

Solutions 8

Solid chemicals 8

Mixtures of natural materials $\mathbf{8}$

Glass samples for major and minor elements 8

Glass samples for trace elements 9

Dust and particulate samples 9

Gelatin samples 10

Implantation, dip, and urea samples $\mathbf{1 0}$

Resin and polymer samples $\mathbf{1 0}$

Silica gel samples $\mathbf{1 0}$

Sludge ash sample $\mathbf{1 0}$

Waste incineration ash 11

General synthetic samples 11

Natural samples of economic interest 11

United States 11

Great Britain 11

France 12

Germany 12

Canada 12

South Africa 12

CMEA Countries 12

Czechoslovakia 12

German Democratic Republic 13

Poland 13

U.S.S.R. 13

Austria 14

BCR (Community Bureau of Reference, Brussels) 14

Brazil 15

Japan 15

People's Republic of China $\mathbf{1 5}$

Scandinavia 16

Natural samples of geologic interest 16

Geological and geochemical samples 16

Geochemical exploration samples 17

Archaeology 17

Bauxite 17

Clays and clay minerals 17

Coals, coal ash, and cokes 18

Counting standards 18

Laterites 18

Meteorites 18

Minerals 19

General 19 
Samples for geology and geochemistry-Continued

Natural samples of geologic interest-Continued

Minerals-Continued

For microprobe 19

For age determinations

Phosphates 19

Sediments 19

Bay (Estuarine) 19

Canal (River) 20

Lake 20

Marine 20

Pond 20

River (Radioactivity) 20

Soils 20

General 20

Low-level radioactivity $\mathbf{2 0}$

"Natural matrix" vs. spiked samples for radioactivity $\mathbf{2 0}$

Stable isotope $\mathbf{2 1}$

Geobotanical samples 22

Topics and problems for reference samples and their data 23

Reasons for reference samples $\mathbf{2 3}$

Amount of a rock reference sample $\mathbf{2 4}$

Reference samples vs. in-house standards $\mathbf{2 5}$

Comminution and grindability 25

Homogeneity, sampling errors, and the sample for analysis $\mathbf{2 5}$

Small samples-Precautions and preparation 28

Excess grinding and the $\mathrm{FeO}$ contents of rocks $\mathbf{3 0}$

Large samples-Precautions and preparation $\mathbf{3 0}$

Sieving 32

Contamination by steel 33

Homogeneity of reference samples 33

Outliers 35

Estimation of best values 36

Certification factor $\mathbf{3 7}$

Nomenclature for reference samples $\mathbf{3 7}$

Are "best values" best? 38

Confidence limits for a single datum $\mathbf{3 9}$

Comparisons of data $\mathbf{4 0}$

The analyst and the producer $\mathbf{4 1}$

Reference samples identified through $1984 \quad 41$

References cited 56

FIGURES

1. Plot of the free iron $\left(\mathrm{Fe}^{0}\right)$ contents of some reference samples determined by two chemical methods 33

2. Confidence limits for a calibration line 39

3. Confidence rectangles for assigning points $x, y$ to rock fields $\mathbf{4 0}$

TABLES

1. $\mathrm{K}_{2} \mathrm{O}$ in commercial fertilizers, determined by the chloroplatinate method 2

2. $\mathrm{K}_{2} \mathrm{O}$ in commercial fertilizers, determined by variations of the chloroplatinate method 3

3. $\mathrm{K}_{2} \mathrm{O}$ determined by the Association-recommended method $\mathbf{3}$

4. Summary of methods relating sampling, errors, and particle size $\mathbf{2 8}$

5. Reference samples 42

6. Suppliers of reference samples $\mathbf{5 5}$ 


\title{
Reference Samples in Geology and Geochemistry
}

\author{
By F. J. Flanagan
}

\section{Abstract}

The use of geologic reference samples may have started in the last quarter of the 19th century after analysts in England, Germany, and the United States deplored the large variation in data obtained by different analysts for the same constitutent in the same sample. Early samples involved in cooperative analysis, also known as "round robins," were mainly industrial or agricultural materials of economic value, or products derived from them. Data from some round robins were so diverse that "uniformity in analysis" was a part of early committee names. The first two geologic samples of the National Bureau of Standards were analyzed cooperatively.

Samples for geology and geochemistry are classified as artificial samples or as natural materials of either economic or geochemical interest - the latter distinction not always possible. Artificial samples have been prepared in several substrates, and samples in other substrates may be limited only by the ingenuity of the analyst.

The principal suppliers of samples of economic interest are discussed, by country, to show the range of samples prepared by organizations. Natural samples of geochemical interest are mentioned by sample type. Because of their intended use, some geochemical samples are restricted to analysts using specific techniques.

Methods used for and precautions to be observed while preparing large or small rock samples are discussed. Excess grinding of small rock samples reduces the amount of FeO found in a rock analysis. Unavoidable contamination occurs when processing rocks in steel. Tungsten carbide, and some mechanical equipment, should be avoided. A review of the allied subjects of homogeneity of a sample, sampling errors, and size of the sample grains shows that we have reinvented the wheel since 1885 .

Methods used to (1) test the homogeneity of samples, (2) eliminate outliers which some scientists reject repeatedly despite warnings of statisticians, and (3) estimate best values when the method for estimating should be part of the program for a sample are discussed. Calibration lines may be used to determine if "best values" in a series of several samples are really "best" and to furnish confidence limits for a single datum.

The agreement of data by an analyst for a reference sample with data preferred by an issuing organization is usually described by one of several adjectives, a subjective procedure. $A$ variation of a $x^{2}$ method may be used if a producer specifies the exact number of data for the cooperative analytical program to be furnished by each analyst and then calculates the population estimates of the mean and standard deviation for an element in a sample.
Because of the large increase in the number of reference samples of all types, a revised table listing samples that may be useful in geochemistry is included. It is not known if the samples, other than those of the U.S. Geological Survey, were collected in conformance with provisions of the Plant Pest Control Regulations of the U.S. Department of Agriculture, or of similar organizations in other nations.

\section{INTRODUCTION AND HISTORICAL REVIEW}

Reference samples in geology and geochemistry are now used so widely that many of us take for granted their availability. Yet little more than three decades ago, before the results of a cooperative study on $\mathrm{G}-1$ and $\mathrm{W}-1$ were published (Fairbairn and others, 1951), no reference samples of silicate rocks were available. The rocks in the cooperative study were generally known as granite G-1 and diabase $\mathrm{W}-1$ by those concerned both with the study and with the distribution of the samples, but the two samples were soon promoted by users to the status of "standards." Reasons for this promotion may become evident if we consider why and when samples of geologic materials were first prepared and used.

A search of the chemical and geological literature to determine when geologic reference samples were first used highlights the pertinence of the following remark by Pirsson $(1918$, p. 250) about the rise of petrology: "The beginnings of a particular branch of science are generally obscure and rooted so imperceptibly in the foundations on which it rests that it is difficult to point to any particular place in its development and say that this is the start." Standard samples went through an extended period of incubation, and the greatest hindrance to determining when geologic reference samples were first used has been the several changes in nomenclature since the last century.

The trend in the last decade has been to refer to such materials as either reference samples, standard reference materials, or certified reference materials, with CRM as the accepted abbreviation for the latter. The term "standard sample" was used perhaps universally during the preceding half century. Prior to that, Hillebrand (1909), shortly after he transferred from the U.S. Geological Survey to the National Bureau of Standards, published the short note "The Bureau of Standards' Analyzed Samples," but in the following year [National] Bureau of Standards (1910) Circular 25 
had the title "Standard Analyzed Samples-General Information."

Until this time (1909-10), samples of geologic materials that had been well analyzed during cooperative analyses were known by such simple terms as raw cement mixture (one sample was a mixture of two limestones), argillaceous limestone, or zinc ore, without such modifiers as "standard" or "analyzed." In England over half a centruy ago, steel samples were known, as they are today, as chemical standards-defined as "samples in suitable condition for analysis which have been already analytically standardized and are taken as having a definite recognized composition" (Ridsdale and Ridsdale, 1919, p. 15T).

\section{Analysis of Natural Materials and Mixtures}

Analysts of almost a century ago faced one problem that is still with us-the variation in data obtained by analysts determining the same constituent in presumably the same sample was unacceptably large. Many problems then concerned industrial or agricultural materials. The Potash Committee of the Association of Official Agricultural Chemists (AOAC) may have been among the first to distribute samples for analysis that were test samples but might be considered standard samples of either rocks, minerals, or ores, if one is allowed to define "standard sample" very loosely.

Agricultural chemical work in the United States at that time (1880) was described by H.W. Wiley as "chaotic" (Bogert, 1908, p. 174). Agricultural commissioners and chemists met in 1880 to secure uniformity in analytical methods and formed a division of the chemistry subsection of the American Association for the Advancement of Science. The division existed for 4 years before the independent AOAC was formed on September 9, 1884.

The chairman of the Potash Committee, the aforementioned H.W. Wiley, sent to members of the AOAC (Dabney, 1885) samples of six fertilizers containing potash. The set contained a commercial kainite (a mineral with the formula $\mathrm{MgSO}_{4} \cdot \mathrm{KCl} \cdot 3 \mathrm{H}_{2} \mathrm{O}$ ), a commercial high-grade phosphate with nitrate of potash, a commercial superphosphate, and three other samples of mixtures that were used as fertilizers. Of these, only the kainite may be considered a geologic sample. No details of the samples were given in the letter of transmittal, but Wiley noted that "the greatest care has been taken to secure uniformity in the samples sent out."

The data, obtained in four laboratories by eight chemists, are given in tables 1 and 2 . Table 1 contains data obtained by the chloroplatinate method recommended by the Potash Committee at a meeting of the AOAC in Philadelphia in 1884 , and table 2 contains data obtained by slight variations of the method. The high and low values for each sample are indicated; in both tables, kainite is sample 1 .

Analyst $\mathrm{E}$ in table 1 obtained the highest data for five of the six samples, and analysts $\mathrm{F}$ and $\mathrm{H}$ each obtained lowest values for two samples. In table 2 , analyst $\mathrm{C}$ determined three highest values and analyst $G^{\prime}$ two, whereas analysts B and $B^{\prime}$ each furnished two lowest values. Of greater importance are the higher means for five samples determined by the method recommended by the AOAC and the wider ranges of data by the same method with variations introduced by the analysts.

In the following year another set of six samples, identified by number only, was sent by W.J. Gascoyne, then chairman of the Potash Committee. The report was published by Richardson (1886), who described the samples as (1) potassium sulfate, C.P., (2) commercial kainite, and (3-6) acid phosphates to which apparently had been added potassium sulfate and other salts so that the four samples had different $\mathrm{K}_{2} \mathrm{O}$ contents. The data are given in table 3 .

There is less variation in these data than in those in tables 1 and 2, except for the large range for the kainite data (sample 2). The low value of 12.06 percent by analyst $L$ for the kainite accounts for 0.80 of the range of 3.40 percent, the high value of 15.46 by analyst $K$ accounts for another 1.81 percent, and the range, when these high and low values are removed, is a modest 0.79 percent. Analyst I had the dubious distinction of reporting the highest data for four samples, and analyst $L$, the lowest data for four samples.

The analysis of phosphate rocks continued to be a problem for the fertilizer industry, and the committee on the

Table 1. $\mathrm{K}_{2} \mathrm{O}$ in commercial fertilizers, determined by the chloroplatinate method [In weight percent. $\mathrm{H}$, high value; $\mathrm{L}$, low value]

\begin{tabular}{|c|c|c|c|c|c|c|}
\hline \multirow[b]{2}{*}{ Analyst } & \multicolumn{6}{|c|}{ Sample } \\
\hline & 1 & 2 & 3 & 4 & 5 & 6 \\
\hline \multicolumn{2}{|c|}{ D 12.81} & 4.01 & $2.24 \mathrm{~L}$ & 2.46 & 3.20 & 3.54 \\
\hline \multicolumn{2}{|c|}{$\mathrm{E}-13.58 \mathrm{H}$} & $4.64 \mathrm{H}$ & $2.58 \mathrm{H}$ & 2.66 & $3.23 \mathrm{H}$ & $3.58 \mathrm{H}$ \\
\hline \multicolumn{2}{|c|}{ F $\ldots 12.04 \mathrm{~L}$} & $3.98 \mathrm{~L}$ & 2.32 & 2.64 & 2.90 & 3.38 \\
\hline \multicolumn{2}{|c|}{ G $\ldots \ldots-12.44$} & 4.24 & 2.37 & $2.74 \mathrm{H}$ & $2.80 \mathrm{~L}$ & 3.38 \\
\hline \multicolumn{2}{|c|}{ H } & 4.33 & 2.26 & $2.41 \mathrm{~L}$ & 2.99 & $3.34 \mathrm{~L}$ \\
\hline \multicolumn{2}{|c|}{ Mean - - 12.85} & 4.24 & 2.35 & 2.58 & 3.02 & 3.44 \\
\hline \multicolumn{2}{|c|}{ Range $\ldots \ldots$} & .66 & .34 & .33 & .43 & .24 \\
\hline
\end{tabular}


Table 2. $\mathrm{K}_{2} \mathrm{O}$ in commercial fertilizers, determined by variations of the chloroplatinate method [In weight percent. $\mathrm{H}$, high value; $\mathrm{L}$, low value]

\begin{tabular}{|c|c|c|c|c|c|c|}
\hline \multirow[b]{2}{*}{ Analyst } & \multicolumn{6}{|c|}{ Sample } \\
\hline & 1 & 2 & 3 & 4 & 5 & 6 \\
\hline \multicolumn{2}{|c|}{ A $\cdots 13.77$} & 4.21 & 2.03 & 2.38 & 3.07 & $3.27 \mathrm{~L}$ \\
\hline \multicolumn{2}{|c|}{ B $\ldots 12.41$} & 3.61 & $1.68 \mathrm{~L}$ & $2.25 \mathrm{~L}$ & 3.28 & 3.38 \\
\hline \multicolumn{2}{|c|}{$\mathrm{B}^{\prime}-\ldots-12.03 \mathrm{~L}$} & $3.45 \mathrm{~L}$ & 1.76 & 2.27 & 3.23 & 3.47 \\
\hline \multicolumn{2}{|c|}{$\mathrm{C} \ldots \ldots . .14 .24 \mathrm{H}$} & 4.23 & 2.48 & 2.29 & $3.55 \mathrm{H}$ & $3.59 \mathrm{H}$ \\
\hline \multicolumn{2}{|c|}{$F^{\prime}-\ldots$} & 4.21 & 2.34 & $2.74 \mathrm{H}$ & 3.14 & 3.47 \\
\hline \multicolumn{2}{|c|}{$G^{\prime}-\ldots-12.80$} & $4.47 \mathrm{H}$ & $2.54 \mathrm{H}$ & 2.61 & $2.90 \mathrm{~L}$ & 3.38 \\
\hline \multicolumn{2}{|c|}{ Mean - 12.55} & 4.03 & 2.14 & 2.41 & 3.39 & 3.42 \\
\hline \multicolumn{2}{|c|}{ Range - . . 2.21} & 1.02 & 0.86 & .49 & .65 & .32 \\
\hline
\end{tabular}

analysis of phosphate rocks of the National Fertilizer Association published a report by Hagedorn and others (1909). The committee prepared four samples of phosphate rock (Tennessee Brown, Tennessee Blue, South Carolina, and Florida) and submitted portions to chemists of the Association and to analysts who specialized in fertilizer analysis. The object of the study was to determine which methods yielded uniform data so that the methods might be adopted by the Association.

The National Bureau of Standards sample of Tennessee phosphate rock, NBS-56, was issued on February 2, 1934 , with a provisional certificate of analysis. The certificate notes that concordant data were obtained for "soluble iron" by the methods recommended by the Fertilizer Division of the American Chemical Society (Cameron and others, 1915), but that the amount of "soluble alumina" obtained by the methods was more than the total alumina content of the sample. The certificate for a second phosphate rock (Florida Land Pebble), NBS-120, was issued on April 11, 1939.

Among industrial materials submitted to chemists for cooperative analysis was a mixture prepared by Eustis (1883), with the sample made to contain about 50 percent copper and all the impurities ordinarily present in a copper ore. Although the sample was an artificial mixture and not a natural material, the data obtained by 14 analysts ranged from 43.90 to 53.34 percent $\mathrm{Cu}$, presenting a dismal picture of the state of the art in 1883 for determinations of copper in copper ore. Eustis also reported determinations for copper borings (samples obtained by drilling through pig copper), for which the agreement was much better, contrary to his expectations.

At about the same time, there were similar problems in England caused by the diversity of data obtained by

Table 3. $\mathrm{K}_{2} \mathrm{O}$ determined by the Association-recommended method [In weight percent. $\mathrm{H}$, high value; $\mathrm{L}$, low value]

\begin{tabular}{|c|c|c|c|c|c|}
\hline & \multicolumn{5}{|c|}{ Sample } \\
\hline Analyst & 2 & 3 & 4 & 5 & 6 \\
\hline A $-\ldots . .-53.99$ & 12.86 & 2.75 & 3.95 & 3.26 & 2.19 \\
\hline B $\cdots 54.09 \mathrm{H}$ & 13.11 & 2.56 & 3.80 & 2.61 & $1.20 \mathrm{~L}$ \\
\hline C $\ldots \ldots-54.02$ & 13.05 & 2.68 & 3.92 & 3.20 & 2.21 \\
\hline D $\ldots \ldots .76$ & 13.33 & 2.71 & 3.79 & 3.18 & 2.17 \\
\hline E - . 53.88 & 13.42 & 2.71 & 3.75 & 3.07 & 2.19 \\
\hline$F-1.98$ & 13.04 & 2.57 & 3.91 & 3.20 & 2.20 \\
\hline G - & 13.32 & 2.76 & 3.87 & 3.50 & 2.34 \\
\hline H & 13.65 & 2.58 & 3.89 & 3.22 & 2.13 \\
\hline $\mathrm{I} \ldots \ldots \ldots-53.12 \mathrm{~L}$ & 13.43 & $3.10 \mathrm{H}$ & $4.05 \mathrm{H}$ & $3.59 \mathrm{H}$ & $2.62 \mathrm{H}$ \\
\hline $\mathrm{J}-\ldots-58$ & --- & --- & --- & --- & --- \\
\hline K $\cdots-53.33$ & $15.46 \mathrm{H}$ & 2.57 & 3.76 & 2.71 & 2.05 \\
\hline L $\ldots \ldots$ & $12.06 \mathrm{~L}$ & $2.42 \mathrm{~L}$ & $3.40 \mathrm{~L}$ & $1.95 \mathrm{~L}$ & 1.86 \\
\hline Average- - - 53.88 & 13.33 & 2.67 & 3.83 & 3.03 & 2.10 \\
\hline Range $\ldots . . . .97$ & 3.40 & .68 & .65 & 1.64 & 1.42 \\
\hline
\end{tabular}


chemists analyzing the same sample. Carter-Bell (1883, p. 109) wrote:

To the purely scientific man, whose aim is searching after truth, it must be sad to see his practical brethren disagree, and also to think that work, although done by so many, is often worse than useless,

and (p. 110),

It is no use disguising the fact that there has existed, and, unfortunately, does still exist, great discrepancies between the analyses of chemists.

Carter-Bell also recalled (p. 111) a suggestion in 1871 by the president of the Newcastle [England] Chemical Society that researches be instituted to explain the varying results obtained in the examination and valuation of material. The problem may have been universal, as Grossman, a discussant of Carter-Bell's paper, stated (p. 113) that "the German Society of Chemical Industry has recommended certain methods for chemists connected with alkali works."

\section{Zinc Ores}

A committee of the Colorado Scientific Society was appointed to establish uniformity in the technical methods of analysis used in the Western United States, and the committee (Hawkins and others, 1893) reported determinations of zinc in five samples of ore by eight analysts. The data obtained by one analyst, L.G. Eakins of the U.S. Geological Survey, were accepted as the standard to which other data were compared. The minerals of the ore were listed, but other than the notation that the "greatest care [was] taken in the mixing of each large sample, so that uniformity *** might be assured," no information was given. The cooperative determinations apparently did not deplete the supply of the five samples, as the report noted that "the committee will be glad to aid $* * *$ in furnishing requisite material" (p. 191).

In 1903, a subcommittee on zinc ore analysis of the central committee of the New York section of the Society of Chemical Industry (SCI) prepared three samples of zinc ore that were analyzed by 42 chemists. The Committee on Uniformity in Technical Analysis of the American Chemical Society (ACS) summarized (Hillebrand and others, 1904) the past work of the SCI's central committee, including the data for the three zinc ores obtained by the 42 chemists. The committee noted (p. 1651) that

The showing of Tables I to IV is ample demonstration that analytical chemistry, as ordinarily practiced, is anything but an exact branch of the chemical profession.

The subcommittee on zinc ore analysis, then a subcommittee of the ACS Committee on Uniformity in Technical Analysis, published a complete report (Stone and Waring, 1907), including a discussion of the data on the zinc ores. After a brief introduction, they remarked that "the results were very bad"- - a rather mild comment compared with that made by the committee.

\section{Products Made from Ores}

The last quarter of the 19th century was a period of rapid industrial development in the United States, but it was also a time of questioning of analytical data on products of industry because of the variations in data obtained by the same or different chemists. In 1881, Dudley, in an expansion of a study in two related papers presented orally 3 years earlier, tried to relate the contents of carbon, manganese, phosphorus, and silica to physical tests on steel rails for railroads to obtain an index for resistance to wear. The discussants of his papers, among whom were engineers, metallurgists, and steel producers, were reluctant to accept the word of a chemist (even though Dudley was employed by a railroad) on the proposed amounts of these elements necessary for a rail to wear well, and many questioned the state of the art of the determinations of these elements in steel.

In the following year, Kent (1882) published a paper on the determination of manganese in steel, noting in his introduction the doubts of several discussants of Dudley's (1881) paper about the general accuracy of chemical analysis of steel made by "iron-works chemists." He also noted that, since the meeting at which Dudley presented his paper, "the practical value of chemical analyses" had been discussed at some length in the columns of "Iron Age." Kent reported data for a sample of drillings from a steel plate, $6 \times 2 \times 1 / 4$ in, that had been analyzed by 33 chemists. The data obtained by several methods ranged from 1.14 to 0.303 percent $\mathrm{Mn}$. Many papers on determinations of $\mathrm{C}, \mathrm{P}$, $\mathrm{Mn}$, and Si were soon published.

Langley (1891) recalled his 1888 suggestion that a set of steel samples, analyzed with extreme care, could serve as standards, thereby resulting in greater uniformity of analyses. The seven members of the American Committee on International Standards for the Analysis of Iron and Steel met on February 19, 1890, and decided that, rather than begin work on international standards, they should make a preliminary study of methods for determining carbon because of the many discrepancies and differences of opinion. Thereafter, reports of the Committee on International Standards appeared (Langley, 1892, 1893; Langley and Dudley, 1894a, 1894b), as did papers on the need for standard methods by Dudley and Pease (1893) and by Jüptner (1896). Dudley and Pease (1893, p. 502) pointed out that lack of agreement among different chemists working on the same sample "is no new state of affairs."

The accuracy of commercial assays for silver in ores was questioned (Dewey, 1894). Dewey (1896) also discussed the accuracy of chemical analysis, including determinations for (1) manganese and phosphorus in steels, (2) $\mathrm{P}_{2} \mathrm{O}_{5}$ and $\mathrm{KCl}$ in studies by the Association of Official Agricultural Chemists (U.S. Department of Agriculture, Bureau of Chemistry Bulletin 43), and (3) copper, gold, and silver in copper borings and copper matte. The latter study 
had been suggested as a plan of cooperative action by Ledoux (1894), and Raymond (1895), to whom the data were sent at the request of Ledoux, reported the data after describing the preparation and sampling of the matte and the borings.

A proposal for cooperative analyses of a copper slag published in 1901 was followed by a report by Smith (1903) on the chemical analyses by 22 chemists and by W.F. Hillebrand of the U.S. Geological Survey, whose data were used as the standard by which all other data were judged. Hillebrand was also requested to review the data critically. Smith noted that another set of samples would be prepared and that applications would be welcomed, not only from those employed in the copper industry, but from all who were interested in the advance of accurate chemical analysis.

Cement, a product essential to industrial development, was the subject of a continued paper, "The Chemical and Physical Examination of Portland Cement," published by Stillman $(1893,1894)$ in five parts. In spite of the title, the papers were principally devoted to physical testing while reporting the chemical analyses of 11 cements. Later papers in the series (Stillman, 1894) contained references on cement from 1870 to 1892 , but the references were principally concerned with production and testing.

\section{1 and Precursors of Geochemical Standards}

Activity in the analysis of materials for the cement industry increased after the start of the 20th century. As a result of a circular in April 1901, Richardson (1902) published a report of the Society of Chemical Industry's Subcommittee on Uniformity in Analysis of Materials for the Portland Cement Industry. The report described the analyses of two samples by 14 analysts. As he had for other studies, W.F. Hillebrand analyzed the two samples, described as "Sample No. 1. Limestone from Vulcanite, N.J. and Ahnville, Penn., mixed in proper proportions for making Portland cement; Sample No. 2. Finished Portland cement made from material No. 1." The data contained in the tabulations, analyses I and II (Richardson, 1902, p. 14), are analyses by Hillebrand entered in the laboratory recordbook on June 22,1901 . Hillebrand critically reviewed the methods used by the 14 analysts. Richardson concluded the report by a suggested method for analyzing limestone, raw mixture, and Portland cement.

A dissent from proposed standard methods of analysis was soon published by Stanger and Blount (1902). In addition to critically reviewing the second series of analyses of cements, Hillebrand (1903 p. 1207) recommended that

the committee see to the preparation of a large sample of limestone mixture, sufficiently large to last for many years, which could be issued to all applying for it.

Blount (1904) published a method for the analysis of cement. Hillebrand (1905) discussed the condition of analytical chemistry.
The central committee of the New York Section of the Society of Chemical Industry had dissolved and the Council of the American Chemical Society directed the appointment of a new committee to pursue the aims of the former committee of the Society of Chemical Industry. The new committee published (Hillebrand and others, 1904) a summary of past work and listed as its policy the accomplishment of six objectives. In addition to an objective to test the accuracy and suitability of various methods in conjunction with the National Bureau of Standards, the objectives pertinent to standard or reference samples were (p. 1653)

4. To prepare samples of materials of different character whose exact composition shall have been determined by the most careful analyses of experts.

5. To place such samples in the care of the National Bureau of Standards for preservation and distribution to persons desiring to test their methods of analysis or of manipulation, or to check the work of students or technical chemists employed in works.

Two authors of this committee report were employed by the U.S. Geological Survey (USGS) and later by the NBS. H.N. Stokes worked for the USGS from 1889 to 1892 , and from 1984 until he transferred to the NBS in 1903. W.F. Hillebrand joined the USGS in 1880 and founded its first chemical laboratory in Denver, Colo. He worked there and in Washington, D.C., until he transferred in 1908 to the NBS to become its chief chemist, a position he held until his death.

Andrews (1908) published a short note related to objective 5 . He reasoned that, just as the NBS furnished industry with official standards of weight and volume, so also it might furnish chemical standards for industries dependent on chemical processes. He suggested two groups of materials to be standardized: (1) substances to be used for standardizing volumetric solutions, the solutions themselves, or both, and (2) standardized samples of commercial materials by which a manufacturer could control his entire analytical process.

A material that corresponds to our present concept of a reference sample is the argillaceous limestone for which cooperative analyses were reported by Hillebrand, Dudley, Richardson, and Stokes (1906). The sample of about $200 \mathrm{lb}$ was prepared and furnished by the Northhampton Portland Cement Company of Stockerton, Pa.; 94 percent of the powder passed a 200-mesh sieve. Determinations of silica in six small lots taken at intervals from the top to the bottom of the barrel were used to demonstrate the homogeneity of the material. Although preparers of other samples mentioned earlier had assured analysts and readers about the care taken to secure uniformity of their samples, this appears to have been the first sample for which the sampling and the constituent determined as a test for homogeneity were mentioned.

The averaged analysis for the argillaceous limestone in National Bureau of Standards (1910) Circular 25 (and supplements issued later) appears to be the average of data 
obtained by W.F. Hillebrand of the USGS and by C.E. Waters of the NBS that had been previously reported by Hillebrand and others (1906). NBS-2, described as Zinc Ore $\mathrm{D}$, is listed in the circular as having a zinc content of 31.43 percent, and a reference to the report by Stone and Waring (1907) is given. Stone and Waring indicate (p. 264) that a new sample was prepared by grinding together three ores similar to those used earlier (i.e., samples A, B, and C, Hillebrand and others, 1904, p. 1648, 1649), and that this sample, D, was sent out for analysis.

Parenthetically, there are items in NBS Circular 25 and in a more recent source that are of historical interest in determining the beginning of the NBS standard sample program. NBS Circular 25 (p. 5) notes: "In 1905, the committees of the American Chemical Society upon uniformity of technical analysis, and upon zinc ore analysis, assigned their samples to the Bureau of Standards for distribution." In his official history of the National Bureau of Standards, Cochrane (1966, p. 93), when discussing the NBS standard sample program writes: "This began in 1905 when the American Foundrymen's Association turned over to the Bureau its work of preparing and distributing samples of standardized irons to its member industries."

Further history of the standardized irons of the American Foundrymen's Association is given in the 1981-83 edition of the NBS Standard Reference Materials Catalogue, in which the four-page Bureau Circular 11, dated February 1,1906 , is reproduced. The circular briefly describes the four cast irons and the one steel sample and gives the methods of analysis that were used.

\section{Uniformity in Rock Analysis}

Hillebrand (1894) tried to achieve some measure of uniformity when he published a plea for greater completeness in rock analysis. He used as an example an earlier analysis of a rock whose constitutents summed to 99.58 percent without determinations of $\mathrm{TiO}_{2}, \mathrm{Cr}_{2} \mathrm{O}_{3}, \mathrm{MnO}, \mathrm{SrO}$, $\mathrm{BaO}, \mathrm{H}_{2} \mathrm{O}^{-}, \mathrm{P}_{2} \mathrm{O}_{5}, \mathrm{SO}_{3}, \mathrm{~F}$, and $\mathrm{Cl}$, when a later analysis that included the constituents omitted summed to 100.21 percent. Washington (1903, p. 41) classified rock analyses as excellent, good, fair, poor, and bad, depending on their accuracy and completeness. One committee (Richardson, 1902) had the word "uniformity" as part of its title. Ridsdale and Ridsdale (1919) discussed chemical standards in relation to the unification of analysis.

The papers on completeness and on uniformity, and Washington's classification of rock analyses, did not produce a permanent effect. Larsen (1938) found that the chemical analyses of amphiboles and other silicates by presumably competent analysts showed a surprising lack of agreement. He advocated that petrologists check analyses by comparing the norm and the mode, a procedure by which any experienced petrographer can find large errors in the analysis.
The rock analyses of G-1 and W-1 in U.S. Geological Survey Bulletin 980 (Fairbairn and others, 1951) shocked the geologic community sufficiently that improvements in rock analysis could be noted in later reports on these and other rock standards. Determinations of trace elements, principally the domain of optical emission spectroscopists three decades ago, are now being made by a variety of physical and chemical techniques. Many trace element data still leave much to be desired, if one can judge the data by forming ratios of several pairs of elements.

\section{Plant Pest Control Regulations}

Plant pest control regulations have existed in the United States since the Plant Quarantine Act of 1912 and the Federal Plant Pest Act of 1957. Canada is said to have regulations similar to those of the United States, and other nations may have their own restrictions. Some States in the United States may also have local regulations.

The plant pest control regulations of the U.S. Department of Agriculture apply to all naturally occurring samples, but not to synthetic samples. One scarcely, if ever, finds these regulations, or their foreign equivalents, mentioned in the literature on reference samples. The U.S. regulations apply both to samples obtained in the United States and to those that are imported.

The regulations cover the importation of plants, rocks, soils, and perhaps laterites into the United States and the interstate shipment of these materials among the several States. The quarantine is intended to prevent the introduction of the Imported Fire Ant, Japanese Beetle, Gypsy Moth, Browntail Moth, Whitefringed Beetle, Witchweed, Golden Nemathode, Burrowing Nematode, and Soybean Cyst Nematode into areas currently uninfested.

One may safely assume that the 12 soil samples in Barnhisel (1978) were collected in conformance with the regulations, as many collaborators were from State agricultural experimental stations. Two authors of the report (Bowman and others, 1979) on four Canadian soils were members of Agriculture Canada. The three soil samples of the six geochemical exploration samples discussed by Allcott and Lakin (1975) were collected by USGS geologists under the provisions of a formal agreement between the USGS and the U.S. Department of Agriculture. This agreement, renewed yearly, has been in effect for more than two decades.

Rock samples are generally examined before entry into the United States is permitted. Thus, the bulk sample of the Icelandic basalt, now USGS-BIR-1, was held in quarantine for more than a week at Norfolk, Va., the port of entry, while the pieces of rock were inspected.

For many soil samples mentioned above, one must assume that the shipment of the large sample and the distribution of smaller portions as reference samples were made in conformance with the plant pest control regulations of the 
U.S. Department of Agriculture (Flanagan, 1975, p. 699). Soil samples and the Department of Agriculture quarantine regulations were mentioned earlier (Flanagan, 1974, p. 1731).

\section{Sources of Information on Reference Samples}

The short list of samples available from the [National] Bureau of Standards (Hillebrand, 1909) appears to have been the first for samples of interest to earth scientists. Silicate rock standards were mentioned by Curtiss and others (1940), who gave the rock names of the 12 samples that were later known as Rock Standards-Radium Rock Samples in National Bureau of Standards Circular 552, 3d ed., (1959).

Taylor and Kolbe (1964) published a short list of sources of standards useful to earth scientists, and three other lists (Flanagan and Gwyn, 1967; Flanagan, 1970, 1974) soon followed. Hague and others (1965) listed sources of standard reference samples, but not all of the 61 sources listed furnished such samples. The guide to U.S. reference materials by Cali and Plebanski (1978) does not mention sources of internationally recognized rock samples under the heading of minerals, ores, and rocks (p. 10).

The most valuable source of information for those in geochemistry is the journal "Geostandards Newsletter," for which volume 1, number 1, appeared in January 1977. The contents of the journal span a wide range of interest, from data on reference samples to announcements of new samples. A recent paper in the journal by Jecko and others (1980) gives the compositions of about 96 iron ore standards and related materials from 12 countries and from the European Coal and Steel Community (ECSC). A column on standards for microprobe work has been a feature of the journal for some time, and recent issues have featured a "GeostandaRef Corner," bibliography of paperscontaining data on geochemical reference samples starting in 1979.

A recent bibliography in "Atomic Spectroscopy" by Lawrence (1980) has a cross index under the heading "Geochemistry," with sections on minerals, ores, rocks, silicates, and others. One occasionally finds lists of standard reference samples such as that of Lontsikh and Parshin (1980). Sobornov (1977) has determined uranium, thorium, and potassium in 14 USSR (domestic) rocks, ores, and concentrates, 9 of which were listed by Lontsikh and Parshin (1980).

The journal "X-Ray Spectrometry" started a section, "Calibration Standards," in 1977 (v. 6, no. 3, p. 171), and such sections were published occasionally until what appears to be the final column in 1979 (v. 8, no. 3, p. 140). These sections briefly discuss standards that are available from commercial and government sources. The volume, number, page, and year of the issue of the journal in which these calibration standards sources appeared are listed below. v. 6, no. 3, p. 171 (1977), Columbia Scientific Industries ${ }^{1}$

v. 6, no. 4, p. 218 (1977), Brammer Standard Company, Inc. which, in addition to its own standards, distributes samples from (1) Iron and Steel Institute of Japan, (2) Bureau of Analysed Samples, Ltd, (3) CTIF (Centre Technique des Industries de la Fonderie), (4) IRSID (Institut de Recherches de la Sidérurgie), (5) BAM (Bundesanstalt für Materialprüfung), (6) British Non-Ferrous Metals Research Association, (7) Henry Wiggin \& Co., Ltd. (England), (8) International Alloys Ltd. (England), (9) G.L. Willan Ltd. (England), (10) Zinc et Alliages (France), and (11) Alpha Resources, Inc. (see later section on "Coals, Coal Ash, and Cokes").

v. 7, no. 1, p. 44 (1978), BNF Metals Technology Centre (formerly British Non-Ferrous Metals Research Association)

v. 7, no. 3, p. 174 (1978), MBH Analytical Ltd.

v. 7 , no. 2, p. 99 (1978), a reprinting of Abbey (1977a)

v. 7, no. 4, p. 249 (1978), U. S. Department of Energy, New Brunswick Laboratory (see later section on "Counting Standards").

v. 8, no. 3, p. 140 (1979), Bureau of Analysed Samples, Ltd. (see later section on "Great Britain").

Another journal, "American Laboratory," started a column on reference materials in the June 1980 (v. 12, no. 6) issue. A companion journal, "International Laboratory," published by the same organization, has not contained a similar column on reference materials.

"Pure and Applied Chemistry" occasionally publishes information on reference samples. Koch (1978) published a two-part paper on standard reference materials for trace analysis. He lists a number of ores and other reference materials in part 2, as well as the names and addresses of suppliers. Steinnes (1981) listed compositions he derived from the available data for the rocks described in USGS Professional Paper 840 (Flanagan, 1976b). Wainerdi (1979) published a similar report for Bowen's kale (Bowen, 1967).

The International Organization for Standardization (ISO) published its first edition of the ISO Directory of Certified Reference Materials in 1982. The directory lists certified reference materials in 17 classes, of which the categories of (1) geology, (2) environmental, (3) glasses, ceramics, and refractories, and (4) biological, botanical, and foods may contain samples applicable to the general fields of geology and geochemistry.

The ISO Directory mentions certified reference materials only in general terms and does not identify specific samples. The categories and general types of samples in table 1 are coded to the names and addresses of suppliers in table 2 . Thus, the interested user must obtain a catalog or list of samples from a supplier before determining if the supplier has a specific sample.

There are undoubtedly lists of reference samples that have not been published. One such list by John Winter (Freer Gallery of Art, Smithsonian Institution, Washington, DC, 20560) was titled "Sources of Reference Materials for Museum Laboratories" and was distributed at the 5th Triennial Meeting of the ICOM (International Council of Museums) Committee for Conservation, Zagreb, Yugoslavia, 1978. Sources are identified for such materials as rocks,

\footnotetext{
${ }^{1}$ Company names and trade names are used for identification only and do not constitute endorsement by the U.S. Geological Survey.
} 
ores, minerals, metals and alloys, and glasses, and for standards for x-ray microanalysis, Munsell color, pigments, fibers, woods, and particles of known size.

\section{SAMPLES FOR GEOLOGY AND GEOCHEMISTRY}

Reference samples for determinations of elements in geologic samples represent a variety of materials. Many reference samples are recognized internationally, while others have been prepared as "in-house" standards for use with a limited distribution. Other samples were used in studies of the accuracy or precision of ore analysis. The samples differ widely in composition and in the purpose for which they were prepared. A convenient general classification for these materials is as follows:

Artificial

- Mixtures of chemicals as solutions or solids

- Mixtures of natural materials

- Glasses for major, minor, and trace elements

- Samples made with other substrates

Natural

- Samples of economic interest

- Samples of geologic and geochemical interest

- Samples for geochemical exploration

- Minerals for several purposes

- Isotopic samples

- Sediments, soils, laterites, and miscellaneous samples

\section{Artificial Samples}

\section{Solutions}

Solutions of one or more chemicals, still needed for many methods, have been used to prepare standards for thin-film x-ray fluorescence analysis. Thus, Champion and others (1966) prepared a strontium standard of $250 \mu \mathrm{g}$ per gram by dissolving analytical reagent grade $\mathrm{SrCO}_{3}$ in dilute $\mathrm{HNO}_{3}$ and making to volume with water. They then used aliquots of the solution for the $\mathrm{x}$-ray fluorescence determination of $\mathrm{Sr}$ in biological and geological samples, including G-1 and $\mathrm{W}-1$.

One commercial company, Columbia Scientific Industries (see "X-Ray Spectrometry," 1977, v. 6, no. 3, p. 171), micropipettes aliquots of solutions of one or more elements onto a cellulose fiber or a cellulose membrane filter and dries the solutions for use in thin-film $\mathrm{x}$-ray work. The company also furnishes, either as dried solutions or as particulate deposits, standard reference strips for the analysis of air particulates.

\section{Solid Chemicals}

$\mathrm{X}$-ray spectroscopists frequently use mixtures of pure chemicals as standards for determinations of major, minor, and trace elements. Mixtures of solids have been used in optical emission spectroscopy. Bastron and others (1960) described the preparation of such standards for quantitative spectrochemical analysis, and Myers and others (1961) prepared similar samples for semiquantitative analysis. Both sets of standards for emission spectroscopy could be classified as mixtures of chemicals and natural materials. The major component of the two sets of standards is a feldspar selected for its high purity and for the absence of specific trace elements. Trace elements as pure oxides were then mixed with the feldspar.

Knott, Mills, and Belcher (1978) prepared synthetic standards and listed the compositions of 3 base standards and of 10 iron ore calibration standards. They advocate the use of synthetic calibration standards for optical emission and $\mathrm{x}$-ray fluorescence analysis.

\section{Mixtures of Natural Materials}

Mixtures have been used for various techniques, both as small portions for a specific purpose in a laboratory and as a large reference sample for wide distribution. A 50 percent mixture of G-1 and W-1 was used by Rose, Adler, and Flanagan (1963) to furnish an additional calibration point for oxides for the $\mathrm{x}$-ray fluorescence analysis of rocks. Because of the increase in the number of rock reference samples in the last two decades, a seemingly infinite number of mixtures in varying proportions can now be prepared by an analyst.

One large Canadian sample, CCRMP-SY-3, is a mixture of natural materials. Faye and Sutarno (1976) note that a batch of syenite from the same source as SY-2 was ground autogenously with lumps of a concentrate containing uraninite, allanite, and betafite and that this material was coded as SY-3.

The procedure of preparing a rock reference sample by adding concentrates of heavy minerals can be dangerous. Because of differences between the specific gravities of the rock (syenite, 2.6-2.7) and of the minerals (allanite, 3.0 4.2; betafite, $\sim 4$; uraninite, massive, 6.4 and greater), the minerals may separate if the sample is stored in a laboratory subject to vibration. If an analyst does not thoroughly mix the contents of a bottle before sampling, heterogeneous data may be obtained.

Data were reported by Lister and Gallagher (1970) for the first interlaboratory investigation of accuracy in ore analysis for which all but 2 of the 19 samples were mixtures of an ore and quartz. The samples analyzed for the second series reported by Lister $(1977,1978)$ were ores and concentrates.

\section{Glass Samples for Major and Minor Elements}

Because of the disturbingly large dispersion of data for G-1 and W-1 (Fairbairn and others, 1951), Fairbairn and Schairer (1952) prepared a glass whose composition 
was selected to approximate that of G-1. The amount (92 g) of the synthetic standard was limited, and analysts were selected because of the nearness of their determinations for $\mathrm{G}-1$ and $\mathrm{W}-1$ to the mean values. The precision of the determinations for this silicate mixture, called a haplogranite by Fairbairn and Schairer and, informally, "happy granite" by those associated with it, was scarcely different from the precision obtained by the same analysts for $\mathrm{G}-1$. The supply of the glass was soon exhausted.

Heidel (1971) used a glass standard in the electron probe analysis of lunar glass spheres. Smellie (1972) prepared nine glasses as electron probe standards for which he varied the percentage of $\mathrm{SiO}_{2}, \mathrm{TiO}_{2}, \mathrm{Al}_{2} \mathrm{O}_{3}, \mathrm{Fe}_{2} \mathrm{O}_{3}, \mathrm{MgO}$, $\mathrm{MnO}$, and $\mathrm{CaO} . \mathrm{Na}_{2} \mathrm{O}$ was not included as a constituent because of its erratic behavior under electron bombardment, and $\mathrm{K}_{2} \mathrm{O}$ was omitted because glasses containing 8 to 10 percent $\mathrm{K}_{2} \mathrm{O}$ showed unacceptable heterogeneity. Smellie and others (1978) prepared six glasses for microprobe use. The basic flux consisted of $\mathrm{SiO}_{2}, \mathrm{Al}_{2} \mathrm{O}_{3}$, and $\mathrm{CaO}$, and the sums of these oxides amounted to 85,95 , and 99 percent for two sets of three samples each. They added approximately 15,5 , and 1 percent of $\mathrm{U}_{3} \mathrm{O}_{8}$ to one set of three samples and similar amounts of $\mathrm{ThO}_{2}$ to the other three samples.

The Society of Glass Technology (1980) listed the compositions of six standard glasses and of five glass sands.

\section{Glass Samples for Trace Elements}

Glasses were prepared for trace element analysis and for determinations of rare earths. Both the National Bureau of Standards (NBS) and the U.S. Geological Survey (USGS) had melts of a glass prepared by Corning Glass Works, and amounts of a large number of trace elements were added to result in samples with trace elements present at four concentration levels.

The processing of the NBS samples from 100kilogram batches to 1- or 3-millimeter-thick slices of the glass canes has been described by Barnes and others (1973). They also present data obtained by isotope dilution mass spectrometry for lead, uranium, thorium, and thallium and note that some radial heterogeneity was observed in the wafers. A single whole wafer is therefore always used as the standard sample, and no subsampling of a wafer is permitted.

The samples for the USGS were prepared similarly, but the glass canes furnished to the USGS were broken and powdered. Preliminary data on the USGS glass samples were reported by Myers and others (1970), and a compilation of data was published (Myers and others, 1976).

A set of four glass standards for determinations of rare earths was prepared by Drake and Weil (1972). These samples, intended for microprobe work, were prepared in small quantities. The rare earths are present at about the 4 percent level, a factor of almost 100 times greater than the highest level in the NBS and USGS samples.
Roche and Govindaraju (1973) reported data for two experimental glasses, VS-1 and VS-2, prepared in small amounts and for a larger sample, ANRT-VS-N. The first experimental glasses were prepared as lots of about $300 \mathrm{gm}$, whereas VS-N was prepared as a lot of about $10 \mathrm{~kg}$. Both VS-2 and VS-N were made from a silicoaluminate glass to approximate the major composition of a phonolite. For the three samples, amounts of trace elements were added to the glasses to obtain a final concentration of $1,000 \mathrm{ppm}$ of the elements expressed as the oxides, with 28 elements being added to the melt for VS-N. Data for nine other elements introduced into VS-N as impurities were also reported. Because of the phonolitic composition of the glass, VS-N might be considered a standard for major, minor, and trace elements, but its use for determinations of the major and minor oxides might soon deplete the amount of sample prepared.

\section{Dust and Particulate Samples}

Hashimoto and others (1976) prepared a homogeneous dust sample, AS-1, for comparisons of data on atmospheric dust samples. The airborne particulate matter was collected on a filter cloth attached to an air inlet of an air conditioning unit on an office building $50 \mathrm{~m}$ high. While those in geology may think of dust as finely powdered rock, the approximate average contents of several elements in the dust indicate that the sampling location may have been downwind from one or more commercial activities.

Jecko and Ridsdale (1978) list certified values for two steel furnace dusts that were prepared to assist in pollution control of dusts discharged into the atmosphere by the iron and steel industries. Steger and others (1981) prepared a nonferrous reference dust, PD-1, from a zinc-copper smelter in Manitoba, Canada. The 200-gram units of the sample were heat-sealed in polyester-aluminum foilpolyethylene laminated pouches to prevent possible oxidation of the sulfide and metallic components of the sample while the portions were stored for future distribution. Recommended values for $\mathrm{Pb}$ ( 2.75 percent), As ( 0.77 percent), and $\mathrm{Hg}(389 \mu \mathrm{g} / \mathrm{g})$ were assigned.

Dust samples are also known as particulate matter. NBS SRM-1648, Urban Particulate Matter, is a sample collected in St. Louis, Mo., in a bag-house especially designed for this purpose. Certified values are given for $\mathrm{Al}$, $\mathrm{Fe}, \mathrm{K}, \mathrm{Pb}, \mathrm{Na}$, and $\mathrm{Zn}$ in percent, and for $\mathrm{As}, \mathrm{Cd}, \mathrm{Cr}, \mathrm{Cu}$, $\mathrm{Ni}, \mathrm{Se}, \mathrm{U}$, and $\mathrm{V}$ in ppm. Values are also listed for 22 major, minor, and trace constituents for which there were insufficient data for certification.

Another urban dust, NBS SRM-1649, was collected in the Washington, D.C., area and is certified for five polycyclic aromatic hydrocarbons. Inorganic data include uncertified values for 5 elements present as minors and for 21 elements present as traces. 


\section{Gelatin Samples}

Anderson and others (1972, 1976) made reference materials with gelatin as the matrix. They first made a series of three samples with mercury at the $1.3,0.12$, and 0.02 ppm levels. They note that the mercury contents remained constant for over a year and that gelatin of photographic quality, stored at room temperature and low relative humidity, remains stable for 10 years or more. They also made a gelatin base standard containing 25 trace elements ranging in concentration from 27 to $62 \mu \mathrm{g} / \mathrm{g}$, and this was analyzed by 11 laboratories. A summary of the test data for this sample, TEG-50A, is given in table 1 of Anderson and others (1976). The company, Eastman Kodak, has since issued two other gelatin multicomponent trace element reference materials, TEG-50-B, with data for 20 elements, and TEG-50-C, with data for 22 elements.

\section{Implantation, Dip, and Urea Samples}

Standards of these types were prepared by Gries and Norval (1975). Implantation standards are made by atomizing and ionizing an element and then accelerating the ions so that they penetrate a matrix. Such standards are limited to trace elements whose mass numbers are greater than those of the matrix element.

Dip standards, used for confirmation of the implantation standards, are made by dipping aluminum foil in an aqueous solution of thallium sulfate. Urea standards are made by dissolving thallium sulfate in melted $\left(140^{\circ} \mathrm{C}\right)$ urea. Diluted standards are made by melting and mixing known quantities of a master standard and pure urea.

Bellon and others (1981) implanted ${ }^{38} \mathrm{Ar}$ ions in an aluminum foil target for use in the determination of radiogenic ${ }^{40} \mathrm{Ar}$ in rocks and minerals. Matus and others (1981) used ion implantation to make low concentration standards for use in spark source mass spectrometry.

$\mathrm{Wu}$ and others (1982) used neutron activation analysis to measure the number of arsenic atoms per square centimeter that were implanted in silicon. Sun and others (1982) studied the implantation of phosphorus in silicon. They used neutron activation analysis to measure the phosphorus, and present two curves to show that the number of phosphorus atoms per square centimeter decreases with depth of penetration from 1,000 to $4,000 \mathrm{~A}$.

\section{Resin and Polymer Samples}

Kolomi'tsev and others (1974) prepared standards for neutron activation analysis with phenol-formaldehyde resin as the substrate. The samples were prepared as pellets about $5 \mathrm{~mm}$ in diameter and 1 to $2 \mathrm{~mm}$ thick; the pellets weigh about $5 \mathrm{mg}$. The authors note that the technique is practically universal for all elements. Standards were prepared as single elements or as mixtures such as $\mathrm{Al}+\mathrm{Ni}+\mathrm{Zn}+\mathrm{In}$ or
$\mathrm{Co}+\mathrm{Sb}+\mathrm{Ag}$. These preparations are apparently unaffected by exposures to $10^{19}$ to $10^{22} \mathrm{n} \cdot \mathrm{cm}^{-2}$.

Kayasth and others (1980) made standards for activation analysis by absorbing known amounts of ions on ionexchange resins. Feng and others (1983) reported data for rare-earth elements in reference samples obtained by $\mathrm{x}$-ray fluorescence analysis after concentration of the elements on ion-exchange resin membranes.

Rakovskii and others (1980) prepared irradiation standards using 3(5)-methylpyrazol that had been studied by Myasoedova and others (1976). The reagent, which forms complexes with many transition elements, undergoes a condensation reaction with formaldehyde and resorcinol in the presence of ammonia to form a solid polymer. Single elements or mixtures may be used. The standards are described as stable in the presence of the irradiation in a reactor with a wall temperature of up to $200^{\circ} \mathrm{C}$.

Lu and Cao (1982) describe their preparation of standards made from phenol formaldehyde resin (PFR). Three sets of such standards for (1) $\mathrm{Fe}, \mathrm{Co}, \mathrm{Cr}, \mathrm{Zn}$, and $\mathrm{Ag}$, (2) $\mathrm{Se}, \mathrm{Sb}$, and $\mathrm{Sc}$, and (3) $\mathrm{Cu}, \mathrm{W}, \mathrm{Mo}, \mathrm{Au}, \mathrm{As}$, and $\mathrm{Na}$ were prepared for irradiation in a reactor with a flux of $7 \times 10^{15} \mathrm{n} \cdot \mathrm{cm}^{-2} \cdot \mathrm{s}^{-1}$ for 10 to $20 \mathrm{hr}$.

\section{Silica Gel Samples}

The technique of coprecipitating silica gel has been used for a quarter of a century for preparing materials for hydrothermal experiments. Roy (1956) found that coprecipitating gels is an effective method for preparing homogeneous mixtures. Hamilton and Mackenzie (1960) used the technique to prepare homogeneous materials of the required compositions for their system, $\mathrm{NaAlSiO}_{4}-\mathrm{KAlSiO}_{4}-\mathrm{SiO}_{2}$. Luth and Ingamells (1965) used a volumetric combination of carefully standardized aqueous solutions of metal nitrates and hydroxides, and a soda- or ammonia-stabilized silica sol of high purity. Hamilton and Henderson (1968) prepared silicate compositions by a gelling technique and included an appendix listing recommended starting chemicals and their sources.

Date (1978) prepared trace element reference materials by a coprecipitated gel technique. The multielement calibration standards were intended for use in the analysis of geologic materials by direct-reading emission spectrography. Date presented data for a number of elements and oxides in 10 rock reference samples. Breitwieser and Lieser (1978) prepared standards of trace elements in silica gel for the determinations of elements in rocks and minerals by $\mathrm{X}$-ray fluorescence spectroscopy.

\section{Sludge Ash Sample}

A sample of sludge ash was prepared by Knechtel and Fraser (1980) to serve as a reference sample for studies of the incineration of sewage sludge to reduce sludge volume. 
The chemical composition of the ash reflects the industrial nature of the city (Hamilton, Ontario) from whose municipal incinerator the sludge ash was obtained. Flegal (1980) has discussed the need for reference samples for environmental research and monitoring programs and gives data for nine trace elements in a homogenized digestor sludge sample obtained by two laboratories.

\section{Waste Incineration Ash}

Schmitt and others (1980) describe the preparation of and table data for a small reference sample $(10 \mathrm{~kg})$ of a waste incineration ash. The sample was prepared because (1) there was an unlimited amount of material available, (2) the material, after the burning process, was fairly homogeneous, and (3) the composition proved favorable for instrumental trace element analysis.

Another batch of $500 \mathrm{~kg}$ of the ash was collected, and B.F. Schmitt (written commun., 1983) notes that the sample was sent to the Ispra Research Center in July 1979 for processing. After the material was sieved, dried, powdered, homogenized, and bottled, an analytical program for the sample was started under the aegis of BCR (Community Bureau of Reference). As the deadline for analytical data has expired, it is anticipated that the reference sample will be available not earlier than the second half of 1984 .

\section{General Synthetic Samples}

Many investigators using instrumental neutron activation analysis make irradiation standards to fit their specific problems. Among others, Mitchell and others (1977) added solutions of isotopically labeled trace elements to hydrated silica gel and dried these gels for $1 \mathrm{hr}$ at $850^{\circ} \mathrm{C}$. Leypunskaya and others (1975) prepared synthetic multielement standards to approximate the compositions of three Russian samples, trap rock ST-1, gabbro-diorite SGD-1, and albitized granite SG-1, and of two USGS samples, BCR-1 and GSP-1. Eddy and others (1980) prepared synthetic standards from solutions of pure chemicals by weighing mercury, scandium, and barium compounds as individual masses. They did not apply heat during the preparation of a solution containing arsenic, antimony, selenium, tellurium, and osmium.

\section{Natural Samples of Economic Interest}

The many reference samples of materials of economic interest generally reflect the interests of the preparer, of an industry, of a nation, or of some combination of these. Examples of institutes furnishing such samples are given for several countries. There are also commercial companies in several countries that prepare and sell reference samples.
Organizations in several countries have samples of both economic and geochemical interest.

Many powdered samples were prepared for other purposes, such as tests of the accuracy and precision of analysis, but were promoted to the status of standards, often by users of the samples. Such promotions are not entirely unjustified because of the data collected during the test. An early example of a promotion is the Zinc Ore D of Stone and Waring (1907), which was assigned the standard sample number NBS-2.

\section{United States}

The National Bureau of Standards has furnished standards for industry since the announcement by Hillebrand (1909) of the availability of the argillaceous limestone (NBS-1) and Zinc Ore D. In contrast to this humble beginning, a recent (1979-80) edition of the NBS Standard Reference Materials Catalog of 102 pages lists a seemingly infinite number of reference samples.

The NBS also issued rocks for more than a decade, under the title "Rock Standards," with the subtitle "Radium Rock Standards." Twelve rock samples are listed in NBS Circular 552 (3d ed., April 8, 1959, p. 15) with the rock names and average radium contents. These rocks, first considered standards in 1951, were not listed as available in NBS Miscellaneous Publication 241 issued March 12, 1962. The certificate for the former NBS 4984, Triassic Diabase, indicates that the sample was obtained from the Centreville Quarry, the source of USGS-W-1 and W-2.

An industry standard sample of metallurgical chrome ore was described by Hartford (1953). The report notes that portions would be made available to industrial laboratories needing such a standard.

\section{Great Britian}

The Bureau of Analysed Samples, Ltd. (BAS), was formed in 1935 to assume the task of preparing British Chemical Standards (BCS), a job that had been performed by Ridsdale \& Co. since the first samples were prepared by C.H. Ridsdale and N.D. Ridsdale in 1916. The BAS devotes most of its efforts to spectrographic standards for cast irons and ferrous and nonferrous alloys. It also furnishes about 30 ores, fluxes, sinters, slags, and ceramic materials and several Euro-Standards of iron ores (Jecko, Pohl, and Ridsdale, 1977). Data have been published (Jecko and Ridsdale, 1978) for two Euro-Standards of steel furnace dusts. Croudace (1981) has determined the rare earth and other trace element contents of BCS soda and potash feldspar samples. Croudace and others (1982) report data obtained by neutron activation analysis for these two samples plus samples of bauxite (BCS 295), firebrick (EuroStandard 776-1), magnesite (BCS 389), dolomite (BCS 368), and limestone (BCS 393). 
Certified bulk compositions of 13 IRSID (Institut de Recherches de la Sidérurgie) reference samples have been published (Jecko, 1977). The group consists of eight iron ores, a laterite, two iron ore sinters, a calcite, and a dolomite. Bourdieu and others (1970) and Jecko and Matraski (1973) discuss IRSID's nonmetallic samples.

Jecko, Pohl, and Ridsdale (1977) list the compositions of six Euro iron ore standards and the addresses of the suppliers from whom samples can be obtained. Jecko, Ravaine, and Wittman (1980) discuss analytical methods used for IRSID's iron ores and table the compositions of 83 iron ore standards from the European Community, Germany, France, Japan, South Africa, Australia, Canada, Sweden, The United States, Romania, Poland, Czechoslovakia, and the U.S.S.R.

The Fédération Européenne des Fabricants de Produits Réfractaires (PRE) was mentioned by Neider $(1975$, p. 169) as one of the European organizations with which the Bundesanstalt für Materialprüfung (BAM) cooperates. The PRE furnishes several samples that are of economic and geochemical interest. The samples include clays, several chamottes (refractory clays), a calcined clay shale, and a bauxite. Palmer and others (1983) used x-ray fluorescence spectrometry to determine 20 trace elements in a PRE clay, two chamottes, the calcined clay shale, and the bauxite. Other samples of minor geochemical interest are available from the PRE.

\section{Germany}

Neider (1975) discussed the general scope of reference materials programs in the Federal Republic of Germany (FRG). Although the Bundesanstalt für Materialprüfung (BAM) and the Physikalisch-Technisches Bundesanstalt (PTB) have leading roles in the production, certification, and distribution of reference samples, there are commercial firms and private institutes in the FRG that produce reference samples.

Pohl and Oberhauser (1978) of BAM list certified values for six iron ores, one iron ore sinter, and a manganese ore, and they include a reproduction of a certificate of analysis. Although two samples of slag were listed in its recent catalog, the major emphasis of BAM is on reference samples of cast irons, steels, and special alloys that are intended as analytical control samples.

\section{Canada}

Canadian activities are devoted largely to samples of economic interest. The first two samples, a syenite rock, SY -1 , and a sulfide ore, SU-1, were distributed by the Canadian Association for Applied Spectroscopy (CAAS), and an initial report with data was published (Canadian
Association for Applied Spectroscopy, 1961). Reports containing accumulated data were published by Webber (1965) and by Sine and others (1969). Russell (1984) published a list of standards for use in the analysis of marine materials.

The name of the CAAS was changed in June 1967 to the Spectroscopy Society of Canada (SSC), whose Standards Committee continued the work on reference samples. By mutual consent, the functions of the Standards Committee were transferred to the Mines Branch, Department of Energy, Mines, and Resources, in 1971, and the Canadian Certified Reference Materials Project (CCRMP) assumed and expanded the previous program. Faye and Sutarno (1976, 1977) described CCRMP samples available for the earth sciences. A later list of CCRMP samples available was compiled by Steger (1980). Steger (1981) described the amended procedure for certification of CCRMP samples and summarized certified values for 30 elements in CCRMP samples of economic interest.

\section{South Africa}

The National Institute for Metallurgy (NIM) has published a number of in-house reports on its reference samples since the mid-1960's. In addition to reports on NIMROC samples (Steele and others, 1978; Steele and Hansen, 1979), NIM's efforts have been devoted to samples associated with the growing mineral industry of South Africa. Thus, there are reports on two ferrochrome slags, a series of fluorspar samples, a precious metal ore (PTO-1, from the Merensky Reef), a series of several minerals or ores containing rare earths, a magnetite and a hematite ore, two samples of chromium ore (Stoch and others, 1979), and three ferromanganese slags. Samples containing uranium were analyzed (Hansen and others, 1982) for use as standards by the South African uranium industry. NIM samples are available through the South African Bureau of Standards. The name of NIM was changed to the Council for Mineral Technology, and the organization and its reports are now known by the acronym MINTEK.

\section{CMEA Countries}

Reference samples of both economic and geologic interest that have been prepared as a cooperative effort by the member countries (Czechoslovakia, German Democratic Republic, Poland, the Soviet Union, Bulgaria, and Hungary) of the Council for Mutual Economic Assistance (CMEA) were listed by Valcha (1977), who also listed samples being prepared, or planned. Ostroumov (1979) gave the compositions of 18 reference samples prepared in five CMEA countries.

\section{Czechoslovakia}

Dempir (1978) listed several reference samples of rocks and ores being prepared by the Institute of Mineral 
Raw Materials, Kutna Hora, and gave estimates of the compositions of a granite, a gabbro, and a serpentinite. Dempir and Valcha (1982) discussed a standard reference material of fluorite, FM.

Valcha (1979) briefly described the geology and mineralogy of a magnesite, MK, from Košice, Czechoslovakia. After briefly describing the preparation of the material as a standard, he gives tables of attested or recommended values for several oxides and elements and a table of averages for 28 elements.

\section{German Democratic Republic}

The 1980 catalog of the Amt für Standarisierung Messwesen und Warenprüfung (ASMW) lists the three minerals, galena GF-1, sphalerite SF-1, and pyrite PS-1, for which data were reported by Schrön and others (1975). In addition to the original rocks (Grassmann, 1972; Schindler, 1972) prepared by the Zentrales Geologisches Institut (ZGI), the catalog also lists ZGI samples anhydrite AN, feldspar sand FK, greisen GnA, and serpentinite SW, for which usable values were given by Abbey (1980).

The ASMW can also furnish two chrome ores $(\mathrm{Cr}-$ Erz 1 and 2), two manganese ores (Mn-Erz 1 and 2), a tin ore (Sn-ERZ 1), a fluorspar, a sinter, and three slags.

\section{Poland}

Plebanski (1975) discussed the national standard reference material program of Poland. He notes in his table 2 that 36 standard reference materials of glass and ceramics were made up to 1972 and that 66 such samples, of which 9 were to be under the control of PKNMiJ (Polish Committee for Standardization, Measures, and Quality Control), were planned for the period 1975-80. He also lists 16 samples of ores and minerals that were made up to 1972, of which 2 were under the control of PKNMiJ, and a total of 49 such samples, with 29 under the control of PKNMiJ, planned for the period, 1975-80.

Plebanski also lists the types of samples and the sources from which information may be obtained, as follows:

- Ferrous metallurgy materials and ores:

Instytut Metalurgii Zelaza

ul. Karola Miarki 12

Gliwice, Poland

- Nonferrous metallurgy materials and ores:

Instytut Metali Niezelaznych

ul. Sobieskiego 11

Gliwice, Poland

- Rocks:

Instytut Geologiczny

ul. Rakowiecka 4

Warszawa, Poland

Valcha (1977, table 1) listed three Polish rock salt samples ( $\mathrm{S}-1, \mathrm{~S}-2$, and $\mathrm{S}-3)$ and a zinc ore $(\mathrm{ZnU})$ that were mentioned in Schindler and Scheutzow (1975, p. 130). Valcha (1977, table 3) also listed a sample of native sulfur planned by Poland. Jecko, Ravaine, and Wittman (1980) gave the composition of a Polish iron ore, sample 2.8/1.

Plebanski (1979) edited a 57-page catalog (WZORMAT's Guide-Book) with the title "Physiochemical Certified Reference Materials." The text was consulted in the hope that geostandards for use by physiochemical measurement techniques might be mentioned, but the standards are for density, viscosity, relative humidity, $\mathrm{pH}$, electrolytic conductance, ion activity, refractive index, optical rotation, spectrophotometry, atomic absorption, and pesticides.

\section{U.S.S.R.}

Gorozhanina and others (1971) of the All-Union Scientific Research Institute of Metrology, Sverdlovsk Branch, All-Union Scientific Research Center of the State Service for Standard Samples, prepared a list of standard samples issued in the U.S.S.R. The report in Russian, published in 1969 by the Committee of Standards, Measures, and Measuring Instruments of the Soviet of Ministers of the U.S.S.R., was translated by M.C. Selby (National Bureau of Standards, Boulder, CO 80302), and the translation was published as NBS Special Publication 260-30 in 1971.

Although most of the list is concerned with metals and alloys, there are many samples of interest to geochemists. For example, we find on page 19 of NBS Special Publication 260-30 a section "SS [Standard Sample] for the Determination of the Absolute Age of Geological Formations." In table 9 (p. 20), we find SS $2 / 65$, amazonite-microcline, with certified values for $\mathrm{Rb}$ of "about 0.11 percent" and for radiogenic $\mathrm{Sr}$ of "about $1.75 \mu \mathrm{g} / \mathrm{g}$." Another amazonitemicrocline, SS 3/66, has a certified Rb content of "about 0.8 percent" and a certified radiogenic Sr content of "about 4.0 $\mu \mathrm{g} / \mathrm{g}$." A third sample for age determinations, SS $1 / 65$, a felsitic quartzitic liparitic porphyry, has a certified potash $\left[\mathrm{K}_{2} \mathrm{O}\right.$ ?] content of $4.013 \pm 0.38$ percent and a certified radiogenic Ar content of $79.27 \pm 1.35 \mathrm{ng} / \mathrm{g}$.

Among other samples of possible interest are 10 slags (table 20), 12 ore [?] concentrates (table 21), and 21 ores (table 22). Data for "general iron in conversion to iron oxide" [?], $\mathrm{CaO}, \mathrm{MgO}, \mathrm{SiO}_{2}, \mathrm{MnO}, \mathrm{Al}_{2} \mathrm{O}_{3}$, and $\mathrm{P}_{2} \mathrm{O}_{5}$ are given in table 37 for a set of seven slags, SS 81 through SS 87.

Data for $\mathrm{SiO}_{2}, \mathrm{CaO}, \mathrm{MgO}$, phosphorus [ $\mathrm{P}$ or $\mathrm{P}_{2} \mathrm{O}_{5}$ ?], and sulfur are given for a dolomite, SS 60-B, and a limestone, SS 59-V. No data are given for another limestone, SS 59-g. Data for three refractories, SS 56-b (Dinas brick), SS 239 (chrome-magnesite), and SS 55a chamotte (refractory clay) are found in table 24 .

Four rock samples are mentioned in a short paragraph in Gorozhanina and others $(1971$, p. 53). Three rocks, diabase DIM-1, miaskite MIV-1, and peridotite (no sample designation), are also listed in Egranova and others (1981). 
Egranova and others (1981) have a sample designation, PIM-1, for the peridotite and, in addition, list IGEM (Institute of the Geology, Geochemistry, Petrology, and Mineralogy of Ore Deposits, Academy of Sciences of the U.S.S.R., Moscow) numbers for the four samples. One sample, "faceted diorite 'Rizhik'," mentioned in Gorozhanina and others (1971) may be the same as "granodiorite 'Ryzhik" in Egranova and others (1981) as the compositions of the two rocks are very similar.

Lontsikh and Parshin (1980) listed reference samples prepared in their laboratory during the period 1968-78. Included in the list are 29 samples of various ores or concentrates and 3 rocks from the Institute of Geochemistry, Irkutsk (IGI). Tauson and others (1976) published estimates of the constituents normally determined in a rock analysis and of about 40 trace elements for the 3 rocks, ST-1A (trap), SGD-1A (essexite gabbro), and SG-1A (albitized granite), that were prepared as U.S.S.R. national standard samples. Lontsikh and others (1980) summarized the trace element data for the Irkutsk samples, including data reported by Abbey and Govindaraju (1978).

There are also in the list two bauxites, three soils, and three samples prefixed by SDO which are described as clay or silt. The first of these three samples has an asterisk following "clay" in the listing "SDO-1, terrigenous clay," and the footnote for the table begins, "The reference samples of bottoms (SDO) ${ }^{* * *}$." Because the term "bottoms" is not definitive, the original paper by Lontsikh and Parshin (1979, "Zhurnal Analiticheskoi Khimii," v. 34, no. 12, p. 2446-2452) was consulted. The final word in the description for SDO-1, "Glina," is translated "clay;" for SDO-2 and SDO-3, the final transliterated word, "il," may have the meanings of silt, mud, ooze, or sediment.

The footnote in the Russian paper may be translated "standard specimens of bottom sediments" and, in view of the four alternate translations of "il," the samples may be sediments from lakes, rivers, or oceans. Berkovits and Lukashin (1984) published data for three marine sediment samples, SDO-1, SDO-2, SDO-3, without U.S.S.R. state register (SR) numbers. Sample locations are as follows: SDO-1, eastern Pacific Ocean; SDO-2, central Pacific near Hawaii; and SDO-3, Red Sea.

Egranova and others (1981), in their table 1, "Composition of Standard Samples," list four samples that are not listed in Lontsikh and Parshin (1980). These samples, RUS-1 through RUS -4 , are apparently ore samples. Rather than the compositions indicated by the title of the table, 11 trace elements usually considered heavy metals are listed as certified components, without data.

Egranova and others (1981) also list certified components, mainly trace elements without data, for four rocks, Miaskite MIV-1, Peridotite PIM-1, Diabase DIM-1, and "Ryzhik" granodiorite, that are identified by IGEM numbers rather than the usual U.S.S.R. State Register numbers for standards. Khitrov (1984) tabled certified values for major and minor oxides and for 23 trace elements in samples of ultrabasic, basic, acidic, and alkalic rocks.

Ginzburg and others (1983) discussed the idea of creating a state service for standard mineralogical samples. They suggest three classes of samples: diagnostic samples, samples for mineral properties, and samples for phase composition.

\section{Austria}

Suschny and Richman (1975) describe the analytical quality control program of the International Atomic Energy Agency (IAEA) in Vienna. They list in their table 3 (p. 94) the $\mathrm{U}_{3} \mathrm{O}_{8}$ contents and sample numbers of six uranium ores: torbernite (S-1 and S-2), carnotite (S-3), uraninite (S-4), and pitchblende (S-12 and $\mathrm{S}-13$ ). One still finds determinations of the uranium contents of these ores, such as the data reported by Kuleff (1979), even though no stock of most samples remains.

In addition to the ores, two marine sediments (SD-B-1 and SD-B-2) and a lake sediment (SL-1) are listed. A report on Soil-5, composed of the top $20 \mathrm{~cm}$ of soil collected at the Agricultural Experimental Station, La Molina, Lima, Peru, was published by Dybczyński and others (1979). One might assume that the NBS soil, SRM4355 , mentioned later may be the same as IAEA-soil-5, as they were collected at the same location.

A comparison of the determinations of uranium, thorium, and potassium in three sedimentary rocks (two shales and a limestone) was published by Heinonen and others (1973) as an IAEA report. Suschny and Richman (1975) also list five plant materials that may interest geobotanists. Four water samples for isotopic work discussed elsewhere, V-SMOW (Vienna SMOW), SLAP, NBS-1, and NBS1A, are also included in Suschny and Richman (1975).

Recent IAEA lists (IAEA, 1983, 1984) no longer contain the six uranium ores discussed above, and the two older marine sediments, SD-B-1 and SD-B-2, are now listed as out of stock. However, four phosphate samples for uranium, Soil-6 for ${ }^{90} \mathrm{Sr},{ }^{137} \mathrm{Cs}$, ${ }^{54} \mathrm{Mn}$, and ${ }^{239} \mathrm{Pu}$, Soil-7 for multielement trace analysis, and three new marine sediments, SD-N-1/1, SD-N-1/2, and SD-N-2, are expected to be available in 1984 .

In place of the depleted uranium ore samples (S-1 through $S-6)$ there are now four pitchblendes ( $\mathrm{S}-7,-8,-12$, and -13$)$, and three thorium ores $(S-14,-15$, and -16$)$ that may be available in late 1983 either as reference materials or as certified reference materials. A feldspar, IAEA-F-1, is a reference material for uranium and potassium. Belyaev and Sobornov (1981) reported determinations of uranium, thorium, and potassium in a number of reference samples, including IAEA-F-1.

\section{BCR (Community Bureau of Reference, Brussels)}

In addition to the four cokes, the six concentrates (three zinc, two lead, and one tin), the copper ore mentioned 
in Colombo and Rossi (1978), and the Moroccan phosphate (BCR-32) mentioned in the paper by Serrini (1981), BCR has reference samples for oxygen in nonferrous metals and alloys.

BCR is preparing a coal for ash, sulfur, volatile constituents, and specific heat. Three samples of plants and one of milk powder are intended for determinations of $\mathrm{Cd}, \mathrm{Cu}$, $\mathrm{F}, \mathrm{Hg}, \mathrm{Mn}, \mathrm{Pb}$, and $\mathrm{Zn}$. Schramel and Xu (1982) determined beryllium in three reference samples by ICPS (inductively coupled plasma spectrometry); one sample was a BCR plant sample, BCR-61, Riparioides.

In addition to three zinc concentrates for 8 elements, two lead concentrates for 10 elements, six zinc concentrates (BCR-26 through BCR-31) for their zinc contents, and a manganese ore for its $\mathrm{Mn}$ content, samples of lead from three sources are being analyzed for 10 trace elements, and copper from three sources is being analyzed for $\mathrm{Au}$ and $\mathrm{Ag}$. Other samples such as superphosphate and glasses are being analyzed for major and minor constituents. Bastin and others $(1981,1982,1983)$ described the BCR certification process for the zinc concentrates, BCR-26 through BCR31 , in a three-part paper.

BCR also has a fly ash sample. Griepink and others (1983) described the certification of a fly ash resulting from the combustion of a pulverized coal. Although the specific reference sample (BCR-38) is not mentioned in the text of Griepink and others (1983), one may safely assume that the sample is BCR-38 because the certified values in table 6 of the text agree exactly with those in an addendum to a catalog (1982) of BCR-certified materials.

\section{Brazil}

Rasberry (1981) reports in a column on reference materials that, in addition to 18 steel and bronze alloys, the Instituto de Pesquisas Tecnológicas do Estado de São Paulo (IPT) has available 4 iron ores, 4 argillaceous clays, a phosphate, and a limestone, for each of which the particle size is less than $0.074 \mathrm{~mm}$ ( $200 \mathrm{mesh})$. Information on these samples of economic or geochemical interest may be obtained from the Chief of Analytical Standards, IPT, Caixa Postal 7141, 01000 São Paulo-SP-Brazil. IPT added a burnt refractory, IPT-51, a manganese ore, IPT-52, and a potash feldspar, IPT-53, in 1984.

\section{Japan}

The Iron and Steel Institute of Japan (ISIJ) is reported in "X-Ray Spectrometry" (1977, v. 6, no. 4, p. 218) as having two fluorspar standards, two ferroalloys, and eight ores. Jecko and others (1980) list the chemical compositions of 13 Japanese iron ore standards, but they do not give the source from which the samples may be obtained. Terashima (1979) reported determinations of carbon and sulfur in four iron ore samples and one chromium ore from the ISIJ, and
Feret (1982) reported data for six iron ore standards from the ISIJ.

\section{People's Republic of China}

The People's Republic of China (PRC) has started a program of geochemical reference samples. Yang and Liu (1983) reported methods and data for seven ore samples for uranium, thorium, and radium. The samples were prepared by the Bureau of Uranium Geology, Beijing.

A set of eight stream sediments for use in geochemical prospecting was prepared under the general direction of the Research Group of Geochemical Reference Standards of the Ministry of Geology and Mineral Resources, Beijing. Data for the major and minor oxides and for trace elements for the samples, numbered GSD-1 through GSD-8, appear as "usable" values in table $40 \mathrm{~A}$ of Abbey (1983). There are uncertain values or magnitudes for 22 trace elements that were not published. Included among the 22 elements are several rare earths. Zhang and others (1982) and Yuan and Chen (1982) reported determinations of rare earths and other elements using neutron activitation analysis.

C.H. Tong (Chengdu College of Geology, Chengdu, Sichuan, written commun., 1983) sent the author the compositions of two ultrabasic rocks, DZ -1 and DZ $\Sigma-2$, and of two chromite reference samples, DZCr-1 and DZCr-2. The data for each set of samples include the constituents usually determined in a rock analysis and the contents of the 6 platinum group metals and of 19 trace elements. Abbey (1983, table 120) included most data for the two ultrabasic rocks but did not include data for the chromites. Chen and others (1982) reported determinations by neutron activation methods for the two rocks. Both C.H. Tong and Xuejing Xie (Institute of Geophysical and Geochemical Prospecting, Langfang, Hebei, 102801, PRC, written commun., 1983) note that there are eight soil reference samples.

Reports containing data on new reference samples appeared in the June 1984 issue (no. 3) of "Ho Chi Shu" [Nuclear Techniques]. The number of reference samples of stream sediments has increased from 8 to 12 , and Chen and others (1984) reported determinations of $\mathrm{La}$ and of nine rare earth elements in samples, GSD-1, to GSD-12. A set of 17 secondary reference samples of stream sediments from Gilin Province, PRC, was prepared, and Zhao (1984) reported instrumental neutron activation (INAA) determinations of 3 major and minor elements $(\mathrm{Fe}, \mathrm{K}$, and $\mathrm{Na}$ ) and of 18 trace elements in samples GRD-30 through GRD-46.

Data for two types of reference samples for archaeometry were reported by Li (1984). Determinations of $\mathrm{Na}, \mathrm{K}$, and $\mathrm{Fe}$, and of 16 trace elements, are reported for a porcelain reference sample, KPS-1. Seven samples of bronze containing copper in the range $68-86$ percent, tin in the range 10-26 percent, and lead in the range 5-11 percent were perepared as flat cylinders $20 \mathrm{~mm}$ in diameter by $3 \mathrm{~mm}$ high. Tong and others (1984) report determinations of $\mathrm{Cu}$ 
and $\mathrm{Fe}$ in percent and of 21 trace elements for a secondary basalt reference sample, S-CRB. S-CRB is a small sample of the Columbia River Basalt, and the determinations agree well with values for BCR-1 from a source not cited. INAA data for reference samples of peach leaves, a coal fly ash, and a river sediment were reported by Su and Zhang (1984) and by Sun and others (1984).

\section{Scandinavia}

Christie (1975) gives the rock names and geologic references for three samples, larvikite (ASK-1), schist (ASK-2) and sulfide ore (ASK-3), prepared by the Analytisk Sporelement Komite (ASK). He describes sample preparation and tests for homogeneity and tables recommended trace element contents resulting from roundtable discussions involving most of the 22 Nordic analysts.

Compositions of two iron ores, Nr. 9 and Nr. 10, are listed by Jecko and others (1980) in their table 6. Footnote 2 of the table notes that the samples are from Sweden and that the producer is "IMF" (the acronym is not explained).

Feret (1982) described an X-ray fluorescence method for routine analysis of iron ores. Standards analyzed were four samples of the Krivoi Roj ore (U.S.S.R.), two BCS ores, six samples from the Iron and Steel Institute of Japan, five concentrates, described as standards, from LKAB, Malmberget, Sweden, and a sample of Malmberget pellets. The acronym LKAB is not explained, and the availability of the LKAB samples is not known.

Leif Ericson (scientific attache, Swedish Embassy, Washington, D.C., written commun., 1983) notes that IMF is probably Institutet för Metallforskning (Institute for Metal Research, Drottning Kristinas vag 48, S-1 1428 Stockholm) but that the acronym has not been adopted by the Institute. LKAB is an abbreviation for Luossavaara-Kirunavaara Aktiebolag (Sturegatan 38, Box 26044, S-100 41, Stockholm).

The 1983/84 catalog of Analytical Standards AB (PI. 2366, S-434 00 Kungsbacka, Sweden) lists numerous standards of different types from many producers. The list includes three fluorspars and four iron ores produced by the Swedish Institute for Metal Research, whose sample numbers are prefixed by JK (Jernkontorets Analysnormaler).

\section{Natural Samples of Geologic Interest}

\section{Geological and Geochemical Samples}

The preparation of a reference sample of "a" rock, ore, or mineral may lead to future misinterpretation. A laboratory may wish to have, for example, a powdered granite to use as a "control" for analyses and may select any granite for the purpose. This sample may eventually be promoted to a sample of "the granite," though the promotion may not be warranted because of deficiencies in the selection or sampling of the rock or in the preparation of the powdered sample.
The preparation of " $a$ " granite should be avoided, as the precautions necessary for processing a sample from a specified locality require only a little additional effort and may result in a reference sample of geologic and geochemical significance. A geologist who knows the area should select and sample the rock, and contamination during the mechanical processing to a powder should be minimized. There are now many samples that meet these criteria.

Data for rock or mineral samples that meet these criteria, as well as artificial materials such as glass, slag, and fly ash that may be useful in silicate analysis, were discussed by Abbey (1980). The principal preparers of reference samples for geology, in alphabetical order of their acronyms, are (1) ANRT-CRPG (Association Nationale de la Recherche Technique-Centre de Recherches Pétrographiques et Géochimiques), (2) ASK (Analytisk Sporelement Komite); (3) CCRMP (Canadian Certified Reference Materials Project); (4) GSJ (Geological Survey of Japan); (5) NIM (National Institute for Metallurgy); (6) USGS (U.S. Geological Survey ); and (7) ZGI (Zentrales Geologisches Institut, East Berlin).

Abbey (1977a) also discusses data for samples from three other institutions, Queen Mary College (U.K.), Leningrad University, and Institute of Geochemistry (Irkutsk, U.S.S.R.). Either the samples from these sources were prepared for limited distribution or insufficient data for them exist in the literature. The three samples from Irkutsk have been identified by two different sample numbers. Abbey and Govindaraju (1978) published determinations by their organizations for constituents of the Irkutsk samples, along with the established, certified, or unreliable results given by Tauson and others (1976).

Determinations of several constituents of a new Japanese andesite (JA-1) and a new basalt (JB-2) were reported by Kato and others (1978), and the mercury contents of the two samples were reported by Flanagan and others (1982). Atsushi Ando, Geological Survey of Japan, recently announced (written commun., 1982) the availability of a rhyolite, JR-1. New samples JB-3 (a basalt from Mount Fuji), JGb-1 (a gabbro from Abukuma), JR-2 (another rhyolite, from Wada-Toge), and JP-1, peridotite, as well as replacement samples JB-1a and JG-1a, are available for analysis. Geochemists will eventually be able to make some interesting comparisons of data for these new samples with data for similar samples of continental origin. Ando (1984) summarized the status of all GSJ rock reference samples. Terashima and others (1984) published rock analyses and the contents of 16 trace elements for JA-1, JB-2, JB-3, JGb-1, JR-1, and JR-2.

A gabbro, GOG-1 (Gruppo Ofioliti, Gabbro, 1), from a northern Appenine ophiolite sequence, the Bracco Massif (A. Mazzucotelli, written commun., 1980), is being used by the Gruppo di Lavoro sulle Ofioliti Mediterrannee of CNR, Italy, as an interlaboratory standard, and data have been published by Boy and Mazzucotelli (1976), Benedetti 
and others (1977), Mazzucotelli and others (1976), and Harris and others (1981). A preliminary report was published by Ivanov (1981) on a Bulgarian granite, G-B, that was prepared and introduced (Aleksiev and Boyadjieva, 1966).

An International Working Group of the Association Nationale de la Recherche Technique has been established, and samples for this group are prepared and distributed by the Centre de Recherches Pétrographiques et Géochimiques, Nancy, France. A report on recent samples of ANRT, an anorthosite (AN-G), a basalt (BE-N), and a granite (MA$\mathrm{N})$, was published by Govindaraju (1980).

A tonalite, T-1, from the Msusule pluton, Tanganyika, was prepared and distributed (Burks and Pallister, 1961) and data for the sample were published (Thomas and Kempe, 1963). Bowden and Luena (1966) published a short note cautioning against the use of the limited trace element data for T-1 to establish working curves. G. Luena (written commun., 1975) confirmed that the supply of $T-1$ was exhausted and that no replacement was contemplated.

Potts and others (1981) prepared a fine-grained granite as an in-house irradiation standard. They calibrated several rare earths in the sample by the method of standard additions. Potts (1983) proposed adoption of the microgranite, AC(OURS), as a trace element reference sample.

S.Y. Taha reported (written commun., 1975) that the Jordan oil shale JOS-1 was destroyed in a laboratory fire. Another shale, SDO-1, was prepared by the USGS as an analytical reference sample at the request of the U.S. Department of Energy, Morgantown (W.V.) Energy Research Center. Leventhal and others (1978) published preliminary data for the sample. Moore (1978) described the preparation of the Purington shale sample, $\mathrm{KnC}-\mathrm{ShP}-1$, and tabled the available data.

\section{Geochemical Exploration Samples}

Reference samples for geochemical exploration were described by Allcott and Lakin (1975), and the analytical data were published (Allcott and Lakin, 1974, 1978). Rose, Hawkes, and Webb (1979) prefer these as reference samples for exploration geochemistry because of their relatively high contents of most elements of interest.

\section{Archaeology}

Both artificial and natural samples have been used as standards for archaeological investigations. The artificial samples were the pottery standard PS-1 of Perlman and Asaro (1969), whose supplies are exhausted, and the medieval ceramic samples of Pigeat and Lahanier (1974), who restricted distribution to those in archaeology. The USGS series of rocks G-2 through BCR-1 is frequently requested by those in archaeology, but the supplies of GSP-1, PCC -1 , DTS-1, and BCR-1 are exhausted.
John Winter, Freer Gallery of Art, Smithsonian Institution, distributed a list, "Sources of Reference Materials for Museum Laboratories," at the 5th Triennial Meeting of the ICOM (International Council of Museums) Committee for Conservation held in Zagreb, Yugoslavia, in 1978.

\section{Bauxite}

The National Bureau of Standards issued four replacement bauxites, NBS-69b (Arkansas), NBS-696 (Suriname), NBS-697 (Dominica), and NBS-698 (Jamaica). Another bauxite, ANRT-BX-N (Roche and Govindaraju, 1971), was obtained from Mine de Maou, Brignoles (Var), France. Both the BAS (BCS) and the PRE have a bauxite reference sample. A lateritic bauxite, SLB-1, was prepared by the IVIC (Instituto Venezolano de Investigaciones Cientifícas, Caracas).

\section{Clays and Clay Minerals}

The National Bureau of Standards issued certificates for NBS-97, flint clay, and NBS-98, plastic clay, on August 31,1931 . These were replaced on October 8,1969 , by NBS-97a and NBS-98a. Flanagan and others (1977) listed determinations of trace elements in the older clays by other analysts, sample localities (where known) of the available samples of clays and feldspars, and determinations of trace elements in the clay and feldspar samples by instrumental neutron activation analysis.

The American Petroleum Institute sponsored a project on clay minerals (API Project 49, Clay Mineral Standards). Starting in 1949, the project issued eight reports, separately paginated, that included $\mathrm{x}$-ray diffraction data, chemical analysis, $\mathrm{pH}$, differential thermal analysis, base exchange, magnetic susceptibility, particle size, staining tests, and infrared spectra. The preliminary reports, starting with a glossary of clay mineral names by Kerr and Hamilton (1949), were later reprinted, bound in a single volume, and issued by the American Petroleum Institute (1951). The 1968-69 catalog of Ward's Natural Science Establishment, Inc., listed 32 reference clay minerals collected from the same localities as those of API Project 49, but the samples were not listed in the 1976-77 catalog.

Two other organizations have prepared clay materials and other nonmetallic minerals. Van Olphen and Fripiat (1979) give a brief history of the two projects, sponsored by the Clay Minerals Society (CMS) and the Organization for European Cooperation and Development (OECD), and the samples that are available. Chemical analyses of the samples are included in tables, but few trace element data are available. Flanagan and others (1982) reported the mercury contents of the CMS clay minerals.

Other organizations have clay samples available. The IPT (Instituto de Pesquisas Technológicas do Estado de São Paulo, Brazil) has three clays, including a plastic clay. The 
PRE (Fédération Européenne des Fabricants de Produits Réfractaires) has one clay and two samples of chamotte (refractory clay).

\section{Coals, Coal Ash, and Cokes}

Coal ashes and cokes, even though they are artificial samples, are included in this category because they are prepared from coals.

The present NBS catalog lists two samples, SRM 1632a, Trace Elements in Bituminous Coal, and SRM 1633a, Fly Ash. Khalil and others (1980) report the oxygen contents of the coal and its predecessor, of the present fly ash and its predecessor, and of four commercial coal standards, AR 216, 217, 218, and 220.

The last four samples are no longer listed in a descriptive price list by Alpha Resources (P.O. Box 199, 3090 Johnson Road, Stevensonville, MI 49127), but the firm has 11 coals and 2 coke standards for $S$ in the range 0.4 to 5 percent, and 9 coal ashes listing the ash contents and the analysis for 10 of the 14 constituents usually determined in a rock analysis. Alpha Resources also furnishes 11 coals and 2 cokes for S, ash, volatile matter, fixed carbon, and BTU, and another series of 2 cokes and 10 coals for proximate analysis, ultimate analysis, forms of sulfur, and the analysis for ash.

The establishment at Argonne National Laboratory of a Premium Coal Sample Program to prepare and furnish homogenized coal samples of several types was announced in "Chemical and Engineering News" (September 26, 1983, v. 61 , no. 39 , p. 18). One objective of the program is to furnish coal samples for research in the physical and chemical properties of the coals. The coals, mined from freshly exposed seams, will be sealed immediately in stainless steel drums under argon to prevent oxidation and to control humidity. Some part of the mined coal will remain stored in the stainless steel drums to provide a reserve supply of large pieces, but most of any sample will be pulverized into two different sizes and smaller sample portions will be sealed in glass vials. The first sample is expected to be processed in 1984 , and a total of eight coal types is expected by 1986 . An advisory committee with members from industry, academia, and government will select the types of coal for the program.

Colombo and Rossi (1978) list the C, H, S, P, and ash contents and the calorific values for four coke samples, BCR-1 through BCR-4. The 1982 International Organization for Standardization (ISO) Directory of Certified Reference Materials notes that two lignites for the determination of $\mathrm{U}_{3} \mathrm{O}_{8}$ are available from Junta de Energia Nuclear, Ciudad Universitária, Madrid, 3, Spain.

\section{Counting Standards}

The U.S. Department of Energy, New Brunswick Laboratory, lists a number of counting standards and other materials in "X-Ray Spectrometry" (1978, v. 7, no. 4, p. 249). The counting standards are made by diluting pitchblende with either dunite or silica, and by diluting monazite sand with either dunite or silica. Historically, such standards, made by diluting either pitchblende or monazite sand with dunite, were prepared by the NBS between 1945 and 1950 , and the standards were available to organizations involved in search for uranium and thorium deposits on behalf of the U.S. Atomic Energy Commission (USAEC). When the USAEC established a laboratory in New Brunswick, N.J., in about 1953, the remaining supplies of these samples were transferred to the New Brunswick Laboratory.

The Environmental Monitoring Systems Laboratory of the U.S. Environmental Protection Agency also furnishes counting standards. The laboratory's major emphasis appears to be on radionuclide samples in solution that were prepared and calibrated by the NBS, but it also has a number of special reference samples of naturally occurring materials. For example, the laboratory has (1) a pitchblende and a dilution of this sample for measurements of ${ }^{238} \mathrm{U}$ and ${ }^{235} \mathrm{U}$; (2) a monazite and a diluted monazite for measurements of ${ }^{232} \mathrm{Th}$ and ${ }^{228} \mathrm{Th}$; and (3) a sample of uranium mill tailings and a dilution of this sample, plus another mill tailings sample (a composite from 16 mills), all three samples designed for measurements of the daughter products, ${ }^{230} \mathrm{Th}$, ${ }^{226} \mathrm{Ra}$, and ${ }^{210} \mathrm{~Pb}$. A sample of the Mancos Shale, prepared by the NBS and calibrated for ${ }^{228} \mathrm{Ra}$ and ${ }^{226} \mathrm{Ra}$, is also included.

\section{Laterites}

The terms "laterite" and "soil" may be used indiscriminately by some of us, but they have specific meanings for soil scientists and geologists. The composition of a lateritesample, M10-1, available from IRSID (Institut de Recherches de la Sidérurgie) was given by Jecko (1977). Two Venezuelan laterites, VL-1 and VL-2, were prepared by the IVIC. A certificate of analysis for $\mathrm{SiO}_{2}, \mathrm{Al}_{2} \mathrm{O}_{3}, \mathrm{TiO}_{2}$, $\mathrm{Fe}_{2} \mathrm{O}_{3}$, and loss on ignition has been issued for $\mathrm{VL}-1$. Schorin and LaBreque (1983) published details of and data for $\mathrm{VL}-1$ and reproduce the certificate of analysis.

\section{Meteorites}

Hohenberg and Kennedy (1981) present previously unpublished data for the Bjurböle standard meteorite for I-Xe dating and discuss the homogeneity of the sample. The Smithsonian Institution has prepared a portion of the Allende meteorite for analysis, and data for the sample appear frequently. Clarke and others (1970) describe the recovery of specimens from the strewnfield for the Allende meteorite, a type III carbonaceous chondrite, and discuss the morphology, mineralogy, petrography, and chemical composition of specimens. 


\section{General}

Hügi and others (1975) summarized data obtained at 18 laboratories and gave recommended values for the major and minor oxides for Basel-1b, biotite, and Basel-1h, hornblende. They give tentative values for Basel-1a, anorthoclase, a sample from Mount Kibo, Kilimanjaro, Tanzania. Stern (1969) discussed the chemical composition of the anorthoclase. Only mercury data have been published (Flanagan and others, 1982) for biotite, USGS-Btt-1, and hornblende, USGS-Hbl-1.

A calcite, DOI-1, and a dolomite, DO2-1, are among 13 samples for which Jecko (1977) listed average bulk compositions as the elements. After $\mathrm{Ca}$ and $\mathrm{Mg}$ were converted to carbonates and the $\mathrm{Si}, \mathrm{Al}, \mathrm{Fe}\left(\right.$ as $\left.\mathrm{Fe}_{2} \mathrm{O}_{3}\right), \mathrm{Ti}, \mathrm{P}, \mathrm{Mn}$, and $\mathrm{S}$ were converted to the oxides, the average analysis of the calcite summed to 99.17 percent, including 94.15 percent $\mathrm{CaCO}_{3}$ and 1.25 percent $\mathrm{MgCO}_{3}$ (sum, 95.40 percent). Similarly, the analysis of the dolomite summed to 100.13 percent, including 53.70 percent $\mathrm{CaCO}_{3}$ and 42.92 percent $\mathrm{MgCO}_{3}$ (sum, 96.62 percent).

Schrön and others (1975) published the accumulated data for three sulfide mineral standards, Galena GF-1, Sphalerite SF-1, and Pyrite PS-1.

\section{For Microprobe}

Minerals for microprobe use have been in laboratories for some time but have been available among scientists only on a personal basis. The arsenopyrite microprobe standards Asp-200 and Asp-57 mentioned in Lowell and Gasparrini (1982, p. 237) appear to be such in-house standards. Ingamells (1978) lists 16 minerals that are available in small quantities. He discusses the compositions of these and other minerals in a "Microprobe Column," a feature of "Geostandards Newsletter" since volume 2, number 2 (1979).

Jarosewich (1972) published the compositions of minerals (hornblende, pyrope, omphacite, and two garnets) used as microprobe standards and later reported (Jarosewich, 1975) the compositions of another hornblende and a basaltic glass for similar use. Jarosewich, Nelen, and Norberg $(1979,1980)$ listed the compositions of 25 minerals, 4 natural glasses, and 1 synthetic glass prepared as microprobe reference samples at the Smithsonian Institution.

A variety of reference samples for electron probe analysis are available from Tousimis Research Corporation (P.O. Box 2189, Rockville, MD 20852). In addition to about 60 elements purified ( 99.7 percent or better) and prepared as reference samples, the company furnishes about 50 binary compounds and about 75 minerals for electron probe analysis. Mori (1983) uses chemicals and minerals as electron-probe standards, but sample numbers for minerals are not given.
A sample of muscovite, USGS-P-207, a reference sample for both $\mathrm{K}-\mathrm{Ar}$ and $\mathrm{Rb}-\mathrm{Sr}$ measurements, has been exhausted since 1972 and a final compilation of data was published (Lanphere and Dalrymple, 1976). The availability of a hornblende, $\mathrm{MMhb}-1$, for ${ }^{40} \mathrm{Ar}-{ }^{39} \mathrm{Ar}$ dating was announced in "Geochimica et Cosmochimica Acta" (1979, v. 43, p. 278), and details of the preparation and calibration were given by Alexander and others (1978).

GL-O, a pure glauconite weighing about $28 \mathrm{~kg}$, was prepared by Roche and others (1976). Odin (1976) discussed the analytical data for argon, potassium, strontium, and rubidium. Cassignol and others (1977) discuss measurements on GL-O to determine its ${ }^{40} \mathrm{Ar}$ content.

Following the suggestion of Compston and others (1969), the NBS issued NBS 607, made from the -200 +325 mesh fraction of NBS 70a, potash feldspar. They certify $\mathrm{Rb}(523.90 \mathrm{ppm}), \mathrm{Sr}(65.485 \mathrm{ppm})$, and ${ }^{87} \mathrm{Sr} /{ }^{86} \mathrm{Sr}$ $\left(1.20039\right.$, normalized to $\left.{ }^{86} \mathrm{Sr} /{ }^{88} \mathrm{Sr}=0.1194\right)$.

\section{Phosphates}

In addition to the latest phosphate rock of the NBS, other phosphate samples have been announced. Serrini (1981) published a short note on a Moroccan phosphate rock (BCR-32), and the certificate of analysis is reproduced in the paper. Gliksman and others (1980) report the $\mathrm{CaO}$ contents of 10 IMC samples and of 4 AFPC samples. The IMC samples were developed by the International Minerals and Chemical Corporation for use as standards in the phosphate industry, and the AFPC samples are available from the Association of Florida Phosphate Chemists. Jenke and Diebold (1982) present major and minor oxide data by ICPS (inductively coupled plasma spectrometry) and AAS (atomic absorption spectrometry) for two phosphates, NBS$120 \mathrm{~b}$ and WPO 42 (Western Phosphate Organization). The source from which WPO 42 may be obtained is unknown, but NBS-694, a sample of western U.S. phosphate from Conda, Idaho, is being prepared.

\section{Sediments}

\section{Bay (Estuarine)}

The NBS issued SRM 1646, Estuarine Sediment, a bottom sediment furnished by the Virginia Institute of Marine Sciences, Gloucester Point, Va. The material was dredged from the Chesapeake Bay $\left(37^{\circ} 11.1^{\prime} \mathrm{N}, 76^{\circ} 17.1^{\prime}\right.$ W). Certified values are given for 16 major, minor, and trace elements, and noncertified values are given for 19 elements. The certified value for As (11.6 ppm) and the noncertified values for $\mathrm{Ce}(80 \mathrm{ppm})$ and thorium $(10 \mathrm{ppm})$ may reflect the industrial nature of the Newport NewsPortsmouth area on the James River, about $15 \mathrm{~km}$ southwest of the collection point. 
Canal (River)

The NBS issued SRM 1645, River Sediment, which was collected from the Indiana Harbor Canal, near Gary, Ind. The rather high values for $\mathrm{Pb}(714 \mathrm{ppm}), \mathrm{Hg}$ (1.1 ppm), $\mathrm{Sb}(51 \mathrm{ppm})$, and As (66 ppm) may be due to the industries, including iron and steel, in Gary.

\section{Lake}

A lake sediment, IAEA-SL-1, for determinations of trace elements has been available for almost a decade from the International Atomic Energy Agency. Merritt (1980) describes the collection and preparation of gyttja, a highorganic bottom sediment from Perch Lake at the Chalk River Nuclear Laboratories. Gyttja is a gelatinous sediment containing about 8 percent solids; approximately 50 percent of these solids is organic matter. Perch Lake in the Chalk River Nuclear Laboratories Waste Management Area has received low levels of ${ }^{90} \mathrm{Sr},{ }^{60} \mathrm{Co}$, and other radionuclides for more than 25 years, but the radioactivity is confined to the top $30 \mathrm{~cm}$ of material. The National Bureau of Standards is handling analytical program, and certification of the material is expected shortly.

\section{Marine}

Two marine sediments, IAEA-SD-B-1 and IAEASD-B-2, for measurement of fission products were available from the IAEA for about a decade. There is no more stock of these sediments, but three new standards have been prepared and are being analyzed. A marine sediment, USGS-MAG-1, was described by Manheim and others (1976), and Gladney and Goode (1981) summarized the data in the literature for this and other USGS samples. Two other marine sediments, MESS- 1 and BCSS- 1 , were announced by Berman (1981) of the National Research Council of Canada; he lists reliable values for 24 constituents of the samples.

\section{Pond}

Iwata and others (1981) collected a pond sediment at the University of Tokyo and tabled the contents of 4 major elements and 10 trace elements. The preparation of this pond sediment may have been prompted by the study of Goldberg and others (1976) of the metal pollution in sediments of the Palace moat, Tokyo.

\section{River (Radioactivity)}

A river sediment for the measurement of environmental radioactivity was issued by the NBS as SRM-4350-B. The certificate lists eight certified radionuclides and another nine radionuclides for which no corroborative measurements were available for comparison. The sediment was collected from the Columbia River, about $20 \mathrm{mi}(\sim 32 \mathrm{~km})$ downstream from Hanford, Wash.
Soils

\section{General}

Twelve soil samples were prepared by the Soil Mineralogy Work Group of the Southeastern United States. The samples were described and the data given by Barnhisel (1978). These soil samples were intended for soil scientists rather than geochemists. Trace element data for Soil-5 of the International Atomic Energy Agency were published by Dybczyński and others (1979). IAEA-Soil-6 and -7 may be available in 1984 .

Among the reference samples of the U.S.S.R. listed by Lontsikh and Parshin (1980) are soils SP-1, -2, and -3. Egranova and others (1981) list the 14 trace elements, but not the data, that were certified for the three soils.

Four soil samples issued by the CCRMP were described and data given in CANMET Report 79-3 (Bowman and others, 1979). Steger (1980) summarized the data on these and other CCRMP samples. Three soil samples were among the six geochemical exploration samples described by Allcott and Lakin (1975). The very high mercury content (Flanagan and others, 1982) of one soil from Utah reflects the mineralized area from which the sample was collected.

\section{Low-Level Radioactivity}

A soil for the measurement of environmental radioactivity, prepared as NBS SRM-4353, was collected at the Rocky Flats Plant $\left(\sim 105^{\circ} 00^{\prime} \mathrm{W}, 39^{\circ} 50^{\prime} \mathrm{N}\right)$, near Golden, Colo., and is certified for 13 radionuclides. An outline map of the location is given by Volchok and others (1980), who also describe the mechanical processing of the sample. A table of the probabilities that $k$ analytical samples out of $n$ contain hot particles of ${ }^{239+240} \mathrm{Pu}$ is given in the certificate for $n=1, k=1$, to $n=4, k=4$, for sample sizes of $1,2,5$, 10 , and $20 \mathrm{~g}$. As one might expect, the probabilities of sampling hot particles increase with increasing sample weights.

Another sample, NBS SRM-4355, is a soil collected at the IAEA Agricultural Experiment Station, La Molina, Lima, Peru (where IAEA-Soil-5 was also collected; Inn and others, 1984, p. 95). As many fallout nuclides cannot be measured, the sample is intended as a blank, or a very low-level standard for the measurement of environmental radioactivity. The sample is certified for six nuclides and for upper limits for five other nuclides. The certificate lists concentrations of 15 elements that can be recommended with a relatively high degree of confidence, of 19 elements with a reasonable degree of confidence, and of 23 elements given for information only.

"Natural Matrix" vs. Spiked Samples for Radioactivity

There are differing opinions about the efficiency of spiked samples or "natural matrix" samples. Bowen (1978) contends that the most generally useful standard materials 
are those that have been in contact, in their natural environments, with the radionuclides sought for the longest time possible and under the least special conditions. He notes that such materials would be analogous to samples in the biological literature described as "metabolically contaminated."

Olson (1980) prefers synthesized standards in natural matrices. He notes that standardized samples of individual nuclides may be combined quantitatively to produce a standard with selected ratios and levels of nuclides, and that such standards can be added to a chosen matrix to provide an optimum test. Olson notes that, for a natural matrix standard, nuclides are determined in the presence of the other nuclides in the material and at the levels at which they occur. Analyzed samples contain the biases of the analytical methods used in their standardization, and these biases are passed on to the procedures the sample is intended to check.

Volchok and Matuszek (1980), in a comment following Olson's (1980) paper, note that "spiking" can introduce biases from the presumption that the spike has been introduced in the same chemical form, valence state, or particle size as the radionuclide in the "real" sample. They note that Olson failed to discuss public acceptance of radiological data, and that public acceptance is enhanced when reference is provided to interlaboratory comparison using natural standards.

Bowen and Volchok (1980) discuss the merits of spiked sample standards. In addition to listing five criteria that calibrated test samples must meet if they are to be useful, they discuss special problems that require spiked samples and give suggestions for preparers and users of spiked samples. As examples of successful cases of spiked standards, they cite the soils prepared by Sill and Hindman (1974) and by Schulz, Tompkins, and Babcock (1976), and the spiked standard pottery clay prepared by the NBS.

Sill and Hindman (1974) described the preparation of standard soils containing known quantities of a desired radionuclide. They used water to make a paste of $100 \mathrm{~g}$ of the $-200+325$ mesh fraction of a soil in a platinum dish. They slowly added $1 \mathrm{~mL}$ of a solution of a purified carrier-free nuclide, stirring the mud during and after the addition to ensure homogeneous distribution of the nuclide. After drying the mud and weighing it, they weighted the soil remaining in the dish. After determining the activity of the soil in the dish, they corrected the activity of the large sample. They then added -200 mesh material of the same unspiked soil to obtain a sample of about $1,800 \mathrm{~g}$, which was blended overnight to ensure homogeneity. They prepared a second standard from a different soil and heated it for $1 \mathrm{hr}$ at $700^{\circ} \mathrm{C}$ to approximate conditions in laboratory ignitions. They diluted an aliquot of this standard 54-fold with no detectable loss of homogeneity or accuracy of the diluted standard. Another standard, diluted 934 times from the original $100 \mathrm{~g}$ of spiked soil, showed evidence of heterogeneity.

Schulz, Tompkins, and Babcock (1976) chose three California soils, (1) a forest soil rich in organic matter and slightly acid, (2) a neutral fertile valley alluvial soil, and (3) an alkaline calcareous soil. The soils were passed through a 16-mesh ( $\sim 1$-millimeter) sieve before blending. They prepared stock solutions of ${ }^{239,}{ }^{240} \mathrm{Pu}$ and ${ }^{241} \mathrm{Am}$ and diluted portions of these solutions to $100 \mathrm{~mL}$ with distilled water. They added each of these 100 -milliliter solutions to $16 \mathrm{~kg}$ of a soil in a Patterson-Kelley liquid-solid blender, rinsing the containers for the solutions with two 50-milliliter portions of distilled water to ensure complete transfer of the nuclides to the soil. They then blended the soil plus the added solutions.

The NBS prepared a standard pottery clay spiked with ${ }^{65} \mathrm{Zn},{ }^{113} \mathrm{Sn},{ }^{113} \mathrm{~m} \mathrm{In},{ }^{137} \mathrm{Cs},{ }^{137} \mathrm{~m} \mathrm{Ba}$, and ${ }^{139} \mathrm{Ce}$ by the method of Sill and Hindman (1974). Radionuclides in solution were added to about $100 \mathrm{~g}$ of slurried clay which was then dried and blended into about $20 \mathrm{~kg}$ of the same clay.

\section{Stable Isotope}

There are a number of reference samples for comparisons of stable isotope ratios. Gonfiantini (1978) notes that V-SMOW (Vienna Standard Mean Ocean Water) was prepared by mixing distilled water with small amounts of other waters to bring its isotopic composition as close as possible to that of SMOW defined by Craig (1961). Another sample, known by the acronym SLAP (Standard Light Antarctic Precipitation), was made by melting Antarctic ice and firn collected by E. Picciotto, Université Libré de Bruxelles, Belgium. SLAP is depleted in the heavy hydrogen and oxygen isotopes. GISP (Greenland Ice Sheet Precipitation) is a water sample prepared by $\mathrm{W}$. Dansgaard, University of Copenhagen, Denmark, by melting Greenland firn, and its isotopic composition is intermediate between those of $\mathrm{V}-$ SMOW and SLAP. Two other water samples are NBS-1, prepared by distilling Potomac River water, and NBS-1A, prepared from snow from Yellowstone National Park, Wyo. Some isotopic compositions versus SMOW are given for these five water samples in table 6 in Gat and Gonfiantini (1981, p. 39). Wit and others (1980) published data on the absolute hydrogen isotopic ratio of V-SMOW and SLAP.

Friedman and Gleason (1973) prepared a silicate reference sample for ${ }^{18} \mathrm{O}$ analysis. A glass sand from Africa, NBS-28, was examined both microscopically and isotopically. It was found to be relatively free of mineral grains other than quartz and to have a minor amount of inclusions relative to other sands examined. Matsuhisa (1974) determined the ${ }^{18} \mathrm{O}$ value of the sample to be +9.5 per mil relative to SMOW, a value 0.5 per mil lower than that reported by Friedman and Gleason.

Friedman and others (1982) published isotopic data for two new carbonate stable-isotope standards, TS Limestone (NBS-19), a marble of unknown origin, and Carbonatite (NBS-18) collected from Fen, Norway. The preparation of stable-isotope carbon dioxide reference samples, NBS-16 and NBS-17, from tanks of commercial liquified carbon dioxide and of commercial $\mathrm{CO}_{2}$ gas is described by 
Coplen and Kendall (1982). A paper on a new carbonate standard (Iceland Spar) for ${ }^{18} \mathrm{O}-{ }^{13} \mathrm{C}$ by Gary P. Landis (1983) was published in a new journal, "Isotope Geoscience." The sample was obtained outside the main portal of the Harding mine, and an Iceland Spar pit is shown on the geologic map of the Harding pegmatite in Montgomery (1950).

An undated informal information sheet of the International Atomic Energy Agency (P.O. Box 100, A-1400, Vienna, Austria) lists several other stable isotope standards, as follows:

- NBS-30: a sample of biotite separated by I. Friedman, J.R. O'Neil, and G. Cebula, U.S. Geological Survey, from a portion of the Lakeview Mountain Tonalite, Southern California Batholith (Larsen, 1948) collected by L.T. Silver, California Institute of Technology.

- OGS : a sample of barium sulfate precipitated from ocean water sulfate by Y. Horibe, University of Tokyo. The sample is intended for intercalibrating ${ }^{34} \mathrm{~S}$ and ${ }^{18} \mathrm{O}$ measurements in sulfates.

- Soufre de Lacq: a sample of natural elemental sulfur from the Lacq (France) deposit provided by E. Roth, Centre d'Etudes Nucleaires, Saclay, France. Its ${ }^{34} \mathrm{~S} /{ }^{32} \mathrm{~S}$ ratio, measured in Saclay versus CDT (Cañon Diablo Troilite), is $+17.3 \pm 0.4$ per mil.

- IAEA N-1 and N-2: two artificial samples of ammonium sulfate prepared by E. Salati, Centro de Energia Nuclear na Agricultura, Piracicaba, Brazil. The ${ }^{15} \mathrm{~N} /{ }^{14} \mathrm{~N}$ ratios of the samples, measured in Piracicaba versus NBS-14 (atmospheric nitrogen), are $+1.36 \pm 0.20$ per mil for $\mathrm{N}-1$ and $+20.85 \pm 0.20$ per mil for $\mathrm{N}-2$.

Another sample, NBS-20, is mentioned in Coplen and Kendall (1982). The sample is briefly described by Neir (1950, table 6) as a Jurassic limestone from Solenhofen, Bavaria, and it is one of a number of reference samples listed by Mohler (1955) as available from the NBS for isotopic work.

Craig (1957, table 5) lists averages of determinations of $\delta^{13} \mathrm{C}$ and $\delta^{18} \mathrm{O}$ in eight samples. Included among the samples are a portion of the Solenhofen limestone obtained from Nier (1950) and a portion of NBS-20. Craig (1957, p. 146) notes that the material from Nier and NBS-20 represent different samples of the Solenhofen limestone, the NBS sample having been recently acquired from the USGS. Historically, thick slabs of the fine-grained Solenhofen limestone were used in the USGS printing plant for maps, a practice essentially discontinued in the mid-1930's when copper plates became the principal method used for maps. NBS-20, prepared from a slab weighing approximately 100 $\mathrm{lb}$, was given to the NBS by Irving Friedman (U.S. Geological Survey, Denver, CO 80225, written commun., 1984).

Craig (1957) also listed the averages for a sample of the Te Kuiti limestone. Blattner and Hulston (1975) announced the availability of a sample of the Te Kuiti limestone and a sample of an unnamed low- ${ }^{18} \mathrm{O}$ coarse-grained calcite. Blattner and Hulston (1978) reported data resulting from an interlaboratory comparison of proportional variations of geochemical $\delta^{18} \mathrm{O}$ scales, designating the Te Kuiti limestone TKL-1, and the unspecified but pure calcite (Kaikoura) K-2. Their table 2 contains a summary of determinations of carbon isotope compositions of TKL-1 and $\mathrm{K}-2$ by different analysts.

Coplen and others (1983) published averages, obtained by one laboratory, of $\delta^{18} \mathrm{O}$ values of 13 reference samples relative to V-SMOW and PDB. Craig (1957, p. 135) had defined PDB as a Cretaceous belemnite, Belemnitella americana, from the Peedee Formation of South Carolina. Coplen and others (1983) also listed in their table 2 average determinations of $\delta^{13} \mathrm{C}$ relative to PDB for eight reference samples.

\section{Geobotanical Samples}

There are a number of biological reference samples that can be used for geobotanical investigations. Among the earlier such samples is the powdered kale sample for which Bowen (1967) discussed the elemental analyses. Wainerdi (1979) critically examined the published data on Bowen's kale. He recommended values for 12 major, minor, and trace constituents, gave "indicated values" for 16 major, minor, and trace elements, and made no recommendations for 15 other elements.

The wheat flour (SRM 1567), the rice flour (SRM 1568), the citrus leaves (SRM 1572, in preparation), the tomato leaves (SRM 1573), and the pine needles (SRM 1575) of the NBS might be useful for geobotanical investigations. Pinta (1977a, 1977b) lists data for leaves from nine trees-cotton, palm, and rubber trees from Africa, eucalyptus, olive, and orange trees from Spain, peach and apple trees from France, and a golden apple tree from Belgium. $\mathrm{He}$ also gives data for codia (a globular shrub) from New Caledonia, maize from Spain, and an unspecified vine from France. Troll and Farzaneh (1980) determined fluorine in the samples listed by Pinta (1977a).

Japanese tea leaves were prepared by Fuwa and others (1978) as a possible standard reference material. Okamoto and others (1978) prepared leaves of the pepperbush tree, known to accumulate $\mathrm{Zn}, \mathrm{Mn}, \mathrm{Co}, \mathrm{Ni}$, and $\mathrm{Cd}$, as a standard reference material. The homogeneity of a Chinese sample, peach leaves, was tested by Tu and Leiser (1984a, 1984b).

Schramel and Xu (1982) reported the beryllium content of a reference sample of riparioides, an aquatic plant. The sample of riparioides, undergoing certification at the time of publication, appears to be a sample from the Community Bureau of Reference with the number BCR-61, and the sample is so listed in the 1982 BCR catalog. The catalog lists two other botanical samples, BCR-60, aquatic plant (lagarosiphon), and BCR-62, olive leaves.

The latest IAEA catalog, titled "Analytical Quality Control Services Program, 1983-1984," lists several botan- 
ical samples, as follows: hay (powder), $\mathrm{V}-10$; seaweed, AG-B-1; rye flour, V-8; and cotton cellulose, V-9.

The U.S.S.R. also has botanical reference samples. Shafrinskii (1977) gives a very brief and general discussion, almost the equivalent of an announcement, of the development of standard samples of plant materials. Nalobin and others (1980) table estimates of the parameters of regression equations but give no analytical data. The plant sample names (subject to later change) and numbers are as follows: grain-grass mixture, SBMT-01; wheat grain, SBMP-01; and potato tubers, SBMK-01. Nalobin and others do not list the U.S.S.R. state registry numbers (USSR SRN) for standard samples; this seems to be a practice for reference samples of rocks, ores, and soils.

Savinova and others (1981) discuss the direct simultaneous spectrographic determination of copper and molybdenum in soils and plants. Their emphasis, however, is on soils; they give in table 2 the certified contents and amounts of $\mathrm{Cu}, \mathrm{Co}, \mathrm{Mo}, \mathrm{Mn}, \mathrm{Ni}$, and $\mathrm{V}$ found in three soil standards, SP-1, -2 , and -3 . A figure shows calibration curves for determining $\mathrm{Cu}, \mathrm{Co}$, and $\mathrm{Mo}$ in plants.

Karpukova and others (1982) report $\mathrm{x}$-ray fluorescence determinations of $\mathrm{Na}, \mathrm{Mg}, \mathrm{Al}, \mathrm{Si}, \mathrm{S}$, and $\mathrm{Cl}$ in the potato, wheat, and grass standards using the same sample numbers as in Nalobin and others (1980). They also report, in table 2, determinations of $\mathrm{P}, \mathrm{K}$, and $\mathrm{Ca}$ in these samples and in 14 other botanical samples. Samples in a column titled "Standard Sample (SS)" have numbers such as "SS of wheat straw No. 1-78," where 1-78 may be a State Registry Number.

Zvyagintsev (1983) tables "standard accuracies" for plant analysis of standard samples of potato, wheat, and mixed grass, the materials being further identified as SS1483-78, SS1418-78, and SS1485-78, respectively. Lacking other evidence, one might assume that samples identified in Nalobin and others (1980) by prefixes such as SBMT may, in fact, be the same samples identified in Zvyagintsev (1983) by what appear to be U.S.S.R. State Registry Numbers.

\section{TOPICS AND PROBLEMS FOR REFERENCE SAMPLES AND THEIR DATA}

\section{Reasons for Reference Samples}

The most obvious reason a reference sample is available is that some person or institute prepared a sample to help solve an existing problem. Whereas there were no standards about a century ago, but only samples that had been analyzed cooperatively by a number of chemists, we now seem to have an ever-increasing number of reference samples designed for specific purposes. In addition to reference samples analyzed by many chemists throughout the world, we often find internal, or in-house, standards such as the limestone and the clay-slate of the Geochemical Institute of the University of Göttingen for which data were reported by Abo-Rady (1979). As one might expect, the scientific value of the numerous formal and informal reference samples ranges from very good to questionable.

The age of standards in the United States began with the establishment of the National Bureau of Standards (31 Statutes at Large, Fifty-Sixth Congress, Sess. II, Chapter 872, An act to establish the National Bureau of Standards) on March 3, 1901. A few years later, Andrews (1908) addressed the question, "What can be done to enhance the value of the work of the Bureau of Standards to the chemical industries?" He suggested two groups of materials to be standardized: (1) substances used for standardizing volumetric solutions (or the solutions themselves), and (2) standardized commercial materials by which manufacturers can control their analytical processes.

In the following year, Ebaugh (1909) mentioned in an editorial the preparation of iron standards by a foundrymen's association [American Foundrymen's Association (Cochrane, 1966, p. 93)], the standardized irons and steels of the NBS (Hillebrand, 1909), the four phosphate rocks of the American Fertilizer Association (Hagedorn and others, 1909), and the samples of products that were prepared and distributed by the Committee on Analysis of Fats, Soaps, and Glycerine of the American Chemical Society (ACS). Ebaugh believed that the ACS Division of Industrial and Engineering Chemistry might do yeoman's service by preparing, standardizing, and distributing samples for which there might be a demand. Ebaugh's editorial was followed shortly by a letter to the editor by Jones (1909), who suggested that standardized samples of bituminous coals and cokes be the first to be considered.

Although many reference samples have been prepared for specific reasons, it has been evident for more than two decades that one should no longer prepare a rock, mineral, or ore standard for a single purpose. The USGS rocks G-1 and $\mathrm{W}-1$, and the older NBS samples, were prepared mainly for determinations of their major and minor constituents. However, the literature of two decades ago contains many papers on determinations of trace elements in G-1 and W-1 and in NBS samples of economic rather than geologic interest by, among others, Shimp and others (1957), Grabowski and Unice (1958), Turekian and Carr (1961), Clark and Swaine (1963), Filby (1964), Taylor and Kolbe (1964), and Ball and Filby (1965). Another example of a use for which a sample was not intended is discussed in the paper by Compston and others (1969) on the feasibility of using NBS 70a $\mathrm{K}$-feldspar as a $\mathrm{Rb}-\mathrm{Sr}$ age reference sample.

As scientific inquiry is obviously not inhibited by the purpose for which reference samples were prepared, the preparer should try to anticipate future needs by conforming to the requirements for the most sensitive, accurate, and precise methods available now and in the foreseeable future. 
If reference materials are prepared carefully for these refined methods, they should be satisfactory for methods with less stringent requirements. Because newer methods with better sensitivity might be developed in the future, preparers of geochemical reference samples should ensure that their method of preparation does not add significant amounts of contaminating elements that may change the geochemistry of the rock samples.

There is no easy answer to the question of which rock standards should be prepared. The potential preparer might consult the paper by Nockolds (1954) to determine which igneous rocks are not represented in a list of available standards. Although most work in geology concerns igneous rocks, similar consideration might be given to metamorphic rocks - and Parker (1977) has inquired about the need for sedimentary rock samples. Appel (1980) discussed a possible reference sample of a banded-iron formation, including the economic implications for the mineralization of gold and other elements. Abbey and others (1983) published data on four Canadian iron-formation samples, and a report was published (Govindaraju, 1984b) on two GIT-IWG samples, iron formation, IF-G, and albite, AL-1.

One can obtain a number of samples in which some constituent, say $\mathrm{SiO}_{2}$, will cover the entire range for the igneous rocks in Nockolds (1954), but it would be time consuming to prepare these rocks as reference samples. It would then be a more difficult problem to find geoanalysts willing to contribute good data to establish the compositions of these samples. Many geochemists are involved in topical studies representing only part of the spectrum of igneous rocks, and they may be reluctant to contribute data that may not be immediately applicable to their study.

A better criterion for selecting rocks as candidate reference samples may be based on trace element geochemistry, specifically a large void that may exist in the information about the trace element contents of existing samples. As an example, the best value for $\mathrm{Ce}$ in $\mathrm{W}-1$ divided by the average of the best Ce values for DTS -1 and PCC -1 yields a concentration ratio of $3 \times 10^{2}$. The similar ratio for the $\mathrm{La}$ contents is also $10^{2}$.

Because the supply of $\mathrm{W}-1$ was depleted in 1972, several of us collected another large sample of the Centreville Diabase, a sample now known as W-2. P.C. Ragland and J.R. Butler of the University of North Carolina collected a large portion of a North Carolina dolerite, now DNC-1, and Karl Gronwold of the Nordic Volcanological Institute, Reykjavik, collected a large portion of an Icelandic basalt, BIR-1. The best estimates for $\mathrm{Ce}$ and $\mathrm{La}$ in these new samples show two levels of $\mathrm{Ce}$ and La between $\mathrm{W}-1$ and the two ultramafic samples.

\begin{tabular}{|c|c|c|c|c|c|c|c|}
\hline DTS-1 & PCC-1 & BIR-1 & DNC-1 & W-1 & W-2 & BHVO-1 & BCR-1 \\
\hline 0.06 & 0.09 & 1.6 & 9.1 & 23 & 23.4 & 41 & 54 \\
\hline .04 & .15 & .63 & 3.6 & 9.8 & 10.4 & 17 & 26 \\
\hline
\end{tabular}

Another criterion for selecting a sample is the replacement of an important but now depleted sample, provided the original sampling location is precisely known. Thus, when the supply of the Twin Sisters Dunite, DTS-1, was nearly depleted, R.W. Tabor of the USGS, one of the original collectors of DTS -1 , collected about $600 \mathrm{lb}(\sim 270 \mathrm{~kg})$ of the same rock at the original location. This sample has been processed at DTS-2 and, except for trace elements in the thin veins of chromite in the rock, the compositions of DTS -1 and DTS -2 may be similar.

\section{Amount of a Rock Reference Sample}

G-1 and $\mathrm{W}-1$ were prepared as 90 and $210 \mathrm{lb}$ of powder, respectively (Fairbairn and others, 1951), and the portions of the samples were contained in 2-ounce (60milliliter) bottles. After 15 years of distributing the samples, the contents of the 2-ounce bottles were subsampled into 4-dram ( $\sim 14$ milliliter) vials, thereby extending the supply of G-1 until 1965, and of W-1 until 1972.

When considering the program of rock samples that resulted in the series $\mathrm{G}-2$ through $\mathrm{BCR}-1, \mathrm{I}$ decided to process enough rock to yield at least 2,000 one-ounce (30milliliter) bottles of each sample. I estimated that these amounts would last about $25 \mathrm{yr}$, but requests from scientists in the NASA Lunar Program resulted in an accelerated distribution of portions, thereby reducing their anticipated lifetimes.

The production of rock reference samples is costly to both producers and analysts. On the basis of experience with two sets of rock samples, I believe that a reference sample should be not less than $250 \mathrm{~kg}$, an amount that should last about 30 years. Tauson and others (1976) recommended amounts of at least $500-600 \mathrm{~kg}$, and Govindaraju and others (1977) prepared a 1-ton granite reference sample. Govindaraju and Mevelle (1983) list the amounts of CRPGANRT samples prepared.

A greater amount should be processed if the geochemistry of the rock indicates that it may be more important than samples currently available. The problems of processing a 500-kilogram sample are less than twice those of processing a 250-kilogram sample. A large amount may be processed through the steps of powdering and mixing, the powder sampled into a number of bottles estimated to last some years, and the remaining mixed powder stored in airtight plastic containers for future sampling into bottles.

A word of caution is in order for those who would prepare a large portion of a rock as a reference sample: Whether we crush the large sample to a grain size of $1 / 4$ in $(\sim 6 \mathrm{~mm})$ or to a powder passing a 200 -mesh screen, the distribution of the minerals and of the particle sizes may be described by one of several statistical distributions, the Poisson being the simplest.

If we crush a granite to pass a 1/4-inch screen, excluding the dubious procedure of selecting material in some size 
range, say $-1 / 4$-inch +100 mesh, there are problems to consider. Information on which of several minerals in a rock is crushed more readily to a powder is scarce. Biotite, often occurring in rocks as "books," is difficult to crush to fine grain sizes: some methods of size reduction may affect the $\mathrm{H}_{2} \mathrm{O}$ contents or the crystal structure of the mineral.

Zircon crystals smaller than 200 mesh have been found between leaves of the books of mica in this laboratory. A producer might decide to subsample the $1 / 4$-inch material into five lots, powdering one lot now and the other four lots later as more reference sample is needed.

In the extreme case in which only one book of mica is present in the bulk sample, only one of the five lots can contain the book of mica. By subsampling the coarse material, the producer introduces an error in the determinations of zirconium and hafnium and of trace elements concentrated in the mica, and the error cannot be corrected by powdering the five lots individually, assuming that the five lots are not then mixed as a unit. The producer should therefore subsample only after the entire amount of bulk material is powdered as a unit to some specification, say passing 200 mesh.

\section{Reference Samples vs. In-House Standards}

The relation between reference samples and in-house standards is emphasized by the depletion of four USGS rocks of the 1964 series. In spite of an urging that, "university laboratories and other organizations * * * consider the preparation of in-house standards that will both conserve the supply of valuable international reference materials and ensure the individual organization of a plentiful supply of secondary standards for their own use" (Flanagan, 1974, p. 1739), less than 1 percent of those requesting USGS rocks indicate that they intend to prepare in-house standards and calibrate them. I have the impression (as may other producers) that many scientists feel they can request and receive samples as often as they wish.

Members of organizations are again urged to prepare a portion, say $10 \mathrm{~kg}$, of two or more local rocks as in-house standards. They could then determine the contents of several elements in the rocks by the method of standard additions. This would both conserve the supply of reference samples and ensure a lasting supply of two or more in-house standards. Potts and others (1981) calibrated a granite as an in-house irradiation standard by the method of standard additions. Despite the failure of requesters of samples to mention that they intend to prepare their own standards, the number of reference samples that may be called, collectively, "in-house" standards has increased greatly in the last decade.

Pérez and others (1979) prepared four samples of igneous rocks weighing 10 to $15 \mathrm{~kg}$ each; "in-house" was included in the formal title of the report. Two olivine basalts were collected at an outcrop at Ciudad Universitaria,
Mexico City, and a dacite and a rhyolite were obtained from road cuts at nearby locations. The samples were the first to be collected for a project on Mexican Reference Samples for Geochemistry. The report gives chemical analyses and C.I.P.W. norms (Cross and others, 1902) for the four samples, plus determinations by instrumental neutron activation analysis and some preliminary data obtained by spark source mass spectrometry.

\section{Comminution and Grindability}

The preparer of a rock standard should have some idea of the potential difficulties before starting to process a sample. One might expect, for example, that a crystalline igneous rock would be much easier to crush than a glassy or microcrystalline rock.

One measure of the difficulty of crushing is the work index - the work required to reduce a unit weight of a rock from a theoretically infinite size to the size at which $\mathbf{8 0}$ percent will pass a 100 -micrometer screen. Table 8-3, Average Work Indexes for Various Materials, in the "Chemical Engineers' Handbook" (Snow and others, 1973) lists several crystalline rocks whose work indices approach those of glassy rocks. The work indices for the several rocks range from 14 to 22 . Mica has a high index of 134 because of its crystalline form and the work necessary to crush the flat plates of mica to pass a 100 -micrometer screen.

Other sources of information on crushing rocks include the "Handbook of Mineral Dressing; Ores and Industrial Minerals" by Taggart (1945) and the summary of investigations on crushing by Gross (1935), which includes a bibliography of 128 references. Gross (1938), in U.S. Bureau of Mines Bulletin 402, discusses the many variables in crushing and grinding and gives an annotated bibliography of 142 references. Texts on mineral dressing similar to that of Gaudin (1939) should contain similar information.

\section{Homogeneity, Sampling Errors, and the Sample for Analysis}

Many powdered rock reference samples are homogeneous. When considering the preparation of a rock as a reference sample, the first question for both the collecting geologist and the preparer is whether the candidate rock is suitably homogeneous. Chayes (1967), as a result of point counting of thin sections of the rock now known as G-2, concluded that there should be no concern about the rock being heterogeneous prior to crushing. By inference, the powdered sample should also be homogeneous for determinations of major and minor oxides. If a reference sample of a coarse-grained rock is desired, a similar study of the rock might be made prior to other work.

For reassurance about the grain size to which rock samples should be crushed so that the powders will be homogeneous, one might consult the section on Sampling and 
Testing by Behre and Hassialis (1945) in Taggart's "Handbook of Mineral Dressing." They derived, starting with the binomial distribution, a rigorous expression that may be used to calculate the amount of sample necessary, given a specified grain size, or the error that may be incurred for a given amount of sample. The several examples in tables may be used as models to calculate the grain size of a crushed rock not to be exceeded if one wishes to set an upper limit for the error that may be incurred when sampling the rock powders.

In a pair of related papers, Reiss and others (1945) and John and others (1945) used the binomial distribution for an expression to reduce misrepresentation of data (errors) to some desired value. The authors include a graph relating the percent relative sampling error, the number of particles in the sample, and the percentage of the desired constituent.

Bennett and Franklin (1954) discuss the size-weight ratio,

$$
\frac{\text { weight of largest particle of impurity } \times 100}{\text { weight of reduced sample }}=b,
$$

for sampling coal. The variance component due to subsampling is unlikely to exceed $b x$ where $x$ is the percentage proportion of impurity in the large sample. Bennett and Franklin note that this value provides an overestimate of the variance component due to subsampling since the impurity is unlikely to consist of particles all of which are of the maximum size.

Benedetti-Pichler (1956) has an excellent section on the theory and principles of sampling for chemical analysis in which he discusses sampling error and its relation to particle size distribution. Laffitte (1957) use the Poisson distribution to calculate errors, giving examples for $\mathrm{CaO}$ in a granodiorite, $\mathrm{SiO}_{2}$ in a granite, and $\mathrm{P}_{2} \mathrm{O}_{5}$ in a gneiss containing grains of apatite. Visman $(1962,1969)$ discussed sampling constants, defining his sampling constant on page 12 of the earlier paper. Gy (1967) also discussed a sampling constant and published a text (Gy, 1979) on the sampling of particulate matter.

Other papers on sampling errors and related topics published in the 1960's are by Wickman (1963), who used the Poisson distribution, Wilson (1964), the multinomial, and Kleeman (1967), the binomial. Kleeman (1967, p. 46) recommended that "all standard rock powders $* * *$ be ground initially to pass a 230-mesh sieve and that where the analyst wishes to take samples smaller than $0.5 \mathrm{~g}$, a portion of the main bulk be ground to an impalpable powder." Clifton and others (1969) used the Poisson distribution in their discussion of sample size and meaningful gold analysis.

Ingamells and others (1972) tabled sampling constants for several components of reference samples and minerals in their discussion of laboratory sampling error in geochemistry and geochronology. Scilla and Morrison
(1977) and Drummer, Fassett, and Morrison (1978) used the sampling constant concept in their papers on sampling error in ion microprobe analysis. Harris and Kratochvil (1974) used the binomial distribution for sampling error and gave the formula by Benedetti-Pichler (1956) for the number of grains required to obtain a representative sample. Flanagan (1976a) used the Poisson distribution without the covariance term as an approximate method for computing errors due to sampling rock powders. Birger and Bruk (1977) used the Poisson distribution to ensure that a sample of gold-bearing ore was representative. Moore (1979) used the Poisson distribution to derive an expression for sampling errors.

The allied subjects of particle size, sample size, and sampling error have been discussed in texts and journals devoted to mining and metallurgy since the start of this century. Errors in assays may have concerned postMedieval assayers (Agricola, 1950), as one may infer from the English translation of the first Latin edition (1556) of De Re Metallica a suggestion that replicate samples be assayed.

Brunton (1896) published a study whose aim was to determine the fineness to which crushing must be carried to obtain data within an allowable limit of error when sampling gold and silver ores. In addition to diagrams for determining this fineness, he concluded that the size to which ore should be crushed before sampling so that assays would be within an allowable limit of error depends on:

1. The weight of the sample. The smaller the sample, the finer the material must be crushed.

2. The relative proportion between the value of the richest mineral and the average value of the ore. High-grade ores may be crushed more coarsely and the data will still be within the same percentage error.

3. The specific gravity of the richest mineral. A high specific gravity for the richest mineral will affect the assay of the sample, and fine grinding is indicated.

4. The number of particles of the richest mineral in the sample. Fine grinding is necessary when there are few such particles.

The principles underlying the four conclusions of Brunton (1896) were mentioned earlier by Reed (1885). After summarizing three rules (adequate mixing, impartial selection (sampling), and proper relative comminution) that should govern a properly conducted ore sampling operation (Reed, 1882), Reed (1885, p. 353) wrote:

*** what rule is to guide us as to the degree of fineness to which we should crush or grind before each successive reduction? I conceive the principle involved to be the following:

The divergence of any portion of a lot of ore from the average percentage composition of the whole is due to the excess or deficit of one or more particles. The effect on the result will be the greatest when pieces causing this divergence are of the largest size and richest quality.

Reed then gives a formula for the diameter of the largest particle size to which a lot of ore must be crushed or 
ground so that the largest allowable error will not be exceeded. The variables in the formula,

$$
D=0.05[m p e] /[s k(f-1) a]^{1 / 3}
$$

are the diameter, $D$, of the largest particle, the grade, $m$, and quantity, $p$, of the lot of ore, the largest allowable error, $e$, the specific gravity, $s$, and the gold or silver content, $k$, of the richest specimens, the number of parts, $f$, into which the lot is divided, and the number of pieces, $a$, of size, $D$, and value, $k$, that can be in excess or deficit in the portion chosen for the sample.

Reed (1885) gave a table for crushing amounts of ore of three grades. The maximum permissible diameters of pieces for combinations of amounts and grades of ore are listed in inches, but he added the practical equivalents of the diameters as coconut, fist, orange, egg, walnut, chestnut, pea, and wheat.

Hofman (1901), in his discussion of crushing and sampling, gave a table prepared by Vezin (uncited work, 1866). The table contains data for the minimum weight of sample in pounds for the diameter of the largest piece of ore in inches or millimeters, and the table reflects the constant ratio between the weight of the sample and the size of the largest particle that should be maintained through every stage of commercial crushing and sampling. Hofman included a table of safe sample weights to be taken, based on the diagrams of Brunton (1896), and a slightly condensed version of the table of Reed $(1885$, p. 357) in which the maximum permissible sizes of ore for a given grade are listed only as the practical units of coconut, fist, or orange.

Richards (1903), after discussing Brunton's (1896) paper, plotted sample weights versus diameters of the largest particles, where the weights are proportional to the squares of the diameters of the particles. Samter (1908) in his short review paper on the theory and practice of sampling granular materials, listed the four conclusions of Brunton (1896) and derived a formula for the largest piece of ore that is similar to the formula of Reed (1885). He also reproduced the tabulation in Richards $(1903$, p. 850$)$ for amounts of ore to be taken for different grain sizes, and the larger table of Richards (1903, p. 852) for sample weights to be taken when sampling ores of six different grades. Griffin (1909), after discussing the paper of Brunton (1896), showed that variations in analytical data are normally distributed.

Bailey (1909a, 1909b) used the "size-weight percentage" in his paper on sampling coal. This criterion is the same as the size-weight ratio in Bennett and Franklin (1954, p. 485), who refer to Bailey (1909a), but the size-weight ratio is a percentage because of the multiplication by 100 . Bailey's size-weight percentage is a formal name given to the ideas in Hofman (1901) and Richards (1903), and it appears to be a simplification of the formula of Reed (1885).

Demond and Halferdahl (1922a) in their paper on the mechanical sampling of ore used the expression

$$
W=k D^{a},
$$

where $W$ is the weight of ore, $D$ is the diameter of the largest particle, and $k$ and $a$ are constants. They tabled sampling data for several crushing plants where $a$, the exponent to which the diameter is raised, ranged from 1.0 to 3.76. They noted that an $a$ as low as 1.4 should never be used and that $a$ should never be as great as 3.0. In a later paper on sampling spotty gold ores (Demond and Halferdahl, 1922b), their example of the amount of gold ore necessary for particles of various sizes reminds one of the similar example in Wickman (1963).

Behre, in his section 21 on sampling in the earlier edition of Taggart's (1927) "Handbook of Ore Dressing," mentioned the four factors (allowable error, worth of the valuable mineral, size of largest pieces in the lot, and the size and number of pieces of valuable mineral) that govern the minimum weight of sample allowable. Among other items, he discussed the diagrams of Brunton (1896) and the formula of Demond and Halferdahl (1922a), but he did not give the formula in Behre and Hassialis (1945) derived from the binomial.

Analysts have recognized errors in their work for many years. Benedetti-Pichler (1922) discussed the sources and magnitude of percentage errors in quantitative analysis. For the electrolytic determination of copper in various materials containing copper, including alloys, he recommended (Benedetti-Pichler, 1923, p. 321) that a 5- to 10-gram sample in a 250 - or 500 -milliliter flask be dissolved in nitric acid, the solution filled to the mark, and a 50-milliliter aliquot taken for analysis. He later made a similar suggestion about a large powdered sample and a small aliquot of a solution of this sample in his text on the microtechniques of inorganic analysis (Benedetti-Pichler, 1942, p. 238).

Mika (1928), in his contribution to sampling, derived the relation between the minimum weight of sample and the amount of pulverization required. Baule and BenedettiPichler (1928) started with the binomial distribution to derive a formula that allowed one to calculate the error resulting from the sampling procedure. The formula could also serve for determining the necessary particle size as well as the minimum weight of sample. Baule and BenedettiPichler also noted that one equation in Mika (1928) applies only for a special case.

The preceding discussion of the several methods is not intended to be exhaustive. The summary of methods by author, year, and abbreviated method in table 4 shows that many of us have reinvented the wheel. Five authors, not including Bennett and Franklin, used the size-weight relation, three used sampling constants, five used the binomial distribution, and six started with the Poisson distribution, which may be derived from the binomial.

One may infer from the differences between years of publications in table 4 that the list of references is not exhaustive. A search of literature published during the first half of the century may depend as much on luck as on 
Table 4. Summary of methods relating sampling, errors, and particle size

\begin{tabular}{|c|c|}
\hline Author & Method \\
\hline Reed $\ldots \ldots \ldots \ldots \ldots \ldots 1885$ & Sample weight/size of largest particle \\
\hline Brunton $\ldots \ldots \ldots \ldots \ldots \ldots 1896$ & Four written conditions (see text) \\
\hline Hofman $\ldots \ldots \ldots \ldots \ldots 1901$ & Sample weight/size of largest particle \\
\hline Richards . . . . . . . . 1903 & Sample weight/size of largest particle \\
\hline Griffin $\ldots \ldots \ldots \ldots \ldots 1909$ & Variation in data and normal distribution \\
\hline Bailey ............. 1909a & Size-weight percentage \\
\hline Demond and Halferdahl $\ldots \ldots$ 1922a & $W=k D^{a}$ \\
\hline Baule and Benedetti-Pichler . . 1928 & Binomial \\
\hline Behre and Hassialis . . . . . 1945 & Binomial \\
\hline Reiss and others $\ldots \ldots \ldots 1945$ & Binomial \\
\hline Bennett and Franklin . . . . 1954 & Size-weight ratio \\
\hline Laffitte . . . . . . . . . 1957 & Poisson \\
\hline Visman . . . . . . . . . 1962 & Sampling constant \\
\hline Wickman $\ldots \ldots \ldots \ldots \ldots 1963$ & Poisson \\
\hline Wilson $\ldots \ldots \ldots \ldots \ldots 1964$ & Multinomial \\
\hline Gy $\ldots \ldots \ldots \ldots \ldots \ldots 67$ & Sampling constant \\
\hline Kleeman . . . . . . . . . . 1967 & Binomial \\
\hline Clifton and others $\ldots \ldots \ldots 1969$ & Poisson \\
\hline Visman . . . . . . . . . 1969 & Sampling constant \\
\hline Ingamells and others $\ldots \ldots \ldots 1972$ & Sampling constant \\
\hline Harris and Kratochvil . . . . 1974 & Binomial \\
\hline Flanagan . . . . . . . . 1976b & Poisson \\
\hline Birger and Bruk . . . . . . . 1977 & Poisson \\
\hline Moore . . . . . . . . . . . . . . 1979 & Poisson \\
\hline
\end{tabular}

perserverance, as the titles of earlier papers on the subject are not always as explicit as those of Samter (1908, "Theorie und Praxis der Probenahme körniger Materialien (Erze)"), of Mika (1928, "Theoretische Beiträge zur Probenahme"), and of Baule and Benedetti-Pichler (1928, "Zur Probenahme aus körnigen Materialien").

Most of the methods relating particle size, sampling errors, and the amount of analytical sample to be taken may be used to (1) calculate the error that might be incurred, given a specified weight of sample, (2) specify the amount of sample to be taken to keep sampling errors at or below some level, or (3) specify the grain size to which a sample must be crushed so that significant sampling errors may be avoided. Calculations by most methods should show that errors due to sampling heterogeneous materials may be ignored if the material is powdered to pass a 200-mesh sieve or, for Kleeman (1967), a 230-mesh sieve.

\section{Small Samples-Precautions and Preparation}

Inspection of either compilation of data on the USGS samples (Flanagan, 1969, 1976c) shows numerous data obtained by the isotope dilution-mass spectrometric (IDMS) method for elements in the series of samples G-2 through BCR-1. The possible use of IDMS for lead isotopes was considered prior to preparation of these reference samples, but the numerous determinations resulting from the NASA
Lunar Program were not anticipated in 1963. The samples were, therefore, not sieved, for two reasons: (1) the task of sieving at least $100 \mathrm{~kg}$ of powder for each rock sample would have been enormous; and (2) lead might have been introduced into the samples if the screen was soldered to a sieve frame.

The decision to avoid sieving is not new: in 1908, Hillebrand advocated not sieving rock samples prepared for analysis. He did not specify the material of the wire cloth for the sieves, and the frames may have been made of brass. Since brass scratches readily, brass would be removed from any surfaces of the sieves by ground silicate rocks, whose hardness may vary from 5.5 to 6.5 on Moh's scale of hardness.

Thompson and Bankston (1970) describe tests for contamination using Specpure $\mathrm{SiO}_{2}$ and $\mathrm{CaCO}_{3}$ and a natural quartz sand. Half-gram portions, about the size used in their analytical program, were powdered in several small grinding devices and sieved through several screen materials. The authors present emission spectrographic data to indicate the level of contamination.

Hillebrand (1908), in a paper on the effect of grinding on the water and ferrous iron contents of rock and minerals, confirmed the conclusion of Mauzelius $(1907$, p. 7$)$ that "the percentage of ferrous iron is diminished by pulverizing, and no other explanation can be given for this than that one of the minerals contained in the rock has been oxidized during the grinding." Both authors used some form of a "diamond" steel mortar, although Hillebrand's was called an "Ellis' mortar" (Hillebrand, 1907, p. 46). Both men used agate mortars to grind to a grain size of $0.18 \mathrm{~mm}$ (100 mesh) or finer. Mauzelius did not state if his was a hand operation, but Hillebrand noted that grindings for 20 or 30 min were by hand and that those for a longer time were by a McKenna mechanical grinder. The latter was a primitive version of automatic mortar grinders, for example, the Fisher grinder, which has been used for at least the last three decades.

Grinding can cause changes both in some chemicals and in the crystallography of some minerals. Lea (1893) reported some decomposition of silver chloride, sodium chloraurate, and other chemicals when compounds were ground with a mortar and pestle. Jamieson and Goldsmith (1960) reported some changes in natural and synthetic carbonates when portions were ground in a mechanical mortar for periods of up to 3 days. The changes were noted in $\mathrm{x}$-ray diffraction patterns after grinding for several intervals of time.

Burns and Bredig (1956) showed that calcite, the stable form of calcium carbonate, can be converted to the metastable form, aragonite, by grinding. $\mathrm{X}$-ray diffractometer traces of $\mathrm{CaCO}_{3}$ after grinding for periods of 0.5 to 38.3 hr showed an increase in peak heights for aragonite and a simultaneous decrease in peak heights for calcite. The metastable form reverts rapidly to calcite when heated to about $400^{\circ} \mathrm{C}$. 
The effects of grinding on the water and ferrous iron contents of rock samples have been amplified since the introduction of mechanical grinders not of the mortar-andpestle design. The most common type of grinder formerly used to powder samples is the disc or plate grinder. The older models were driven by belts connecting the motor and the drive shaft for the disc, but direct-drive models have been available for at least two decades. For both types, the stationary plate through which the sample is fed is hinged to the frame of the grinder and the movable plate is attached to the shaft. The distance between the stationary and movable plates may be adjusted for the desired grain size of the finished product.

Another grinder for small amounts of rock sample is the vertical Braun sample grinder which has curved movable and stationary plates. This grinder is useful for small amounts $(\leq 200 \mathrm{~g})$ of sample. The curvature of both plates may be roughly described as the bottom half of a hyperboloid of a single sheet, the hyperboloid being generated by revolving a hyperbola around its axis of symmetry erected vertically. The movable lower plate is threaded to the vertical shaft, and the stationary plate, with a hole in the center through which sample is fed, is attached to the unit. Grinding occurs between the upper surface of the movable plate and the undersurface of the stationary plate, which may be adjusted for the desired grain size of the product. Steel plates of several compositions and ceramic plates are available.

One should avoid using steel plates for either the disc grinder or the vertical Braun grinder. Particles of rock being powdered between the surfaces of plates may be smeared with iron and, probably, with some of the elements used for making the steel alloys. The free iron $\left(\mathrm{Fe}^{0}\right)$ introduced into the sample will be determined as part of the $\mathrm{FeO}$, thus destroying some of the usefulness of the $\mathrm{Fe}^{+3} / \mathrm{Fe}^{+2}$ ratio as a measure of the oxidation state of the rock unit. The amount of heat generated by the grinding action of plates of any material on the powdered material may oxidize some of the original ferrous iron and may cause loss of either $\mathrm{H}_{2} \mathrm{O}^{-}$or $\mathrm{H}_{2} \mathrm{O}^{+}$, which are normally determined in a rock analysis.

Ceramic plates have the advantage that the principal contaminant will be the main constituent of the ceramic, alumina. It is not known if one can correct for the alumina introduced as excess corundum in the calculated C.I.P.W. norms. The ceramic plates will also become warm or hot to the touch, thereby, perhaps, causing some oxidation of the ferrous iron and some loss of either water. The ceramic plates cannot be operated continuously and must be allowed to cool. While cooling, the plates frequently crack and small pieces of either plate may break and fall.

The most promising equipment for powdering small amounts $(\sim 50-100 \mathrm{~g})$ of rock reduced to a small grain size $(\sim 10$ mesh or $2 \mathrm{~mm}$ ) are ring and puck mills, of which the Spex Shatterbox and the Siebtechnik Mill are examples. The puck, ring, and inside of the container may be made of porcelain or agate. Neither material causes significant contamination (but see Reay, 1981, for oxidation of $\mathrm{FeO}$ ), and the porcelain or agate parts do not become too warm during intermittent laboratory operations.

The more costly agate containers are liable to break along natural fracture planes in the agate when rather coarse material $(\sim 1 / 4 \mathrm{in}, 6 \mathrm{~mm}$, or larger) is powdered, and it is recommended that rock fragments not larger than 10 mesh $(2 \mathrm{~mm})$ be used. In normal use in this laboratory, a sample load of 50 to $75 \mathrm{~g}$ can be reduced in 3 to $5 \mathrm{~min}$ to a powder, most of which will pass through a 200-mesh screen.

A tungsten carbide container is available for these small mills, but it should be avoided at all costs in a laboratory that prepares geologic samples for analysis. Agus and Hesp (1974) report a study in which 20-gram portions of a sand, with no determinable tungsten and cobalt, were processed for periods of $15,25,35$, and $45 \mathrm{~s}$ in a tungsten carbide container. The powdered samples, in order of increasing grinding times, contained 600 to $2,000 \mathrm{ppm} \mathrm{W}$ and 80 to $300 \mathrm{ppm}$ Co. The operation of a tungsten carbide container is efficient but dangerous in a laboratory dealing with geologic materials. The grinding medium may be noted in several places, but records may be lost and a future geoscientist may search for nonexistent tungsten deposits.

Schroll $(1975$, p. 27) discusses the introduction of contaminants, including tungsten and cobalt from tungsten carbide, into a sample during rock powdering. Joron and others (1980), in a study of basalts from the East Pacific Rise, found that some samples were contaminated because they were processed aboard the ship by a tungsten carbide container for the Shatterbox. In addition to the usual tungsten and cobalt, they mention possible contamination by tantalum and niobium.

A pulverizer useful for soft materials, but not for silicate rocks, is the MIKRO-SAMPLMILL, or MikroPulverizer. This laboratory used one of these pulverizers, known locally as a hammer mill, for processing lignites because the lignites would become warm, partially oxidize, and stick to both plates of a disc grinder. Similar pulverizers with hammers of different shapes are used industrially for materials softer than silicate rocks, including mica for beneficiation.

The hammer mill with brass or steel hammers works efficiently for soft materials, but the hammers and the materials of which the mill body and screens are made will cause significant contamination if used for silicate rocks. The pulverizing action of the mill may result in a short lifetime for hammers made of porcelain.

Moore (1978) powdered the Purington Shale sample, $\mathrm{KnC}-\mathrm{ShP}-1$, by processing the sample through a hammer mill having stainless steel hammers. He first tested his crushing and powdering procedure by passing a 10-kilogram aliquot of the shale through a jaw crusher, then passing it twice through a roller mill set at different openings, and finally powdering it in the hammer mill. The stainless steel 
screens of the hammer mill lost $6.08 \mathrm{~g}$ during processing. Moore assumed a proportional loss of the same order of magnitude for the hammers and calculated that 25 to $50 \mathrm{ppm}$ of iron were added to the sample.

Beaulieu (1971) described a dust-free grinding installation in which he used a miniature jaw crusher and a miniature disc pulverizer. The ceramic jaw plates were about $5 \mathrm{~cm}$ wide by $13 \mathrm{~cm}$ long and the pulverizer had ceramic plates about $4 \mathrm{~cm}$ in diameter.

A laboratory cylinder mill for small samples, principally coal, is described by Schlesinger and others (1963). A small ball mill using an alumina ball inside a Pyrex tube (45 $\mathrm{mm}$ outside diameter) is described by Kita (1981). The mill can be evacuated to $10^{-3}$ torr or can be operated under $3 \mathrm{~atm}$ pressure, but the lower piece of glass tubing must be replaced after it has been used several times. A pulverizer for mica (Neuman, 1956) has sharp knife edges to split mica particles floating in air without causing lattice distortions for x-ray work. Abbey and Maxwell (1960) used a common kitchen device, a Waring blender, to pulverize up to $15 \mathrm{~g}$ of a bulk sample of mica in water.

Small laboratory ball mills of either the centrifugal or the planetary type are available commercially. The grinding bowls and balls are made of agate, sintered corundum (either 99.7 or 85 percent $\mathrm{Al}_{2} \mathrm{O}_{3}$ ), tungsten carbide ( 93 percent WC, 6 percent $\mathrm{Co}$ ), chrome steel ( 12 percent $\mathrm{Cr}, 2$ percent C), stainless steel ( 18 percent $\mathrm{Cr}, 8$ percent $\mathrm{Ni}$ ), and zirconium oxide (97 percent $\mathrm{ZrO}_{2}$ ). Only the agate and the sintered corundum bowls and balls are appropriate for powdering small rock samples.

Several suppliers of laboratory apparatus and reagents in the United States advertise a small, high-speed grinding apparatus called the MICRO-MILL. The grinder, with dimensions $51 / 2 \times 7 \times 11$ in $(140 \times 178 \times 278 \mathrm{~mm})$, can accept sample volumes of between 20 and $50 \mathrm{~mL}$ and has interchangeable grinding chambers and milling blades. As the blades may rotate up to 20,000 .rpm, the temperature of the grinding chamber may be maintained by heat exchangers, for which hose connections for $6.4 \mathrm{~mm}$ (inner diameter) tubing are provided. The chamber and the blades may be stainless steel "hard faced" with stellite. There are two compositions, in percent, for stellite given in Gardner and Cooke (1968): (1), Co 59.5, Mo 22.5, Cr 10.77, Fe 3.11, Mn 2.04, C 0.87, Si 0.77, S 0.08, and P 0.04; and (2) Co 75, Cr 20, and $\mathrm{W} 5$. These three materials for the chambers and blades should be avoided, as they will introduce some important trace elements into rock samples at the speed at which the blades rotate.

\section{Excess Grinding and the FeO Contents of Rocks}

The effects of excess grinding on the $\mathrm{FeO}$ contents of rocks should not be underestimated. French and Adams (1972) found that when they ground a portion of the doler- ite, I-3, from Queen Mary College for $20 \mathrm{~min}$, the original $\mathrm{FeO}$ content of just over 10 percent was reduced by 0.5 percent and that this rate of oxidation was maintained as the grinding time continued to about $60 \mathrm{~min}$, when the measured $\mathrm{FeO}$ content was about 8 percent.

Reay (1981) studied the effect of disc mill (ring and puck) grinding on some rock-forming minerals. There were observable losses in the $\mathrm{FeO}$ contents of a chlorite, a biotite, and a greenschist, but not of an actinolite, when sample portions were analyzed after several different grinding times of up to $360 \mathrm{~s}$. The most dramatic change is shown in figure 2 of Reay $(1981$, p. 180), in which the FeO contents of a chlorite are plotted against the number of times the grinding mill was opened for sampling. The FeO content, about 18 percent for material sampled after the first opening, was slightly less than 13 percent after the mill was opened the ninth time.

Keller (1955) noted that, during laboratory grinding of montmorillonite, the iron in the clay may be oxidixed sufficiently so that the effect is observable by simple tests. Mackenzie and Milne (1953) dry-ground a muscovite in a mechanical agate mortar for up to $24 \mathrm{hr}$ and plotted the increase of cation-exchange capacity with increasing grinding times. Fitton and Gill (1970) attribute oxidation of ferrous iron in a rock powdered in a puck and disc mill to atmospheric oxidation. A sample ground in a sealed mill for 6 min contained 6.1 percent $\mathrm{FeO}$, but another portion contained 5.5 percent when the mill was opened and resealed at each minute for $6 \mathrm{~min}$.

\section{Large Samples-Precautions and Preparation}

Implicit in the preparation of small samples for analysis in a laboratory is the question, "With what should I contaminate the sample?" The question is more important for rock reference samples, as contamination introduced at any step between the rock formation and the powdered product will be included in the composition of the reference sample.

It is therefore incumbent upon the preparer of a reference sample to avoid all possibilities of contamination. If the preparer of a sample has, for example, only one jaw crusher, one roller crusher, and one ball mill for processing rock samples, each piece of machinery should be thoroughly cleaned before starting to prepare a sample. It is obviously more efficient to finish processing a large sample, even over a period of several days, before using the equipment for other rocks, as it would not be necessary to reclean the machinery.

There is another source of contamination, commonly referred to as cross-contamination. This can occur not only from machinery that was not cleaned, but also from dust in the air arising from the processing and from chips of another rock being processed adjacent to the reference rock. The 
apparatus used to process reference rocks should be isolated from all other crushing and grinding activities; in a large organization that also prepares other rocks, ores (or mineralized samples), and coals, the equipment for preparing the four types of samples should be isolated from one another.

One institution prepared samples with a minimum of contamination. Ando (1967), in a notice about the availability of the granodiorite GSJ-JG-1, noted that the larger pieces of the rock were broken with a mortar and pestle made of the rock and the sample was powdered between two large pieces of the same rock. The basalt GSJ-JB-1 was prepared similarly (Kurasawa, 1968).

A common contaminant of many powdered rock standards is iron, together with some unknown fraction of other elements used in making steel. Some iron is first introduced in the field when the geologist hits an outcrop with a steel pick or sledge hammer to obtain the sample to be prepared. The contamination may be in the form of metallic streaks; the pieces of rock may be examined in either the field or the laboratory and the suspect pieces discarded.

If one obtains the sample from a quarry, drill bits may cause some contamination and one should be careful that blasting caps containing mercury fulminate are not used. Mercury is an element of environmental concern (U.S. Geological Survey, 1970; Friberg and Vostal, 1972), and the mercury contents of rock standards may be used as background levels for environmental studies. Flanagan and others (1982) infer that the high and extremely variable mercury content of USGS-W-1 may be due to the use of blasting caps containing mercury fulminate before the collection of the sample in December 1946.

When large pieces of rock are brought to the laboratory, they are generally hit with a geologist's pick or a sledge hammer to reduce the pieces to a size about half that of a man's fist, a size that will fit readily between the jaws of the laboratory crusher. The nature and amount of contamination introduced is about the same as in the field, and inspection of the pieces is recommended.

A jaw crusher is usually the first mechanical step in size reduction by most organizations that prepare rock standards. Crushers may range in size from a heavy-duty laboratory model having steel jaw plates about $4 \times 8$ in to pilot plant models whose plates may measure $1 \times 1 \frac{1}{1 / 2} \mathrm{ft}$. Jaw crushers and other machinery used for primary particle size reduction are illustrated and discussed in many texts on ore and mineral dressing.

The jaw crusher used for processing USGS standards has flat plates, about $4.5 \times 9.5$ in, made of high-manganese steel that resists machining. The plates are attached by flatheaded bolts whose heads are beveled to fit a beveled hole at the intersection of the diagonals of the plates. The maximum opening between the bottoms of the two plates is about $3 / 8$ in, but this gap may be reduced by inserting "shims" (thin metal plates of the same size as that of the jaw plate but of varying thicknesses) between the stationary plate and the frame of the crusher to which the plate is attached.

It is frequently advantageous when processing a large amount of sample $(>100 \mathrm{~kg}$ ) to operate a crusher first with the maximum gap between plates and then to reprocess this crushed material through a narrower gap. One should not feed too much rock between the jaw plates at one time, as some partially crushed material may not pass between the bottom edges of the plates. This may cause pieces to be crushed or rubbed numerous times by the plates, thereby increasing the possibility of contamination by iron and manganese. The smaller particle sizes passing the narrower gap are more amenable to the text step in size reduction.

Another jaw crusher commonly used has plates that are ostensibly designed to grasp the pieces of rock during crushing, thus preventing the pieces from slipping on the steel plates and perhaps resulting in more efficient crushing. When viewed from the end, the working side of either plate is a series of rounded ridges and valleys.

The ridges wear or chip away fairly readily, with maximum wear occurring down to or below the intersection of the diagonals of the plates. One make of jaw crusher has ridged plates attached by recessed bolts at the four corners. Maximum wear for any jaw plates occurs at the intersections of the diagonals of the plates, but contamination by iron from flat plates is less severe. If there were a choice, the ideal crusher for a rock standard would have flat plates attached at the four corners of the plates. Maximum wear occurs on the jaw plate that moves.

Graff (1973) showed different compositions for crushed rocks and for the dust collected during jaw crushing. Dust-collection systems should remove only dust that would escape the container for catching the product. Dust should be collected at an elevation lower than that of the container for receiving the crushed sample.

The next step in size reduction is usually a roller crusher. The two rolls, which rotate in opposite directions, introduce little or no contamination by iron into the sample when the crusher is operating properly. The bearings for the shaft on either side of a roll are held in place by a large spring. These springs allow the space between the rolls to widen sufficiently to pass an oversize piece of hard rock that is too large to be crushed between the rolls. Experience has shown that is is preferable to pass the granular material through the rolls twice, first with the rolls about 1/8 in apart and then with the rolls touching. This two-stage treatment, plus a system to mechanically feed coarser materials into the rolls at a constant rate, will produce a crushed product having a fairly uniform size distribution and a minimum of oversized particles.

The first two USGS rocks, G-1 and W-1, were powdered in ball mills. Both samples were screened through sieves, G-1 to pass an 80-mesh screen and $\mathrm{W}-1$ to pass a 100-mesh screen. The Canadian sulfide ore (SU-1) was not ground, but the syenite rock $(\mathrm{Sy}-1)$ was pulverized (Cana- 
dian Association for Applied Spectroscopy, 1961, p. 160) in a Braun pulverizer whose plates were set to yield -100 mesh material. The material of which the plates were made was not specified, but it is known that the sample was not screened. Ignoring possible contamination by iron and the heating effect of the plates on the powder, the plate or disc grinders are efficient for samples of small size but an inordinate amount of processing time is required as the sample size increases from an ounce or two to $100 \mathrm{~kg}$ or more.

Ball mills for powdering rock samples are now used by at least three organizations, the Canadian Certified Reference Materials Project, the National Institute for Metallurgy, and the U.S. Geological Survey. Ball mills are made for different capacities, and both conical and cylindrical mills are used. The mills may be unlined, the steel body of the mill serving as the liner, or they may be lined. The linings include Belgian burr stone (a silicate of unknown composition, judging from the commercial literature on ball mills), rubber, porcelain, and other materials. The balls may be made of steel, Belgian burr stone (sized, rounded cobbles), porcelain, or other materials.

It is reasonable to avoid steel liners and balls to prevent the introduction of iron into the powdered rocks. A rubber or plastic liner for the mill should not be used because of determinations of carbon in igneous rocks (Flanagan and others, 1976b). The use of Belgian burr stone is not unreasonable, but if contamination occurs the mode of occurrence of the contaminating element or the average chemical composition of the stone must be determined for possible corrections. I decided to use a liner and balls made of porcelain, the principal component of which is alumina $\left(\sim 88\right.$ percent $\left.\mathrm{Al}_{2} \mathrm{O}_{3}\right)$. I estimated the amount of alumina added ( $\sim 0.1$ percent) during the preparation of rock powders (Flanagan, 1967), but I doubt if one can correct for this alumina as excess corundum in the C.I.P.W. norms (Cross and others, 1902). Semiquantitative spectrochemical estimates of the trace elements in a powdered ball indicate that, with the estimated wear on the balls, trace elements are not added in amounts that will affect the trace element compositions of the rocks.

It is not always necessary to avoid steel, rubber, or plastic liners when powdering a sample. The magnetite reference sample (Stoch, 1978b) is an obvious exception. The ore was received as damp-ground material that was air-dried in the sun on drying racks. After screening through 150 mesh and initial blending, final blending and grinding were done in a rubber-lined mill using 110-kilogram batches of material with $125 \mathrm{~kg}$ of steel balls. The steel balls would not add detectable contamination by iron and alloying elements, and the use of the rubber-lined mill seems permissible because it is unlikely that carbon will ever be determined in this reference sample as it has been in volcanic rocks.

There is an additional advantage of using a ball mill for powdering samples. During the preparation of the USGS samples issued in 1964, I noticed that the steel shell of the mill was slightly warmer than room temperature. I therefore stopped the operation of the mill several times, removed its cover (a procedure requiring an elapsed time of less than 1 min), and measured the temperaure of the powder in the mill. An average of several measurements showed that the powder was about $5^{\circ} \mathrm{C}$ warmer than room temperature. Therefore, powdering in a mill should not affect the $\mathrm{FeO}$ or $\mathrm{H}_{2} \mathrm{O}$ contents of the reference sample.

\section{Sieving}

Some organizations sieve the entire batch of a sample, while others avoid screening entirely. Although Hillebrand (1907) emphasized that metal sieves should not be used, determinations of isotopic compositions by IDMS make it almost imperative that sieving be avoided. If lead solder is used to attach the screen to a frame, determinations of major, minor, and most trace elements should not be affected, but there may be a disastrous effect on geologic ages that depend on IDMS determinations of lead isotopes. If silver solder is used, some contamination might be expected, even though silver solder is much harder and hence more resistant to wear. If a rock standard is sieved, details of the sieving operation should be given in a prominent place in an introductory paper on the reference sample. USGS samples were not sieved. Small portions used to test particle-size distributions are always discarded.

This laboratory uses nylon cloth screens with a frame made of two pieces of either nylon or acrylic tubing, rather than the usual brass or stainless steel. The diameter of the tubing is $51 / 2$ in, and the wall thickness is $1 / 4$ in. One half $(1 / 8$ in) of the outside wall thickness is removed to a depth of about 0.2 in by machining the bottom end of the top piece for a frame, and a similar amount is removed from the inside wall thickness of the upper end of the lower piece for the frame. A piece of nylon screen material is placed between the two matched ends, and the top and bottom pieces of the frame are firmly pressed together to hold the nylon cloth tightly. Excess nylon cloth outside the frame is removed.

Sieves varying in diameter from 2 to 12 in have been available for years from chemical supply houses. Larger round screens with diameters of $18,24,30,48,60$, and 72 in are used commercially. These screens are also called separators, as each screen may have an exit spout through which oversized material not passing a screen is removed. Such screens or separators are generally used in industry, where some particle-size separation of a commercial product is desired.

One company furnishes a sieve-testing apparatus that has screen trays 18 in wide by 26 in long, a clear screen area of $21 / 3 \mathrm{ft}^{2}$, and a screen capacity of $1 \mathrm{ft}^{3}$. This sieve-tester might be used by a producer who wishes to sieve a rock reference sample of about $100 \mathrm{~kg}$, but the screen wire cloth, made of steel, brass, or phosphor bronze, may introduce contamination into the sample. 


\section{Contamination by Steel}

In addition to the contamination of small samples by tungsten and cobalt discussed by Agus and Hesp (1974) and by Joron and others (1980), large reference samples may contain free iron $\left(\mathrm{Fe}^{0}\right)$ owing to the processing of rocks in a jaw crusher. Ritchie (1968) determined free iron in a number of standards; the data he obtained by two chemical methods are plotted in figure 1 . The solid diagonal line extending from the origin at an angle of $45^{\circ}$ may be called the line of equivalence, as all plotted points would fall on this line if the methods were equivalent. The dashed line is the least squares line of regression showing the relation between the two methods. The plotted points for the USGS rocks released in 1964 show that these rocks are generally less contaminated by free iron than are other samples.

Because of the importance of $\mathrm{FeO}$ in a rock analysis, the free iron contents of all geochemical reference samples should be determined. The $\mathrm{FeO}$ contents of the rocks determined by analysis may then be corrected, if necessary, by subtracting the $\mathrm{FeO}$ equivalent of $\mathrm{Fe}^{0}$.

One might expect negligible contamination from a jaw crusher used to crush relatively soft materials such as coals, but Senftle and others (1982), in a study of the magnetic properties of pulverized coal, found a total steel contamination of about 0.02 percent. This estimate is about the same as the free iron contents of some silicate rock reference samples reported by Ritchie (1968). Senftle and others (1982) present a scanning electron microscope photograph showing curled shavings of magnetic particles whose compositions are major $\mathrm{Fe}$ and minor $\mathrm{Mn}$.

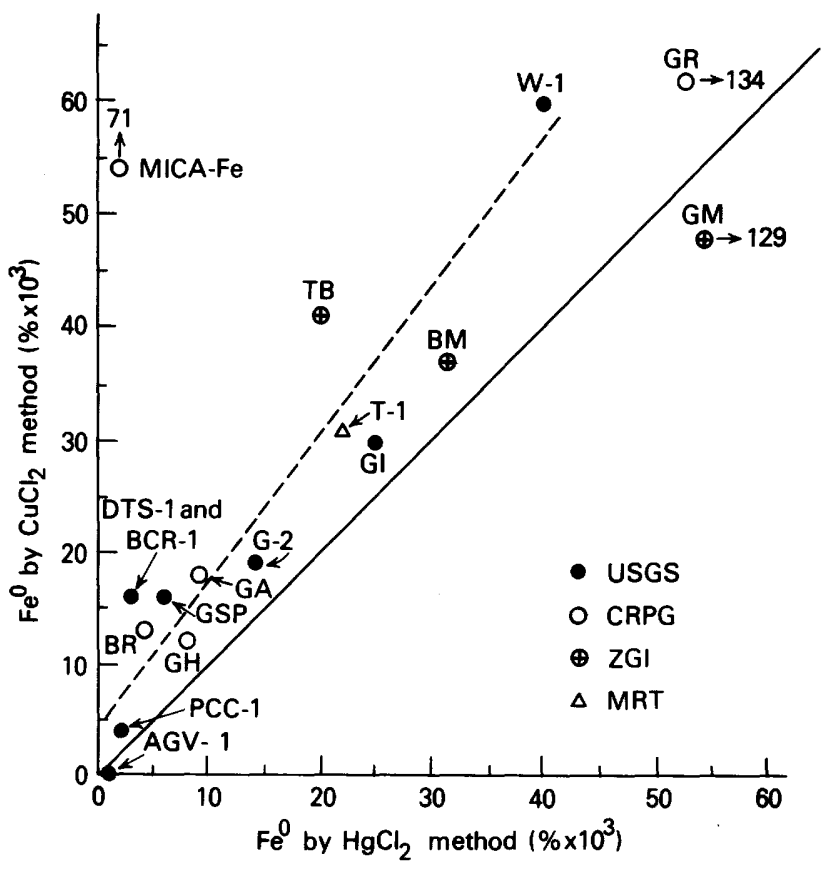

Figure 1. Free iron $\left(\mathrm{Fe}^{0}\right)$ contents of some reference samples determined by two chemical methods. (Data from Ritchie, 1968.)

\section{Homogeneity of Reference Samples}

Methods for determining the homogeneity of reference samples are numerous and depend on the physical state of the sample and the analytical technique used. For powdered samples, the methods depend on whether the test is made before or after bottling, or both. The methods range in complexity from simple statements about the precision of the method to several statistical techniques and designs.

Barnes and others (1973), using the IDMS method, determined uranium, thorium, lead, and thallium in wafers cut from 2-meter rods of the NBS trace-elements-in-glass standards. The wafers were randomly selected from 100 or more rods, thereby representing concentrations of the elements over the length of the glass cane pulled for a specific sample. The authors write that "within the experimental limits show in Table 1, the results indicate that this material, on the basis of 1-gram samples, is remarkably homogeneous for the four elements analyzed over a length of $\mathbf{4 0 0}$ or more feet." They later indicate that "the homogeneity ${ }^{*}{ }^{*}$ * may be further demonstrated by plotting these data ${ }^{* * *}$." They note that some radial heterogeneity exists across the face of a single wafer and specify that a whole wafer should be used as the analytical sample.

During the discussion following a talk by Flanagan (1975), W.R. Shields of the National Bureau of Standards noted that USGS-BCR-1 had been found to be heterogeneous for thorium. He used the criterion that data on sample portions differed between bottles by more than one order of magnitude beyond the capabilities of the IDMS method.

Such statements are common in the literature of analytical chemistry. They suffer, however, the disadvantage that the statements about homogeneity, or the lack thereof, cannot be made with an assigned probability.

Boyd, Finger, and Chayes (1969), in a paper on computer reduction of electron-probe data, used the homogeneity index, defined as the ratio of the observed standard deviation to the standard deviation predicted from counting statistics. A sample is considered heterogeneous if the index is greater than 3 . Under the assumption that the counts are normally distributed, the index is a standardized normal deviate and the index of 3 will cover about 99 percent of the area under the normal curve.

Jarosewich and others $(1979,1980)$ used the same homogeneity index. Drake and Weill $(1972$, p. 180) approach this index when they write," a sample is considered homogeneous when the standard deviation of the mean of a large number of spot analyses is equal to the uncertainty due to counting statistics."

A routine procedure for testing the homogeneity of electron microprobe data was described by Marinenko and others (1979). The total counts acquired in a preset time, usually $10 \mathrm{~s}$, are fed to both a teletype and a fast strip recorder. The specimen stage of the probe, controlled by a periodic ratemeter, can be advanced in steps of from 1 to 10 
$\mu \mathrm{m}$, and data can be collected at each new spot. The homogeneity required depends on the intended use of the sample, and measurement conditions can be chosen so that the Poisson limits are within the desired level of homogeneity. The technique was used to test the homogeneity of a research material, Glasses for Microanalysis (RM-30), and several alloys.

Another method used to reflect sample heterogeneity is that of Myers and others (1976). They made quantitative spectrochemical determinations for 23 elements in two portions from four bottles of each powdered glass sample. Because line intensities in emission spectrography are exponentially related to concentration, they transformed the data logarithmically and calculated $s_{A}^{2}$, an estimate of the $\log$ variance among bottles of sample. They then obtain a factor for predicting the limits of variation introduced by heterogeneity by $F=\operatorname{antilog} s_{A}$, and the factor, $F$, is a geometric deviation. The authors table such geometric deviations for the 23 elements in the samples but do not specify an acceptable upper limit for the deviations.

Valcha (1977) suggested the $F$ ratio for testing homogeneity, and Dempir (1978) gave an example for a reference sample of glass sand. Using x-ray fluorescence and an iron line, Dempir counted the responses from single portions taken from each of 50 randomly selected bottles of the sand and calculated the variance, $s_{2}^{2}$, of these counts. He then took 50 subsamples from a single randomly chosen bottle, counted the responses from these portions, and calculated the variance, $s_{1}^{2}$, of these 50 counts. As a result of the nonsignificance of the variance ratio, $F=s_{2}^{2} / s_{1}^{2}$, he accepted the alternate hypothesis that iron is distributed homogeneously among the bottles of glass sand. Similar conclusions were reached for $\mathrm{TiO}_{2}$ and $\mathrm{MnO}$. This $F$ ratio differs from that in the usual analysis of variance for an experimental design as there is only a single datum per bottle, except for the bottle from which 50 subsamples were taken, and the variation within bottles cannot be estimated.

The Mines Branch, Ottawa (now CANMET), published a series of reports (McAdam and others, 1971, 1973a, 1973b; Faye and others, 1974; Steger and others, 1975; Ingles and others, 1977) on their reference samples of economic interest. In many reports, the $t$ test or the "standard" $t$ test at 5 percent probability is used to determine the homogeneity of one or more elements in two bottles of sample. It may be assumed that the $t$ test is the usual test of the difference between two means, but the $F$ ratio, necessary to determine if the two variances are homogeneous prior to pooling the variances for the $t$ test, is not mentioned.

Steele and others (1975) used both $F$ ratios and $t$ tests to determine if a reference sample of a precious metal ore, PTO-1, was homogeneous, and they discuss the mode of occurrence of related pairs of precious metals for which a few significant differences were found. Stoch and Steele (1978) used the $t$ test on the analytical data submitted, after rejecting averages that were outliers. The $t$ test on analytical data was also used by Stoch (1978b) and by Stoch and others (1979).

Scheaffer (1971) discussed a test for the homogeneity of a mixture composed of particles of different types and sizes. The test is based on variances and covariances, with $\chi^{2}$ as the test statistic.

The analysis of variance for demonstrating homogeneity now appears to be the technique used most frequently. The method has been used both before and after a sample has been bottled. After bottling, the technique may be used in testing preliminary data for one or more elements before the samples are issued for analysis, and the analysis of variance is frequently used to test data submitted by contributing laboratories.

The experimental designs include one-way (a single variable of classification - the bottles) and two-way (two variables-laboratories and bottles) analysis of variance, and a one-way nested classification (Faye and others, 1975) in which the variance components are between laboratories, between bottles within laboratories, and within bottles. The one-way analysis of variance was used for USGS rocks (Flanagan, 1976b), for USGS manganese nodules (Flanagan and Gottfried, 1980), and for clay and feldspar reference samples (Flanagan and others, 1977).

Lister (1978) used the one-way analysis of variance to show that Co in samples IGS 22 and IGS 23 was homogeneously distributed. He determined Co by neutron activation analysis in two portions from each of 10 containers of the samples, and the between-container variance was not significantly larger than the within-container variance at the 5 percent level.

There are problems concerning the use of the analysis of variance in the literature. One problem is the possible introduction of a variance component related to the day on which determinations were made. This may occur when a large number ( 75 to 100 , or more) of portions of several samples are randomized in a single large random order and then analyzed over a period of several days or weeks. This procedure may introduce the variance component of between days or between weeks into the error term, which normally consists of the error of the method, errors due to sampling the heterogeneous powdered material, and random error.

When such components are introduced, the information generally cannot be retrieved unless the experiment was designed for this purpose. There are designs by which variations due to time may also be estimated, including the Youden Squares discussed in Cochran and Cox (1950) and in other texts on statistics and experimental design.

The problem of negative unit (bottle) variances occurs even when the design appears appropriate. Negative bottle variances are embarrassing, as variances are, by definition, positive. Statisticians have not solved the problem of negative variances, and bottle standard deviations resulting from them have been tabled both as "Neg." (Flanagan, 1976b) 
and as a numerical standard deviation followed by an italicized "i" (Flanagan and others, 1977) to indicate a negative variance as the source of the estimate. Until statisticians solve the problem, the use of "Neg." in tables of data seems less objectionable.

\section{Outliers}

The rejection of suspected outliers has been of intense interest to both analysts and statisticians for several decades. Many analysts reject outliers on the basis of their knowledge of the analytical methods, while statisticians have approached the problem from both practical and theoretical viewpoints. Grubbs (1950, p. 30) notes that the rejection of outliers may be just as much a practical or commonsense problem as a statistical one and that sometimes the practical or experimental viewpoint may outweigh any statistical contributions. Kruskal (1960) notes that it is very important to say something about outlier observations, that it is a dangerous oversimplification to discuss apparently wild observations in terms of inclusion in, or exclusion from, a more or less conventional analysis, and that the anomalous observation may be saying that here is something from which we may learn a lesson.

Anscombe (1960) discussed some history of the rejection of outliers. "Statistics of Extremes" by Gumbel (1958) is an early text devoted to the theory of extreme values; a more recent text on outliers is that of Barnett and Lewis (1978). Grubbs (1969, p. 2) gave both general rules and statistical criteria for outliers. Harvey (1974) discussed the detection and correction of outliers in geochemical analysis. Prescott (1979) gave a sequential test for many outliers, to be used in place of repeated applications of procedures for single outliers. Tietjen and Moore (1972) discussed several outliers and the masking effect. Rosner (1975) compared several "many outlier" procedures, finding that the extreme Studentized deviate (ESD) is slightly more efficient. Mikeshina (1966) published a short review on the occurrence and elimination of anomalous values.

Several methods have been used for rejecting outliers in data for reference samples. The methods are used for rejection from a set of data by a laboratory, from means of sets of data by several laboratories, and from averages in compilations of data. Frequently, those who eliminate outliers are not sufficiently specific about the kind of data considered.

Steele and others (1975) used three procedures for the precision metal sample PTO-1. They first discarded any data differing by more than three standard deviations from means of sets of data. After calculating new estimates of the means and standard deviations from the remaining data, they again rejected data beyond 3 standard deviations, and repeated the process until there were no further rejections. Stoch and Steele (1978) and Stoch (1978a, 1978b) also used this procedure, whereas Stoch, Steele, and Copelowitz (1976) used $\bar{x} \pm 2 s$ as their criterion for retaining data from which best values are calculated. Roche and Govindaraju (1971) eliminated data outside of $\bar{x} \pm s$ before arriving at preferred means $\left(\bar{x}_{1}\right)$ and medians $\left(M_{1}\right)$.

Steele and others (1975) also used the coefficient of kurtosis, $b_{2}$, and the coefficient of skewness, $\sqrt{b_{1}}$. These tests were also repeated until no further data were rejected. They also used one of the applicable Dixon (1953) criteria, repeating the process until no further rejections occurred. The Dixon criteria were among several procedures discussed by Grubbs (1969), who notes (p. 13) that "these techniques are not generally recommended for repeated rejection, since if several outliers are present in the sample the detection of one or two spurious values may be 'masked' by the presence of other anomalous observations."

Geary's " $a$ " statistic (Pearson and Hartley, 1956) was used iteratively in several NIM (National Institute for Metallurgy, South Africa) reports to identify and reject outliers. The test, the ratio of the mean deviation to the standard deviation, was proposed by Geary (1935) as a test of normality.

The robust standard deviation was used by Stoch (1978a, 1978b) to eliminate gross outliers. He obtained this standard deviation by arranging observations in ascending order of magnitude, removing one-sixth of the results from each extreme, and dividing the range of the remaining data by two. This estimate of the standard deviation is about one-third of the range, a procedure used by statisticians when a quick but not necessarily accurate estimate of the standard deviation is desired.

Christie and Alfsen (1977) constructed histograms of data in compilations and fitted third-degree polynomials to the histograms. They calculated the partial correlation coefficient and the maximum of the polynomial, where the maximum serves to estimate the mode of the distribution. When the partial correlation coefficient was less than 0.7 , extreme values were gradually removed, but in no case was more than 10 percent of the data eliminated.

Christie and Alfsen also used a gamma transformation to obtain a symmetrical distribution. The mean and standard deviation of the distribution are calculated and transformed back to the original data. The mean is a reliable estimate of the true concentration, but the standard deviation (an "interlaboratory" estimate) yields a confidence interval that is more or less asymmetric around the mean. The authors note that it is possible to establish strict criteria for rejecting outliers.

Ellis, Copelowitz, and Steel (1977) used the dominant cluster method iteratively to reject outliers until one of four alternate conditions was met so that the iterations could be halted. After the rejections had stopped, the mean of the remaining data was reported as the mode. The mode may be estimated without curve-fitting, and the technique is independent of the distribution. 
In his critical study of published data on the USGS rocks Abbey (1970), after noting that 18 percent of the data for USGS-G-2 were beyond one standard deviation from the mean, decided to reject the 15 percent of the data farthest removed from the means. He then calculated preferred means for the data not rejected. Noting that not all laboratories reported the same number of data per USGS sample, he used an arbitrary rating system for data obtained by laboratories that could be classified as major contributors. He then calculated averages of data obtained by the eight "best" laboratories, i.e., those that scored highest in his rating procedure.

I previously rejected, formally or informally, data beyond three standard deviations as not belonging to the same population as the remainder of the data. In the formal sense, the average and standard deviation of the data, not including the suspected outlier(s), were calculated and data beyond there standard deviations were rejected as not belonging to the population. Informally, one-third of the range of the data was used to estimate the standard deviation. An occasional wild datum would be summarily rejected for, as Anscombe (1960, p. 124) notes, in sufficiently extreme cases where a reading may be grossly spurious, no one hesitates about such rejections.

Colombo (1980) proposed a plot method to determine the mode of a set of skewed data. He arranged $n$ data in ascending order of magnitude, ranking the lowest datum 1 and the highest, $n$. He then plotted each rank against its paired determination and estimated the mode. The method is the same, except for the transposed $x$ - and $y$-axes, as the S-curves used by Stevens and Niles (1960) for the distributions of constituents in G-1 and W-1. Das (1979) discussed geometric means as probable values for data.

Lister (1978) notes that in a paper on the accuracy of ore analysis (Lister and Gallagher, 1970), the $t$ test, three standard deviations, skewness, and kurtosis were used to eliminate outliers. Lister (1978) shows S-curves for $\mathrm{Zn}$ in a nickel concentrate, IGS 20 . The plot contains 8 data near 0.5 percent $\mathrm{Zn}$ and 26 data near 0.1 percent. The interval for the mean and standard deviation contained none of the 34 data. He, therefore, rejected the eight high data solely on the basis of analytical common sense.

Dybczyński (1980) compared the effectiveness of various procedures for the rejection of outliers. He showed that the concurrent use for four criteria (Dixon's test, Grubbs test, the skewness test, and the kurtosis test) at small $(p=0.01)$ or moderate $(p=0.05)$ significance levels gives better results than the use of any single test. He also compared results by his method with those by Student's $t$, the dominant cluster mode, and the gamma transformation.

\section{Estimation of Best Values}

The estimation of best values is concerned both with compilations of data and with analytical programs by issu- ing organizations to establish values for the samples furnished. The techniques range from roundtable meetings of the analysts involved to the analysis of variance of data submitted by cooperating laboratories.

Christie (1975) noted that recommended values for three geologic samples were selected in a series of roundtable meetings of participating analysts. The means were based on two or more values in good agreement that were reported by at least two analysts who were from different laboratories and who used different methods.

Abbey (1970) calculated averages of data by the eight "best" laboratories that scored highest in his rating procedure. Abbey and others (1975) used the same scoring system to obtain "select means" of the 9 laboratories that were major contributors of data and of 11 laboratories that were minor contributors of data, the laboratories in both sets having scored 51 or greater in his rating system. These select means yielded high summations for the rock analysis; after the data were reexamined and conspicuous outliers rejected, new select means were calculated as recommended values.

Roubault and others (1966) and Roche and Govindaraju $(1971,1973,1976)$ calculated preferred means, $\bar{x}_{1}$, and medians, $M_{1}$, from those data within $\bar{x} \pm s$ for all data in compilations. Ando and others $(1971,1974)$ calculated consensus means, $\bar{x}_{\mathrm{c}}$, from data included in $\bar{x} \pm 2 s$.

McAdam and others (1971) list three methods to obtain the mean and 95 percent confidence limits: (1) analysis of variance, generally after rejecting data beyond $2 s$ from the mean, and treating all sets of data from laboratories as independent, (2) weighted means to give a minimum variance, and (3) weighted means by the inverse of the square root of the variance. Method 1 was used to obtain the mean and confidence limits for the alluvial sand, PTA, and method 2 was used for estimates for the $\mathrm{Cu}-\mathrm{Ni}$ matte, PTM. Most Mines Branch (CANMET) reports (McAdam and others, 1973a, 1973b; Faye and others, 1974, 1975; Steger and others, 1975; Ingles and others, 1977; Sutarno and others, 1978) used analysis of variance to arrive at best values and confidence limits.

Stoch (1974a, 1974b), after rejecting outliers, used the means of the data not rejected as recommended values. Stoch and others (1976), after rejecting outliers from some limited data for a series of five samples containing 0.2 to 44 percent rare earth oxides, used two criteria for preferred values. If there were more than six values that were not rejected, preferred means were calculated if the coefficient of variation was less than (1) 15 percent for values exceeding 0.1 percent, or (2) 30 percent for values less than 0.1 percent.

Stoch and Steele (1978) derived means and medians for three ferromanganese slags, after rejecting outliers. Means were accepted when the distribution of the data was approximately normal, and the median was accepted for a non-normal distribution. 
Steel and others (1975) considered four methods to obtain best values: (1) the mean of averages of sets of data, (2) minimum variance, (3) inverse variance, and (4) analysis of variance. Although there was close agreement among the means, except for those obtained by minimum variance, they accepted as preferred values the means calculated by the inverse variance method because the weighting is more equitable. Stoch (1978a, 1978b) accepted as certified values the means calculated by the inverse variance method.

Ellis and Steele (1982) discuss five robust indicators of central value, noting that the mean is unreliable. Lister (1982, p. 181), in his discussion of weighting results, notes that bias may occur if one laboratory submits 10 data and another only 2 .

Another method for obtaining best values is one Flanagan and Gottfried (1980) used for manganese nodule samples. Although the method involves iteration, it avoids the numerous repetitions of one or more different tests for outliers that others use to arrive at final values. In many reports on reference samples in which the analysis of variance, following the rejection of outliers, is used, the reader will find no reference to the assumptions underlying the analysis of variance (Eisenhart, 1947), or to the consequences when these assumptions are not satisfied (Cochran, 1947).

The method is the sequential procedure of (1) determining which of $k$ sets of $n$ data have a common variance, thus satisfying one of the assumptions, (2) from this common variance, calculating the standard deviation of the means of $n(=6)$ determinations, and (3) with this standard deviation and the Studentized range, determining which laboratory means could have been derived from the same population mean. The average of the means so selected is taken as the best estimate.

\section{Certification Factor}

A certification factor is used by Sutarno and Faye (1975). They define this factor as the ratio of the confidence interval of the consensus value, $c$, for a selected element, expressed as a percentage, to the mean within-laboratory coefficient of variation. They note that the recommended certification factor of $\leq 4$ can be explained on the basis that the confidence interval is twice the product of the value taken from the $t$-distribution and the magnitude of the coefficient of variation of the censensus value. They note that for a large number of laboratories $(\geq 20), t_{0.95} \rightarrow 2$. For the confidence interval, therefore, $2 t_{0.95} \rightarrow 4$.

Colombo and Rossi (1978) discussed as a criterion of quality the ratio $S_{L} / M$, called a certification parameter. $S_{L}$ is the between-laboratories standard deviation obtained in the analysis of variance and $M$ is the consensus (certified) value of the element being estimated.

\section{Nomenclature for Reference Samples}

The nomeclature for the samples with which we deal has varied greatly over the last eight decades. From the original terms "analyzed samples" and "standard analyzed samples," used for the early products of the National Bureau of Standards, and "chemical standards," used by the Bureau of Analysed Samples, we progressed through "NBS standard samples" and "standard rocks G-1 and W-1" in the literature up to the 1960's.

The term "standard rocks" seems especially inappropriate as Krech and others (1974) described a standard rock suite, but they remove any doubt about the purpose of the rocks by giving their report the full title "A Standard Rock Suite for Rapid Excavation Research." One of their rocks is the Westerly Granite, the source of G-1 and G-2.

Many of us knew NBS samples by the formal designation NBS Standard Sample XX, generally reduced to NBSXX. Circular 552 (3d ed.) of the National Bureau of Standards, published in 1959, was titled "Standard Materials Issued by the National Bureau of Standards." The 1965 edition of NBS Miscellaneous Publication 260 introduced the subject as "Standard Reference Materials," with "Standards of Certified Chemical Composition" as the title of the first table. The NBS now calls its samples "certified reference materials" if the data for samples are of sufficient merit to warrant a certificate of analysis, and "reference materials" if the data are insufficient.

Outer producers who certify samples are the National Institute for Metallurgy (Stoch and others, 1979), whose samples and certificates are distributed by the South African Bureau of Standards, the International Atomic Energy Agency (Dybczyński and others, 1979), the Council for Mutual Economic Assistance (CMEA) countries (Valcha, 1977), the IRSID (Institut de Recherches de la Sidérurgie), which distributes iron ores and other nonmetallic samples (Jecko, 1977), the Bundesanstalt für Materialoprüfung for the German iron ores and other samples (Pohl and Oberhauser, 1978), the BCR (Community Bureau of Reference; see Colombo and Rossi, 1978), and the Bureau of Analysed Samples in England.

The first two Canadian samples were called "syenite and sulfide standards" by Webber (1965) and "sulfide ore and syentite rock standards" by Sine and others (1969). Canadian samples a decade ago were called "standard reference materials" (McAdam and others, 1971), but shortly thereafter "certified reference materials" (Faye and others, 1974), a practice that has continued (Steger, 1980).

Recent practice has been to call such samples "geological reference mateials" (Steele, 1978), "rock reference samples" (Govindaraju, 1980), or "geochemical reference samples" (Govindaraju, 1980), the latter being abbreviated GRS. Valcha (1977) uses both "standard reference materials" and "geochemical standard reference materials." Lontsikh and Parshin (1980) use "standard reference sam- 
ples" and Lontsikh and others (1980), "reference rock samples." Because our profession has dealt with reference samples of geologic interest for most of this century, perhaps we should standardize our nomenclature for such samples.

One can argue that the terms "geological reference sample" and "rock reference sample" are not sufficiently definitive, as the standard rock suite prepared by Krech and others (1974) might be included in the definition in the absence of information on the purpose of the rocks. The term "geochemical reference sample" used in Govindaraju (1980, p. 49) would, therefore, seem the most appropriate generic name for the samples with which we deal. The term could include rocks, minerals, ores, soils, and sediments. By inference, the name could be extended to plant or leaf samples used in geobotanical investigations, and to fresh or marine waters used in studies of the interaction of water and sediments.

Nomenclature also concerns the name applied to estimates given by producers of samples or by others who feel qualified to judge the validity of the data. Thus, the adjectives that modify, "values" are "certified," "attested," "recommended," "usable," "preferred," "probable," "possible," and "best." The terms "average" or "magnitude" may be used when an author feels that the quality of the data does not warrant a more precise description.

"Certify" or "attest," which have a legal connotation, have the same approximate meaning in English-confirm formally, or affirm to be correct, true, or genuine. The legal connotation in "certified" or "attested values" may have some undesirable effects if one can demonstrate unequivocally that the certified or attested value is incorrect. One certified value shown to be incorrect is mentioned in Rose, Adler, and Flanagan (1963, p. 84).

"Recommend" has the less forceful meaning of "commend to the attention of another as reputable, worthy, or desirable." Definitions for "usable" and "preferred" are obvious, and "best," as used in Flanagan and Gottfried (1980), indicates that the population of data for a constituent in a sample has been determined by Studentizing the range of averages of sets of data by the standard deviation of the means of $n$ determinations. This procedure is a method of rejecting means of sets of data as outliers, that is, the rejected means are not part of the population.

For some certified or attested values, one sees only these values; for others, all data are available. For example, for the Moroccan phosphate BCR-32, Serrini (1981) published an introductory paper with a copy of the certificate of analysis but noted that a technical report on the several aspects of the certification is available. Other organizations publish averages of the data, or the entire set of data including the averages, that are used in the calculations for final values.

Steele (1978) notes that a producer of a sample should consider the requirements of a potential user. The user may be dissatisfied if the certificate or accompanying report does not contain sufficient information to enable him to judge the quality of the compositional values, or to use the sample in the correct manner.

Thus, the producer of a geochemical reference sample might furnish in a published paper, or in a separate report, a brief description of the location and geology of the site from which the sample was taken, a reference to a more detailed geologic report, the entire set of analytical data, and the method, including references, for deriving the final estimates.

\section{Are "Best Values" Best?}

The question of which "best values" are really "best" must bother analysts who wish to use any set of reference samples, including a mixture of samples from several organizations, as points on a calibration line for their work. Abbey (1977b) notes that many workers use numerical data without reading and understanding the pertinent backgound information. For most analytical work in the literature, the most important background information, the data for the calibration line, is not available.

Producers of new reference samples receive data from analysts of these samples with a note that reference samples $\mathrm{x}, \mathrm{y}$, and $\mathrm{z}$, plus appropriate values, were used for the calibration. Although this information is important, it will not allow a producer or user to judge the value of the new data. The analyst should furnish the equation for the calibration line, and the mean, variance, and range of both the elemental contents of the standards and the responses of the analytical system to these standards (Flanagan, 1981).

Even if the analyst furnishes the data described above, there may be a problem with the calibration line. Many analysts routinely subtract the blank value from the responses of their standards and then plot or calculate the calibration line. If the blank is zero, there is no problem; however, blanks are generally some value greater than zero.

Higgins (1964) discussed some consequences of subtracting the blank prior to calculating the calibration line. After giving the equations for the variance of the slope with and without subtracting blanks, he tables the ratio of the two variances for $n$ selected values of the calibration points. While the variances are equal for one calibration point, the ratio of the variances with and without subtracting blanks increases with the number of calibration points, or with the number of times the blank is subtracted. Thus, the variance of the slope after subtracting blanks for eight points is 1.98 times the variance when no subtraction is made.

Both Abbey (1977b) and Flanagan (1981) suggested determining some element(s) in a number of reference samples by a reliable method. Abbey suggested plotting the signal obtained against the assigned concentrations to see if the plotted points are sufficiently close to a straight line. It would be better to calculate the equation for the line, as the 
intercept (or blank), $a$, is part of the equation $y=a+b x$. Further, two or more portions of each sample for a calibration point should be analyzed for an element, especially if one is to make a judgement about the inadequacy of one or more best values.

If an analyst finds that a best value for one or more reference samples is incorrect, this information should be published, together with supporting data, for the benefit of all users. I doubt that any scientist who has calculated best values is so sensitive that he believes his estimates are infallible.

\section{Confidence Limits for a Single Datum}

The calibration (regression) line suggested in the previous section to check the linearity of best values can also be used to obtain confidence limits for a single determination. Equations for calculating the two branches of the hyperbola that form the confidence limits around a line of regression are given in statistical texts, including Bennett and Franklin (1954), Mandel (1964), and Brown and Hollander (1977). An example of the confidence limits for a calibration line is shown in figure 2 , in which the equation in Bennett and Franklin (1954, p. 229) was used with data from one of the several calibration lines in Flanagan and others (1982).

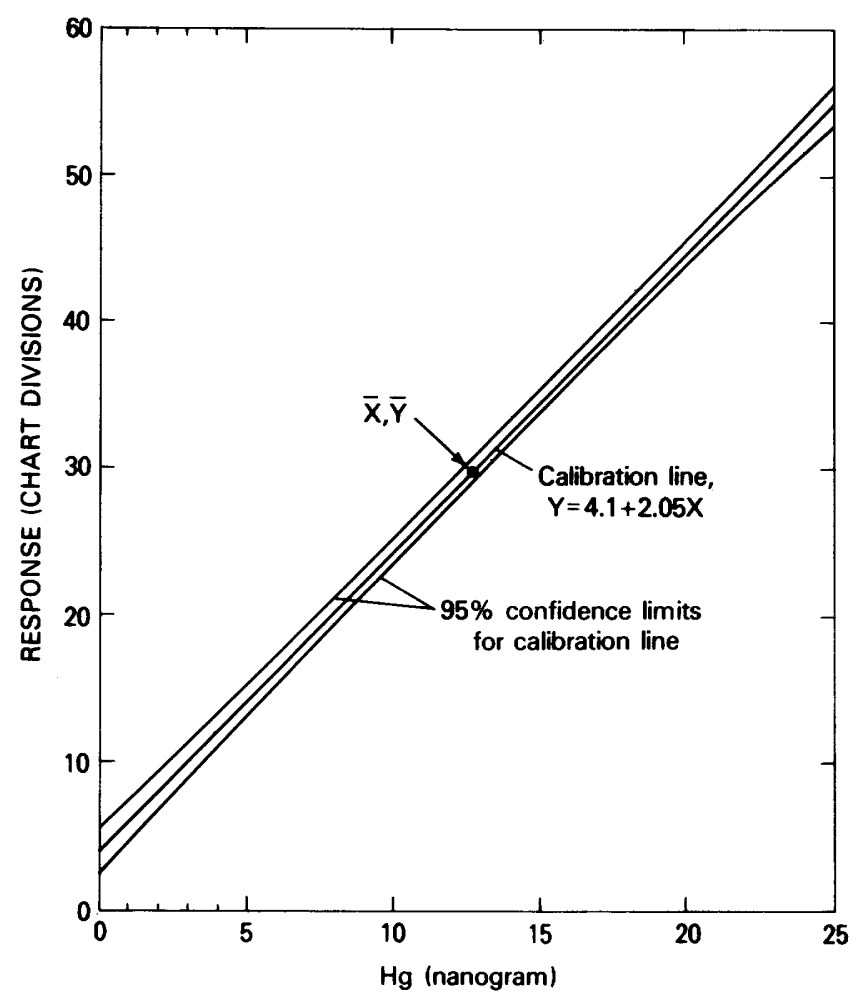

Figure 2. Confidence limits for a calibration line. (Data from Flanagan and others, 1982.)
Calibration lines are familiar to all analysts. As normally used, one takes the response, $y$, of an element, $x$, in an unknown sample and extends a horizontal line from the $y$-axis to intersect the calibration line, then extends a vertical line from this intersection to the $\mathrm{x}$-axis, from which one estimates the amount, $x$, of the element in the unknown sample.

One might think, (as I assumed, erroneously) that confidence limits for $x$ could be obtained by intersecting both branches of the hyperbola that form the confidence band by the horizontal line from the $y$-axis and by extending vertical lines from both intersections to the $x$-axis. The intersection of both vertical lines with the $x$-axis would yield confidence limits for a single datum. Mandel and Linnig (1957) mentioned this procedure for estimating limits for $x$, given $y$, and the asymmetric confidence limits for $x$ that are obtained.

The equation, however, yields only limits for an estimated $y$, given $x$, and Natrella (1969, p. 242) notes that one must reverse the usual roles of $x$ and $y$ in the calculations to obtain the confidence bands around the line $x=a^{\prime}+b^{\prime} y$. These confidence limits for $x$, given $y$, are symmetrical and will furnish confidence limits for a single determination of an element, $x$, in an unknown sample. Eisenhart (1939) discussed the theoretical aspects of both regression lines, $y=a+b x$ and $x=a^{\prime}+b^{\prime} y$.

There is a practical application of confidence limits for a single determination. Geologists and geochemists study rocks of the same type from different geographic areas and may wish to decide if the same magma could be responsible for the formation of the several rocks. To accomplish this, they usually plot a number of points $x, y$ of data for two elements in samples. The correlation diagram thus obtained eventually shows fields for the plots $x, y$ of the same rock type where the fields may differ among geographic areas.

The definition of these fields might be hastened if analysts would furnish geologists with confidence limits for single determinations of elements $x$ and $y$. The geologist could then plot both elements with their limits. Since, for every $x$ within an interval $\mathrm{C}<x<\mathrm{D}$, there may be a corresponding $y$ in the interval, $\mathrm{E}<y<\mathrm{F}$, the points $x, y$ and their limits may be plotted, as an approximation, in the form of a confidence rectangle. Such rectangles may help define the rock fields in preliminary stages of the investigation.

Figure 3 shows plotted confidence rectangles for points $x, y$ (small circles), where neither or both rectangles intersect both rock fields (large circles). In the upper figure, the rectangle intersects both rock fields, but the point $x, y$ may be said to belong to field $B$ because of the greater area (and therefore greater confidence) that is common to the rectangle and the field.

In the lower figure, where the rectangle intersects neither field, one has three choices: (1) measure the distance from point $x, y$ to both fields and assign the point to the nearer field, (2) measure the distance between the nearest 


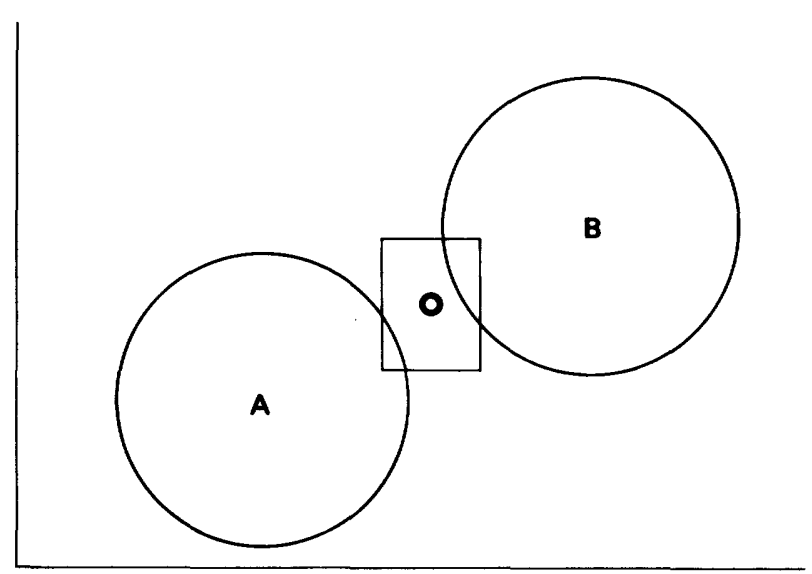

$\mathbf{Y}$

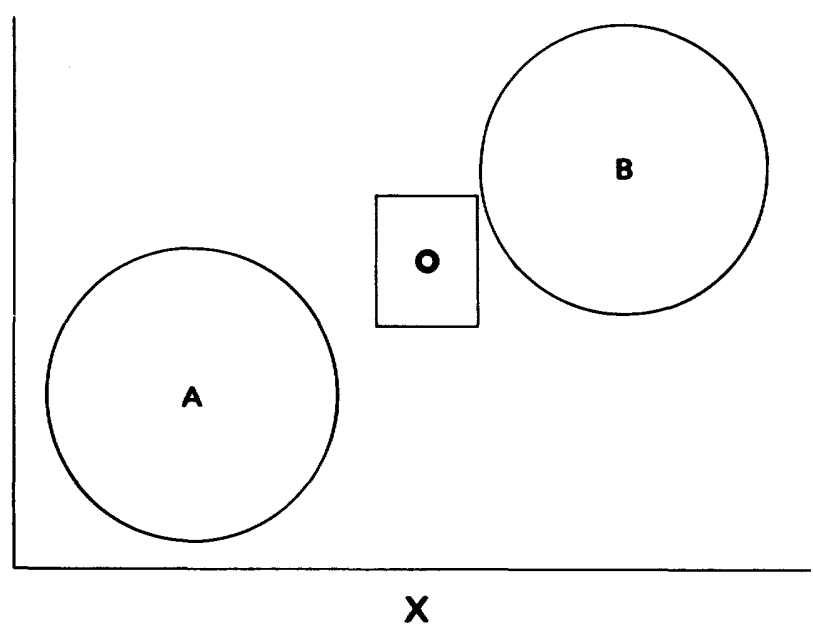

Figure 3. Confidence rectangles for assigning points $x, y$ to rock fields.

point on the rectangle and both fields, and assign the point to the field for which the distance is a minimum, or (3) change the value of $\alpha$ in $t_{n-2, \alpha}$ in the equation to calculate confidence limits for the calibration line and recalculate so that there will be an area common to one field and the rectangle.

Small computers now available in many laboratories may be programmed to calculate the confidence limits for a single observation. Blaedel and Iverson (1976) discuss a calculator program that yields confidence limits for either regression (calibration) line, $y=a+b x$ or $x=a^{\prime}+b^{\prime} y$. There are subroutines in the program that allow one to calculate the confidence limits for a single datum, $x$, given a response, $y$. They note that an outline of the program is available on request.

\section{Comparisons of Data}

The confidence limits for a single datum, as described in the preceding section, could serve as an answer to the question, How good are your data? The same question may have been asked implicitly by those who have analyzed reference samples since the limestone, NBS-1, was issued.

Authors, after analyzing a reference sample, frequently table their determinations adjacent to data preferred by the organization issuing the sample. The authors then describe the agreement of their data with those preferred by the issuing organization by such words as "excellent," "good," "fair," or "poor." A similar procedure has been used, either implicitly or explicitly, by authors of papers on the lunar samples, where their analyses of BCR-1 or other samples are listed.

I suggested a solution to the problem for rock analysis (Flanagan, 1964), but the method is only an approximation, as no effort was or could be made in Stevens and Niles (1960) to define the population estimates for the means and standard deviations of the data for G-1. Sample BCR-1 may be one of the most analyzed samples still in existence in many laboratories, but estimates I gave in two compilations (Flanagan, 1969, 1976c) are only best scientific guesses. There was, and still is, no reasonable method to estimate population values for the mean and standard deviation of the data for BCR-1, or other samples in the series, as analysts published data for portions of a sample ranging from $n=1$ to $n>10$ for the same constituent. Lister $(1982$, p. 181) notes that bias may occur when one laboratory submits 10 data and another only 2 . I do not remember any compilations of data on samples for which such bias cannot occur.

I calculated, whenever possible, the grand mean $\overline{\bar{x}}$, and the standard error of the mean, $s_{\bar{x}}$, of sets of six determinations for a number of constituents for recent USGS samples (Flanagan and Gottfried, 1980; Flanagan, 1984). I used the technique of $\chi^{2}$ (Flanagan, 1984) to show that the probability that 39 constituents of $\mathrm{W}-1$ and $\mathrm{W}-2$ differed is less than 0.05 percent.

An analyst may make valid comparisons of his or her data with some norm by calculating (observed-expected)/ $s$, where "observed" is the datum of the analyst, "expected" is the grand mean, $\overline{\bar{x}}$, of the constituent, and $s$ is the population standard deviation for W-2 obtained by multiplying $s_{\bar{x}}$ by $\sqrt{6}$. The result of the calculation is a standardized normal deviate, and the square of such a deviate is a chi square with one degree of freedom.

These values of $\chi^{2}$ and the degrees of freedom are additive and thus, by referring to tables of $\chi^{2}$, the analyst can determine if his or her reported constituent is part of the population of data represented by $\overline{\bar{x}}$, or if his single determinations of several constituents may be part of the population data for these elements. In addition to yielding an overall estimate of the agreement between a set of determinations for elements and the population estimates for these elements, the magnitudes of individual values of $\chi^{2}$ may indicate those elements for which there may be analytical problems. The technique may be used with USGS samples W-2, DNC-1, and BIR-1 and with the two manganese nodule 
samples for constituents for which $\overline{\bar{x}}$ and $s_{\bar{x}}$ were calculated, but I am unaware of other reference samples that may be used to make such calculations.

\section{The Analyst and the Producer}

Steele (1978) published a guide for reporting analytical data on geochemical reference samples. The 13 instructions in the guide, a consensus of 15 members of a committee to consider the subject, were designed so that the producer of a sample could extract maximum information from the data. In addition to the 13 instructions, the analyst might add the equation for the calibration line and other data (Flanagan, 1981). He might also note whether he subtracted the blank from the responses of his standards (Higgins, 1964).

The producer should furnish as much preliminary information on the sample as possible so that those who might wish to cooperate in the analytical program can have the maximum information on which to base a decision. Thus, the information might include

1. The rock type and location (including coordinates), and an abstracted description of the geologic setting, mineralogy, and petrography if a reference to a geologic report is not available;

2. A somewhat detailed description of the method of preparation, if the method was not described elsewhere; minor changes in published methods may be noted;

3. Possible contaminants introduced into the sample. Free iron resulting from jaw crushing should be determined so that the $\mathrm{FeO}$ content of the rock may be corrected, if necessary;

4. The experimental design to be used by the analyst or the producer;

5. A list of elements for which determinations are desired and their approximate ranges for ores. Some rocks or minerals may be prepared for determinations of a few elements, which should be listed. For some rocks, a producer might list elements believed to be more important than others;

6. A closing date for submission of data.

\section{REFERENCE SAMPLES IDENTIFIED THROUGH 1984}

The number of both reference samples and their suppliers has increased dramatically since a previous list (Flanagan, 1974), and a revision of the latter should have been made several years ago. The older list contained 217 entries, but the revised list given here (table 5) has more than 830 entries, some of which list more than one sample of the same type by the same supplier.

During the past decade, many needs in the general field of geostandards mentioned in the previous list (Flana- gan, 1974) have been satisfied. There are now many minerals for microprobe work, though ores for microprobe studies seem to be confined to "in-house" standards. Ore reference samples for analysis are now quite numerous and are available from suppliers throughout the world.

There has been a welcome increase in the number of rock samples of all types, including dolomites and limestones. However, more trace element data should be reported for the dolomites and limestones and for the several bauxites now listed in the table. The number of limestones and dolomites, after trace element data are acquired, should be gratifying to the numerous scientists who have asked about carbonate rocks with known amounts of trace elements. The number of large samples of rock-forming minerals has increased.

Reference samples of manganese nodules, along with two "in-house" samples, have been prepared. The need for a better method of communication among producers and users of reference samples was mentioned in the previous list (Flanagan, 1974, p. 1741), and this void has been filled by publication, in January 1977, of the first semiannual issue of "Geostandards Newsletter," a journal devoted to all aspects of geochemical reference samples.

Archaeology seems, on the basis of my limited acquaintance with archaeologists and analysts of archaeological specimens, to be the one field for which reference samples are still restricted or nonexistent. The use of one or more clays as reference samples for pottery analysis (Flanagan and others, 1977) is not an adequate solution to the problem, because clays, when fired, lose volatile constitutents and the clay material undergoes changes in composition, the changes depending on the temperature of firing.

A reference sample might be made from a commercially fired brick used for houses. The use of such brick has both advantages and disadvantages. One immediate question is which clay to use, as pottery specimens are collected from numerous sites throughout the world. Even if one could obtain a consensus from archaeologists about a specific clay, the costs of collecting and shipping the clay to a brick yard and of the subsequent firing of the brick would be prohibitive.

Thus, on the theory that some reference sample is better than no sample, a local clay deposit might be inspected and, if the clay is suitable, $200 \mathrm{lb}(90 \mathrm{~kg})$ or more of brick could be processed as a reference sample that might last 50 years. The grog used to stiffen the wet clay should be broken pieces of fired brick, not rocks such as phyllite or schist that are often added by brick manufacturers when a house brick of a different color is desired. Most brick makers can specify their firing temperature within a narrow range, and thin sections of the brick may help to determine firing temperatures achieved by ancient potters.

Table 5 is arranged in the same format as the 1974 list. Rocks, minerals, and classes of samples such as botanical, glasses, isotopic, ores, refractories, sediments, and 
soils are entered alphabetically. Samples within these several classes are also ordered alphabetically.

The four headings within table 5 give the following information: (1) the name of the material, (2) the abbreviation of the organization that prepared the material and the sample number, if available, (3) the number assigned to the supplier from which the sample must be obtained, and (4) remarks, notes, or references that may assist the reader in the selection of samples. Compositions of many rocks, minerals, sediments, and soils are given in Govindaraju (1984a).

The names and addresses of the suppliers and the number assigned each supplier are given in table 6. A samples must be obtained from, and generally only from, the organization that corresponds to the supplier number in table 5. Some published reports list the suppliers from whom samples may be obtained. Thus, Jecko, Pohl, and Ridsdale (1977, p. 131) list the addresses from which EuroStandards prepared by their organizations may be purchased. Valcha $(1977$, p. 113) gives a table listing the exporting companies responsible for the sale of reference samples for the six CMEA (Council for Mutual Economic Assistance) countries.

Some explanation of the material in table 5 is desirable. Dashes in the Number column indicate that no sample number is given. Dashes in the Supplier column may indicate one of several things: (1) the sample is an "in-house" sample that may be available only to scientists working on a specific problem, (2) the sample is out of stock, (3) the supplier is not identified in a reference, or (4) two sediment samples, prepared and numbered by two organizations, that were renumbered by a third organization when the samples were used for an analytical "round robin" test.

Questions marks (?) in the Supplier column indicate the source is unknown. The largest number of such entries is for U.S.S.R. samples; it was difficult to find in the original or translated journal articles the source from which the samples may be obtained. A question mark in the Remarks or References column following the term "in-house" indicates that the sample was mentioned in a journal article but that the status of the sample was not specified.

"Price list" in the Remarks or References column generally indicates that a catalog and price list are available from the supplier.

Table 5. Reference samples

[Conc, concentrate; In prep., in preparation; mixt., mixture; qtz, quartz; SS, standard sample for some U.S.S.R. samples; SRN, State Registry Number for U.S.S.R. samples. Acronyms for organizations used in sample identification numbers are given in the text. Some acronyms are included with or may be derived from the names of organizations in table 6]

\begin{tabular}{|c|c|c|c|}
\hline Name & Number & Supplier & Remarks or References \\
\hline $\begin{array}{c}\text { Actinolite, see } \\
\text { Amphibole }\end{array}$ & 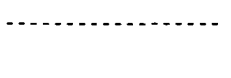 & …. & \\
\hline $\begin{array}{l}\text { Adularia, see } \\
\text { Feldspar }\end{array}$ & $\cdots$ & & \\
\hline
\end{tabular}

Table 5. Reference samples-Continued

\begin{tabular}{|c|c|c|c|}
\hline Name & Number & Supplier & Remarks or References \\
\hline $\begin{array}{l}\text { Alabaster, see } \\
\text { Gypsum }\end{array}$ & $\ldots .$. & - . n & \\
\hline $\begin{array}{l}\text { Albite, see } \\
\text { Feldspar }\end{array}$ & n & $\ldots$ & $\cdots \cdots$ \\
\hline $\begin{array}{l}\text { Alevrolite }= \\
\text { Aleurite }\end{array}$ & $\mathrm{SA}-1$ & 54 & $\begin{array}{l}\text { IGI. U.S.S.R. SRN 811- } \\
\text { 76, Lontsikh and } \\
\text { Parshin (1980). }\end{array}$ \\
\hline $\begin{array}{l}\text { Almandine, see } \\
\text { Garnet }\end{array}$ & - & ......... & 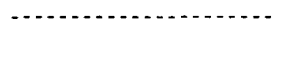 \\
\hline Amphibole & $\mathrm{R}-2535$ & 30 & $\begin{array}{l}\text { Microprobe. Ingamells } \\
\text { (1980b). }\end{array}$ \\
\hline Actinolite & & 20 & Microprobe. Price list. \\
\hline Crocidolite & OECD-07 & 31 & $\begin{array}{l}\text { Van Olphen and Fripiat } \\
\text { (1979). }\end{array}$ \\
\hline Engels & - & 30 & $\begin{array}{l}\text { Microprobe. Ingamells } \\
\text { (1978). }\end{array}$ \\
\hline Grunerite & $R-2469$ & 30 & $\begin{array}{l}\text { Microprobe. Ingamells } \\
\text { (1980b). }\end{array}$ \\
\hline \multirow[t]{6}{*}{ Hornblende } & USNM 111356 & 26 & $\begin{array}{l}\text { Microprobe. Jarosewich } \\
\text { and others (1980). }\end{array}$ \\
\hline & USNM 143965 & 26 & $\begin{array}{l}\text { Microprobe. Jarosewich } \\
\text { and others }(1980) .\end{array}$ \\
\hline & Basel 1-h & 2 & Hügi and others (1975). \\
\hline & MMhb-1 & 14 & $\begin{array}{l}\text { Alexander and others } \\
(1978) \text {. For }{ }^{40} \mathrm{Ar} /{ }^{39} \mathrm{Ar} \text {. } \\
\text { Geochimica et Cos- } \\
\text { mochimica Acta, v. } 43 \text {, } \\
\text { p. } 278 \text { (1978). }\end{array}$ \\
\hline & $4-190,4-234$ & 30 & $\begin{array}{l}\text { Microprobe. Ingamells } \\
\text { (1980b). }\end{array}$ \\
\hline & USGS-Hb1-1 & 7 & Not analyzed. \\
\hline Riebeckite & PSU 4-222 & 30 & $\begin{array}{l}\text { Microprobe. Ingamells } \\
\text { (1980b). }\end{array}$ \\
\hline sodium & PSU 6-040 & 30 & $\begin{array}{l}\text { Microprobe. Ingamells } \\
\text { (1979). }\end{array}$ \\
\hline Tremolite & PSU 4-206 & 30 & $\begin{array}{l}\text { Microprobe. Ingamells } \\
\text { (1978). }\end{array}$ \\
\hline & n & $\cdots$ & $\begin{array}{l}\text { Microprobe. Müller and } \\
\text { Strauss (1984). }\end{array}$ \\
\hline \multirow[t]{7}{*}{ Andesite } & USGS-AGV-1 & 7 & Flanagan (1976b) \\
\hline & USGS-AGV-2 & 7 & $\begin{array}{l}\text { Replacement for AGV-1 } \\
\text { from the same location. } \\
\text { Not processed. }\end{array}$ \\
\hline & USGS-AMH-1 & 7 & $\begin{array}{l}\text { From Mount Hood, Ore. } \\
\text { Not analyzed. }\end{array}$ \\
\hline & GSJ-JA-1 & 11 & Kato and others (1978). \\
\hline & GSJ-JA-2 & 11 & $\begin{array}{l}\text { In prep. A. Ando (written } \\
\text { commun., 1984). }\end{array}$ \\
\hline & GSR-2 & 54 & Chinese sample. \\
\hline & DFG-KA-3 & $\cdots$ & $\begin{array}{l}\text { DFG in-house sample. } \\
\text { Meyer and others } \\
\text { (1981). }\end{array}$ \\
\hline Lanti- & (n) & .......... & $\begin{array}{l}\text { DFG in-house sample. } \\
\text { Meyer and others } \\
\text { (1981). }\end{array}$ \\
\hline Anhydrite & ZGI-AN & 37 & $\begin{array}{l}\text { AMSW price list. Ostrou- } \\
\text { mov (1979). }\end{array}$ \\
\hline $\begin{array}{l}\text { Anorthite, see } \\
\text { Feldspar }\end{array}$ & (n) & ......... & - \\
\hline \multirow[t]{2}{*}{$\begin{array}{l}\text { Anorthoclase, } \\
\text { see Feldspar }\end{array}$} & Basel 1-a & 2 & Hügi and others (1975). \\
\hline & USNM 133868 & 26 & $\begin{array}{l}\text { Microprobe. Jarosewich } \\
\text { and others (1980). }\end{array}$ \\
\hline \multirow[t]{2}{*}{ Anorthosite } & ANRT-AN-G & 24 & Govindaraju (1980). \\
\hline & MO-6 & 55 & $\begin{array}{l}\text { IGEM 1040. Khitrov } \\
\text { (1984). }\end{array}$ \\
\hline Apatite & USNM 104021 & 26 & $\begin{array}{l}\text { Microprobe. Fluorapatite. } \\
\text { Jarosewich and others } \\
\text { (1980). }\end{array}$ \\
\hline
\end{tabular}


Table 5. Reference samples-Continued

\begin{tabular}{|c|c|c|c|c|c|c|c|}
\hline Name & Number & Supplier & Remarks or References & Name & Number & Supplier & Remarks or References \\
\hline \multicolumn{4}{|c|}{ Apatite-Continued } & \multicolumn{4}{|c|}{ Bauxite-Continued } \\
\hline \multirow[t]{2}{*}{ Beeson } & (n) & 30 & $\begin{array}{l}\text { Microprobe. Ingamells } \\
\text { (1978). }\end{array}$ & & SB-1 & 54 & $\begin{array}{l}\text { U.S.S.R. SRN 729-75. } \\
\text { Sobornov (1977). }\end{array}$ \\
\hline & & 20 & Microprobe. Price list. & & SB-2 & 54 & U.S.S.R. SRN 730-75. \\
\hline Aragonite & - & 20 & Microprobe. Price list. & & & & Sobornov (1977). \\
\hline \multicolumn{2}{|l|}{ Archaeological } & & & & PRE 72/6 & 36 & Price list. For trace ele- \\
\hline Bronze & KBS 1-1 & -...... & 7 samples. Li (1984). & & & & ments, Palmer and oth- \\
\hline Porcelain & KPS-1 & -........ & $\mathrm{Li}(1984)$ & & & & ers (1983). \\
\hline Ardennite & PSU 5-144 & 30 & $\begin{array}{l}\text { Microprobe. Ingamells } \\
\text { (1978). }\end{array}$ & & B-1 & $\cdots$ & $\begin{array}{l}\text { Also B-2, B-3. Rojas Pi- } \\
\text { mentel (1984). }\end{array}$ \\
\hline \multirow[t]{3}{*}{ Arsenopyrite } & - & 20 & Microprobe. Price list. & calcined & BCS-394 & 22 & Price list. \\
\hline & ASP-57 & .......... & Microprobe. Two in-house & lateritic & IVIC-SLB-1 & 39 & - \\
\hline & & & $\begin{array}{l}\text { samples. Lowell and } \\
\text { Gasparrini (1982). }\end{array}$ & Benitoite & USNM 86539 & 26 & $\begin{array}{l}\text { Microprobe. Jarosewich } \\
\text { and others (1980). }\end{array}$ \\
\hline \multirow{2}{*}{$\begin{array}{l}\text { Augite, see } \\
\text { Pyroxene }\end{array}$} & - & $\ldots$ & - & & - & 20 & Microprobe. Price list. \\
\hline & & & & Beryl & - & 20 & Microprobe. Price list. \\
\hline \multirow[t]{2}{*}{ Azurite } & (1) & 20 & Microprobe. Price list. & Biotite & USGS-Btt-1 & 7 & Not analyzed. \\
\hline & & & & & Basel 1-b & 2 & Hügi and others (1975) \\
\hline \multirow{2}{*}{$\begin{array}{l}\text { Barite (see } \\
\text { Ores) }\end{array}$} & - & 20 & Microprobe. 2 samples. & & Bern 4-B & 2 & For $\mathrm{Rb}-\mathrm{Sr}$ dating. \\
\hline & & & Price list. & & PSU 5-110 & ......... & Out of stock. \\
\hline \multirow[t]{32}{*}{ Basalt } & USGS-BCR-1 & $\ldots$ & Out of stock. & & PSU 5-112 & 30 & Microprobe. Ingamells \\
\hline & UCB-BCR-2 & 25 & For $\mathrm{Xe}-\mathrm{I}$. & & & & (1980a). \\
\hline & GSJ-JB-1 & -......... & $\begin{array}{l}\text { Out of stock, A. Ando } \\
\text { (written commun., }\end{array}$ & & R 2208 & 30 & $\begin{array}{l}\text { Microprobe. Ingamells } \\
\text { (1980b). }\end{array}$ \\
\hline & & & 1982). & & $4-166$ & 30 & Microprobe. Ingamells \\
\hline & GSJ-JB-1a & 11 & Available, 1984 & & & & (1980b). \\
\hline & GSJ-JB-2 & $\ldots \ldots$ & $\begin{array}{l}\text { Out of stock, A. Ando } \\
\text { (written commun., }\end{array}$ & & LP-6 Bio & 30 & $\begin{array}{l}\text { Microprobe. Ingamells } \\
\text { (1978). }\end{array}$ \\
\hline & & & 1982). & & & 20 & Microprobe. Price list. \\
\hline & GSJ-JB-3 & 11 & $\begin{array}{l}\text { From Mount Fuji, Japan. } \\
\text { Available } 1983 .\end{array}$ & $\begin{array}{l}\text { Boracite } \\
\text { Botanical }\end{array}$ & (................. & 20 & Microprobe. Price list. \\
\hline & USGS-BHVO-1 & 7 & Flanagan (1976b). & Aquatic plant & & & \\
\hline & USGS-BIR-1 & 7 & $\begin{array}{l}\text { From Iceland. Flanagan } \\
\text { (1984). }\end{array}$ & $\begin{array}{l}\text { Lagarosiphon } \\
\text { m major }\end{array}$ & BCR-60 & 16 & Price list. \\
\hline & ANRT-BE-N & 24 & Govindaraju (1980). & Platihypnidium & & & \\
\hline & CRPG-BR & 24 & Govindaraju and de la & riparioides & BCR-61 & 16 & Price list. \\
\hline & & & Roche (1977). & Barley, grains & SS 6-77 & $?$ & Karpukova and others \\
\hline & ZGI-BM & 37 & AMSW list. Ostroumov & & & & (1982). \\
\hline & & & (1979). & Bean? & SS 5-78 & $?$ & Karpukova and others \\
\hline & GSR-3 & 33 & Chinese sample. & & & & (1982). \\
\hline & NBS-688 & 6 & Price list. & Cereal? & SS 3-77 & $?$ & Also SS 4-78. Karpukova \\
\hline & S-CRB & $\ldots$ & In-house. Tong and others & & & & and others (1982). \\
\hline & DSDP-BOB-1 & ... & $\begin{array}{l}\text { (1984). } \\
\text { In-house. Croudace (1981); }\end{array}$ & Feed, cattle? & SS 3-78 & $?$ & $\begin{array}{l}\text { Karpukova and others } \\
\text { (1982). }\end{array}$ \\
\hline & & & $\begin{array}{l}\text { Marsh and others } \\
\text { (1983). }\end{array}$ & chicken? & SS $5-77$ & $?$ & $\begin{array}{l}\text { Karpukova and others } \\
\text { (1982). }\end{array}$ \\
\hline & DSDP-A Il 92 & $\ldots+\ldots$ & In-house, DFG. Erzinger & Flour, corn & IAEA V-1 & 27 & IAEA (1984). For $\mathrm{Hg}$. \\
\hline & & & and Puchelt (1980); & rice & NBS 1568 & 6 & Price list. \\
\hline & & & Meyer and others & wheat & NBS 1567 & 6 & Price list. \\
\hline & & & (1981). & & IAEA V-2 & 27 & IAEA (1984). For Hg. \\
\hline & Pu-la & - n & $\begin{array}{l}\text { Also Pu-lb, Pu-II. In- } \\
\text { house, DFG. Meyer and }\end{array}$ & & IAEA V-2/1 & 27 & $\begin{array}{l}\text { IAEA (1984). For trace el- } \\
\text { ements. }\end{array}$ \\
\hline & & & others $(1981)$ & & IAEA V-5 & 27 & IAEA (1984). For I. \\
\hline & MO-2 & 55 & $\begin{array}{l}\text { IGEM 1023/1029. } \\
\text { Sobornov (1983); }\end{array}$ & $\begin{array}{l}\text { Grass, mix- } \\
\text { ture }\end{array}$ & SBMT-1 & $?$ & $\begin{array}{l}\text { U.S.S.R. SRN 1485-78. } \\
\text { Zvyagintsev (1983). }\end{array}$ \\
\hline & & & Khitrov (1984). & Hay, flour & IAEA-V-10 & 27 & For trace elements. IAEA \\
\hline & NS-43 & ......... & In-house. Van der Sloot & & & & (1984). \\
\hline & & & and Zonderhuis (1979). & grass & SS $4-77$ & $?$ & Also SS 7-77. Karpukova \\
\hline & BARC-B-78 & .......... & In-house. Reddy and & & & & and others (1982). \\
\hline & & & others (1982) & Kale, & - & $\cdots$ & Wainerdi (1979). \\
\hline \multirow[t]{9}{*}{ Bauxite } & ANRT-BX-N & 24 & Mine de Marou, Brignoles & Bowen's & & & \\
\hline & & & $\begin{array}{l}\text { (Var), France. Govin- } \\
\text { daraju (1982). }\end{array}$ & $\begin{array}{l}\text { Leaves } \\
\text { Apple, }\end{array}$ & & & \\
\hline & NBS-69b & 6 & Arkansas. Price list. & golden & - & -........ & Pinta (1977a). \\
\hline & NBS-696 & 6 & Suriname. Price list. & orange & - & -....... & Pinta (1977a). \\
\hline & NBS-697 & 6 & Dominica. Price list. & Artichoke & (- & n....... & Pinta (1977a). \\
\hline & NBS-698 & 6 & Jamaica. Price list. & Citrus & (1, & - & Pinta (1977a). \\
\hline & BCS-395 & 22 & Price list. & Codia & & ......... & Pinta (1977a). \\
\hline & $\mathrm{BaH}$ & $?$ & Hungary. Ostroumov & discolor & 1 & & \\
\hline & & & (1979). & Cotton & - & -........ & Pinta (1977a). \\
\hline
\end{tabular}

Table 5. Reference samples-Continued 
Table 5. Reference samples-Continued

\begin{tabular}{|c|c|c|c|c|c|c|c|}
\hline Name & Number & Supplier & Remarks or References & Name & Number & Supplier & Remarks or References \\
\hline \multicolumn{4}{|c|}{ Botanical-Continued } & \multicolumn{4}{|c|}{ Carnotite-Continued } \\
\hline \multicolumn{4}{|c|}{ Leaves-Continued } & & IAEA-S-3 & 27 & Out of stock. \\
\hline \multicolumn{4}{|c|}{ Cotton-Continued } & Cassiterite (see & -...... & 20 & Microprobe. Price list. \\
\hline & IAEA-V-9 & 27 & For trace elements. IAEA & also, Ores) & & & \\
\hline Eucalyptus & 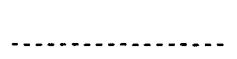 & $\ldots$ & $\begin{array}{l}(1984) \\
\text { Pinta (1977a). }\end{array}$ & $\begin{array}{l}\text { Cement, Port- } \\
\text { land }\end{array}$ & BCS-372 & 22 & Price list. \\
\hline Maize & (n) & - . & Pinta (1977a). & & NBS -633 & 6 & Price list. NBS-633 to \\
\hline \multirow{2}{*}{ Olive } & (n) & - n...... & Pinta (1977a). & & & & -639 \\
\hline & BCR 62 & 16 & Price list. & & IPT-38 & 38 & Price list. Also IPT-46. \\
\hline Orange & (n) & -.......... & Pinta (1977a). & & 6 samples & $?$ & Control samples, \\
\hline Orchard & NBS 1571 & 6 & Price list. & & & & Forschungs-institut für \\
\hline Palm & (n) & $\ldots . . .$. & Pinta (1977a). & & & & Zementindustrie. Troll \\
\hline \multirow[t]{2}{*}{ Peach } & - & $\cdots$ & Pinta (1977a). & & & & and Farzaneh (1978). \\
\hline & 82301 & 54 & $\begin{array}{l}\text { Su and Zhang (1984); Sun } \\
\text { and others (1984). }\end{array}$ & & AR-5170 & 23 & $\begin{array}{l}\text { Price list. } 4 \text { samples. For } \\
\text { major and minor oxides. }\end{array}$ \\
\hline Pepperbush & NIES-1 & 34 & $\begin{array}{l}\text { Okamoto and others } \\
\text { (1978); Nakahara and } \\
\text { others (1982). }\end{array}$ & $\begin{array}{l}\text { Chalcocite } \\
\text { Chondrite, see } \\
\text { Meteorite }\end{array}$ & n & 20 & Microprobe. Price list. \\
\hline Rubber & - n & $\ldots \ldots$ & Pinta (1977a). & Chromite & USNM 117075 & 26 & Microprobe. Jarosewich \\
\hline Tea & - & $?$ & Fuwa and others (1978). & & & & and others (1980). \\
\hline Tomato & - n & $\ldots+\ldots$ & Pinta (1977a). & & PSU 1436 & 30 & Microprobe. Ingamells \\
\hline Vine ? & n & 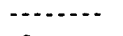 & Pinta (1977a). & & & & (1978) \\
\hline \multirow[t]{2}{*}{ Peas } & SS 7-78 & $?$ & Karpukova and others & & - n & 20 & Microprobe. Price list. \\
\hline & & & (1982). & & $\mathrm{DZCr}-1$ & 33 & Also DZCr-2. Chinese \\
\hline Pine needles & NBS 1575 & 6 & Price list. & & & & samples. \\
\hline \multicolumn{2}{|l|}{ Plant tissue } & & & Chrysotile, see & $\cdots$ & $\cdots$ & (n) \\
\hline Cotton & AR-4401 & 23 & Price list. For $\mathbf{S}$. & Serpentine & & & \\
\hline Peach & AR-4402 & 23 & Price list. For $\mathbf{S}$. & Cinnabar & n & 20 & Microprobe. Price list. \\
\hline Soybean & AR-4403 & 23 & Price list. For $\mathbf{S}$. & Clays, clay min- & & & \\
\hline \multirow[t]{6}{*}{ Potato } & SBMK & $?$ & Karpukova and others & erals & & & \\
\hline & & & (1982). U.S.S.R. SRN & Bentonite & (n) & $\ldots$ & Dempir (1978). \\
\hline & & & 1483-78, Zvyagintsev & Clay & 2 samples & -........ & Dempir (1978). \\
\hline & & & (1983). & & 3 samples & 49 & No sample numbers in ISO \\
\hline & IAEA V-4 & 27 & IAEA (1984). For trace el- & & & & (1982). \\
\hline & IAEA Y-8 & 27 & $\begin{array}{l}\text { ements. } \\
\text {. }\end{array}$ & & PRE $72 / 2$ & 36 & Price list. Palmer and oth- \\
\hline 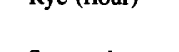 & IAEA $v-0$ & 21 & $\begin{array}{l}\text { IAEA (1984). For trace el- } \\
\text { ements. }\end{array}$ & & & & $\begin{array}{l}\text { ers }(1983) \text { for trace ele- } \\
\text { ments. }\end{array}$ \\
\hline \multirow[t]{2}{*}{ Seaweed } & IAEA AG-1-1 & 27 & Out of stock. & Brick & NBS -679 & 6 & In prep. \\
\hline & IAEA AG-B-1 & 27 & $\begin{array}{l}\text { IAEA (1984). For radionu- } \\
\text { clides. }\end{array}$ & $\begin{array}{l}\text { Calcined } \\
\text { shale }\end{array}$ & PRE 72/5 & 36 & $\begin{array}{l}\text { Price list. Palmer and oth- } \\
\text { ers (1983) for trace ele- }\end{array}$ \\
\hline Spinach & NBS 1570 & 6 & Price list. & & & & ments. \\
\hline \multirow[t]{2}{*}{ Straw, wheat } & SS 8-77 & $?$ & Also SS 1-78. Karpukova & Flint & NBS-97a & 6 & Price list. \\
\hline & & & and others (1982). & & NBS-97b & 6 & In prep. Same area as \\
\hline \multirow{3}{*}{$\begin{array}{l}\text { Sunflower, } \\
\text { cake }\end{array}$} & & & & & & & NBS-97. \\
\hline & SS 8-78 & $?$ & Karpukova and others & Para & IPT-28 & 38 & Price list. \\
\hline & & & (1982). & plastic & NBS-98a & 6 & Price list. \\
\hline ground & SS $1-77$ & $?$ & $\begin{array}{l}\text { Karpukova and others } \\
\text { (1982). }\end{array}$ & & NBS-98b & 6 & $\begin{array}{l}\text { In prep. Same area as } \\
\text { NBS-98. }\end{array}$ \\
\hline \multirow[t]{2}{*}{ Wheat, grains } & SBMP-1 & $?$ & $\begin{array}{l}\text { Karpukova and others } \\
\text { (1982). U.S.S.R. SRN }\end{array}$ & refractory & $\cdots$ & (n) & $\begin{array}{l}\text { Bulgaria. Planned. Table } \\
\text { 3, Valcha (1977). }\end{array}$ \\
\hline & & & $\begin{array}{l}\text { 1484-78, Zvyagintsev } \\
\text { (1983). }\end{array}$ & chamotte & SS-55a & $?$ & $\begin{array}{l}\text { Gorozhanina and others } \\
\text { (1971). }\end{array}$ \\
\hline \multirow{3}{*}{$\begin{array}{l}\text { Brick } \\
\text { Fire }\end{array}$} & & & & Fe-poor & PRE 72/3 & 36 & Price list. Palmer and oth- \\
\hline & BCS 315 & 22 & Price list. & & & & ers (1983) for trace ele- \\
\hline & ES 776-1 & 22 & BCS price list. & & & & ments. \\
\hline Silica & BCS 267 & 22 & Price list. & Fe-rich & PRE 72/4 & 36 & Price list. Palmer and oth- \\
\hline high purity & BCS 313 & 22 & Price list. & & & & ers (1983) for trace ele- \\
\hline Brookite & (n) & 20 & Microprobe. Price list. & & & & ments. \\
\hline & & & & São Simao & IPT -42 & 38 & Price list. \\
\hline Calcite & 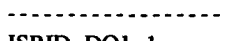 & 20 & Microprobe. Price list. & terrigene, & SDO-1 & 54 & U.S.S.R. SRN 1757-80, \\
\hline & ISRID-DOI-1 & 28 & Jecko (1977). & see & & & Lontsikh (1981). \\
\hline & OECD-12 & 31 & $\begin{array}{l}\text { Van Olphen and Fripiat } \\
\text { (1979). }\end{array}$ & $\begin{array}{l}\text { Sediment, } \\
\text { Marine }\end{array}$ & & & \\
\hline Calcsilicate & QMC-M-3 & 44 & Status unknown. In-house? & Cookeite & CMS-CAr-1 & 15 & Van Olphen and Fripiat \\
\hline Carbonatite & USGS-COQ-1 & 7 & Not analyzed. & & & & (1979). \\
\hline & CCRMP-OKA-1 & 5 & For Nb. Price list. Steger & Corrensite & CMS-CorWa-1 & 15 & From Packwood, Wash. \\
\hline & & & (1983). & Gibbsite & OECD-10 & 31 & Van Olphen and Fripiat \\
\hline & SAROCK S-8 & 21 & $\begin{array}{l}\text { National reference sample, } \\
\text { Frick (undated) }\end{array}$ & mite & CMS-IMt-1 & 15 & (1979). \\
\hline Carnotite & NBL -4 & 18 & Also NBL-5. Price list. & & & & $\begin{array}{l}\text { Van Ulphen and Fripiat } \\
\text { (1979). }\end{array}$ \\
\hline
\end{tabular}

Table 5. Reference samples-Continued 
Table 5. Reference samples-Continued

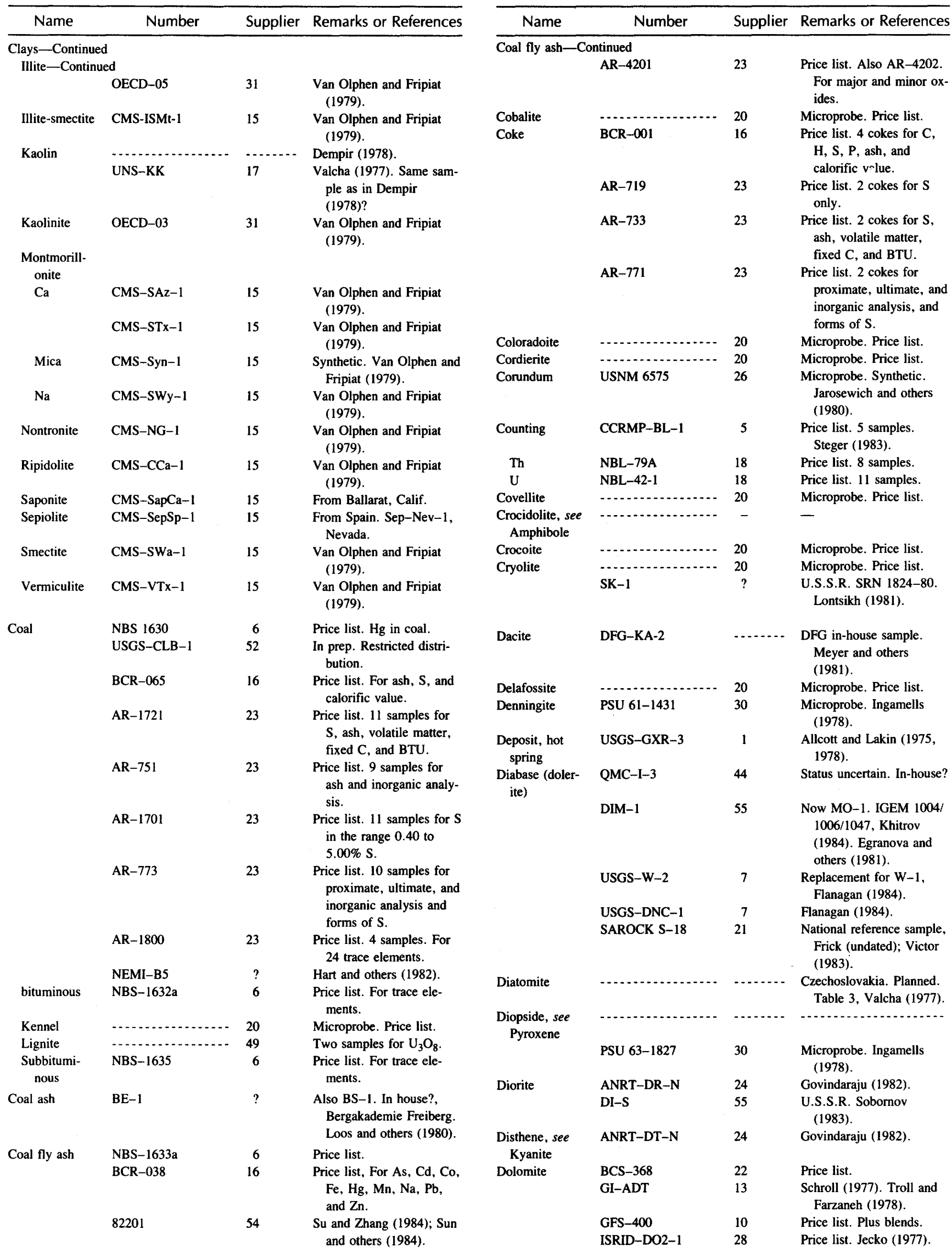

Table 5. Reference samples-Continued 
Table 5. Reference samples-Continued

\begin{tabular}{|c|c|c|c|}
\hline Name & Number & Supplier & Remarks or References \\
\hline \multicolumn{4}{|c|}{ Dolomite-Continued } \\
\hline & SS-60-8 & $?$ & $\begin{array}{l}\text { Gorozhanina and others } \\
\text { (1971). }\end{array}$ \\
\hline & n & $\ldots$ & $\begin{array}{l}\text { Bulgaria. Planned, Table } \\
\text { 3, Valcha (1977). }\end{array}$ \\
\hline & (n) & 20 & Microprobe. Price list. \\
\hline , Mn & $R-2027$ & 30 & $\begin{array}{l}\text { Microprobe. Ingamells } \\
(1980 \mathrm{~b}) \text {. }\end{array}$ \\
\hline \multirow[t]{2}{*}{ Dunite } & USGS-DTS-2 & 7 & $\begin{array}{l}\text { Replacement for DTS-1. } \\
\text { Not analyzed. }\end{array}$ \\
\hline & MU-2 & 55 & $\begin{array}{l}\text { IGEM 1021. Khitrov } \\
\text { (1984). }\end{array}$ \\
\hline , chrysolite & NIM-D & 21 & $\begin{array}{l}\text { Price list. Now SARM-6. } \\
\text { Steele and others (1978); } \\
\text { Steele and Hansen } \\
\text { (1979). }\end{array}$ \\
\hline \multicolumn{4}{|l|}{ Dust (particulate) } \\
\hline \multirow[t]{3}{*}{ Atmospheric } & AS -1 & - & $\begin{array}{l}\text { Hashimoto and others } \\
\text { (1976). }\end{array}$ \\
\hline & NBS-1648 & 6 & $\begin{array}{l}\text { Price list. For } 6 \text { major and } \\
\text { minor, and } 8 \text { trace ele- } \\
\text { ments. }\end{array}$ \\
\hline & NBS-1649 & 6 & $\begin{array}{l}\text { Price list. For } 5 \text { polycyclic } \\
\text { aromatic hydrocarbons. }\end{array}$ \\
\hline \multicolumn{4}{|l|}{ Ferrous } \\
\hline Electric & ES-876-1 & 28 & $\begin{array}{l}\text { Price list. Jecko and Rids- } \\
\text { dale (1978). }\end{array}$ \\
\hline $\begin{array}{l}\text { LD con- } \\
\text { verter }\end{array}$ & ES-877-1 & 28 & Price list. \\
\hline Nonferrous & CCRMP-PD-1 & 5 & Price list. Steger (1983). \\
\hline $\begin{array}{l}\text { Elbaite, see } \\
\text { Tourmaline }\end{array}$ & - n & -....... & - \\
\hline Epidote & , & 20 & Microprobe. Price list. \\
\hline Eskolaite & - & 20 & Microprobe. Price list. \\
\hline $\begin{array}{l}\text { Essonite, see } \\
\text { Garnet }\end{array}$ & - & $\cdots$ & 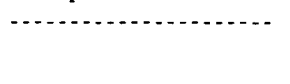 \\
\hline Fayalite & USNM 85276 & 26 & $\begin{array}{l}\text { Microprobe. Jarosewich } \\
\text { and others (1980). }\end{array}$ \\
\hline \multirow[t]{2}{*}{ Fe formation } & IWG-IF-G & 24 & Govindaraju (1984b). \\
\hline & CCRMP-FeR-1 & 5 & $\begin{array}{l}4 \text { samples. Abbey and oth- } \\
\text { ers (1983). }\end{array}$ \\
\hline \multirow[t]{4}{*}{ Feldspar } & R 701 & 12 & Uchida and others (1979). \\
\hline & 1 sample & 49 & $\begin{array}{l}\text { No sample number in ISO } \\
(1982) \text {. }\end{array}$ \\
\hline & - & - n & $\begin{array}{l}3 \text { samples. No numbers or } \\
\text { suppliers in Dempir } \\
(1978) \text {. }\end{array}$ \\
\hline & GSJ-JF-1 & 11 & $\begin{array}{l}\text { In prep. A. Ando (written } \\
\text { commun., 1984). }\end{array}$ \\
\hline Adularia & (n) & 20 & Microprobe. Price list. \\
\hline \multirow[t]{3}{*}{ Albite } & 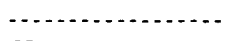 & 20 & Microprobe. Price list. \\
\hline & GIT-IWG-AL-1 & 24 & Govindaraju (1984b). \\
\hline & MAS-3 & 33 & Chinese sample. \\
\hline Anorthite & USNM 137041 & 26 & $\begin{array}{l}\text { Microprobe. Jarosewich } \\
\text { and others (1980). }\end{array}$ \\
\hline \multirow[t]{3}{*}{ Anorthoclase } & $\ldots$ & 20 & Microprobe. Price list. \\
\hline & Basel 1-a & 2 & Hügi and others (1975) \\
\hline & USNM 133868 & 26 & $\begin{array}{l}\text { Microprobe. Jarosewich } \\
\text { and others (1980). }\end{array}$ \\
\hline Microcline & USNM 143966 & 26 & $\begin{array}{l}\text { Microprobe. Jarosewich } \\
\text { and others }(1980) .\end{array}$ \\
\hline \multirow[t]{2}{*}{ Orthoclase } & PSU Or-1A & 30 & $\begin{array}{l}\text { Microprobe. Ingamells } \\
\text { (1978). }\end{array}$ \\
\hline & - & 20 & Microprobe. Price list. \\
\hline Plagioclase & n & 20 & Microprobe. Price list. \\
\hline Labradorite & USNM 115900 & 26 & $\begin{array}{l}\text { Microprobe. Jarosewich } \\
\text { and others (1980). }\end{array}$ \\
\hline potassium & BCS-376 & 22 & Price list. \\
\hline
\end{tabular}

Table 5. Reference samples-Continued

\begin{tabular}{|c|c|c|c|}
\hline Name & Number & Supplier & Remarks or References \\
\hline \multicolumn{4}{|c|}{$\begin{array}{l}\text { Feldspar-Continued } \\
\text { potassium-Continued }\end{array}$} \\
\hline & ANRT-FK-N & 24 & $\begin{array}{l}\text { Govindaraju (1984b), in } \\
\text { press. }\end{array}$ \\
\hline & NBS 70a & 6 & $\begin{array}{l}\text { Price list. See also NBS } \\
607\end{array}$ \\
\hline & NBS 607 & 6 & Price list. For $\mathbf{R b}$ and $\mathrm{Sr}$. \\
\hline & IAEA-F-1 & 27 & $\begin{array}{l}\text { IAEA (1984). U, Th, and } \\
\mathrm{K} \text { in Belyaev and } \\
\text { Sobomov (1981). }\end{array}$ \\
\hline & IPT-53 & 38 & Price list. \\
\hline \multirow[t]{2}{*}{ sodium } & BCS-375 & 22 & Price list. \\
\hline & NBS 99a & 6 & Price list. \\
\hline Feldspar sand & ZGI-FK & 37 & $\begin{array}{l}\text { Price list. Ostroumov } \\
\text { (1979). }\end{array}$ \\
\hline Fluorapatite & USNM 104021 & 26 & $\begin{array}{l}\text { Microprobe. Jarosewich } \\
\text { and others (1980). }\end{array}$ \\
\hline \multirow[t]{2}{*}{ Fluorite } & UNS-FM & 17 & $\begin{array}{l}\text { Price list. Dempir and } \\
\text { Valcha (1982). }\end{array}$ \\
\hline & (1) & 20 & Microprobe. Price list. \\
\hline \multirow[t]{4}{*}{ Fluorspar } & BCS 392 & 22 & Price list. \\
\hline & SARM 14 & 21 & Also SARM 15. Price list. \\
\hline & NBS 79a & 6 & Price list. \\
\hline & $\mathrm{JK}-\mathrm{C}$ & 53 & $\begin{array}{l}\text { Also JK-D and -E. Swe- } \\
\text { den, Institutet för } \\
\text { Metallforskning. }\end{array}$ \\
\hline high grade & NBS 180 & 6 & Price list. \\
\hline $\begin{array}{l}\text { Fly ash (see } \\
\text { also Coal Fly } \\
\text { Ash) }\end{array}$ & EPA-9 & 19 & For $226 \mathrm{Ra}$ and $228 \mathrm{Ra}$. \\
\hline \multirow[t]{8}{*}{ Gabbro } & CCRMP-MRG-1 & 5 & Price list. Steger (1983). \\
\hline & USGS-GSM-1 & 7 & Not analyzed. \\
\hline & GSJ-JGb-1 & 11 & Available. \\
\hline & GLOM-GOG-1 & 45 & $\begin{array}{l}\text { Mazzucotelli and Vannucci } \\
\text { (1980). }\end{array}$ \\
\hline & $\mathrm{MO}-3$ & 55 & $\begin{array}{l}\text { IGEM 1013. Khitrov } \\
\text { (1984). }\end{array}$ \\
\hline & MO-5 & 55 & $\begin{array}{l}\text { IGEM 1039. Khitrov } \\
\text { (1984). }\end{array}$ \\
\hline & $\mathrm{MO}-4$ & 55 & $\begin{array}{l}\text { IGEM 1014. Sobornov } \\
\text { (1983). Khitrov (1984). }\end{array}$ \\
\hline & (n- & $?$ & $\begin{array}{l}\text { Composition of unknown } \\
\text { gabbro, table 6, Dempir } \\
\text { (1978). }\end{array}$ \\
\hline Gabbro-diorite & SGD-1 & $?$ & $\begin{array}{l}\text { Malyshev and others } \\
\text { (1980). }\end{array}$ \\
\hline Gabbro-essexite & SGD-1A & 54 & $\begin{array}{l}\text { U.S.S.R. SRN 521-74. } \\
\text { Tauson and others } \\
\text { (1976), Sobornov } \\
\text { (1977). }\end{array}$ \\
\hline Gahnite & USNM 145883 & 26 & $\begin{array}{l}\text { Microprobe. Jarosewich } \\
\text { and others (1980). }\end{array}$ \\
\hline \multirow[t]{2}{*}{ Galena } & GF-1 & 37 & $\begin{array}{l}\text { Price list. Schrön and oth- } \\
\text { ers (1975). }\end{array}$ \\
\hline & - & 20 & Microprobe. Price list. \\
\hline \multirow[t]{2}{*}{ Garnet } & USNM 87373 & 26 & $\begin{array}{l}\text { Microprobe. Jarosewich } \\
\text { and others (1980). }\end{array}$ \\
\hline & USNM 110752 & 26 & $\begin{array}{l}\text { Microprobe. Jarosewich } \\
\text { and others (1980). }\end{array}$ \\
\hline Almandine & 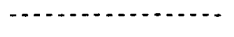 & 20 & Microprobe. Price list. \\
\hline Essonite & - & 20 & Microprobe. Price list. \\
\hline Pyrope & USNM-143968 & 26 & $\begin{array}{l}\text { Microprobe. Jarosewich } \\
\text { and others (1980). }\end{array}$ \\
\hline Gases & Several & 6 & Price list. \\
\hline Glass & No. 2 & 32 & $\begin{array}{l}\text { Price list. } 6 \text { samples. Soc. } \\
\text { of Glass Technology } \\
(1980) \text {. }\end{array}$ \\
\hline & Several & 49 & $\begin{array}{l}\text { No sample numbers in ISO } \\
\text { (1982). }\end{array}$ \\
\hline
\end{tabular}


Table 5. Reference samples-Continued

\begin{tabular}{|c|c|c|c|c|c|c|c|}
\hline Name & Number & Supplier & Remarks or References & Name & Number & Supplier & Remarks or References \\
\hline \multicolumn{4}{|c|}{ Glass-Continued } & \multicolumn{4}{|c|}{ Granite-Continued } \\
\hline & 2 samples & 51 & $\begin{array}{l}\text { No sample numbers in ISO } \\
\text { (1982). }\end{array}$ & & Gran-1 & (......... & $\begin{array}{l}\text { In-house, Netherlands. } \\
\text { Van der Sloot and Zon- }\end{array}$ \\
\hline & OCB-66-15 & 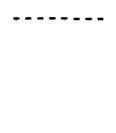 & $\begin{array}{l}\text { In-house? Anderson and } \\
\text { Fleer (1982). Table 1, } \\
\text { Rosholt and others } \\
\text { (1971). }\end{array}$ & & NS-8 & $\ldots$ & $\begin{array}{l}\text { derhuis (1979). } \\
\text { In-house, Netherlands. } \\
\text { Van der Sloot and Zon- } \\
\text { derhuis (1979). }\end{array}$ \\
\hline basaltic & USNM 113716 & 26 & $\begin{array}{l}\text { Microprobe. } 3 \text { glasses. } \\
\text { Jarosewich and others } \\
\text { (1980). }\end{array}$ & Abtal- & , & $-\ldots$. & $\begin{array}{l}\text { Analysis of a granite, table } \\
\text { 5, Dempir (1978). } \\
\text { In-house, DFG, Meyer and }\end{array}$ \\
\hline fission track & NBS 961 & 6 & Price list. 4 glasses. & & & & others (1981). \\
\hline high B & NBS 93 & 6 & Price list. & Alaskite & SG-2 & ? & USSR SRN 812-76. \\
\hline low B & NBS 92 & 6 & Price list. & & & & Sobornov (1977). \\
\hline opal & NBS 91 & 6 & Price list. & albitized & SG-1A & 54 & USSR SRN 520-74. Tau- \\
\hline $\mathrm{Pb}-\mathrm{Ba}$ & NBS 89 & 6 & Price list. & & & & son and others (1976), \\
\hline phonolitic & ANRT-VS-N & 24 & $\begin{array}{l}\text { Synthetic. Roche and } \\
\text { Govindaraju (1973). }\end{array}$ & aplitic & QMC-I-1 & 44 & $\begin{array}{l}\text { Sobornov (1977). } \\
\text { In-house? Status uncertain. }\end{array}$ \\
\hline rare earths & - & 4 & $\begin{array}{l}\text { Microprobe. Drake and } \\
\text { Weill (1972). }\end{array}$ & F-bearing & SAROCK S-16 & 21 & $\begin{array}{l}\text { National reference sample, } \\
\text { Frick (undated). }\end{array}$ \\
\hline rhyolitic & USNM 72854 VG568 & 26 & $\begin{array}{l}\text { Microprobe. Jarosewich } \\
\text { and others (1980). }\end{array}$ & high & GVCH-1 & $?$ & $\begin{array}{l}\text { USSR SRN 344-73. } \\
\text { Lontsikh (1981). }\end{array}$ \\
\hline soda lime & & & & Hypersthene & G2-S & ? & Sobornov (1983). \\
\hline \multirow{2}{*}{$\begin{array}{l}\text { container } \\
\text { flat }\end{array}$} & NBS 621 & 6 & Price list. & micro- & AC(OURS) & 8 & Potts and others (1981). \\
\hline & NBS 620 & 6 & Price list. & & & & Potts (1983). \\
\hline tektite & USNM 2213 & 26 & $\begin{array}{l}\text { Microprobe. Jarosewich } \\
\text { and others (1980). }\end{array}$ & Granitoid & $\mathrm{SO}-2 \mathrm{~B} / 74$ & $?$ & $\begin{array}{l}\text { USSR SRN 707-75. } \\
\text { Sobornov (1977). }\end{array}$ \\
\hline \multirow[t]{4}{*}{ trace elements } & NBS 608 & 6 & $\begin{array}{l}\text { Price list. Also NBS 609- } \\
619 .\end{array}$ & Granodiorite & USGS-GSP-1 & $\cdots$ & $\begin{array}{l}\text { Out of stock. A replace- } \\
\text { ment sample is being }\end{array}$ \\
\hline & USGS-GSB & $\cdots$ & Also GSC, GSD, and & & & & considered. \\
\hline & & & GSE. Myers and others & & GSJ-JG-1 & 11 & Ando and others (1974). \\
\hline & & & (1976). & & GSJ-JG-1a & 11 & Available, 1984 \\
\hline \multirow[t]{3}{*}{ Glass sand } & No. 1 & 32 & $\begin{array}{l}\text { Price list. Also samples } \\
\text { 2-5. Soc. of Glass Tech- } \\
\text { nology (1980). }\end{array}$ & & "Ryzhik" & 55 & $\begin{array}{l}\text { IGEM 1003. Egranova and } \\
\text { others (1981). Now } \\
\text { MK-1, Khitrov (1984). }\end{array}$ \\
\hline & NBS 81a & 6 & Price list. & & MK-2 & 55 & IGEM 1012/1028. \\
\hline & UNS-SS & 17 & Ledger and others (1980). & & & & Sobornov (1983). \\
\hline low $\mathrm{Fe}$ & NBS 165a & 6 & Price list. & & & & Khitrov (1984). \\
\hline \multirow[t]{2}{*}{ Glauconite } & GL-O & 24 & For ${ }^{40} \mathrm{Ar}$ and for chem. & Greigite & (n) & 20 & Microprobe. Price list. \\
\hline & USGS-GQS-1 & & $\begin{array}{l}\text { analysis. Roche and oth- } \\
\text { ers (1976). } \\
\text { Out of stock. }\end{array}$ & Greisen & ZGI-GnA & 37 & $\begin{array}{l}\text { Price list. Belyaev and } \\
\text { Sobornov (1981). Os- } \\
\text { troumov (1979). }\end{array}$ \\
\hline \multirow[t]{18}{*}{ Granite } & GIB-G-B & 43 & $\begin{array}{l}\text { Aleksiev and Boyadjieva } \\
\text { (1966). Ivanov (1981). }\end{array}$ & $\begin{array}{c}\text { Grunerite, see } \\
\text { Amphibole }\end{array}$ & (n) & $\cdots$ & - \\
\hline & QMC-I-1 & 44 & In-house? Status uncertain. & Gypsum & - & 20 & Microprobe. Price list. \\
\hline & ANRT-GS-N & 24 & $\begin{array}{l}\text { Govindaraju (1984b), in } \\
\text { press. }\end{array}$ & & OECD-13 & 31 & $\begin{array}{l}\text { Van Olphen and Fripiat } \\
\text { (1979). }\end{array}$ \\
\hline & CRPG-GA & 24 & $\begin{array}{l}\text { Govindaraju and de la } \\
\text { Roche (1977). }\end{array}$ & (alabaster) & 2 samples & 49 & $\begin{array}{l}\text { No sample numbers in ISO } \\
\text { (1982). }\end{array}$ \\
\hline & GRPG-GH & 24 & $\begin{array}{l}\text { Govindaraju and de la } \\
\text { Roche (1977). }\end{array}$ & Halite & - n & 20 & Microprobe. Price list. \\
\hline & NIM-G & 21 & Price list. Now SARM-1. & Hausmannite & (n) & 20 & Microprobe. Price list. \\
\hline & & & Steele and others & Hematite & GFS-453 & 10 & Plus blends. Price list. \\
\hline & & & (1978). Steele and & & (................. & 20 & Microprobe. Price list. \\
\hline & & & Hansen (1979). & Hemimorphite & (n) & 20 & Microprobe. Price list. \\
\hline & GSJ-JG-2 & 11 & $\begin{array}{l}\text { In prep. A. Ando (written } \\
\text { commun., 1984). }\end{array}$ & $\begin{array}{l}\text { Hessonite } \\
\quad=\text { Essonite: }\end{array}$ & (n) & & - \\
\hline & GSR-1 & 33 & $\begin{array}{l}\text { C.H. Tong (written com- } \\
\text { mun., 1984). }\end{array}$ & $\begin{array}{l}\text { see Garnet } \\
\text { Hornblende, see }\end{array}$ & 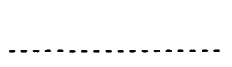 & & \\
\hline & USGS-G-2 & 7 & Flanagan (1976b). & Amphibole & & & \\
\hline & ZGI-GM & 37 & $\begin{array}{l}\text { Price list. Ostroumov } \\
\text { (1979). }\end{array}$ & & USNM 143965 & 26 & $\begin{array}{l}\text { Microprobe. Jarosewich } \\
\text { and others (1980). }\end{array}$ \\
\hline & ANRT-MA-N & 24 & Govindaraju (1980). & & Basel 1-h & 2 & Hügi and others (1975). \\
\hline & MK-3 & 55 & $\begin{array}{l}\text { IGEM 1018. Sobornov } \\
\text { (1983). Khitrov (1984). }\end{array}$ & & MMhb-1 & 14 & $\begin{array}{l}\text { Alexander and others } \\
\text { (1978). For }{ }^{40} \mathrm{Ar} /{ }^{39} \mathrm{Ar}\end{array}$ \\
\hline & MK-4 & 55 & $\begin{array}{l}\text { IGEM 1025/1027. } \\
\text { Sobornov (1983). } \\
\text { Khitrov (1984). }\end{array}$ & & & & $\begin{array}{l}\text { Geochimica et Cos- } \\
\text { mochimica Acta, v. } 43 \text {, } \\
\text { p. } 278 \text { (1978). }\end{array}$ \\
\hline & G1-S & $?$ & Sobornov (1983). & & $4-190,4-234$ & 30 & Microprobe. Ingamells \\
\hline & KA-1 & & $\begin{array}{l}\text { In-house, DFG. Meyer and } \\
\text { others (1981). }\end{array}$ & & USGS-Hbl-1 & 7 & $\begin{array}{l}(1980 \mathrm{~b}) \\
\text { Not analyzed. }\end{array}$ \\
\hline
\end{tabular}

Table 5. Reference samples-Continued 
Table 5. Reference samples-Continued

\begin{tabular}{|c|c|c|c|c|c|c|c|}
\hline Name & Number & Supplier & Remarks or References & Name & Number & Supplier & Remarks or References \\
\hline \multirow[t]{2}{*}{ Hornblendite } & \multirow[t]{2}{*}{ MU-3 } & \multirow[t]{2}{*}{55} & IGEM 1015/1030. Khitrov & \multicolumn{3}{|c|}{ Isotopic-Continued } & \\
\hline & & & $\begin{array}{l}(1984) \\
\ldots\end{array}$ & $15 \mathrm{~N} / 14 \mathrm{~N}$ & IAEA-N-1 & 9 & $\begin{array}{l}\text { Also } \mathrm{N}-2 \text {. Synthetic, from } \\
\text { ammonium sulfate. }\end{array}$ \\
\hline $\begin{array}{l}\text { Hypersthene, } \\
\text { see Pyroxene }\end{array}$ & - nenten & $\ldots$ & & \multirow[t]{2}{*}{180} & & & See ${ }^{13} \mathrm{C}, \mathrm{D}$, and $\mathrm{S}$. \\
\hline \multirow[t]{2}{*}{ Ilmenite } & USNM 96189 & 26 & $\begin{array}{l}\text { Microprobe. Jarosewich } \\
\text { and others (1980). }\end{array}$ & & NBS-28 & 9 & $\begin{array}{l}\text { African glass sand. Fried- } \\
\text { man and Gleason } \\
(1973) .\end{array}$ \\
\hline & 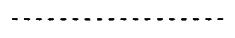 & 20 & Microprobe. Price list. & \multirow[t]{3}{*}{$\mathrm{Pb}$} & \multirow[t]{3}{*}{ NBS 981} & \multirow[t]{3}{*}{6} & Also 982,983 . Price list. \\
\hline \multirow{8}{*}{$\begin{array}{l}\text { Ilvaite } \\
\text { Isotopic, stable }\end{array}$} & (n. & 20 & Microprobe. Price list. & & & & Natural, equal atom \\
\hline & \multirow{3}{*}{ NBS 978} & \multirow{3}{*}{6} & \multirow{3}{*}{ Price list. } & & & & $\begin{array}{l}\text { (206/208), and radio- } \\
\text { genic }(92 \% 206) \text { leads. }\end{array}$ \\
\hline & & & & ${ }^{206} \mathrm{~Pb}$ spike & NBS 991 & 6 & Price list. \\
\hline & & & & $\mathrm{Pu}$ & NBS 946 & 6 & Price list. Also $947,948$. \\
\hline & $B S-1$ & -........ & $\begin{array}{l}\text { Alexander and Davis } \\
(1974, \text { p. } 927)\end{array}$ & & & & $\begin{array}{l}\text { Varying Pu isotopic } \\
\text { compositions. }\end{array}$ \\
\hline & $\mathrm{ZBH}-25$ & $?$ & Wang (1983). & $\mathrm{Rb}$, as $\mathrm{RbCl}$ & NBS 984 & 6 & Price list. \\
\hline & GA 1550 & $?$ & Australian Nat. Univ. & $\mathrm{Re}$, as metal & NBS 989 & 6 & Price list. \\
\hline & & & Wang (1983). & $\mathrm{S}$ & OGS & 9 & IAEA. ${ }^{34} \mathrm{~S} /{ }^{32} \mathrm{~S}$, but not \\
\hline \multirow[t]{7}{*}{ Hornblende } & NL-25 & - n..... & $\begin{array}{l}\text { Alexander and Davis } \\
(1974, \text { p. } 927) .\end{array}$ & & & & $\begin{array}{l}18 \mathrm{O} / 16 \mathrm{O}, \text { measured. } \\
\text { Synthetic } \mathrm{BaSO}_{4} \text { precip- }\end{array}$ \\
\hline & FY12a & …..... & $\begin{array}{l}\text { Univ. of Leeds. Roddick } \\
\text { (1983). }\end{array}$ & & $-\ldots \ldots$ & 9 & $\begin{array}{l}\text { itated from sea water. } \\
\text { Soufre de Lacq. IAEA. }\end{array}$ \\
\hline & \multirow[t]{3}{*}{$\mathrm{Hb} 3 \mathrm{gr}$} & \multirow[t]{3}{*}{$\ldots$} & \multirow{3}{*}{$\begin{array}{l}\text { Alexander and Davis } \\
(1974, \text { p. 927). Roddick } \\
(1983) .\end{array}$} & & & & Naural elemental S. \\
\hline & & & & $\mathrm{Si}$, as metal & NBS 990 & 6 & Price list. \\
\hline & & & & $\mathrm{Sr}$, as $\mathrm{SrCO}_{3}$ & NBS 987 & 6 & Price list. \\
\hline & MMhb-1 & 14 & $\begin{array}{l}\text { Alexander and others } \\
\text { (1978). }\end{array}$ & $\mathrm{U}$, as $\mathrm{U}_{3} \mathrm{O}_{8}$ & NBS U-0002 & 6 & $\begin{array}{l}\text { Price list. Also U-005 to } \\
\text { U-970. Varying U iso- }\end{array}$ \\
\hline & $\mathrm{ZBJ}$ & $?$ & Wang (1983). & & & & topic compositions. \\
\hline Meteroite & St. Severin & $-\ldots$ & $\begin{array}{l}\text { Alexander and Davis } \\
(1974, \text { p. } 927)\end{array}$ & & & & \\
\hline Nepheline & Toronto ? & - n....... & $\begin{array}{l}(1974, \text { p. } 927) \\
\text { Alexander and Davis } \\
(1974, \text { p. } 927)\end{array}$ & Jasperoid & USGS-GXR-1 & 1 & Allcott and Lakin (1978). \\
\hline $\mathrm{B}$, as $\mathrm{H}_{3} \mathrm{BO}_{3}$ & NBS 951 & 6 & Price list. & Kalinite & - & 20 & Microprobe. Price list. \\
\hline B, $95 \% \mathrm{~B}^{10}$ & & & & Kaolin & UNS-KK & 17 & $\begin{array}{l}\text { Ostroumov (1979). Valcha } \\
\text { (1977). }\end{array}$ \\
\hline $\begin{array}{l}\text { enriched } \\
\text { Biotite } \\
13 \mathrm{C}\end{array}$ & $\begin{array}{l}\text { NBS } 952 \\
\text { NBS-30 }\end{array}$ & $\begin{array}{l}6 \\
9\end{array}$ & Price list. & Kimberlite & SAROCK S-7 & 21 & $\begin{array}{l}\text { National reference sample, } \\
\text { Frick (undated). }\end{array}$ \\
\hline limestone & NBS-19 & 9 & $\begin{array}{l}\text { For }{ }^{18} \mathrm{O} \text { and }{ }^{13} \mathrm{C} \text {. Friedman } \\
\text { and others (1982). }\end{array}$ & & MU-4 & 55 & $\begin{array}{l}\text { IGEM 1020. Khitrov } \\
(1984) \text {. }\end{array}$ \\
\hline carbonatite & NBS 18 & 9 & $\begin{array}{l}\text { and others (1982). } \\
\text { For } 18 \mathrm{O} \text { and }{ }^{13} \mathrm{C} \text {. Friedman } \\
\text { and others (1982). }\end{array}$ & Kyanite & ANRT-DT-N & $\begin{array}{l}20 \\
24\end{array}$ & $\begin{array}{l}\text { Microprobe. Price list. } \\
\text { Govindaraju (1982). }\end{array}$ \\
\hline $\begin{array}{l}\text { Iceland } \\
\text { spar }\end{array}$ & - & 50 & $\begin{array}{l}\text { For }{ }^{18} \mathrm{O} \text { and }{ }^{13} \mathrm{C} \text {. Landis } \\
\quad(1983) \text {. }\end{array}$ & Laterite & MO9-1 & 28 & Jecko (1977) \\
\hline $\mathrm{Cl}$, as $\mathrm{NaCl}$ & NBS-975 & 6 & Price list. & & IVIC-VL-1 & 39 & Also VL-2. Schorin and \\
\hline $\mathrm{CO}_{2}$ & NBS-16 & 9 & Prepared from commercial & & & & LaBreque (1983). \\
\hline & & & liquified $\mathrm{CO}_{2}$. Coplen & Larvikite & ASK-1 & 40 & Christie (1975). \\
\hline & & & and Kendall (1982). & Lepidolite & NBS 183 & 6 & Price list. \\
\hline & NBS-17 & 9 & $\begin{array}{l}\text { Prepared from commercial } \\
\mathrm{CO}_{2} \text { gas. Coplen and }\end{array}$ & & PSU 60-1252 & 30 & $\begin{array}{l}\text { Microprobe. Ingamells } \\
\text { (1978). }\end{array}$ \\
\hline & & & Kendall (1982). & & (n) & 20 & Microprobe. Price list. \\
\hline $\mathrm{Cr}$, as $\mathrm{Cr}$ & NBS-979 & 6 & Price list. & Lignite & 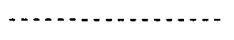 & 7 & Two samples for $\mathrm{U}_{3} \mathrm{O}_{8}$. \\
\hline nitrate & & & & Limestone & GI-LLL-1 & 13 & Schroll (1977). \\
\hline $\mathrm{Cu}$, as metal & NBS-976 & 6 & Price list. & & IAEA-Sed-3 & 27 & Out of stock. For $U, T h$, \\
\hline D & NBS 30 & 9 & Also for ${ }^{180}$ & & & & and $\mathrm{K}$, Heinonen and \\
\hline & V-SMOW & 9 & Also for ${ }^{18} \mathrm{O}$. For $\mathrm{D} / \mathrm{H}$, see & & & & others (1973). \\
\hline & & & $\begin{array}{l}\text { de Wit and others } \\
(1980) \text {. For } 180 / 160\end{array}$ & & ZGI-KH & 37 & $\begin{array}{l}\text { Price list. Ostroumov } \\
\text { (1979). }\end{array}$ \\
\hline & & & Baertschi (1976). & & GFS-401 & 10 & Plus blends. Price list. \\
\hline & SLAP & 9 & Also for ${ }^{18} \mathrm{O}$. de Wit and & & IPT -44 & 38 & Price list. \\
\hline & & & others (1980). Price list. & & SS-59-V & $?$ & Also SS-59-g. \\
\hline & GISP & 9 & $\begin{array}{l}\text { Isotopic comp. between } \\
\text { SLAP and V-SMOW. }\end{array}$ & & & & $\begin{array}{l}\text { Gorozhanina and others } \\
\text { (1971). }\end{array}$ \\
\hline & & & $\begin{array}{l}\text { de Wit and others } \\
(1980) . \text { Available (?) } \\
1985 .\end{array}$ & & AR-4111 & 23 & $\begin{array}{l}\text { Price list. Also AR-4112. } \\
\text { For major and minor } \\
\text { dioxides. }\end{array}$ \\
\hline Limestone, & NBS-20 & 9 & & argillaceous & NBS-1c & 6 & Price list. \\
\hline Solenhofen & & & & calcitic & IPT-35 & 38 & Price list. \\
\hline TS & NBS-19 & 9 & For ${ }^{13} \mathrm{C}$ and ${ }^{18} \mathrm{O}$. Friedman & dolomitic & NBS-88a & 6 & Price list. \\
\hline & & & and others (1982). & & BCS -393 & 22 & Price list. \\
\hline $\mathrm{Mg}$, as metal & NBS 980 & 6 & Price list. & & IPT-47 & 38 & Price list. \\
\hline
\end{tabular}

Table 5. Reference samples-Continued 
Table 5. Reference samples-Continued

\begin{tabular}{|c|c|c|c|c|c|c|c|}
\hline Name & Number & Supplier & Remarks or References & Name & Number & Supplier & Remarks or References \\
\hline \multicolumn{4}{|c|}{$\begin{array}{l}\text { Limestone-Continued } \\
\text { dolomitic-Continued }\end{array}$} & \multirow[t]{2}{*}{ Nodule, Mn } & USGS-Nod-A-1 & 7 & $\begin{array}{l}\text { Also Nod-P-1, Flanagan } \\
\text { and Gottfried }(1980) \text {. }\end{array}$ \\
\hline & GSR-6 & 33 & $\begin{array}{l}\text { C.H. Tong (written com- } \\
\text { mun., 1984). }\end{array}$ & & Schafer-1 & $\ldots$ & $\begin{array}{l}\text { Also -2. In-house? Kor- } \\
\text { kisch and others (1979). }\end{array}$ \\
\hline & SI-1 & 54 & $\begin{array}{l}\text { IGI. U.S.S.R. SRN 813- } \\
\text { 76. Sobornov (1977). }\end{array}$ & \multirow[t]{2}{*}{ Norite } & NIM-N & 21 & $\begin{array}{l}\text { Price list. Now SARM-4. } \\
\text { Steele and others }(1978) \text {; }\end{array}$ \\
\hline Solenhofen & NBS -20 & 9 & $\begin{array}{l}\text { See Isotopic. Nier (1950); } \\
\text { Coplen and Kendall }\end{array}$ & & & & $\begin{array}{l}\text { Steele and Hansen } \\
\text { (1979). }\end{array}$ \\
\hline \multirow[t]{5}{*}{ Lujavrite } & \multirow[t]{3}{*}{ NIM-L } & \multirow[t]{3}{*}{21} & $\begin{array}{l}\text { (1982). } \\
\text { Price list. Now SARM-3. }\end{array}$ & \multirow[t]{2}{*}{ Olivine } & USNM $111312 / 444$ & 26 & $\begin{array}{l}\text { Microprobe. Jarosewich } \\
\text { and others (1980). }\end{array}$ \\
\hline & & & $\begin{array}{l}\text { Steele and others (1978); } \\
\text { Steele and Hansen }\end{array}$ & & USNM 2566 & 26 & $\begin{array}{l}\text { Microprobe. Jarosewich } \\
\text { and others (1980). }\end{array}$ \\
\hline & & & (1979) & \multirow[t]{2}{*}{ Forsterite } & \multirow[t]{2}{*}{ MAS-1 } & \multirow[t]{2}{*}{33} & \multirow{3}{*}{ Chinese sample. } \\
\hline & \multirow[t]{2}{*}{ MSHCH-4 } & \multirow[t]{2}{*}{55} & IGEM 1024/1033. Khitrov & & & & \\
\hline & & & $(1984)$ & $\begin{array}{l}\text { Omphacite, see } \\
\text { Pyroxene }\end{array}$ & - & $\cdots \cdots$ & \\
\hline \multirow[t]{7}{*}{ Magnesite } & BCS 319 & 22 & Price list. & Orthoclase, see & - & $\ldots$ & - \\
\hline & \multirow[t]{2}{*}{ UNS-MK } & 17 & Valcha (1979). Ostroumov & Feldspar & & & \\
\hline & & 31 & $\begin{array}{l}(1979) \\
\text { Van Olphen and Fripiat }\end{array}$ & Osumillite & USNM 143967 & 26 & $\begin{array}{l}\text { Microprobe. Jarosewich } \\
\text { and others (1980). }\end{array}$ \\
\hline & & & (1979). & Ores & & & \\
\hline & (- & 20 & Microprobe. Price list. & $\mathrm{Ag}-\mathrm{Au}$ & - n & $\ldots . . . .$. & Number and supplier not \\
\hline & (n) & $\ldots . . .1$ & 3 samples, Dempir (1978). & & & & given. Dempir (1978). \\
\hline & SAROCK S-11 & $\cdots$ & $\begin{array}{l}\text { National reference sample, } \\
\text { Frick (undatred). }\end{array}$ & $\begin{array}{l}\mathrm{Al} \\
\quad \text { alumina? }\end{array}$ & SS-198-a & $?$ & Gorozhanina and others \\
\hline chrome & BCS 369 & 22 & Also BCS 370 . Price list. & & & & (1971) \\
\hline high purity & BCS 389 & 22 & Price list. & bauxite & SS-190-a & $?$ & Gorozhanina and others \\
\hline low $\mathrm{SiO}_{2}$ & BCS 396 & 22 & Price list. & & & & (1971) \\
\hline Magnetite & GFS -450 & 10 & Price list. & $\mathrm{Au}$ & CCRMP-MA-1 & 5 & Also MA-2. Price list. \\
\hline & USNM 114887 & 26 & Microprobe. Jarosewich & & & & Steger (1983). \\
\hline & & & and others $(1980)$ & & $S Z p-1$ & $?$ & U.S.S.R. SRN 1789-80. \\
\hline & & 20 & Microprobe. Price list. & & & & Lontsikh (1981). \\
\hline Malachite & n & 20 & Microprobe. Price list. & float conc. & SZK-1 & $?$ & U.S.S.R. SRN 1787-80. \\
\hline Manganosite & - & 20 & Microprobe. Price list. & & & & Lontsikh (1981). \\
\hline Mariupolite & MSHCH-2 & 55 & $\begin{array}{l}\text { IGEM 1011. Khitrov } \\
\text { (1984). }\end{array}$ & & SZK-2 & $?$ & $\begin{array}{l}\text { U.S.S.R. SRN 1788-80. } \\
\text { Lontsikh (1981). }\end{array}$ \\
\hline Marl, ferriferous & ISRID MO8-1 & 28 & Jecko (1977). & float tails & SZH-1 & $?$ & U.S.S.R. SRN 1790-80. \\
\hline Mellite & - & 20 & Microprobe. Price list. & & & & Lontsikh (1981). \\
\hline Messelite & $\ldots$ & 20 & Microprobe. Price list. & gravity tails & SZH-2 & $?$ & U.S.S.R. SRN 1791-80. \\
\hline Meteorite & & & & & & & Lontsikh (1981). \\
\hline Allende & - & 26 & Clarke and others $(1970)$. & sulfide & SZR-1 & $?$ & Lontsikh and Parshin \\
\hline Bjurböle & $\cdots$ & $?$ & Hohenberg and Kennedy & & & & $(1980)$ \\
\hline & & & (1981) & $\mathrm{Ba}$, barite & IGS-38 & 41 & Lister (1978). \\
\hline St. Severin & - & $?$ & $\begin{array}{l}\text { For }{ }^{40} \mathrm{Ar} /{ }^{39} \mathrm{Ar} \text {. See Iso- } \\
\text { topic. }\end{array}$ & & - n & $\ldots$ & $\begin{array}{l}\text { Number and supplier not } \\
\text { given. Dempir (1978). }\end{array}$ \\
\hline Miaskite & MIV-1 & 55 & $\begin{array}{l}\text { IGEM } 1001 / 1005, \text { Egra- } \\
\text { nova and others }(1981)\end{array}$ & $\mathrm{Be}$ & SS-288 & $?$ & $\begin{array}{l}\text { Gorozhanina and others } \\
(1971) \text {. }\end{array}$ \\
\hline & & & Now MSHCH-1, & $\mathrm{Co}$ & IGS-24 & 41 & Lister (1978). \\
\hline & & & Khitrov (1984). & & SS-294 & $?$ & Gorozhanina and others \\
\hline Microcline, see & , & - . & - & & & & (1971). \\
\hline & & & & $\mathrm{Co}-\mathrm{Ni}$ & SNK-1 & $?$ & U.S.S.R. SRN 1346-78. \\
\hline Microlite & PSU 5-006 & 30 & $\begin{array}{l}\text { Microprobe. Ingamells } \\
\text { (1978). }\end{array}$ & & & & $\begin{array}{l}\text { Lontsikh and Parshin } \\
\text { (1980). }\end{array}$ \\
\hline & PSU 5-010 & 30 & $\begin{array}{l}\text { Microprobe. Ingamells } \\
\text { (1980b). }\end{array}$ & & SNK-2 & $?$ & $\begin{array}{l}\text { U.S.S.R. SRN 1347-78. } \\
\text { Lontsikh and Parshin }\end{array}$ \\
\hline Molybdenite & - & 20 & Microprobe. Price list. & & & & $(1980)$ \\
\hline Monazite & (n) & 20 & Microprobe. Price list. & $\mathrm{Cr}$ & IGS-30 & 41 & Lister (1978). \\
\hline Monazite sand & NBL-7-A & 18 & Price list. & & JSS-870-1 & 12 & Terashima (1979). \\
\hline Monzonite & - & - n & $\begin{array}{l}\text { Planned. Table 3, Valcha } \\
\text { (1977). }\end{array}$ & & SARM-8 & 21 & $\begin{array}{l}\text { Price list. Also SARM-9. } \\
\text { Stoch and others (1979). }\end{array}$ \\
\hline Mud, see Silt or & - n & $\ldots+\ldots$ & - & & $\mathrm{Cr}-\mathrm{Erz}-1$ & 37 & Price list. Also $\mathrm{Cr}-\mathrm{Erz}-2$. \\
\hline Sediment & & & & & $166-v$ & $?$ & Valcha (1977). Ostroumov \\
\hline Muscovite & Bern 4-m & 2 & Odin and others (1982). & & & & (1979). \\
\hline & & & & chromite & SS-132-a & $?$ & Also SS-166-B. \\
\hline Nealite & - & 20 & Microprobe. Price list. & & & & Gorozhanina and others \\
\hline Nepheline & & & & & & & (1971). \\
\hline syenite & USGS-STM-1 & 7 & Flanagan (1976b) & conc. & SS-275 & $?$ & Also SS-90. Gorozhanina \\
\hline & SNS-2 & 54 & U.S.S.R. SRN 1345-78. & & & & and others (1971). \\
\hline & & & $\begin{array}{l}\text { Lontsikh and Parsnin } \\
\text { (1980). }\end{array}$ & $\begin{array}{l}\text { Grecian } \\
\text { chrome }\end{array}$ & BCS-308 & 22 & Price list. \\
\hline
\end{tabular}


Table 5. Reference samples-Continued

\begin{tabular}{|c|c|c|c|}
\hline Name & Number & Supplier & Remarks or References \\
\hline \multicolumn{4}{|l|}{ Ores-Continued } \\
\hline $\mathrm{Cu}$ & SS-183 & $?$ & $\begin{array}{l}\text { Also SS-184. Gorozhanina } \\
\text { and others (1971). }\end{array}$ \\
\hline $\begin{array}{l}\text { Chalcocite- } \\
\text { qtz. mix. }\end{array}$ & IGS-1 & 41 & $\begin{array}{l}\text { Also IGS-2, }-3 \text {, and }-4 \text {, } \\
\text { Lister (1978). }\end{array}$ \\
\hline $\begin{array}{l}\text { chalcopyrite } \\
\text { conc. }\end{array}$ & IGS-5 & 41 & Lister (1978). \\
\hline \multirow[t]{5}{*}{ conc. } & NBS-332 & 6 & Price list. \\
\hline & CCRMP-CCU-1 & 5 & Price list. Steger (1983). \\
\hline & SS-250 & $?$ & $\begin{array}{l}\text { Gorozhanina and others } \\
\text { (1971). }\end{array}$ \\
\hline & - nen & -........ & $\begin{array}{l}3 \text { samples. No numbers or } \\
\text { supplier. Dempir (1978). }\end{array}$ \\
\hline & CuPl & $\ldots$ & Poland. Valcha (1977). \\
\hline $\begin{array}{c}\text { copperkeis } \\
\text { (chalco- } \\
\text { pyrite) }\end{array}$ & RUS-2 & $?$ & $\begin{array}{l}\text { U.S.S.R. SRN 792-76. } \\
\text { Egranova and others } \\
\text { (1981). }\end{array}$ \\
\hline $\begin{array}{l}\text { dissem- } \\
\text { inated }\end{array}$ & $\ldots+\ldots$ & $?$ & $\begin{array}{c}\text { Bulgaria. Planned. Table } \\
\text { 3, Valcha (1977). }\end{array}$ \\
\hline \multirow[t]{3}{*}{ mill heads } & NBS-330 & 6 & Price list. \\
\hline & NBS-331 & 6 & Price list. \\
\hline & USGS-GXR-4 & 1 & Allcott and Lakin (1978). \\
\hline $\mathrm{Cu}-\mathrm{Mo}$ & CCMP-HV-1 & 5 & Price list. Steger (1983). \\
\hline $\mathrm{Cu}-\mathrm{Pb}$ & $\mathrm{Cu}-\mathrm{Pb} ?$ & $?$ & $\begin{array}{l}\text { Poland. Ostroumov (1979). } \\
\text { Same as CuPI in Valcha } \\
(1977) ?\end{array}$ \\
\hline $\begin{array}{l}\mathrm{Cu}-\mathrm{Zn} \\
\text { sulfide }\end{array}$ & RUS-1 & $?$ & $\begin{array}{l}\text { U.S.S.R. SRN 791-76. } \\
\text { Egranova and others } \\
\text { (1981). }\end{array}$ \\
\hline \multicolumn{4}{|r|}{ 100 } \\
\hline \multirow[t]{3}{*}{ Fluorite } & IGS-39 & 41 & Lister (1978). \\
\hline & UNS-FM & 17 & $\begin{array}{l}\text { Dempir and Valcha } \\
\text { (1982). }\end{array}$ \\
\hline & - & $?$ & $\begin{array}{l}\text { Mongolia. Planned. Table } \\
\text { 3, Valcha (1977). }\end{array}$ \\
\hline \multirow[t]{6}{*}{ Fluorspar } & SARM-14 & 21 & Also SARM-15. Price list. \\
\hline & BCS-392 & 22 & Price list. \\
\hline & NBS 79a & 6 & Price list. \\
\hline & JK-C & 53 & $\begin{array}{l}\text { Also JK-D and -E. Swe- } \\
\text { den, Institutet för } \\
\text { Metallforskning. }\end{array}$ \\
\hline & Flusspat & 37 & Price list. \\
\hline & 3 samples & $?$ & $\begin{array}{l}\text { Numbers and supplier not } \\
\text { given. Table 3. Valcha } \\
\text { (1977). }\end{array}$ \\
\hline \multirow[t]{5}{*}{$\begin{array}{l}\text { high } \\
\text { grade }\end{array}$} & NBS 180 & 6 & Price list. \\
\hline & ES-871-1 & 22 & $\begin{array}{c}\text { BCS Price list. Also ES- } \\
681-1 \text { and ES-682-1. }\end{array}$ \\
\hline & IPT-21 & 38 & $\begin{array}{l}\text { Price list. Also IPT }-23 \text {, } \\
-27 \text {, and }-30 \text {. }\end{array}$ \\
\hline & LKAB N3/1974 & $\ldots \ldots$ & $\begin{array}{l}\text { Sweden. Plant production } \\
\text { conc.'s? Feret (1982). }\end{array}$ \\
\hline & JK-11 & 53 & $\begin{array}{l}4 \text { samples. Sweden, Insti- } \\
\text { tutet för Metallforsk- } \\
\text { ning. }\end{array}$ \\
\hline agglomerate & SS-211 & $?$ & $\begin{array}{l}\text { Gorozhanina and others } \\
\text { (1971). }\end{array}$ \\
\hline Algarrobo & JSS-813-2 & 12 & Terashima (1979). \\
\hline \multirow[t]{2}{*}{ banded } & CCRMP-FeR-1 & 5 & $\begin{array}{l}4 \text { samples. Price list. } \\
\text { Abbey and others } \\
\text { (1983). }\end{array}$ \\
\hline & IWG-IF-G & 24 & $\begin{array}{l}\text { Govindaraju (1984b), in } \\
\text { press. }\end{array}$ \\
\hline \multirow{2}{*}{$\begin{array}{l}\text { Canada } \\
\quad \text { (conc.) }\end{array}$} & NBS -690 & 6 & Price list. \\
\hline & CCRMP-SCH-1 & 5 & $\begin{array}{l}\text { Price list. Also MW-1. } \\
\text { Steger (1983). }\end{array}$ \\
\hline Hematite & SARM-11 & 21 & Price list. \\
\hline
\end{tabular}

Table 5. Reference samples-Continued

\begin{tabular}{|c|c|c|c|}
\hline Name & Number & Supplier & Remarks or References \\
\hline \multicolumn{4}{|l|}{ Ores-Continued } \\
\hline \multicolumn{4}{|c|}{$\mathrm{Fe}-$ Continued } \\
\hline \multicolumn{4}{|c|}{ Hematite-Continued } \\
\hline Rompin & JSS-800-3 & 12 & $\begin{array}{c}\text { Terashima (1979). Jecko } \\
\text { and others }(1980) .\end{array}$ \\
\hline Krivoi Rog & $3-d$ & $?$ & $\begin{array}{l}\text { Valcha (1977). Feret } \\
\text { (1982). Sample 3d-1 in } \\
\text { Ostroumov (1979)? }\end{array}$ \\
\hline Labrador & NBS 692 & 6 & Price list. \\
\hline $\begin{array}{l}\text { Lincoln- } \\
\text { shire }\end{array}$ & BCS 301/1 & 22 & Price list. \\
\hline Magnetite & SARM-12 & 21 & Price list. \\
\hline Musan & JSS-812-2 & 12 & Terashima (1979). \\
\hline Nimba & NBS 693 & 6 & Price list. \\
\hline Philippine & JSS-830-3 & 12 & Terashima (1979). \\
\hline Sibley & NBS 27f & 6 & Price list. \\
\hline Siderite & SS-216-a & $?$ & $\begin{array}{l}\text { Gorozhanina and others } \\
\text { (1971). }\end{array}$ \\
\hline \multirow[t]{4}{*}{ Sinter } & ES-676-1 & 22 & BCS Price list. \\
\hline & BCS-378 & 22 & Price list. \\
\hline & IRSID-A01-1 & 28 & Also A02-1. Jecko (1977). \\
\hline & 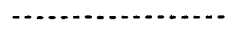 & 37 & Price list. \\
\hline \multicolumn{4}{|l|}{ Fe, general } \\
\hline Australia & 1 sample & $?$ & $\begin{array}{l}\text { Table 5, Jecko and others } \\
\text { (1980). }\end{array}$ \\
\hline $\begin{array}{l}\text { Czecho- } \\
\text { slovakia }\end{array}$ & 13 samples & $?$ & $\begin{array}{l}\text { Table 8, Jecko and others } \\
\text { (1980). }\end{array}$ \\
\hline $\begin{array}{l}\text { European } \\
\text { Com- } \\
\text { munity }\end{array}$ & 7 samples & & $\begin{array}{l}\text { Table 1, Jecko and others } \\
\text { (1980). }\end{array}$ \\
\hline France & 16 samples & 28 & $\begin{array}{l}\text { Table 3, Jecko and others } \\
\text { (1980). }\end{array}$ \\
\hline Germany & 8 samples & 29 & $\begin{array}{l}\text { Pohl and Oberhauser } \\
\text { (1978): Table 2, Jecko } \\
\text { and others (1980). }\end{array}$ \\
\hline Japan & 13 samples & 12 & $\begin{array}{l}\text { Table 4, Jecko and others } \\
\text { (1980). }\end{array}$ \\
\hline Poland & 1 sample & $?$ & $\begin{array}{l}\text { Table 8, Jecko and others } \\
\text { (1980). }\end{array}$ \\
\hline Romania & 4 samples & $?$ & $\begin{array}{l}\text { Table 7, Jecko and others } \\
\text { (1980). }\end{array}$ \\
\hline $\begin{array}{l}\text { Soviet } \\
\text { Union }\end{array}$ & 16 samples & $?$ & $\begin{array}{l}\text { Table 9, Jecko and others } \\
\text { (1980). }\end{array}$ \\
\hline Sweden & 2 samples & $?$ & $\begin{array}{l}\text { Table 6, Jecko and others } \\
\text { (1980). }\end{array}$ \\
\hline $\mathbf{H g}$ & 3 samples & $?$ & $\begin{array}{l}\text { Numbers and suppliers not } \\
\text { given. Dempir (1978). }\end{array}$ \\
\hline \multicolumn{4}{|r|}{ 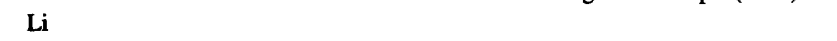 } \\
\hline Lepidolite & NBS 183 & 6 & Price list. \\
\hline Petalite & NBS 182 & 6 & Price list. \\
\hline Spodumene & NBS 181 & 6 & Price list. \\
\hline \multicolumn{4}{|l|}{$\mathrm{Mn}$} \\
\hline & NBS $25 \mathrm{c}$ & 6 & Price list. \\
\hline & SARM-16 & 21 & Price list. Also SARM-17. \\
\hline & BCS $176 / 2$ & 22 & Price list. \\
\hline & ES 633-1 & 22 & $\begin{array}{l}\text { Price list. Pohl and Ober- } \\
\text { hauser (1978). }\end{array}$ \\
\hline & SS-44-b & $?$ & $\begin{array}{l}\text { Gorozhanina and others } \\
\text { (1971). }\end{array}$ \\
\hline & $44 \mathrm{~g}$ & $?$ & $\begin{array}{l}\text { U.S.S.R., Valcha (1977). } \\
\text { Ostroumov (1979). }\end{array}$ \\
\hline & IPT-52 & 38 & Price list. \\
\hline & Mn-Erz-1 & 37 & Price list. Also Mn-Erz-2. \\
\hline conc. & SS-112-a & $?$ & $\begin{array}{l}\text { Also 130a. Gorozhanina } \\
\text { and others (1971). }\end{array}$ \\
\hline \multicolumn{4}{|l|}{ Mo } \\
\hline conc. & $\begin{array}{l}\text { CCRMP-PR-1 } \\
\text { NBS } 333\end{array}$ & $\begin{array}{l}5 \\
6\end{array}$ & $\begin{array}{l}\text { Price list. Steger (1983). } \\
\text { Price list. }\end{array}$ \\
\hline
\end{tabular}


Table 5. Reference samples-Continued

\begin{tabular}{|c|c|}
\hline Name & Number \\
\hline \multicolumn{2}{|l|}{ Ores-Continued } \\
\hline $\begin{array}{l}\text { Mo-Continued } \\
\text { molybdenite } \\
\text { conc. }\end{array}$ & IGS 8 \\
\hline $\begin{array}{l}\text { molybdenite } \\
\text { qtz. } \\
\text { mixt. }\end{array}$ & IGS 6 \\
\hline Mo-W & IGS 27 \\
\hline $\mathrm{Nb}$ & SS-277 \\
\hline carbonatite & CCRMP-OKA-1 \\
\hline columbite & IGS 33 \\
\hline $\begin{array}{l}\text { columbite } \\
\text { conc. }\end{array}$ & SVT-15 \\
\hline $\begin{array}{l}\text { loparite } \\
\text { conc. }\end{array}$ & SVT-16a \\
\hline $\mathrm{Nb}$ conc. & SVT-9 \\
\hline Nepheline & SNS-1 \\
\hline Ni conc. & $\begin{array}{l}\text { IGS } 20 \\
\text { SS-297 }\end{array}$ \\
\hline laterite & IGS 23 \\
\hline norite & IGS 21 \\
\hline serpentinite & IGS 22 \\
\hline $\mathrm{Ni}-\mathrm{Cu}-\mathrm{Co}$ & CCRMP_SUla \\
\hline $\begin{array}{c}\mathrm{Pb} \text { conc. } \\
\text { galena } \\
\text { conc. }\end{array}$ & $\begin{array}{l}\text { CCRMP-CPB-1 } \\
\text { IGS } 12\end{array}$ \\
\hline $\begin{array}{l}\text { galena-qtz. } \\
\text { mixt. }\end{array}$ & IGS 9 \\
\hline $\mathrm{Pb}-\mathrm{Zn}$ & $\cdots$ \\
\hline
\end{tabular}

Supplier Remarks or References

41 Lister (1978).

41 Lister (1978)

Lister (1978)

Gorozhanina and others (1971). Also SS-281.

Price list. Steger (1983).

Lister (1978).

U.S.S.R. SRN 349-73. Lontsikh and Parshin (1980).

U.S.S.R. SRN 350-75. Lontsikh and Parshin (1980).

U.S.S.R. SRN 107-71. Lontsikh and Parshin (1980).

IG1. U.S.S.R. SRN 728 75. Sobornov (1977).

Lister (1978).

Gorozhanina and others (1971).

Lister (1978).

Lister (1978).

Lister (1978).

Price list. Steger (1983).

Price list. Steger (1983).

Lister (1978).

Lister (1978).

4 samples. Numbers and suppliers not given. Dempir (1978).

Gorozhanina and others (1971).

Kuznetsova and Morgulis (1983).

Kuznetsova and Morgulis (1983).

\begin{tabular}{|c|c|}
\hline conc. & IGS 28 \\
\hline Pt & SARM-7 \\
\hline Black sand & CCRMP-PTA-1 \\
\hline $\begin{array}{l}\mathrm{Cu}-\mathrm{Ni} \\
\text { matte }\end{array}$ & CCRMP-PTM-1 \\
\hline $\begin{array}{c}\text { sulfide } \\
\text { conc. }\end{array}$ & CCRMP-PTC-1 \\
\hline \multicolumn{2}{|l|}{ REE } \\
\hline Bastnaesite & IGS 40 \\
\hline monazite & IGS 36 \\
\hline
\end{tabular}

$\mathrm{Sb}$

CCRMP-CD-1 55 Price list. Steger (1983).

? 4 samples. Numbers or suppliers not given. Dempir (1978).

$\begin{array}{llll}\text { Se-Te } & \text { SS-287 } & ? & \begin{array}{c}\text { Gorozhanina and others } \\ \text { Sn }\end{array} \\ & \text { NBS } 137 & 6 & \text { (1971). } \\ & \text { SS-136 } & ? & \begin{array}{c}\text { Gorozhanina and others } \\ \end{array} \\ & \text { Sn-Erz 1 } & 37 & \text { (1971). }\end{array}$

Table 5. Reference samples-Continued

\begin{tabular}{|c|c|c|c|}
\hline Name & Number & Supplier & Remarks or References \\
\hline \multicolumn{4}{|l|}{ Ores-Continued } \\
\hline \multirow[t]{4}{*}{$\begin{array}{l}\text { Sn-Continued } \\
\text { cassiterite }\end{array}$} & & $?$ & $\begin{array}{l}\text { U.S.S.R. SRN 168-71. } \\
\text { Egranova and others } \\
\text { (1981). }\end{array}$ \\
\hline & & $?$ & $\begin{array}{l}\text { U.S.S.R. SRN 169-71. } \\
\text { Egranova and others } \\
\text { (1981). }\end{array}$ \\
\hline & & $?$ & $\begin{array}{l}\text { U.S.S.R. SRN 322-73. } \\
\text { Egranova and others } \\
\text { (1981). }\end{array}$ \\
\hline & & $?$ & $\begin{array}{l}\text { U.S.S.R. SRN } 575-74 . \\
\text { Egranova and others } \\
\text { (1981). }\end{array}$ \\
\hline $\begin{array}{l}\text { cassiterite } \\
\text { conc. }\end{array}$ & IGS-6 & 41 & Lister (1978). \\
\hline $\begin{array}{l}\text { cassiterite- } \\
\text { qtz. } \\
\text { mixt. }\end{array}$ & IGS-13 & 41 & Lister (1978). \\
\hline \multirow[t]{2}{*}{ conc.'s } & SKO-1 & $?$ & $\begin{array}{l}\text { Also SKO-2 to }-8 \text {. } \\
\text { U.S.S.R. SRN 1284-79 } \\
\text { to 1291-79. Lontsikh } \\
\text { and Parshin (1980). }\end{array}$ \\
\hline & SS-138 & $?$ & $\begin{array}{l}\text { Also SS-148. Gorozhanina } \\
\text { and others (1971). }\end{array}$ \\
\hline \multirow[t]{2}{*}{ Sn-W } & IGS-26 & 41 & Lister (1978). \\
\hline & & $?$ & $\begin{array}{l}4 \text { samples. Numbers or } \\
\text { suppliers not given. } \\
\text { Dempir (1978). }\end{array}$ \\
\hline \multirow[t]{2}{*}{$\mathrm{Sn}-\mathrm{W}-\mathrm{Be}$} & & $?$ & $\begin{array}{l}\text { U.S.S.R. SRN 323-72. } \\
\text { Egranova and others } \\
\text { (1981). }\end{array}$ \\
\hline & - & $?$ & $\begin{array}{l}\text { U.S.S.R. SRN 342-73. } \\
\text { Egranova and others } \\
\text { (1981). }\end{array}$ \\
\hline $\begin{array}{l}\text { Sulfide } \\
\quad \text { (poly- } \\
\text { metallic) }\end{array}$ & 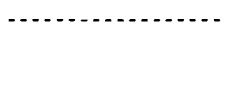 & $?$ & Hungary. Valcha (1977). \\
\hline $\mathrm{Ta}$ & CCRMP-TAN-1 & 5 & $\begin{array}{l}0.236 \% \text { Ta. Price list. In- } \\
\text { formation sheet as an } \\
\text { addendum to Steger } \\
\text { (1983). }\end{array}$ \\
\hline \multirow[t]{2}{*}{ tantalite } & SVT-14 & $?$ & $\begin{array}{l}\text { U.S.S.R. SRN 348-73. } \\
\text { Lontsikh and Parshin } \\
\text { (1980). }\end{array}$ \\
\hline & IGS-34 & 41 & Lister (1978). \\
\hline \multicolumn{4}{|l|}{$\mathrm{Ta}-\mathrm{Nb}$} \\
\hline $\begin{array}{l}\text { albitized } \\
\text { granite }\end{array}$ & SVT-5 & $?$ & $\begin{array}{l}\text { U.S.S.R. SRN 103-71. } \\
\text { Lontsikh and Parshin } \\
\text { (1980). }\end{array}$ \\
\hline $\begin{array}{l}\text { amazonite } \\
\text { granite }\end{array}$ & SVT-1 & $?$ & $\begin{array}{l}\text { U.S.S.R. SRN 101-701. } \\
\text { Lontsikh and Parshin } \\
\text { (1980). }\end{array}$ \\
\hline \multirow[t]{2}{*}{ carbonatite } & SVT-3 & $?$ & $\begin{array}{l}\text { U.S.S.R. SRN 102-71. } \\
\text { Lontsikh and Parshin } \\
\text { (1980). }\end{array}$ \\
\hline & SVT -12 & $?$ & $\begin{array}{l}\text { U.S.S.R. SRN 346-73. } \\
\text { Lontsikh and Parshin } \\
\text { (1980). }\end{array}$ \\
\hline \multirow[t]{3}{*}{ conc. } & SVT-6 & $?$ & $\begin{array}{l}\text { U.S.S.R. SRN 104-71. } \\
\text { Lontsikh and Parshin } \\
\text { (1980). }\end{array}$ \\
\hline & SVT-8 & $?$ & $\begin{array}{l}\text { U.S.S.R. SRN 106-71. } \\
\text { Lontsikh and Parshin } \\
\text { (1980). }\end{array}$ \\
\hline & SVT-17 & $?$ & $\begin{array}{l}\text { U.S.S.R. SRN 651-75. } \\
\text { Lontsikh and Parshin } \\
(1980) .\end{array}$ \\
\hline
\end{tabular}


Table 5. Reference samples-Continued

\begin{tabular}{|c|c|c|c|}
\hline Name & Number & Supplier & Remarks or References \\
\hline \multicolumn{4}{|c|}{ Ores-Continued } \\
\hline \multicolumn{4}{|c|}{$\mathrm{Ta}-\mathrm{Nb}-$ Continued } \\
\hline \multirow[t]{2}{*}{ pegmatite } & SVT -7 & $?$ & $\begin{array}{l}\text { U.S.S.R. SRN 105-71. } \\
\text { Lontsikh and Parshin } \\
(1980) .\end{array}$ \\
\hline & SVT-13 & $?$ & $\begin{array}{l}\text { U.S.S.R. SRN 347-73. } \\
\text { Lontsikh and Parshin } \\
(1980) .\end{array}$ \\
\hline \multirow[t]{3}{*}{ Th } & IAEA-S-14 & 27 & $\begin{array}{l}\text { IAEA (1984). For } U \text { and } \\
\text { Th. Th } 0.1 \% \text {. }\end{array}$ \\
\hline & IAEA-S-15 & 27 & $\begin{array}{l}\text { IAEA (1984). For } U \text { and } \\
\text { Th. Th } 0.05 \% \text {. }\end{array}$ \\
\hline & IAEA-S-16 & 27 & $\begin{array}{l}\text { IAEA (1984). For } U \text { and } \\
\text { Th. Th } 1 \% \text {. }\end{array}$ \\
\hline \multirow[t]{2}{*}{ monazite } & EPA-3 & 19 & For ${ }^{232} \mathrm{Th}$ and $228 \mathrm{Th}$ \\
\hline & EPA-4 & 19 & $\begin{array}{l}\text { EPA-3 diluted } 10: 1 \text { with } \\
\text { low activity soil. }\end{array}$ \\
\hline \multicolumn{4}{|r|}{ 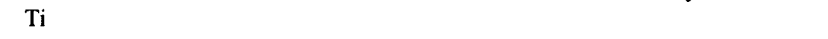 } \\
\hline ilmenite & IGS-31 & 41 & Lister (1978). \\
\hline $\begin{array}{l}\text { ilmenite } \\
\text { conc.? }\end{array}$ & SS-154-a & $?$ & $\begin{array}{l}\text { Gorozhanina and others } \\
\text { (1971). }\end{array}$ \\
\hline rutile & IGS-32 & 41 & Lister (1978). \\
\hline \multirow[t]{7}{*}{$\mathrm{U}$} & CCRMP-BL-2 & 5 & $\begin{array}{l}\text { Also BL-2a, }-3,-4,-4 a \text {, } \\
\text { and }-5 \text {. Price list. } \\
\text { Steger (1983). }\end{array}$ \\
\hline & EJB-1-81 & 52 & $\begin{array}{l}7 \text { samples. Yang and Liu } \\
\text { (1983). }\end{array}$ \\
\hline & USFRS-73.5 & $?$ & $\begin{array}{l}\text { U.S.S.R. Sobomov } \\
\text { (1983). }\end{array}$ \\
\hline & UR-1145 & $?$ & $\begin{array}{l}\text { U.S.S.R. Sobornov } \\
\text { (1983). }\end{array}$ \\
\hline & UR $-47 \mathrm{~S}$ & $?$ & $\begin{array}{l}\text { U.S.S.R. Sobornov } \\
\text { (1983). }\end{array}$ \\
\hline & S-316 & $?$ & $\begin{array}{l}\text { Also 317-319. Australian } \\
\text { AEC ores, table 6, } \\
\text { Hitchen and Zechanow- } \\
\text { itsch (1980). }\end{array}$ \\
\hline & CUP-115 & $?$ & $\begin{array}{l}\text { Canadian Uranium Produc- } \\
\text { ers standard, table 6, } \\
\text { Hitchen and Zechanow- } \\
\text { itsch (1980). }\end{array}$ \\
\hline $\begin{array}{l}\text { acid leach } \\
\text { residue }\end{array}$ & SARM-21 & 21 & $\begin{array}{l}\text { Also SARM-27 and }-28 \text {. } \\
\text { Price list. }\end{array}$ \\
\hline calcrete & SARM-22 & 21 & Price list. \\
\hline \multirow[t]{2}{*}{ carnotite } & NBL-4 & 18 & Price list. Also NBL-5. \\
\hline & IAEA-S-3 & 27 & Out of stock. \\
\hline $\begin{array}{l}\text { head } \\
\text { sample }\end{array}$ & SARM-31 & 21 & Price list. \\
\hline Karoo & SARM-30 & 21 & Price list. \\
\hline \multirow[t]{7}{*}{ pitchblende } & NBL-6A & 18 & Price list. \\
\hline & IAEA-S-7 & 27 & $\begin{array}{l}\text { IAEA (1984). } 0.527 \% \\
\mathrm{U}_{3} \mathrm{O}_{8}\end{array}$ \\
\hline & IAEA-S-8 & 27 & $\begin{array}{l}\text { IAEA (1984). } 0.140 \% \\
\mathrm{U}_{3} \mathrm{O}_{8}\end{array}$ \\
\hline & IAEA-S-12 & 27 & $\begin{array}{l}\text { IAEA (1984). } 0.014 \% \\
\mathrm{U}_{3} \mathrm{O}_{8}\end{array}$ \\
\hline & IAEA-S-13 & 27 & $\begin{array}{l}\text { IAEA (1984). } 0.039 \% \\
\mathrm{U}_{3} \mathrm{O}_{8}\end{array}$ \\
\hline & EPA-1 & 19 & For $238 \mathrm{U}$ and $235 \mathrm{U}$ \\
\hline & EPA-2 & 19 & $\begin{array}{l}\text { EPA-1 diluted 10:1 with } \\
\text { low activity soil. }\end{array}$ \\
\hline $\begin{array}{l}\text { pyrite } \\
\text { conc. }\end{array}$ & SARM-23 & 21 & $\begin{array}{l}\text { Also SARM-25 and }-26 \text {. } \\
\text { Price list. }\end{array}$ \\
\hline slimes & SARM-24 & 21 & Price list. \\
\hline tailings & CCRMP-UTS-1 & 5 & $\begin{array}{l}\text { Also UTS }-2,-3 \text {, and }-4 \text {. } \\
\text { Steger and Smith } \\
\text { (1984). }\end{array}$ \\
\hline torbernite & IAEA-S-2 & 27 & Out of stock. \\
\hline \multirow[t]{2}{*}{ uraninite } & IGS-37 & 41 & Lister (1978). \\
\hline & IAEA-S-4 & 27 & Out of stock. \\
\hline
\end{tabular}

Table 5. Reference samples-Continued

\begin{tabular}{|c|c|c|c|}
\hline Name & Number & Supplier & Remarks or References \\
\hline \multicolumn{4}{|l|}{ Ores-Continued } \\
\hline \multicolumn{4}{|c|}{ U-Continued } \\
\hline $\begin{array}{l}\text { Witwaters- } \\
\text { rand }\end{array}$ & SARM-29 & 21 & Price list. \\
\hline U-Th & CCRMP-BL-1 & 5 & $\begin{array}{c}\text { Price list. Also DL-1a and } \\
\text { DH-1a. Steger (1983). }\end{array}$ \\
\hline \multicolumn{4}{|r|}{ 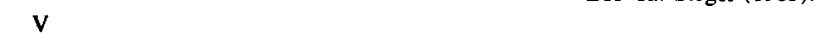 } \\
\hline conc. & SS-290 & $?$ & $\begin{array}{l}\text { Gorozhanina and others } \\
\text { (1971). }\end{array}$ \\
\hline $\mathbf{W}$ & CCRMP-TLG-1 & 5 & $\begin{array}{l}\text { Price list. Steger (1983). } \\
\text { Also samples Ct-1 and } \\
\text { BH-1. }\end{array}$ \\
\hline wolframite & IGS-25 & 41 & Lister (1978). \\
\hline $\mathrm{Zn}$ & $\mathrm{ZnU}$ & $?$ & $\begin{array}{l}\text { Valcha (1977). Ostroumov } \\
\text { (1979). }\end{array}$ \\
\hline conc. & CCRMP-CZN-I & 5 & Price list. Steger (1983). \\
\hline sphalerite & BCR-26 & 16 & $\begin{array}{l}\text { Price list. Also BCR 27- } \\
\text { BCR 31. For } \mathrm{Zn} \text {. }\end{array}$ \\
\hline sphalerite & BCR-108 & 16 & $\begin{array}{l}\text { Price list. Also BCR } 109 \\
\text { BCR 110. For trace ele- } \\
\text { ments. }\end{array}$ \\
\hline conc. & IGS-19 & 41 & Lister (1978) \\
\hline $\begin{array}{l}\text { sphalerite- } \\
\text { qtz. } \\
\text { mixt. }\end{array}$ & IGS-17 & 41 & $\begin{array}{l}\text { Also IGS-18. Lister } \\
\text { (1978). }\end{array}$ \\
\hline $\begin{array}{l}\mathrm{Zn}-\mathrm{Cu} \text { sul- } \\
\text { fide }\end{array}$ & CCRMP-RU-1 & 5 & Price list. Steger (1983). \\
\hline $\begin{array}{l}\mathrm{Zn}-\mathrm{Pb}-\mathrm{Sn}- \\
\mathrm{Cu}\end{array}$ & CCRMP-KC-1 & 5 & $\begin{array}{l}\text { Steger (1983). Out of } \\
\text { stock. Now KC-1a } \\
\text { (Steger and Bowman, } \\
\text { 1984). }\end{array}$ \\
\hline $\begin{array}{l}\mathrm{Zn}-\mathrm{Sn}-\mathrm{Cu}- \\
\mathrm{Pb}\end{array}$ & CCRMP-MP-1 & 5 & $\begin{array}{l}\text { Also MP-1a. Price list. } \\
\text { Steger (1983). }\end{array}$ \\
\hline \multirow[t]{2}{*}{$\mathrm{Zr}$ zircon } & IGS-35 & 41 & Lister (1978). \\
\hline & BCS-388 & 22 & Price list. \\
\hline \multirow[t]{2}{*}{ conc. } & SARM-13 & 21 & Price list. \\
\hline & SS-296 & $?$ & $\begin{array}{l}\text { Gorozhanina and others } \\
\text { (1971). }\end{array}$ \\
\hline Paratellurite & - & 20 & Microprobe. Price list. \\
\hline Pegmatite & $\mathrm{SO}-1 \mathrm{~B} / 74$ & $?$ & $\begin{array}{l}\text { U.S.S.R. SRN 706-75. } \\
\text { Sobomov (1977). }\end{array}$ \\
\hline \multirow[t]{3}{*}{ Peridotite } & USGS-PCC-1 & 7 & Out of stock. \\
\hline & GSJ-JP-1 & 11 & $\begin{array}{l}\text { Available 1984. A. Ando } \\
\text { (written commun. } \\
\text { 1984). }\end{array}$ \\
\hline & PIM-1 & 55 & $\begin{array}{l}\text { IGEM 1002/1007. Egra- } \\
\text { nova and others ( } 1981 \text { ). } \\
\text { Now MU-1, Khitrov } \\
\text { (1984). }\end{array}$ \\
\hline Petalite & NBS 182 & 6 & Price list. \\
\hline Phlogopite & CRPG-Mica-Mg & 24 & Govindaraju (1979). \\
\hline Phonolite & DFG-KA & 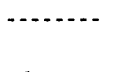 & $\begin{array}{l}\text { Meyer and others (1981). } \\
\text { In-house sample. }\end{array}$ \\
\hline \multirow[t]{8}{*}{ Phosphate } & NBS $120 \mathrm{~b}$ & 6 & Price list. \\
\hline & BCR 32 & 16 & Price list. Serrini (1981). \\
\hline & WPO 42 & $?$ & Jenke and Diebold (1982). \\
\hline & IPT-18 & 38 & Price list. \\
\hline & NBS 694 & 6 & $\begin{array}{l}\text { Western phosphate from } \\
\text { Conda, Idaho. }\end{array}$ \\
\hline & PH-1 & $?$ & $\begin{array}{l}\text { Also PH-2. Iraq standards, } \\
\text { Barbooti and Jasim } \\
\text { (1982). }\end{array}$ \\
\hline & IAEA-S-17 & 27 & $\begin{array}{l}\text { Also S-18 and -19. IAEA } \\
\text { (1983). Interlaboratory } \\
\text { comparisons for U. }\end{array}$ \\
\hline & IAEA-S-20 & 27 & $\begin{array}{l}\text { IAEA (1983). Interlabora- } \\
\text { tory comparisons for } \\
\mathrm{Ra} / \mathrm{U} \text { and } 235 \mathrm{U} \text {. }\end{array}$ \\
\hline
\end{tabular}


Table 5. Reference samples-Continued

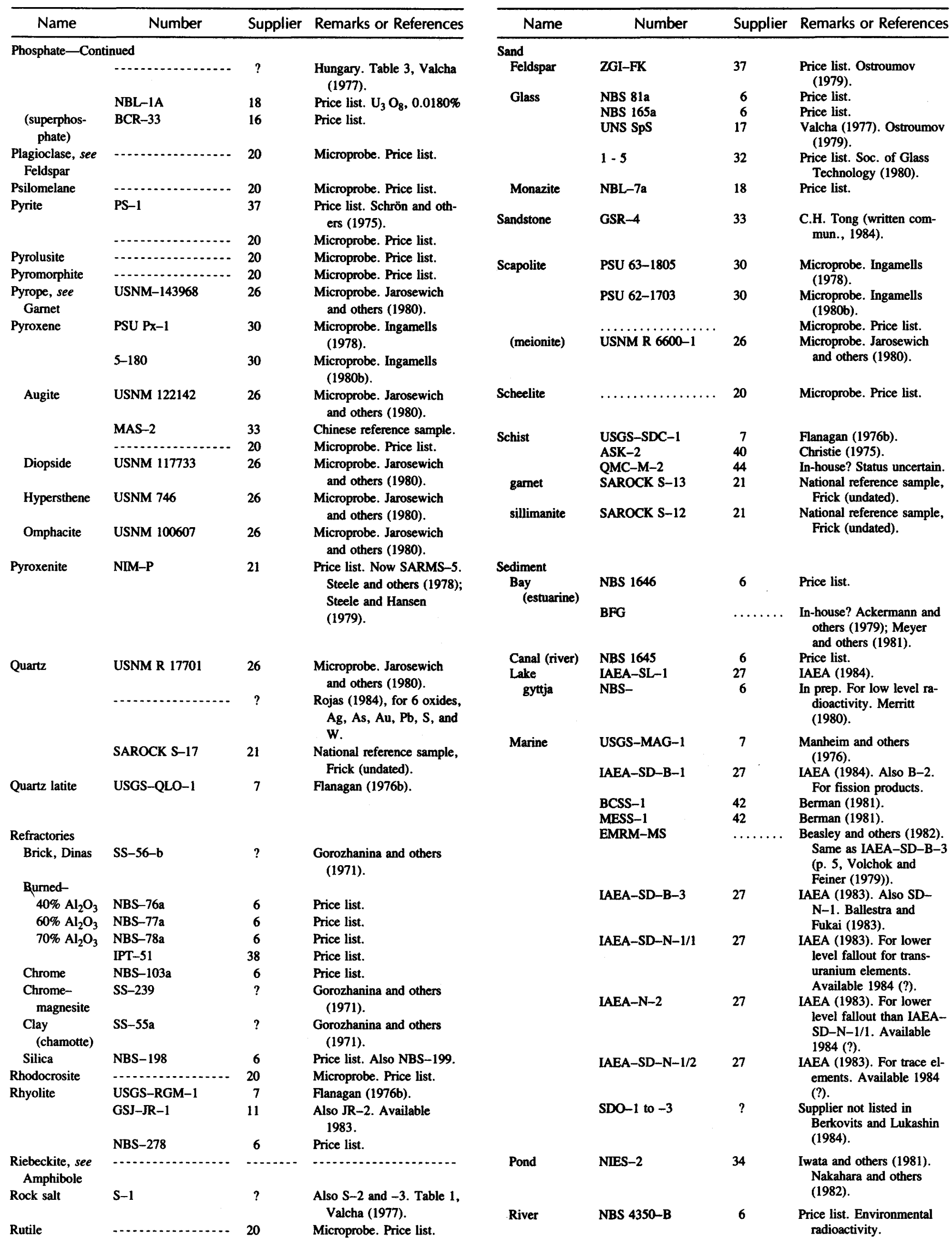

Table 5. Reference samples-Continued 
Table 5. Reference samples-Continued

\begin{tabular}{|c|c|c|c|}
\hline Name & Number & Supplier & Remarks or References \\
\hline \multicolumn{4}{|c|}{$\begin{array}{l}\text { Sediment-Continued } \\
\text { River-Continued }\end{array}$} \\
\hline & GSD-1 & 47 & $\begin{array}{l}\text { Also GSD 2-8. Zhang and } \\
\text { others (1982); Yuan and } \\
\text { Chen (1982). }\end{array}$ \\
\hline & $81-01$ & 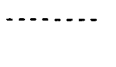 & $\begin{array}{l}\text { Su and Zhang (1984); Sun } \\
\text { and others (1984). }\end{array}$ \\
\hline & S-14 & 21 & $\begin{array}{l}\text { Also } S-19 \text { and }-20 \text {. Victor } \\
(1983) \text {. }\end{array}$ \\
\hline & GRD-30 & 33 & $\begin{array}{l}17 \text { samples from Gilin } \\
\text { Province, China. Zhao } \\
\text { (1984). }\end{array}$ \\
\hline & EMRM-RS & $\ldots$ & $\begin{array}{l}\text { Beasley and others (1982). } \\
\text { Portion of NBS RM 45B } \\
\text { (Volchok and Feiner } \\
\text { (1979)). }\end{array}$ \\
\hline & BFG & $\cdots$ & $\begin{array}{l}\text { In-house? Ackerman and } \\
\text { others (1979). }\end{array}$ \\
\hline & NBS RM 45B & 6 & $\begin{array}{l}\text { Price list. Also see van der } \\
\text { Sloot and Zonderhuis } \\
\text { (1979). }\end{array}$ \\
\hline Senarmonite & - & 20 & Microprobe. Price list. \\
\hline \multirow[t]{3}{*}{ Serpentine } & ANRT-UB-N & 24 & Govindaraju (1982). \\
\hline & ZGI-SW & 37 & $\begin{array}{l}\text { Price list. Ostroumov } \\
\text { (1979). }\end{array}$ \\
\hline & SAROCK S-15 & 21 & $\begin{array}{l}\text { National reference sample, } \\
\text { Frick (undated). }\end{array}$ \\
\hline Chrysotile & OECD-05 & 31 & $\begin{array}{l}\text { Van Olphen and Fripiat } \\
\text { (1979). }\end{array}$ \\
\hline \multirow[t]{6}{*}{ Shale } & $46 \mathrm{~W} 4100$ & 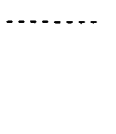 & $\begin{array}{l}\text { In-house, van der Sloot } \\
\text { and Zonderhuis (1979). } \\
\text { From Wards Scientific } \\
\text { Establishment. }\end{array}$ \\
\hline & USGS-SDO-1 & 7 & $\begin{array}{l}\text { Not analyzed. Lechler and } \\
\text { Leininger (1979). Frost } \\
\text { and others (1982) for } \\
\text { INAA data. }\end{array}$ \\
\hline & IAEA-Sed-I & 27 & $\begin{array}{l}\text { For U, Th, and K. } \\
\text { Heinonen and others } \\
\text { (1973). From Schoen- } \\
\text { berg, Germany. }\end{array}$ \\
\hline & IAEA-Sed-2 & 27 & $\begin{array}{l}\text { For U, Th, and K. } \\
\text { Heinonen and others } \\
\text { (1973). From Yxhult, } \\
\text { Sweden. }\end{array}$ \\
\hline & NASC & $\cdots+\ldots$ & $\begin{array}{l}\text { "North American Shale } \\
\text { Composite," Gromet and } \\
\text { others (1984). Supply } \\
\text { nearly exhausted. }\end{array}$ \\
\hline & GSR-5 & 33 & $\begin{array}{l}\text { C.H. Tong (written com- } \\
\text { mun., 1984). }\end{array}$ \\
\hline black & ZGI-TS & 37 & $\begin{array}{l}\text { Price list. Ostroumov } \\
\text { (1979). }\end{array}$ \\
\hline carbonaceous & SAROCK S-9 & 21 & $\begin{array}{l}\text { National reference sample, } \\
\text { Frick (undated). }\end{array}$ \\
\hline Cody & USGS-SCo-1 & 7 & Flanagan (1976b). \\
\hline Green River & USGS-SGR-1 & 7 & Flanagan (1976b). \\
\hline Mancos & EPA-8 & 19 & For ${ }^{226} \mathrm{Ra}$ and ${ }^{228} \mathrm{Ra}$ \\
\hline \multirow[t]{2}{*}{ Oil } & SIND-1 & $-\ldots \ldots$ & $\begin{array}{l}\text { Lechler and Leininger } \\
\text { (1979). Frost and others } \\
\text { (1982). }\end{array}$ \\
\hline & AR-1900 & 23 & $\begin{array}{l}\text { Price list. Also AR-1901. } \\
\text { For oil or water yield. }\end{array}$ \\
\hline Purington & $\mathrm{KnC}-\mathrm{ShP}-1$ & 46 & Moore (1978). \\
\hline Siderite & - & 20 & Microprobe. Price list. \\
\hline Silica & BCS 313 & 22 & Price list. \\
\hline Sillimanite & BCS 309 & $\begin{array}{l}20 \\
22\end{array}$ & $\begin{array}{l}\text { Microprobe. Price list. } \\
\text { Price list. }\end{array}$ \\
\hline
\end{tabular}

Table 5. Reference samples-Continued

\begin{tabular}{|c|c|c|c|}
\hline Name & Number & Supplier & Remarks or References \\
\hline $\begin{array}{l}\text { Silt, see } \text { Sedi- } \\
\text { ment, marine }\end{array}$ & - & $\cdots$ & n \\
\hline $\begin{array}{l}\text { volcanic } \\
\text { terrigene }\end{array}$ & SDO-2 & 54 & $\begin{array}{l}\text { IGI. U.S.S.R. SRN 1756- } \\
\text { 80. Lontsikh (1981). }\end{array}$ \\
\hline calcareous & SDO-3 & 54 & $\begin{array}{l}\text { IGI. U.S.S.R. SRN 1753- } \\
\text { 80. Lontsikh (1981). }\end{array}$ \\
\hline Skarn & (n. & $\ldots \ldots$ & $\begin{array}{l}\text { GDR. Planned. Table 3, } \\
\text { Valcha (1977). }\end{array}$ \\
\hline \multirow[t]{4}{*}{ Slag } & SS-81 & $?$ & $\begin{array}{l}\text { Also SS-82 to }-87 \text {. } \\
\text { Gorozhanina and others } \\
(1971) \text {. }\end{array}$ \\
\hline & 3 samples & 37 & Price list. \\
\hline & BAM 826-1 & 29 & $\begin{array}{l}\text { Price list. Also BAM } 827- \\
\quad 1 .\end{array}$ \\
\hline & JK-51 & 53 & $\begin{array}{l}6 \text { samples. Sweden, Insti- } \\
\text { tutet för Metallforskn- } \\
\text { ing. }\end{array}$ \\
\hline basic & BCS 395 & 22 & $\begin{array}{l}\text { Price list. Also BCS } 381 \\
\text { and } 382 / 1 \text {; ES-879-1. }\end{array}$ \\
\hline $\begin{array}{l}\text { basic open } \\
\text { hearth }\end{array}$ & SS-80-V & $?$ & $\begin{array}{l}\text { Gorozhanina and others } \\
\text { (1971). }\end{array}$ \\
\hline \multirow[t]{3}{*}{ blast furnace } & BCS 367 & 22 & Price list. \\
\hline & SS-79-V & $?$ & $\begin{array}{l}\text { Also } 267 \text { and } 267-a \text {. } \\
\text { Gorozhanina and others } \\
\text { (1971). }\end{array}$ \\
\hline & CCRMP-SL-1 & 5 & Price list. Steger (1983). \\
\hline $\begin{array}{l}\text { conventor, } \\
\text { vanadium }\end{array}$ & SS-311 & $?$ & $\begin{array}{l}\text { Gorozhanina and others } \\
\text { (1971). }\end{array}$ \\
\hline $\mathrm{O}_{2}$ & SS-262 & $?$ & $\begin{array}{l}\text { Gorozhanina and others } \\
\text { (1971). }\end{array}$ \\
\hline open hearth & SS-203-b & $?$ & $\begin{array}{l}\text { Also } 204-\mathrm{a} \text { and } 205-\mathrm{a} \text {. } \\
\text { Gorozhanina and others } \\
\text { (1971). }\end{array}$ \\
\hline phosphate & BAM-826-1 & 29 & Price list. \\
\hline Thomas & IRSID-SO1-1 & 28 & Jecko and Ravaine (1978). \\
\hline $\begin{array}{l}\text { Thomas } \\
\text { phosphate }\end{array}$ & BAM-827-1 & 29 & Price list. \\
\hline \multirow[t]{2}{*}{ Slate } & ZGI-TB & 37 & $\begin{array}{l}\text { Price list. Clay shale in } \\
\text { Ostroumov (1979). }\end{array}$ \\
\hline & ZGI-TB-2 & 37 & Price list. \\
\hline Sludge ash & CCIW-IS-1 & 3 & $\begin{array}{l}\text { Knechtel and Fraser } \\
(1980)\end{array}$ \\
\hline Smithsonite & , & 20 & Microprobe. Price list. \\
\hline Sodalite & PSU 4-296-8 & 30 & $\begin{array}{l}\text { Microprobe. Ingamells } \\
\text { (1978). }\end{array}$ \\
\hline \multirow[t]{9}{*}{ Soil } & - & - n. & $\begin{array}{l}12 \text { soils for soil scientists. } \\
\text { Barnhisel (1978). }\end{array}$ \\
\hline & IAEA-Soil-5 & 27 & $\begin{array}{l}\text { Dybczynski and others } \\
\text { (1979). }\end{array}$ \\
\hline & IAEA-Soil-6 & 27 & $\begin{array}{l}\text { IAEA (1984). For }{ }^{90} \mathrm{Sr} \text {, } \\
{ }^{137} \mathrm{Cs},{ }^{54} \mathrm{Mn} \text {, and }{ }^{239} \mathrm{Pu} \text {. } \\
\text { Available } 1984(?)\end{array}$ \\
\hline & IAEA-Soil-7 & 27 & $\begin{array}{l}\text { IAEA (1984). For trace el- } \\
\text { ements. Available } 1984 \\
(?) .\end{array}$ \\
\hline & CCRMP-SO-1 & 5 & $\begin{array}{l}\text { Also SO-2 to }-4 \text {. Price } \\
\text { list. Steger (1983). }\end{array}$ \\
\hline & USGS-GXR-2 & 1 & $\begin{array}{l}\text { Also GXR-5 and -6. All- } \\
\text { cott and Lakin (1978). }\end{array}$ \\
\hline & USGS-D-C & 35 & $\begin{array}{l}\text { Also D-D. Crock and } \\
\text { Severnson (1980). }\end{array}$ \\
\hline & GSS-1 & 33 & $\begin{array}{l}\text { Also GSS-2 to GSS-8. } \\
\text { C.H. Tong (written } \\
\text { commun., 1984). }\end{array}$ \\
\hline & NBS 4353 & $\ldots$ & $\begin{array}{l}\text { Price list. From Rocky } \\
\text { Flats Plant, Golden, } \\
\text { Colo. } \\
\text { In-house? Meyer and oth- } \\
\text { ers (1981), table } 3 \text {. }\end{array}$ \\
\hline
\end{tabular}


Table 5. Reference samples-Continued

\begin{tabular}{|c|c|c|c|}
\hline Name & Number & Supplier & Remarks or References \\
\hline \multicolumn{4}{|l|}{ Soil-Continued } \\
\hline & ELR-007 & $?$ & $\begin{array}{l}\text { Also ELR-008. McQuaker } \\
\text { and others (1979). }\end{array}$ \\
\hline & ISPRA & $\ldots$ & $\begin{array}{l}\text { Meyer and others (1981), } \\
\text { table } 3 \text {. }\end{array}$ \\
\hline & SP-1 & 54 & $\begin{array}{l}\text { U.S.S.R. SRN 901-76, } \\
\text { Lontsikh and Parshin } \\
(1980) \text {. }\end{array}$ \\
\hline & SP-2 & 54 & $\begin{array}{l}\text { U.S.S.R. SRN 902-76, } \\
\text { Lontsikh and Parshin } \\
(1980) \text {. }\end{array}$ \\
\hline & SP-3 & 54 & $\begin{array}{l}\text { U.S.S.R. SRN 903-76, } \\
\text { Lontsikh and Parshin } \\
(1980) .\end{array}$ \\
\hline $\begin{array}{l}\mathrm{Co}-\mathrm{Cu}-\mathrm{Ni} \\
\text { rich }\end{array}$ & SAROCK S-10 & 21 & $\begin{array}{l}\text { National reference sample, } \\
\text { Frick (undated). }\end{array}$ \\
\hline \multirow[t]{2}{*}{ Sphalerite } & $\mathrm{SF}-1$ & 37 & $\begin{array}{l}\text { Price list. Schrön and oth- } \\
\text { ers (1975). }\end{array}$ \\
\hline & - & 20 & Microprobe. Price list. \\
\hline $\begin{array}{l}\text { Sphene, see Ti- } \\
\text { tanite }\end{array}$ & (n) & $\ldots \ldots$ & - \\
\hline Staurolite & - & 20 & Microprobe. Price list. \\
\hline Stibnite & 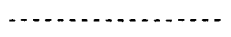 & 20 & Microprobe. Price list. \\
\hline Sulfide & ASK-3 & 40 & Christie (1975). \\
\hline Sulfur & (- & 20 & Microprobe. Price list. \\
\hline \multirow[t]{4}{*}{ Syenite } & CCRMP-SY-2 & 5 & $\begin{array}{l}\text { Also SY-3. Price list. } \\
\text { Steger (1983). }\end{array}$ \\
\hline & NIM-S & 21 & $\begin{array}{l}\text { Price list. Now SARM-2. } \\
\text { Steele and others (1978); } \\
\text { Steele and Hansen } \\
\text { (1979). }\end{array}$ \\
\hline & NS-1 & 48 & $\begin{array}{l}\text { Kukharenko and others } \\
\text { (1968). }\end{array}$ \\
\hline & SRS-S-1 & - n & $\begin{array}{l}\text { In-house. McDonough and } \\
\text { Nelson (1984). }\end{array}$ \\
\hline \multirow[t]{2}{*}{ nepheline } & USGS-STM-1 & 7 & Flanagan (1976b). \\
\hline & SNS-2 & 54 & $\begin{array}{l}\text { U.S.S.R. SRN 1345-78. } \\
\text { Lontsikh and Parshin } \\
(1980) \text {. }\end{array}$ \\
\hline \multirow[t]{2}{*}{ Talc } & OECD-08 & 31 & $\begin{array}{l}\text { Van Olphen and Fripiat } \\
\text { (1979). }\end{array}$ \\
\hline & 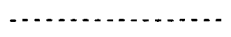 & 20 & Microprobe. Price list. \\
\hline Tellurite & - & 20 & Microprobe. Price list. \\
\hline \multirow[t]{2}{*}{ Titanite } & $\ldots$ & 20 & Microprobe. Price list. \\
\hline & n. & 30 & $\begin{array}{l}\text { Microprobe. Ingamells } \\
\text { (1978). }\end{array}$ \\
\hline \multirow[t]{2}{*}{ Tonalite } & MRT $-\mathrm{T}-1$ & ......... & Supply exhausted. (1975). \\
\hline & USGS-TLM-1 & 7 & Not analyzed. \\
\hline Tourmaline & PSU 4-206 & 30 & $\begin{array}{l}\text { Microprobe. Ingamells } \\
\text { (1980b). }\end{array}$ \\
\hline Elbaite & - & 20 & Microprobe. Price list. \\
\hline Trachyte & BARC-TKT & 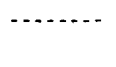 & $\begin{array}{l}\text { In-house. Reddy and } \\
\text { others (1982). }\end{array}$ \\
\hline Trap & ST-1A & $?$ & $\begin{array}{l}\text { IGI. U.S.S.R. SRN 519- } \\
\text { 74. Tauson and others } \\
\text { (1976). Egranova and } \\
\text { others (1981). }\end{array}$ \\
\hline $\begin{array}{l}\text { Tremolite, see } \\
\text { Amphibole }\end{array}$ & (non & $\ldots \ldots$ & - \\
\hline Turquoise & $\ldots$ & 20 & Microprobe. Price list. \\
\hline Ulexite & - & 20 & Microprobe. Price list. \\
\hline Ultrabasic rock & $\mathrm{DZ} \Sigma-1$ & 33 & 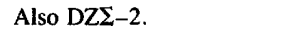 \\
\hline Vanadinite & - n & 20 & Microprobe. Price list. \\
\hline Water & IAEA-W-4 & 27 & $\begin{array}{l}\text { IAEA (1984). For } 19 \text { trace } \\
\text { elements. }\end{array}$ \\
\hline
\end{tabular}

Table 5. Reference samples-Continued

\begin{tabular}{|c|c|c|c|}
\hline Name & Number & Supplier & Remarks or References \\
\hline \multicolumn{4}{|c|}{ Water-Continued } \\
\hline sea & IAEA-SW-N-2 & 27 & $\begin{array}{l}\text { IAEA (1984). For }{ }^{90} \mathrm{Sr} \text {, } \\
{ }^{137} \mathrm{CS} \text {, transuranics. }\end{array}$ \\
\hline Willemite & & 20 & Microprobe. Price list. \\
\hline Wollastonite & $\cdots$ & 20 & Microprobe. Price list. \\
\hline Wulfenite & & 20 & Microprobe. Price list. \\
\hline Zincite & & 20 & Microprobe. Price list. \\
\hline \multirow[t]{2}{*}{ Zircon } & & 20 & Microprobe. Price list. \\
\hline & BCS-388 & 22 & Price list. \\
\hline sand & $\ldots \ldots \ldots \ldots \ldots$ & 51 & $\begin{array}{l}\text { No sample number in ISO } \\
\text { (1982). }\end{array}$ \\
\hline
\end{tabular}

NOTE.-The following information became available too late to be included in the table:

1. A paper with data for and descriptions of four tropical soil reference samples (K-3, CS-1, SAu-1, and SUR-1) and a lateritic bauxite, BAK-1, was published by K.E. Burke (1985, First co-operative study on four tropical soil samples and one lateritic bauxite (Suriname) proposed as geochemical reference samples: Geostandards Newsletter, v. 9, no. 1, p. 69-78).

2. The South African Committee for Certified Reference Materials (SACCRM) announced the availability of four new reference samples, as follows:

1. SARM-18, coal from the Witbank coal field in eastern Transvaal. This sample may be the same as or similar to coal sample NEMI-B5 in table 5;

2. SARM-19, coal from the coal fields of the Orange Free State;

3. SARM-20, coal from the coal fields in the Sasolburg area of the Orange Free State; and

4. SARM-32, phosphate rock from Phalobora, northeastern Transvaal.

3. A paper with a description of and data for an in-house basalt, B-78 (in table 5), was published by P.B. Pawaskar, B.S. Manerkar, and M. Sankar Das (1985, An in-house reference rock standard: Gilbert Basalt, B-78: Analysis and estimates: Geological Society of India Journal, v. 26, no. 3, p. 219-224).

Table 6. Suppliers of reference samples

1. Chief, Branch of Exploration Research, U.S. Geological Survey, Box 25046, DFC, MS 973, Lakewood, CO 80225, U.S.A.

2. Th. Hügi, Mineralogisches-Petrographisches Institut, Universität Bern, CH-3012 Bern, Switzerland.

3. J.L. Fraser, Environment Canada, Environment Protection Service, Waste Water Technology Centre, P.O. Box 5050, 867 Lakeshore Road, Burlington, Ont., Canada L7R 4A6.

4. D.F. Weill, Center for Volcanology, University of Oregon, Eugene, OR 97403, U.S.A.

5. H.F. Steger, Canadian Certified Reference Materials Project, Canada Centre for Mineral and Energy Technology, 555 Booth Street, Ottawa, Canada K1A 0G1.

6. Office of Standard Reference Materials, Room B-311 Chemistry Building, National Bureau of Standards, Washington, DC 20234, U.S.A.

7. Branch of Analytical Chemistry, Stop 972, U.S. Geological Survey, Reston, VA 22092, U.S.A

8. P.J. Potts, Dept. of Earth Sciences, Open University, Walton Hall, Milton Keynes MK7 6AA, United Kingdom.

9. For North and South America:

I.L. Barnes, Room A-23 Physics Building, National Bureau of Standards, Washington, DC 20234, U.S.A.

For Europe and other continents:

R. Gonfiantini, International Atomic Energy Agency, P.O. Box 100, A-1400, Vienna, Austria.

10. G. Frederick Smith Chemical, Co., P.O. Box 23344, Columbus, OH 43223, U.S.A. 
Table 6. Suppliers of reference samples-Continued

11. Atsushi Ando, Geochemistry and Technical Service Department, Geological Survey of Japan, 1-1-3 Higashi, Yatabe, Ibaraki, 305, Japan.

12. Iron and Steel Institute of Japan, 9-4, 1-Chome, Otemachi, Chiyodaku, Tokyo, Japan.

13. E. Schroll, Geotechnisches Institut (BVFA), Arsenal, A-1030 Vienna, Austria.

14. E.C. Alexander, Jr., Department of Geology and Geophysics, University of Minnesota, Minneapolis, MN 55455, U.S.A.

15. W.D. Johns, Source Clay Minerals Repository, Department of Geology, University of Missouri, Columbia, MO 65201, U.S.A.

16. Community Bureau of Reference-BCR, Directorate General XII, Commission of the European Communities, 200, rue de la Roi, B-1049, Brussels, Belgium.

17. Václav Zýka, Director, Institute of Mineral Raw Materials, 28403 Kutná Hora-Sedlec, Czechoslovakia.

18. Nancy M. Trahey, Department of Energy, New Brunswick Laboratory D-350, 9800 South Cass Avenue, Argonne, IL 60439, U.S.A.

19. Environmental Monitoring System Laboratory, U.S. Enivronmental Protection Agency, P.O. Box 15027, Las Vegas, NV 98114.

20. Tousimis Research Corporation, P.O. Box 2189, Rockville, MD 20852, U.S.A.

21. South African Bureau of Standards, Private Bag X191, Pretoria, 0001, South Africa.

22. Bureau of Analysed Samples, Ltd., Newham Hall, Newby, Middlesbrough, Cleveland, England TS8 9EA.

23. Alpha Resources Inc., 3090 Johnson Road, Stevensville, MI 49127, U.S.A.

24. K. Govindaraju, Centre de Recherches Pétrographiques et Géochimiques, C.O. No. 1, 54500 Vandoeuvre-Nancy Cedex, France.

25. John H. Reynolds, Department of Physics, University of California, Berkeley, CA 94720 , U.S.A.

26. Eugene Jarosewich, Department of Mineral Sciences, Smithsonian Institution, Washington, DC 20560, U.S.A.

27. International Atomic Energy Agency, Analytical Quality Control Services, Laboratory Seibersdorf, P.O. Box 100, A-1400 Vienna, Austria.

28. Prolabo, 12, rue Pelée, B.P. 200, 75526 Paris Cedex 11, France.

29. Bundesanstalt für Materialprüfung (BAM), Unter den Eichen 87, 1 Berlin 45, Federal Republic of Germany.

30. C.O. Ingamells, 2970 Xenon Street, Denver, Wheat Ridge, CO 80215, U.S.A.

31. Mlle. S. Caillère, Laboratoire de Minéralogie du Muséum National d'Histoire Naturelle, 61, rue de Buffon, Paris Se, France.

32. Society of Glass Technology, 20 Hattam Gate Road, Sheffield, S10 $5 \mathrm{BT}$, England.

33. Xuejing Xie, Deputy Director, Institute of Geophysical and Geochemical Prospecting, Langfang, Hebei, 102801, People's Republic of China.

34. National Institute for Environmental Studies (NIES), 16-2, Onogawa, Yatabemachi, Tsukuba-Gun, Ibaraki, Japan.

35. J.G. Crock, Branch of Analytical Chemistry, U.S. Geological Survey, Box 25046, DFC, MS 928, Lakewood, CO 80225, U.S.A

36. Fédération Européenne des Fabricants de Produits Réfractaires, 44, rue Copernic, 75016 Paris, France.

37. Amt für Standarisierung, Messwesen und Warenprüfung (ASMW), Wallstrasse 16, 1026 Berlin, German Democratic Republic.

38. Agrupamento de Materials de Referência, Divisão de Quimića e Engenharia Química, Instituto de Pesquisas Tecnológicas do Estado de São Paulo (IPT), Cidade Universitária Armando de Salles Oliveira, 05508 São Paulo-SP-Brazil.

39. J.J. LaBrecque, Instituto Venezolano de Investigaciones Cientifícas (IVIC), Apartado 1827, Caracas, 1010A, Venezuela.
Table 6. Suppliers of reference samples-Continued

40. O.H.J. Christie, Rogaland District High School, Studiesenteret Ullhandhaug, N-4001 Stavanger, Norway.

41. Brian Lister, Institute of Geological Sciences, 64 Gray's Inn Road, London, WCIX 8NG, England.

42. Marine Analytical Chemistry, Standards Program, Chemistry Division, National Research Council, Montreal Road, Ottawa, Canada K1A 0R9.

43. El. Al. Ivanov, Institute of Geology, Bulgarian Academy of Sciences, Sofia, Bulgaria.

44. A.B. Poole, Department of Geology, Queen Mary College, Mile End Road, London, El, 4NS, England.

45. A. Mazzucotelli, Instituto di Petrografia, Universita di Genova, Pallazo delle Scienze, 16132 Genova, Italy.

46. D.M. Moore, Department of Geology, Knox College, Gallesburg, IL 61401.

47. Junta de Energia Nuclear, Ciudad Universitaria, Madrid 3, Spain.

48. A.A. Kukharenko, Department of Mineralogy, Leningrad State University, Leningrad V-164, U.S.S.R.

49. Japan Standard Sample Committee, c/o National Chemical Laboratory for Industry, 1 Higashi 1-Chome, Yatabemachi, Tsukuba-Gun, Ibaraki, Japan.

50. Gary P. Landis, U.S. Geological Survey, MS 405, Federal Center, Denver, CO 80225, U.S.A.

51. Ceramic Society of Japan, 22-17, 2-Chome, Hyakunicho, Shinjyuku$\mathrm{Ku}$, Tokyo, Japan.

52. Research Institute, Bureau of Uranium Geology, Beijing, People's Republic of China.

53. Analytical Standards AB, Pl. 2366, S-434 00, Kungsbacka, Sweden.

54. A.P. Vinogradov Institute of Geochemistry (IGI), Siberian Branch, U.S.S.R. Academy of Sciences, Irkutsk, U.S.S.R.

55. Institute of the Geology, Geochemistry, Petrology, and Mineralogy of Ore Deposits (IGEM), U.S.S.R. Academy of Sciences, Staromonetny 35, Moscow, U.S.S.R., 109017.

\section{REFERENCES CITED}

Abbey, Sydney, 1970, U.S. Geological Survey Standards-A critical study of published analytical data: Canadian Spectroscopy, v. 15 , no. 1 , p. 10-16.

1977a, Studies in "standard samples" for use in the general analysis of silicate rocks and minerals. Part 5: 1977 edition of "usable" values: Canada Geological Survey Paper 77-34, $31 \mathrm{p}$.

1977b, "Standard samples": How "standard" are they?: Geostandards Newsletter, v. 1, no. 1, p. 39-45.

-1980 , Studies in "standard samples" for use in the general analysis of silicate rocks and minerals: Part 6: 1979 edition of "usable" values: Canada Geological Survey Paper 80-14, $30 \mathrm{p}$.

1983, Studies in "standard samples" of silicate rocks and minerals, 1969-1982: Canada Geological Survey Paper 83$15,114 \mathrm{p}$.

Abbey, Sydney, Gillieson, A.H., and Perrault, Guy, 1975, Sy-2, Sy-3 and MRG-1: A report on the collaborative analysis of three Canadian rock samples for use as certified reference materials: Canada Centre for Mineral and Energy Technology Report MRP/MSL 75-132 (TR), 56 p. 
Abbey, Sydney, and Govindaraju, Kuppusami, 1978, Analytical data on three rock reference samples from the Institute of Geochemistry, Irkutsk, USSR: Geostandards Newsletter, v. 2, no. 1, p. 15-22.

Abbey, Sydney, and Maxwell, J.A., 1960, Determination of potassium in micas; a flame photometric study: Chemistry in Canada, v. 12 , no. 9, p. 37-411.

Abbey, Sydney, McLeod, C.R., and Wan, L.G., 1983, FeR-1, FeR-2, FeR-3, and FeR-4: Four Canadian iron-formation samples prepared for use as reference materials: Canada Geological Survey Paper 83-19, 51 p.

Abo-Rady, M.D.K., 1979, Schwermetallbestimmung in zwei biologischen und zwei geologischen Standards mit Hilfe der atom-absorptions Spektroscopie: Fresenius Zeitschrift für analytische Chemie, v. 296 , no. 5, p. 380-382.

Ackermann, F., Bergmann, H., and Schleichert, U., 1979, On the reliability of trace metal analyses: Results of intercomparison analyses of a river sediment and an estuarine sediment: Fresenius Zeitschrift für analytische Chemie, v. 296, no. 4, p. 270-276.

Agricola, Georg, 1950, De Re Metallica, translated from the first Latin ed. of 1556 by Herbert Clark Hoover and Lou Henry Hoover: New York, Dover Publications, 638 p.

Agus, F., and Hesp, W.R., 1974, Factors involved in mineral sample preparation: Australia Commonwealth Scientific and Industrial Research Organization, Minerals Research Laboratories Investigation Report 100, 12 p., 2 figs.

Aleksiev, Elena, and Boyadjieva, R., 1966, Content of rare earths in the standard igneous rocks $\mathrm{G}-1, \mathrm{~W}-1$, and $\mathrm{G}-\mathrm{B}$ : Geochimica et Cosmochimica Acta, v. 30, no. 5, p. 511-513.

Alexander, E.C., Jr., and Davis, P. K., 1974, ${ }^{40} \mathrm{Ar}-{ }^{39} \mathrm{Ar}$ ages and trace element contents of Apollo 14 breccias; an interlaboratory cross-calibration of ${ }^{40} \mathrm{Ar}-{ }^{39} \mathrm{Ar}$ standards: Geochimica et Cosmochimica Acta, v. 38, no. 6, p. 911-928.

Alexander, E.C., Jr., Mickelson, G.M., and Lanphere, M.A., 1978, MMhb-1: A new ${ }^{40} \mathrm{Ar}-{ }^{39} \mathrm{Ar}$ dating standard, in Zartman, R.E., ed, Short papers of the Fourth International Conference on Geochronology, Cosmochronology, and Isotope Geology 1978: U.S. Geological Survey Open-File Report 78-701, p. 6-8.

Allcott, G.H., and Lakin, H.W., 1974, Statistical summary of chemical data furnished by 85 laboratories for six geochemical exploration reference samples: U.S. Geological Survey open-file report, $103 \mathrm{p}$.

1975, The homogeneity of six geochemical exploration reference samples, in Elliott, I.L., and Fletcher, W.K., eds., Geochemical Exploration, 1974-Proceedings of the Fifth International Geochemical Symposium, Vancouver, B.C., Canada, April 1-4, 1974; p. 659-681.

1978, Tabulation of geochemical data furnished by 109 laboratories for six geochemical exploration reference samples: U.S. Geological Survey Open-File Report 78-163, $199 \mathrm{p}$.

American Petroleum Institute, 1951, Research Project 49, Reference clay minerals, preliminary reports: New York, Columbia University.

Anderson, D.H., Murphy, J.J., and White, W.W., 1972, Gelatin as a matrix for a mercury reference material: Analytical Chemistry, v. 44 , no. 12 , p. 2099-2100.

1976, Gelatin multicomponent trace element reference material: Analytical Chemistry, v. 48, no. 1, p. 116-117.
Anderson, R.F., and Fleer, A.P., 1982, Determination of natural actinides and plutonium in marine particulate material: Analytical Chemistry, v. 54, no. 7, p. 1142-1147.

Ando, Atsushi, 1967, A new silicate rock standard, JG-1, issued from the Geological Society of Japan: Geochemical Journal [Japan], v. 1, no. 3, p. 155.

- 1984, New silicate rock reference materials issued from the Geological Survey of Japan, 1984: Geostandards Newsletter, v. 8 , no. 1 , p. 115 .

Ando, Atsushi, Kurasawa, Hajime, Ohmori, Teiko, and Takeda, Eizo, 1971, 1971 compilation of data on rock standards JG-1 and JB-1 issued from the Geological Survey of Japan: Geochemical Journal [Japan], v. 5, no. 4, p. 151-164.

-1974, 1974 compilation of data on the GSJ geochemical reference samples JG-1 granodiorite and JB-1 basalt: Geochemical Journal [Japan], v. 8, no. 4, p. 175-192.

Andrews, Launcelot, 1908, What can be done to enhance the value of the work of the Bureau of Standards to the chemical industries?: Science, v. 28 , no. 718 , p. $450-452$.

Anscombe, F.J., 1960, Rejection of outliers: Technometrics, v. 2, no. 2 , p. $123-147$.

Appel, P.W.U., 1980, Need for an iron-formation reference sample: Geostandards Newsletter, v. 4, no. 1, p. 19.

Baertschi, P., 1976, Absolute ${ }^{18} \mathrm{O}$ content of standard mean ocean water: Earth and Planetary Science Letters, v. 31, no. 3, p. 341-344.

Bailey, E.G., 1909a, Accuracy in sampling coal: Industrial and Engineering Chemistry, v. 1, no. 3, p. 161-178.

_ 1909b, The "size-weight" percentage: Industrial and Engineering Chemistry, v. 1, no. 6, p. 377.

Ball, T.K., and Filby, R.H., 1965, The zinc contents of some geochemical standards by neutron activation and $\mathrm{x}$-ray fluorescence analysis: Geochimica et Cosmochimica Acta, v. 29, no. 7 , p. 737-740.

Ballestra, S., and Fukai, R., 1983, An improved radiochemical procedure for low-level measurements of americium in environmental matrices: Talanta, v. 30, no. 1, p. 45-48.

Barbooti, M.M., and Jasim, Fadhil, 1982, Electrothermal atomicabsorption determination of vanadium: Talanta, v. 29, no. 2 , p. 107-111.

Barnes, I.L., and others, 1973, Determination of lead, uranium, thorium, and thallium in silicate glass standard materials by isotope dilution mass spectrometry: Analytical Chemistry, v. 45 , no. 6 , p. $880-884$.

Barnett, Vic, and Lewis, Toby, 1978, Outliers in statistical data: New York, Wiley, 365 p.

Barnhisel, R.I., ed., 1978, Analyses of clay, silt, and sand fractions of selected soils from the southeastern United States: Lexington, Agricultural Experiment Station, University of Kentucky; Southern Cooperative Bulletin 219, 90 p.

Bastin, J., Bomans, M., Dugain, F., Michaut, C., PujadeRenaud, J.M., and Van Audenhove, J., 1981, Utilisation de matériaux de référence pour analyse commerciale de grande précision. Exemple de minerais concentrés de zinc, Partie 1: Utilisation des résultats d'un circuit d'étalonnage: Analusis, v. 9, no. 9, p. 417-428.

1982, Utilisation de matériaux de référence pour analyse commerciale de grande précision. Exemple de minerais concentrés de zinc, Partie II: Fabrication de matériaux de référence: Analusis, v. 10, no. 6, p 253-265. 
1983, Utilisation de matériaux de référence pour analyse commerciale de grande précision. Exemple de minerais concentrés de zinc, Partie III: Sélection de trois méthodes de référence pour le dosage du zinc: Analusis, v.11, no. 1, p. 2-11.

Bastron, Harry, Barnett, P.R., and Murata, K.J., 1960, Method for the quantitative spectrochemical analysis of rocks, minerals, ores, and other materials by a powder d-c arc technique: U.S. Geological Survey Bulletin 1084-G, p. 165-182.

Baule, Bernhard, and Benedetti-Pichler, A., 1928, Zur Probenahme aus körnigen Materialien: Fresenius Zeitschrift für analytische Chemie, v. 74 , no. 12 , p. 442-456.

Beasley, T.M., Carpenter, R., and Jennings, C.D., 1982, Plutonium, ${ }^{241} \mathrm{Am}$ and ${ }^{137} \mathrm{Cs}$ ratios, inventories and vertical profiles in Washington and Oregon continental shelf sediments: Geochimica et Cosmochimica Acta, v. 46, no. 10, p. 19311946.

Beaulieu, P.L., 1971, Dust-free grinding installation for the silicate laboratory: Analytical Chemistry, v. 43, no. 6, p. 798799.

Behre, H.A., and Hassialis, M.D., 1945, Sampling and Testing, Section 19, in Taggart, A.F., ed., Handbook of mineral dressing: Ores and industrial minerals: New York, Wiley.

Bellon, Hervé., Buu, N.Q., Chaumont, Jacques, and Philippet, J.-C., 1981, Implantation ionique d'argon dans une cible support. Application au traçage isotopique de l'argon contenu dans les minéraux et les roches: Comptes Rendus des Séances de L'Académie des Sciences, Paris, v. 292, sec. II, no. 13 , p. $977-980$.

Belyaev, Yu.I., and Sobornov, O.P., 1981, Uranium, thorium, and potassium in reference samples: Geostandards Newsletter, v. 5, no. 2, p. 109-111.

Benedetti, A., Frache, Roberto, Jaffrezic, H., Joron, J.L., Mazzucotelli, Ambrogio., Meloni, S., and Oddone, M., 1977, Major, minor, and trace element data of ophiolite standard rock, GOG-1: Ofioliti, v. 2, no. 1, p. 29-39.

Benedetti-Pichler, A., 1922, Über die quantitative Mikroanalyse von Substanzgemischen mit besonderer Berücksichtigung der organischen Elementaranalyse: Fresenius Zeitschrift für analytische Chemie, v. 61 , no. 8-9, p. 305-331.

1923, Mikrokupferbestimmung in Werkstättenabfällen, Metallaschen, Spänen und Kupferlegierungen durch Elektrolyse: Fresenius Zeitschrift für analytische Chemie, v. 62, no. 9 , p. 321-329.

1942, Introduction to the microtechnique of inorganic analysis: New York, Wiley, 302 p.

1956, Theory and principles of sampling for chemical analysis, in Berl, W.G., ed., Physical methods in chemical analysis: New York, Academic Press, p. 183-217.

Bennett, C.A., and Franklin, N.L., 1954, Statistical analysis in chemistry and the chemical industry: New York, Wiley, $724 \mathrm{p}$.

Berkovits, L.A., and Lukashin, V.N., 1984, Three marine sediment reference samples: SDO-1, SDO-2, and SDO-3: Geostandards Newsletter, v. 8, no. 1, p. 51-56.

Berman, S.S., 1981, Marine sediment reference mateirals-Trace metals and inorganic constituents: Geostandards Newsletter, v. 5 , no. 2 , p. 218 .

Birger, G.I., and Bruk, B.S., 1977, Assessment of how much sample to take when determining gold in ores and their pro- cessed products: Journal of Analytical Chemistry of the USSR, v. 32 , no. 8 , pt. 2 , p. 1258-1261.

Blaedel, W.J., and Iverson, D.G., 1976, Calculator program yielding confidence limits for least squares straight line regression analysis: Analytical Chemistry, v. 48, no. 13, p. 2027-2028.

Blattner, Peter, and Hulston, J.R., 1975, Announcements: Geochimica et Cosmochimica Acta, v. 39, no. 12, p. 1715 1978, Proportional variations of geochemical $\delta^{18} \mathrm{O}$ scales-An interlaboratory comparison: Geochimica et Cosmochimica Acta, v. 42, no. 1, p. 59-62.

Blount, Bertram, 1904, The analysis of Portland cement: American Chemical Society Journal, v. 26, no. 8, p. 995-1003.

Bogert, M.T., 1908, American chemical societies: American Chemical Society Journal, v. 30, no. 2, p. 163-182.

Bourdieu, J.M., Bubenicek, L., and Jecko, Gerard, 1970, Les échantillons-types non métallique de l'IRSID, lère partie: $\mathrm{Re}$ vue de Métallurgie, v. 67, p. 137-148.

Bowden, P., and Luena, G., 1966, The use of T-1 as geochemical standard: Geochimica et Cosmochimica Acta, v. 30, no. 3, p. 361 .

Bowen, H.J.M., 1967, Comparative elemental analyses of a standard plant material: Analyst, v. 92, no. 1091, p. 124-131.

Bowen, V.T., 1978, Natural matrix samples: Environment International , v. 1, no. 1-2, p. 35-39.

Bowen, V.T., and Volchok, H.L., 1980, Spiked sample standards; Their uses and disadvantages in analytical quality control: Environment International, v. 3, no. 5, p. 365-376.

Bowman, W.S., Faye, G.H., Sutarno, R., McKeague, J.A., and Kodama, H., 1979, New CCRMP reference soils SO-1 to SO-4: Geostandards Newsletter, v. 3, no. 2, p. 109-113.

Boy, M., and Mazzucotelli, Ambrogio, 1976, Atomic absorption determination of silica in rocks and minerals: A review of direct and indirect techniques: Ofioliti, v. 1, no. 2, p. 127-133.

Boyd, F.R., Finger, L.W., and Chayes, Felix, 1969, Computer reduction of electron-probe data: Carnegie Institution of Washington Yearbook 67, p. 210-215.

Breitwieser, E., and Lieser, K.H., 1978, Multielementstandards auf Kieselgelbasis zur Bestimmung von Spurenelementen in silikatischen Proben durch Röntgenfluorescenzanalyse: Fresenius Zeitschrift für analytische Chemie, v. 292, no. 2, p. 126-131.

Brown, B.W., Jr., and Hollander, Myles, 1977, Statistics, a biomedical introduction: New York, Wiley, $456 \mathrm{p}$.

Brunton, D.W., 1896, The theory and practice of ore-sampling: American Institute of Mining Engineers Transactions, v. 25, p. 826-844.

Burks, H.G., and Pallister, J.W., 1961, Standard geochemical sample T-1, Msusule Tonalite: Dar es Salaam, Government Printer, 2 p., 1 fig.

Burns, J.H., and Bredig, M.A., 1956, Transformation of calcite to aragonite by grinding: Journal of Chemical Physics, v. 25, no. 6, p. 1281 .

Cali, J.P., and Plebanski, T., 1978, Standard reference materials: Guide to United States reference materials: U.S. National Bureau of Standards Special Publication 260-57, 46 p.

Cameron, F.K., Breckenridge, J.E., Patten, A.J., Jones, C.H., and Rudnick, Paul, 1915, Report of the committee on research and analytical methods-Phosphate rock: Industrial and Engineering Chemistry, v. 7, no. 5, p. 446-448. 
Canadian Association for Applied Spectroscopy, 1961, Report of Nonmetallic Standards Committee, Canadian Association for Applied Spectroscopy: Applied Spectroscopy, v. 15, no. 6, p. 159-161.

Carter-Bell, J., 1883, On the want of certain standard methods of technical analysis and valuation: Society of Chemical Industry Journal, v. 2, no. 3, p. 109-114.

Cassignol, C., David, B., and Gillot, P.Y., 1977, Contribution au dosage de l'argon dans L'échantillon de glauconite GL-O: Geostandards Newsletter, v. 1, no. 2, p. 105-106.

Champion, K.P., Taylor, J.C., and Whittem, R.N., 1966, Rapid $\mathrm{X}$-ray fluorescence determination of traces of strontium in samples of biological and geological origin: Analytical Chemistry, v. 38 , no. 1, p. $109-112$.

Chayes, Felix, 1967, Modal composition of U.S.G.S reference sample G-2: Geochimica et Cosmochimica Acta, v. 31, no. 3, p. 463-464.

Chen, B.R., Wang, Y.Q., Sun, J.X., and Zhang, Y.J., 1984, Determination of rare earth in Chinese drainage sediment standard samples by instrumental neutron activation analysis; Ho Chi Shu [Nuclear Techniques], no. 3, June, 1984, p. 60-62, [in Chinese].

Chen, B.G., Yuan, Ling, and Fang, C.M., 1982, Multielement neutron activation analysis of two ultrabasic rock (DZ $\sum-1$ and DZ $\Sigma$-2) standard reference materials: Ho Chi Shu [Nuclear Techniques], no. 4, August 1982, p. 34-35, [in Chinese].

Christie, O.H.J., 1975, Three trace-element geological materials certified as a result of a co-operative investigation: Talanta, $\mathrm{v}$. 22 , no. 12 , p. $1048-1050$.

Christie, O.H.J., and Alfsen, K.H., 1977, Data transformation as a means to obtain reliable consensus values for reference materials: Geostandards Newsletter, v. 1, no. 1, p. 47-49.

Clark, M.C., and Swaine, D.J., 1963, Trace-element contents of the National Bureau of Standards reference samples numbers 1a, 98, and 99: Geochimica et Cosmochimica Acta, v. 27, no. $11,1139-1142$.

Clarke, R.S., Jr., Jarosewich, Eugene, Mason, B., Nelen, J.A., Gomez, M., and Hyde, J.R., 1970, The Allende, Mexico, meteorite shower: Smithsonian Contributions to the Earth Sciences No. 5, 53 p. (issued Feb. 17, 1971).

Clifton, H.E., Hunter, R.E, Swanson, F.J., and Phillips, R.L., 1969, Sample size and meaningful gold analysis: U.S. Geological Survey Professional Paper 615-C, 17 p.

Cochran, W.G., 1947, Some consequences when the assumptions for the analysis of variance are not satisfied: Biometrics, v.3, no. 1 , p. 22-38.

Cochran, W.G., and Cox, G.M., 1950, Experimental designs: New York, Wiley, 454 p.

Cochrane, R.C., 1966, Measures for progress, A history of the National Bureau of Standards: U.S. Department of Commerce, National Bureau of Standards, $703 \mathrm{p}$.

Colombo, A., 1980, Another approach to the mode of a skewed set of data: The plot method: Geostandards Newsletter, v. 4, no. 2, p. 239-242.

Colombo, A., and Rossi, G., 1978, Reference materials for ore, ore concentrate, and coke samples, An approach to derive consensus values and associated uncertainties from collaborative studies: Geostandards Newsletter, v. 2, no. 2, p. 109114.
Compston, W., Chappell, B.W., Arriens, P.A., and Vernon, M.J., 1969, On the feasibility of NBS 70a K-feldspar as a $\mathrm{Rb}-\mathrm{Sr}$ age reference sample: Geochimica et Cosmochimica Acta, v. 33 , no. 6, p. 753-757.

Coplen, T.B., and Kendall, Carol, 1982, Preparation and stable isotope determination of NBS-16 and NBS-17 carbon dioxide reference samples: Analytical Chemistry, v. 54, no. 14, p. 2611-2612.

Coplen, T.B., Kendall, Carol, and Hopple, Jessica, 1983, Comparison of stable isotope reference samples: Nature, v. 302, no. 5905 , p. $236-238$.

Craig, Harmon, 1957, Isotopic standards for carbon and oxygen and correction factors for mass-spectrometric analysis of carbon dioxide: Geochimica et Cosmochimica Acta, v. 12, no. 1-2, p. 133-149.

1961, Standards for reporting concentration of deuterium and oxygen-18 in natural waters: Science, v. 133 , no. 3467 , p. $1833-1834$.

Crock, J.G., and Severson, R.C., 1980, Four reference soil and rock samples for measuring element availability in the western energy regions: U.S. Geological Survey Circular 841, 16 p.

Cross, Whitman, Iddings, J.P., Pirsson, L.V., and Washington, H.S., 1902, A quantitative chemico-mineralogical classification and nomenclature of igneous rocks: Journal of Geology, v. 10 , no. 6 , p. $555-690$.

Croudace, I.W., 1981, Neutron activation determination of rare earth and trace elements in two BCS soda and potash feldspar standards: Geostandards Newsletter, v. 5, no. 2, p. 185-187.

Croudace, I.W., Joron, J.-L., Jaffrezic, H., Meyer, G., and Treuil, M., 1982, Neutron activation analysis of seven B.C.S. certified reference materials of geological interest: Geostandards Newsletter, v. 6, no. 2, p. 233-239.

Curtiss, L.F., and others, 1940, Radioactive standards [Letter to editor]: American Journal of Science, v. 238, no. 8, p. 602 603.

Dabney, C.W., Jr., ed., 1885, Methods of analysis of commercial fertilizers. Proceedings of the Second Annual Meeting of the Association of Official Agricultural Chemists, Washington, D.C., Sept. 1-2, 1885: U.S. Department of Agriculture, Division of Chemistry Bulletin 7, $49 \mathrm{p}$.

Das, M.S., 1979, Geometric means as probable values for compiled data on geochemical reference samples: Geostandards Newsletter, v.3, no. 2, p. 199-205.

Date, A.R., 1978, Preparation of trace element reference materials by a co-precipitated gel technique: Analyst, v. 103, no. 1222, p. 84-92.

Demond, C.D., and Halferdahl, A.C., 1922a, Mechanical sampling of ore: Engineering and Mining Journal-Press, v. 114, no. 7 , p. $280-284$.

1922b, Sampling spotty gold ores: Engineering and Mining Journal-Press, v. 114, no. 22, p. 948.

Dempir, J., 1978, Preparation of reference samples of mineral raw materials and their use in analytical practice: Geostandards Newsletter, v. 2, no. 2, p. 117-120.

Dempir, J., and Valcha, Zdeněk, 1982, Standard reference material of fluorite FM: Geostandards Newsletter, v. 6, no. 1, p. 13-16.

Dewey, F.P., 1894, The accuracy of the commercial assay for silver: American Chemical Society Journal, v. 16, no. 8, p. 505-516. 
1896, The actual accuracy of chemical analysis: American Chemical Society Journal, v. 18, no. 9, p. 808-818.

Dixon, W.J., 1953, Processing data for outliers: Biometrics, v. 9, no. 1, p. 74-89.

Drake, M.J., and Weill, D.F., 1972, New rare earth element standards for electron microprobe analysis: Chemical Geology, v. 10, no. 2, p. 179-181.

Drummer, D.M., Fassett, J.D., and Morrison, G.H., 1978, Computerized image processing for evaluation of sampling error in ion microprobe analysis: Analytica Chimica Acta, v. 100, p. 15-22.

Dudley, C.B., 1881, The wearing capacity of steel rails in relation to their chemical composition and physical properties: American Institute of Mining Engineers Transactions, v. 9, p. 321-360.

Dudley, C.B., and Pease, F.N., 1893, The need of standard methods for the analysis of iron and steel, with some proposed standard methods: American Chemical Society Journal, v. 15 , no. 9 , p. 501-518.

Dybczyński, Rajmund, 1980, Comparison of the effectiveness of various procedures for the rejection of outlying results and assigning consensus values in interlaboratory programs involving determination of trace elements or radionuclides: Analytica Chimica Acta, v. 117, p. 53-70.

Dybczyński, Rajmund, Tugsavul, A., and Suschny, Otto, 1979, Soil-5, a new IAEA certified reference material for trace element determinations: Geostandards Newsletter, v. 3, no. 1, p. 61-87.

Ebaugh, W.C., 1909, Standardized samples: Industrial and Engineering Chemistry, v. 1, no. 2, p. 62-63.

Eddy, B.T., Watterson, J.I.W., and Erasmus, C.S., 1980, Preparation of synthetic standards for use in instrumental neutronactivation analysis: Geostandards Newsletter, v. 4, no. 2, p. 229-237.

Egranova, I.G., Vall, G.A., and Solovei, N.N., 1981, Spectrographic determination of trace elements in rocks and minerals: Journal of Analytical Chemistry of the USSR, v. 36, no. 7, pt. 1, p. 876-882.

Eisenhart, Churchill, 1939, The interpretation of certain regression methods and their use in biological and industrial research: Annals of Mathematical Statistics, v. 10, p. 162-186.

1947 , The assumptions underlying the analysis of variance: Biometrics, v. 3, no. 1, p. 1-21.

Ellis, P.J., Copelowitz, I., and Steele, T.W., 1977, Estimation of the mode by the dominant cluster method: Geostandards Newsletter, v. 1, no. 2, p. 123-130.

Ellis, P.J., and Steele, T.W., 1982, Five robust indicators of central value: Geostandards Newsletter, v. 6, no. 2, p. 207216.

Erzinger, J., and Puchelt, H., 1980, Determination of selenium in geochemical reference samples using flameless atomic absorption spectrometry: Geostandards Newsletter, v. 4, no. 1, p. $13-16$.

Eustis, W.E.C., 1883, Comparison of various methods of copper analysis: American Institute of Mining Engineers Transactions, v. 11, p. 120-135.

Fairbairn, H.W., and others, 1951, A cooperative investigation of precision and accuracy in chemical, spectrochemical, and modal analysis of silicate rocks: U.S. Geological Survey Bulletin $980,71 \mathrm{p}$.
Fairbairn, H.W., and Schairer, J.F., 1952, A test of the accuracy of chemical analysis of silicate rocks: American Mineralogist, v. 37, no. 8-10, p. 744-757.

Faye, G.H., Bowman, W.S., and Sutarno, R., compilers, 1974, Zinc-lead-tin-silver ore $\mathrm{KC}$-1: Its preparation and characterization for use as certified reference material: Canada Department of Energy, Mines, and Resources, Mines Branch Technical Bulletin TB 193, 33 p.

1975, Gold ore, MA-1: Its characterization and preparation for use as a certified reference material: Canada Centre for Mineral and Energy Technology Report MRP/MSL/ 7529(TR), 15 p.

Faye, G.H., and Sutarno, R., 1976, Certified compositional reference materials for the earth sciences: Canadian Mineralogist, v. 14 , no. 2 , p. $164-171$.

1977, CCRMP ores and related materials (1976): Geostandards Newsletter, v. 1, no. 1, p. 31-34.

Feng, L.Y., Li, R.L., Zhang, Y.W., Wang, Y.X., Qian, Z.X., and Zhao, Z.H., 1983, X-ray fluorescence (XRF) determination of trace rare-earth elements in geological samples using ion-exchange-resin membrane technique: Geochemistry (English ed.), v. 2, no. 2, p. 153-169.

Feret, Franciszek, 1982, Routine analysis of iron ores by x-ray spectrometry: Spectrochimica Acta, v. 37B, no. 4, p. 349357.

Filby, R.H., 1964, The contents of several trace elements in some rock standards: Geochimica et Comochimica Acta, v. 28, no. 2, p. 265-269.

Fitton, J.G., and Gill, R.C.O., 1970, The oxidation of ferrous iron in rocks during mechanical grinding: Geochimica et Cosmochimica Acta, v. 34 , no. 4 , p. 518-524.

Flanagan, F.J., 1964, Judging the analytical ability of rock analysts by chi-squared: U.S. Geological Survey Professional Paper 501-C, p. C157-C158.

-1967, U.S. Geological Survey rock standards: Geochimica et Cosmochimica Acta, v. 31, no. 3, p. 289-308.

1969 , U.S. Geological Survey standards-II. First compilation of data for the new U.S.G.S. rocks: Geochimica et Cosmochimica Acta, v. 33, no. 1, p. 81-120.

1970 , Sources of geochemical standards-II: Geochimica et Cosmochimica Acta, v. 34, no. 1, p. 121-125.

1974, Reference samples for the earth sciences: Geochimica et Cosmochimica Acta, v. 38, no. 12, p. 1731-1744.

1975 , Meaningful measurements with rock and ore standards, in Seward, R.W., ed., Standard reference materials and meaningful measurements: U.S. National Bureau of Standards Special Publication 408, p. 695-712.

1976a, An approximate method of computing errors in trace analysis due to sampling heterogeneous solids, in LaFleur, P.D., ed., Accuracy in trace analysis: Sampling, sample handling, analysis: U.S. National Bureau of Standards Special Publication 422, p. 421-427.

ed. and comp., 1976b, Descriptions and analyses of eight new USGS rock standards: U.S. Geological Survey Professional Paper 840, 192 p.

1976c, 1972 compilation of data on USGS standards: U.S. Geological Survey Professional Paper 840, p. 131-183.

1981, Editorial: Geostandards Newsletter, v. 5, no. 2, p. 107. 
1984, Three USGS mafic rock samples, W-2, DNC-1, and BIR-1: U.S. Geological Survey Bulletin 1623, 54 p.

Flanagan, F.J., Chandler, J.C., Breger, I.A., Moore, C.B., and Lewis, C.F., 1976, The carbon contents of USGS volcanic rock standards: U.S. Geological Survey Professional Paper 840, p. $123-126$.

Flanagan, F.J., and Gottfried, David, 1980, USGS Rock Standards, III: Manganese-nodule reference samples USGS-NodA-1, and USGS-Nod-P-1: U.S. Geological Survey Professional Paper 1155, $39 \mathrm{p}$.

Flanagan, F.J., and Gwyn, M.E., 1967, Sources of geochemical standards: Geochimica et Cosmochimica Acta, v. 31, no. 7, p. $1211-1213$.

Flanagan, F.J., Moore, R., and Aruscavage, P.J., 1982, Mercury in geologic reference samples: Geostandards Newsletter, v. 6, no. 1 , p. $25-46$.

Flanagan, F.J., Schwarz, L.J., Rowe, J.J., and Dorrzapf, A.F., Jr., 1977, Available clay and feldspar reference samples as standards for archaeological pottery studies: Geostandards Newsletter, v. 1, no. 1, p. 61-66.

Flegal, A.R., 1980, Geostandard needs for environmental research and monitoring programs: Geostandards Newsletter, v. 4, no. 1, p. 17-18.

French, W.J., and Adams, S.F., 1972, A rapid method for the extraction and determinations of iron (II) in silicate rocks and minerals: Analyst, v. 97, no. 1159, p. 828-831.

Friberg, L., and Vostal, J., eds., 1972, Mercury in the environment: Cleveland, CRC Press, 215 p.

Frick, Cornelius, no date, The occurrence and petrography of the SAROCK standards: Pretoria, South Africa Geological Survey, 26 p. [published after 1976].

Friedman, Irving, and Gleason, J.D., 1973, A new silicate reference standard for $\mathrm{O}^{18}$ analysis: Geochimica et Cosmochimica Acta, v. 37, no. 1, p. 180.

Friedman, Irving, O’Neil, J., and Cebula, G., 1982, Two new carbonate stable-isotope standards: Geostandards Newsletter, v. 6 , no. 1 , p. 11-12.

Frost, J.K., Koszykowski, R.F., and Klemm, R.C., 1982, Chemical characterization of gas- and oil-bearing shales by instrumental neutron activation analysis: Journal of Radioanalytical Chemistry, v. 71, no. 1-2, p. 199-214.

Fuwa, Keiichiro, Notsu, Kenji, Tsunoda, Kin-ichi, Kato, Hideaki, Yamamoto, Yuko, Okamoto, Kensaku, Dokiya, Yukiko, and Toda, Shozo, 1978, Japanese tea leaves: A possible biological standard reference material: Chemical Society of Japan Bulletin, v. 51, no. 4, p. 1078-1082.

Gardner, William, and Cooke, E.I., 1968, Chemical synonyms and trade names: A dictionary and commercial handbook: Cleveland, CRC Press, $635 \mathrm{p}$.

Gat, J.R., and Gonfiantini, R., eds., 1981, Stable isotope hydrology: Deuterium and oxygen-18 in the water cycle: Vienna, International Atomic Energy Agency, Technical Reports Series No. 210, 337 p.

Gaudin, A.M., 1939, Principles of mineral dressing: New York, McGraw-Hill, $554 \mathrm{p}$

Geary, R.C., 1935, The ratio of the mean deviation to the standard deviation as a test of normality: Biometrika, v. 27, p. 310 332.

Ginzburg, A.I., Skorobogatova, N.V., and Iovcheva, E.I., 1983, Basis for the creation of a bureau of standard samples for mineralogical studies: Mineralogicheskii Zhurnal,v. 5, no. 1, p. 72-81. [in Russian].

Gladney, E.S., and Goode, W.E., 1981, Elemental concentrations in eight new United States Geological Survey rock standards: A review: Geostandards Newsletter, v. 5, no. 1, p. 31-64.

Gliksman, J.E., Gibson, J.E., and Kandetzski, P.E., 1980, Highprecision determination of calcium in phosphate rock by atomic absorption spectroscopy: Atomic Spectroscopy, v. 1, no. 6 , p. $166-167$.

Goldberg, E.D., Hodge, Vern, Koide, Minoru, and Griffin, J.J., 1976, Metal pollution in Tokyo as recorded in sediments of the Palace Moat: Geochemical Journal [Japan], v. 10, no. 4, p. 165-174.

Gonfiantini, R., 1978, Standards for stable isotope measurements in natural compounds: Nature, v. 271, no. 5645, p. 534-536.

Gorozhanina, R.S., Freedman, A.Y., and Shaievitch, A.B., 1971, Standard reference materials: Standard samples issued in the USSR. Translated from the Russian by M.C. Selby: U.S. National Bureau of Standards Special Publication 260-30, 86 p.

Govindaraju, Kuppusami, 1979, Report (1968-1978) on two mica reference samples: Biotite Mica-Fe, and Phlogopite MicaMg: Geostandards Newsletter, v. 3, no. 1, p. 3-24.

1980, Report (1980) on three GIT-IWG rock reference samples: Anorthosite from Greenland, AN-G: Basalte d'Essey-la-Côte, BE-N; granite de Beauvoir, MA-N: Geostandards Newsletter, v. 4, no. 1, p. 49-138.

1982, Report (1967-1981) on four ANRT rock reference samples: Diorite DR-N, Serpentine UB-N, Bauxite BX-N and Disthene DT-N: Geostandards Newsletter v. 6, no. 1, p. 91-159.

1984a, 1984 compilation of working values and sample descriptions for 170 international reference samples of mainly silicate rocks and minerals: Geostandards Newsletter, Special Issue, July 1984, variously paginated.

1984b, Report (1984) on two GIT-IWG geochemical reference samples: Albite from Italy, AL-1 and iron formation sample from Greenland, IF-G,: Geostandards Newsletter, v. 8 , no. 1 , p. 63-113.

Govindaraju, Kuppusami, and Mevelle, Guy, 1983, Geostandards and geochemical analysis: Spectrochimica Acta, v. 38B, no. 11/12, p. 1447-1456.

Govindaraju, Kuppusami, Morel, J., and L'Homel, N., 1977, Solid sampling atomic absorption determination of silver in silicate rock reference samples. Application to a homogeneity study of silver in a one-ton two-mica granite reference sample: Geostandards Newsletter, v. 1, no. 2, p. 137-142.

Govindaraju, Kuppusami, and Roche, H. de la, 1977, Rapport (1966-1976) sur les éléments en traces dans trois standards géochemiques du CRPG: Basalte BR et granites, GA et GH: Geostandards Newsletter, v. 1, no. 1, p. 67-100.

Grabowski, R.J., and Unice, R.C., 1958, Quantitative spectrochemical determination of barium and strontium: Analytical Chemistry, v. 38, no. 8, p. 1374-1379.

Graff, P.R., 1973, Change in chemical composition of rock samples during preparation for analysis: Norges geologiske undersøkelse, Nr. 300, Bulletin 20, p. 27-31.

Grassman, Hans, 1972, Die Standardgesteinsproben des ZGI.6. Mitteilung: Neue Auswertung der Analysen auf Hauptkomponenten der Proben Granit GM, Basalt BM, Tonschiefer TB, 
Kalkstein KH und erste Auswertung der Proben Anhydrit AN und Schwärzschiefer TS: Zeitschrift für angewandte Geologie, v. 18 , no. 6 , p. $280-284$.

Griepink, B., Colinet, E., Guzzi, G., Haemers, L., and Muntau, H., 1983, Certification of trace element contents (As, Cd, Co, $\mathrm{Cu}, \mathrm{Fe}, \mathrm{Mn}, \mathrm{Hg}, \mathrm{Na}, \mathrm{Pb}$, and $\mathrm{Zn}$ ) in a fly ash obtained from the combustion of pulverized coal: Fresenius Zeitschrift für Analytische Chemie, v. 315, no. 1, p. 20-25.

Gries, W.H., and Norval, E., 1975, New solid standards for the determination of trace impurities in metals by flameless atomic absorption spectrometry: Analytica Chimica Acta, v. 75, no. 2, p. 289-296.

Griffin, M.L., 1909, A mathematical view of sampling, with reference to the degree of accuracy to be obtained: Society of Chemical Industry Journal, v. 28, no. 4, p. 192-194.

Gromet, L.P., Dymek, R.F., Haskin, L.A., and Korotev, R.L., 1984, the "North American shale composite": Its compilation, major and trace element characteristics: Geochimica et Cosmochimica Acta, v. 48, no. 12, p. 2469-2482.

Gross, John, 1935, Summary of investigation of work in crushing: American Institute of Mining and Metallurgical Engineers Transactions, v. 112, p. 116-129.

1938 , Crushing and grinding: U.S. Bureau of Mines Bulletin $402,148 \mathrm{p}$.

Grubbs, F.E., 1950, Sample criteria for testing outlying observations: Annals of Mathematical Statistics, v. 21, no. 1, p. 27-58.

-1969, Procedures for detecting outlying observations in samples: Technometrics, v. 11, no. 1, p. 1-21.

Gumbel, E.J., 1958, Statistics of extremes: New York, Columbia University Press, 375 p.

Gy, Pierre, 1967, L'échantillonnage des minerais en vrac: [France] Bureau de Recherches Géologiques et Minières Mémoire 56, $186 \mathrm{p}$.

1979, Sampling of particulate materials: Theory and practice: New York, Elsevier, 431 p.

Hagedorn, C.F., Dempwolf, C.H., Jr., and Carpenter, F.B., 1909, Report of the committee on the analysis of phosphate rock: Industrial and Engineering Chemistry, v. 1, no. 1, p. 41-44.

Hague, J.L., Mears, T.W., and Michaelis, R.E., 1965, Standard reference materials: Sources of information: U.S. National Bureau of Standards Miscellaneous Publication 260-4, 18 p.

Hamilton, D.L., and Henderson, C.M.B., 1968, The preparation of silicate compositions by a gelling technique: Mineralogical Magazine, v. 36 , no. 282 , p. $832-838$.

Hamilton, D.L., and Mackenzie, W.S., 1960, Nepheline solid solution in the system $\mathrm{NaAlSiO}_{4}-\mathrm{KAlSiO}_{4}-\mathrm{SiO}_{2}$ : Journal of Petrology, v. 1, no. 1, p. 56-72.

Hansen, R.G., Ring, E.J., and Steele, T.W., 1982, The preparation and certification of ten uranium reference materials: Council for Mineral Technology (MINTEK), Randburg, 2125, South Africa, Report M16, 37 p.

Harris, J.L., Schwarz, L.J., d'Angelo, W.M., and Flanagan, F.J., 1981, Additional analytical data for GOG-1: Geostandards Newsletter, v. 5, no. 2, p. 125-128.

Harris, W.E., and Kratochvil, Byron, 1974, Sampling variance in analysis for trace components in solids: Analytical Chemistry, v. 46 , no. 2 , p. $313-315$.
Hart, R.J., Leahy, R., and Falcon, R.M., 1982, Geochemical investigation of the Witbank coalfield using instrumental neutron activation analysis: Journal of Radioanalytical Chemistry, v. 71, no. 1-2, p. 285-297.

Hartford, W.H., 1953, Industrial chrome ore analysis: An industry standard sample of metallurgical chrome ore: Analytical Chemistry, v. 25 , no. 2, p. 290-295.

Harvey, P.K., 1974, The detection and correction of outlying determinations that may occur during geochemical analysis: Geochimica et Cosmochimica Acta, v. 38, no. 3, p. 435-451.

Hashimoto, Yoshikazu, Otoshi, Tsunehiko, and Oikawa, Kikuo, 1976, Preparation of homogeneous dust sample for comparison of analytical results of atmospheric samples: Environmental Science and Technology, v. 10, no. 8, p. 815-818.

Hawkins, E.N., Knight, F.C., Jones, L.J.W., Wood, H.E., and Guiterman, F., 1893, Report on the technical determination of zinc: Colorado Scientific Society Proceedings, 1891, 1892, 1893 , v. 4, p. 176-191.

Heidel, R.H., 1971, Standardization and data reduction for electron probe analysis of geologic materials: American Laboratory, v. 3 , no. 9 , p. 10-14.

Heinonen, J., Suschny, Otto, and Górski, L., 1973, Intercomparison of uranium, thorium, and potassium determinations in sedimentary rocks: International Atomic Energy Agency, Vienna, Austria, Report IAEA/RL/13, 13 p.

Higgins, J., 1964, Subtracting the blank value: Analyst, v. 89, no. 1056, p. 211-215.

Hillebrand, W.F., 1894, A plea for greater completeness in chemical rock analysis: American Chemical Society Journal, v. 16, no. 2, p. 90-93.

1903, Critical review of the second series of analyses of materials for the Portland cement industry made under the auspices of the New York section of the Society of Chemical Industry: American Chemical Society Journal, v. 25, no. 11, p. 1180-1208.

1905 , Some thoughts on the present conditions of analytical chemistry: American Chemical Society Journal, v. 27, no. 3, p. 300-308.

1907, The analysis of silicate and carbonate rocks: U.S. Geological Survey Bulletin 305, 200 p.

1908, The influence of fine grinding on the water and ferrous-iron content of minerals and rocks: American Chemical Society Journal, v. 30, no. 7, p. 1120-1131.

1909, The Bureau of Standards' analyzed samples: Industrial and Engineering Chemistry, v. 1, no. 1, p. 41.

Hillebrand, W.F., Dudley, C.B., Richardson, Clifford, and Stokes, H.N., 1906, Cooperative analysis of an argillaceous limestone: American Chemical Society Journal, v. 28, no. 2, p. 223-239.

Hillebrand, W.F., Dudley, C.B., Stokes, H.N., and Richardson, Clifford, 1904, Contribution from the Committee on Uniformity in Technical Analysis, 1: American Chemical Society Journal, v. 26, no. 12 , p. 1644-1653.

Hitchen, A., and Zechanowitsch, G., 1980, Titrimetric determination of uranium in low-grade ores by the ferrous ionphosphoric acid reduction method: Talanta, v. 27 , no. 5 , p. 383-389.

Hofman, H.O., 1901, The metallurgy of lead and the desilverization of base bullion: New York, The Scientific Publishing Co., 559 p. 
Hohenberg, C.M., and Kennedy, B.M., 1981, I-Xe dating: Intercomparisons of neutron irradiations and reproducibility of the Bjurböle standard: Geochimica et Cosmochimica Acta, v. 45, no. 2 , p. 251-256.

Hügi, T., Schwander, H., and Stern, W., 1975, Preliminary data on mineral standards Basel- $\mathrm{lb}$ (biotite) and $-\mathrm{lh}$ (hornblende): Schweizerische Mineralogische und Petrographische Mitteilungen, v. 55, no. 3, p. 403-406.

Ingamells, C.O., 1978, Analyzed minerals for elecron microprobe standards: Geostandards Newsletter, v. 2, no. 2, p. 115.

1979, Microprobe Column; Geostandards Newsletter, v. 3, no. 2 , p. 207.

-1980a, Microprobe Column; Geostandards Newsletter, v. 4, no. 1 , p. 139.

1980b, Microprobe Column; Geostandards Newsletter, v. 4, no. 2, p. 253-254.

Ingamells, C.O., Engels, J.C., and Switzer, P., 1972, Effect of laboratory sampling error in geochemistry and geochronology: 24th International Geological Congress, Section 10, p. $405-415$.

Ingles, J.C., Sutarno, R., Bowman, W.S., and Faye, G.H., 1977, Radioactive ores $\mathrm{DH}-1, \mathrm{DL}-1, \mathrm{BL}-1, \mathrm{BL}-2, \mathrm{BL}-3$, and BL-4 - certified reference materials: Canada Centre for Mineral and Energy Technology CANMET Report 77-64, 22 p., two app.

Inn, K.G.W., Mullen, P.A., and Hutchinson, J.M.R., 1984, Radioactivity standards for environmental monitoring. II: Environmental International, v. 10, no. 2, p. 91-97.

International Atomic Energy Agency (IAEA), 1983, Analytical Quality Control Service Programme, 1983-1984, Intercomparison runs, certified reference materials, reference materials: Vienna, Austria, $14 \mathrm{p}$.

International Atomic Energy Agency (IAEA), 1984, Analytical Quality Control Service Programme, 1984-1985, Intercomparison runs, certified reference materials, reference materials: Vienna, Austria, $17 \mathrm{p}$.

International Organization for Standardization (ISO), 1982, Directory of certified reference materials (1st ed.): Geneva, Switzerland, $61 \mathrm{p}$.

Ivanov, El.Al., 1981, Rapport préliminaire sur un échantillon géochemique de Bulgarie: Granite G-B: Geostandards Newsletter, v. 5, no. 1, p. 27-29.

Iwata, Yaso, Matsumoto, Kazuko, Haragucki, Hiroki, and Fuwa, Keiichiro, 1981, Proposed certified reference material for pond sediment: Analytical Chemistry, v. 53, no. 7, p. 1136-1138.

Jamieson, J.C., and Goldsmith, J.R., 1960, Some reactions produced in carbonates by grinding: American Mineralogist, v. 45 , no. $7-8$, p. $818-827$.

Jarosewich, Eugene, 1972, Chemical analysis of five minerals for microprobe analysis: Smithsonian Contributions to the Earth Sciences No. 9, p. 83-84.

1975, Chemical analysis of two microprobe standards: Smithsonian Contributions to the Earth Sciences No. 14, p. 85-86.

Jarosewich, Eugene, Nelen, J.A., and Norberg, J.A., 1979, Electron microprobe reference samples for mineral analyses: Smithsonian Contributions to the Earth Sciences No. 22, p. 68-72.

1980, Reference samples for electron microprobe analysis: Geostandards Newsletter, v. 4, no. 1, p. 43-47.
Jecko, Gerard, 1977, Bulk composition of IRSID iron ore and other non-metallic reference samples: Geostandards Newsletter, v. 1, no. 1, p. 11-13.

Jecko, Gerard, and Matraski, A., 1973, Les échantillons-types non métalliques de L'IRSID 2éme partie: Revue de Métallurgie, v. 70, p. $437-460$.

Jecko, Gerard, Pohl, H., and Ridsdale, P.D., 1977, Eruostandards of iron ores: Geostandards Newsletter, v. 1, no. 2, p. 131-135.

Jecko, Gerard, and Ravaine, D., 1978, Compléments d'étalonnage pour des échantillons-types non métalliques de l'ISRID: Geostandards Newsletter, v. 2, no. 2, p. 135.

Jecko, Gerard, Ravaine, D., and Wittmann, A., 1980, L'analyse des minerais de fer à l'Institut de Recherches de la Sidérurgie Française: Geostandards Newsletter, v. 4, no. 1, p. 23-31.

Jecko, Gerard, and Ridsdale, P.D., 1978, Euro-standards of steel furnace dusts: Geostandards Newsletter, v. 2, no. 1, p. 23-26.

Jenke, D.R., and Diebold, F.E., 1982, Characterization of phosphorite ores: Analytical Chemistry, v. 54, no. 6, p. 10081011.

John, G.S., Reiss, H., Calkins, V.P., and Larson, C.E., 1945, Practical applications of a mathematical criterion for the sampling of powdered materials: U.S. Atomic Energy Commission, Technical Information Service, Doc. C-0.360.3, 7 p.

Jones, L.C., 1909, Standardized samples: Industrial and Engineering Chemistry, v. 1, no. 4, p. 269.

Joron, J.L., Briqueu, L., Bougault, H., and Treuil, M., 1980, East Pacific rise, Galapagos spreading center and Siqueiros fracture zone, Deep Sea Drilling Project Leg 54: Hygromagmaphile elements-A comparison with the North Atlantic, in Rosendahl, B.R., Hekinian, Roger, and others, eds., Initial Reports of the Deep Sea Drilling Project, v. 54: Washington, D.C., U.S. Government Printing Office, p. 725-735.

Jüptner, Hanns, 1896, The introduction of standard methods of analysis: Iron and Steel Institute Journal, v. 49, no. 1, p. 80-115; Discussion, p. 116-124; Correspondence, p. 124138.

Karpukova, O.M., Shmatova, L.N., and Illarionova, E.N., 1982, $\mathrm{X}$-ray fluorescnece determination of macrocomponents in plant materials: Journal of Analytical Chemistry of the USSR, v. 37, no. 11, pt. 1, p. 1497-1502.

Kato, Yuzo, Onuki, Hitoshi, and Aoki, Ken-ichiro, 1978, Major element analyses on the geochemical standards JA-1 and JB-2: Japanese Association of Mineralogists, Petrologists, and Economic Geologists Journal, v. 73, no. 9, p. 281-282 [in Japanese].

Kayasth, S.R., Iyer, R.K., and Das, M.S., 1980, Preparation of ion exchange resin based elemental standards for use in activation analysis: Part 1. Use of cation exchange resin: Journal of Radioanalytical Chemistry, v. 59, no. 2, p. 373-379.

Keller, W.D., 1955, Oxidation of montmorillonite during laboratory grinding: American Mineralogist, v. 40, no. 3-4, p. 348-349.

Kent, William, 1882, Manganese determinations in steel: American Institute of Mining Engineers Transactions (1881-1882), v. 10, p. 101-111.

Kerr, P.F., and Hamilton, P.K., 1949, Glossary of clay mineral names: Preliminary Report No. 1, American Petroleum Institute Project 49, Clay Mineral Standards, 66 p. 
Khalil, S.R., Koppenaal, D.W., and Ehmann, W.D., 1980, Oxygen concentrations in coal and fly ash standards: Analytical Letters, v. 13, no. A12, p. 1063-1071.

Khitrov, V.G., 1984, Results of certification of the system of standards of the chemical composition of magmatic rocks: Akademiya Nauk SSSR Izvestiya, Seriya Geologicheskaya 1984, no. 11, p. 37-52 [in Russian].

Kita, Itsuro, 1981, A new type ball mill made of Pyrex glass: Geochemical Journal [Japan], v. 15, no. 5, p. 289-291.

Kleeman, A.W., 1967, Sampling error in the chemical analysis of rocks: Geological Society of Australia Journal, v. 14, pt. 1, p. 43-47.

Knechtel, J.R., and Fraser, J.L., 1980, Sludge ash reference sample: Geostandards Newsletter, v. 4, no. 2, p. 213-215.

Knott, A.C., Mills, J.C., and Belcher, C.B., 1978, Synthetic calibration standards for optical emission and $\mathrm{x}$-ray spectrometry: Canadian Journal of Spectroscopy, v. 23, no. 4, p. 105-111.

Koch, O.G., 1978, Standard reference materials for trace analysis. Part 1. Present status of availability and application. Part 2. Available standard reference materials: Pure and Applied Chemistry, v. 50, no. 11-12, p. 1531-1699.

Kolomi'tsev, M.A., Ambardanashvili, T.S., and Dundua, V.Yu., 1974, Comparison standards for neutron activation analysis on a base of phenol-formaldehyde resin: Journal of Radioanalytical Chemistry, v. 20, no. 2, p. 549-557.

Korksch, J., Steffan, I., and Fisk, M.B., 1979, Chemical analysis of manganese nodules. Part IV. Determination of nickel after anion-exchange separation: Analytica Chimica Acta, v. 108, p. 63-68.

Krech, W., Henderson, F.A., and Hjelmstad, K.E., 1974, A standard rock suite for rapid excavation research: U.S. Bureau of Mines Report of Investigations 7865, 29 p.

Kruskal, H., 1960, Some remarks on wild observations: Technometrics, v. 2 , no. 1, p. 1-3.

Kukharenko, A.A., and others, 1968, Clarke values of the Khibiny alkaline massif: Vsesoyuznoye Mineralogicheskoye Obshschestvo Zapiski, v. 97, pt. 2, p. 133-149 [in Russian].

Kuleff, L., 1979, Determination of uranium by neutron activation and radiochemical separation of the tellurium fission product: Analytica Chimica Acta, v. 108, p. 371-374.

Kurasawa, Hajime, 1968, A new silicate rock standard, JB-1, issued from the Geological Survey of Japan: Geochemical Journal [Japan], v. 2, no. 3-4, p. 185.

Kuznetsova, A.I., and Morgulis, T.E., 1983, Emission spectrochemical analysis of mineral samples containing high concentrations of elements with multiline spectra: Journal of Analytical Chemistry of the USSR, v. 37, no. 9, pt. 1 , p. 1222-1226.

Laffitte, Pierre, 1957, Introduction à l'étude des roches métamorphiques et des gîtes métallifères: Physico-chimie et thermodynamique: Paris, France, Masson et Cie, 357 p.

Landis, G.P., 1983, Harding Iceland spar: A new $\delta^{18} \mathrm{O}-\delta^{13} \mathrm{C}$ carbonate standard for hydrothermal minerals: Isotope Geoscience, v. 1, no. 1 (also pub. as: Chemical Geology, v. 41, no. 1), p. 91-94.

Langley, J.W., 1891, International standards for the analysis of iron and steel. Notes on the work of the American Committee: American Institute of Mining Engineers Transactions (18901891), v. 19, p. 614-638.
1892, International standards for the analysis of iron and steel: American Institute of Mining Engineers Transactions (1891), v. 20, p. 242.

1893, Work of the committees on the "international standards for the analysis of iron and steel": American Chemical Society Journal, v. 15 , no. 8, p. 448-454.

Langley, J.W., and Dudley, C.B., 1894a, International standards for the analysis of iron and steel. Subcommittee on methods. Bulletin No. 1. Organization and work of the committee: American Chemical Society Journal, v. 16, no. 2, p. 140142.

-1894b, International standards for the analysis of iron and steel. Subcommittee on methods. Bulletin No. 2. Circular to iron and steel chemists on method of determining phosphorus: American Chemical Society Journal, v. 16, no. 4, p. 286288.

Lanphere, M.A., and Dalrymple, G.B., 1976, Final compilation of $\mathrm{K}-\mathrm{Ar}$ and $\mathrm{Rb}-\mathrm{Sr}$ measurements on $\mathrm{P}-207$, the USGS interlaboratory standard muscovite: U.S. Geological Survey Professional Paper 840, p. 127-130.

Larsen, E.S., 1938, The accuracy of chemical analyses of amphiboles and other silicates: American Journal of Science, 5th Ser., v. 35, p. 94-103.

1948, Batholith and associated rocks of Corona, Elsinore, and San Luis Rey Quadrangles, Southern California: Geological Society of America Memoir 29, 182 p.

Lawrence, D.M., 1980, An atomic spectroscopy bibliography for July-December 1979: Atomic Spectroscopy, v. 1, no. 1, p. 8-29.

Lea, M.C., 1893, On endothermic decompositions obtained by pressure. Second Part. Transformations of energy by shearing stress: American Journal of Science, 3rd Ser., v. 46, no. 276, p. 413-420.

Lechler, P.J., and Leininger, R.K., 1979, Analysis of black shale by ICAP spectroscopy: Jarrell-Ash Plasma Newsletter, v. 2, no. 1 , p. 8-10.

Ledger, E.B., Tieh, T.T., and Rowe, M.W., 1980, Delayedneutron activation determination of uranium in twelve rock reference standards: Geostandards Newsletter, v. 4, no. 2, p. 153-155.

Ledoux, A.R., 1894, A uniform method for the assay of copper materials for gold and silver: American Institute of Mining Engineers Transactions, v. 24, p. 575-582; Discussion, p. 872-877.

Leventhal, J.S., Crock, J.G., Mountjoy, W., Thomas, J.A., Shaw, V.E., Briggs, P.H., Wahlberg, J.S., and Malcolm, M.J., 1978, Preliminary analytical results for a new U.S. Geological Survey Devonan Ohio Shale standard SDO-1: U.S. Geological Survey Open-File Report, 78-447, 11 p.

Leypunskaya, D.I., Drynkin, V.I., Belenky, B.V., Kolomi'tsev, M.A., Dundua, V.Yu., and Pachulia, N.V., 1975, Synthetic multielement standards used for instrumental neutron activation analysis as rock imitations: Journal of Radioanalytical Chemistry, v. 26, no. 2, p. 293-304.

Li, H.H., 1984, Two kinds of standard reference material for archaeometry: Ho Chi Shu [Nucluear Techniques], no. 3 (June 1984), p. 59-60, [in Chinese].

Lister, Brian, 1977, Second inter-laboratory survey of the accuracy of ore analysis: Institution of Mining and Metallurgy Transactions, Sec. B, Applied Earth Science, v. 86, p. B133-B148. 
-1978 , The preparation of twenty ore standards, IGS 20-39. Preliminary work and assessment of analytical data: Geostandards Newsletter, v. 2, no. 2, p. 157-186.

1982, Evaluation of analytical data: A practical guide for geoanalysts: Geostandards Newsletter, v. 6, no. 2, p. 175205.

Lister, Brian, and Gallagher, M.J., 1970, An inter-laboratory survey of the accuracy of ore analysis: Institution of Mining and Metallurgy Transactions, Sec. B, Applied Earth Science, v. 79, p. B213-B237.

Lontsikh, S.V., 1981, The metrology of spectral analysis of disperse substances and materials: Spectrochimica Acta, v. 36B, no. 12 , p. $1177-1184$.

Lontsikh, S.V., and Parshin, A.K., 1980, Standard reference samples of rocks, soils, rare-metal ores, and concentrates: Journal of Analytical Chemistry of the USSR, v. 34, no. 12, pt. 2, p. 1903-1908.

Lontsikh, S.V., Siderovskii, A.I., and Zakovyrin, O.M., 1980, Chemical composition of the ST-1A, SGD-1A, and SG-1A reference rock samples: Journal of Analytical Chemistry of the USSR, v. 34, no. 12, pt. 2, p. 1909-1912.

Loos, G., Heiser, C., and Schäffer, G., 1980, Borbestimmungen in geologischen Materialien: Journal of Radioanalytical Chemistry, v. 58 , no. 1-2, p. 247-256.

Lowell, G.R., and Gasparrini, C., 1982, Composition of arsenopyrite from topaz greisen veins in southeastern Missouri: Mineralium Deposita, v. 17, no. 2, p. 229-238.

Lu, H.J., and Cao, X.J., 1982, Development of PFR-base multielement standards used for NAA: Ho Chi Shu [Nuclear Techniques], no. 4, August 1982, p. 72-73 [in Chinese].

Luth, W.C., and Ingamells, C.O., 1965, Gel preparation of starting materials for hydrothermal experimentation: American Mineralogist, v. 50, no. 1-2, p. 255-258.

Mackenzie, R.C., and Milne, A.A., 1953, The effect of grinding on micas. I. Muscovite: Mineralogical Magazine, v. 30, no. 222 , p. $178-185$.

Malyshev, V.I., Shiryaeva, M.B., Sokolova, Z.A., Lyubimova, L.M., Salmin, Yu.P., Tatarkin, M.A., Ryumina, K.N., and Shelyakina, A.M., 1980, Application of neutron activation analysis to determine the contents and isotopic ratios of elements in rocks and minerals: Journal of Radioanalytical Chemistry, v. 57, no. 2, p. 287-297.

Mandel, John, 1964, The statistical analysis of experimental data: New York, Interscience Publishers, 410 p.

Mandel, John, and Linnig, F.J., 1957, Study of accuracy in chemical analysis using linear calibration curves: Analytical Chemistry, v. 29 , no. 5 , p. $743-749$.

Manheim, F.T., Hathaway, J.C., Flanagan, F.J., and Fletcher, J.D., 1976, Marine mud, MAG-1, from the Gulf of Maine: U.S. Geological Survey Professional Paper 840, p. 25-28.

Marinenko, R.B., Heinrich, K.F.J., and Ruegg, F.C., 1979, Standard reference materials: Micro-homogeneity studies of NBS standard reference materials, NBS research materials, and other related samples: U.S. National Bureau of Standards Special Publication 260-65, 73 p.

Marsh, N.G., Tarney, J., and Hendry, G.L., 1983, Trace element geochemistry of basalts from hole 504B, Panama Basin, Deep Sea Drilling Project legs 69 and 70, Paper 49, in Stout, L.N., and Bailey, M.G., eds., Initial Reports of the Deep Sea Drilling Project, v. 69, p. 747-763.
Matsuhisa, Yukihiro, $1974,{ }^{18} \mathrm{O} /{ }^{16} \mathrm{O}$ ratios of NBS-28 and some silicate reference samples: Geochemical Journal [Japan], v. 8, no. 2, p. 103-107.

Matus, L., Opauszky, I., Nyáry, I., and Pásztor, E., 1981, Low concentration spectroscopic standards by ion implantation: Fresenius Zeitschrift für analytische Chemie, v. 309, no. 4, p. 316-318.

Mauzelius, Robert, 1907, On the determination of ferrous iron in rock analysis: Sveriges Geologiska Undersökning, Ser. C, No. 206, p. 3-11.

Mazzucotelli, Ambrogio, Frache, Roberto, Dadone, Arduino, and Baffi, Franca, 1976, Ion-exchange separation and atomicabsorption determination of fifteen major, mionor, and trace elements in silicates: Talanta, v. 23, no. 11-12, p. 879-882.

Mazzucotelli, Ambrogio, and Vannucci, R., 1980, Candoluminescence emission analysis of cerium in thirty-six international geochemical reference samples: Geostandards Newsletter, v. 4, no. 2 , p. 149-151.

McAdam, R.C., Sutarno, R., and Moloughney, P.E., 1971, Characterization and preparation of standard reference materials that contain noble metals: (A) PTA (Ores) and (B) PTM (Nickel-copper matte): Canada Department of Energy, Mines, and Resources, Mines Branch Technical Bulletin TB 138, 28 p., 3 app.

1973a, Noble-metals-bearing nickel-copper matte PTM: Its characterization and preparation for use as a standard reference material: Canada Department of Energy, Mines, and Resources, Mines Branch Technical Bulletin TB 182, 33 p., 3 app.

1973b, Noble-metals-bearing sulphide concentrate PTC: Its characterization and preparation for use as a standard reference material: Canada Department of Energy, Mines, and Resources, Mines Branch Technical Bulletin TB 176, 26 p., 2 app.

McDonough, W.F., and Nelson, D.O., 1984, Geochemical constraints on magma processes in a peralkaline system: The Paisano volcano, west Texas: Geochimica et Cosmochimica Acta, v. 48, no. 12, p. 2443-2455.

McQuaker, N.R., Brown, D.F., and Kluckner, P.D., 1979, Digestion of environmental materials for analysis by inductively coupled plasma-atomic emission spectrometry: Analytical Chemistry, v. 51, no. 7, p. 1082-1084.

Merritt, W.F., 1980, Gytța, a low-level, high-organic reference material: Environment International, v. 3, no. 5, p. 399-400.

Meyer, A., Hofer, C., Knapp, G., and Tölg, G., 1981, Selenbestimmung im $\mu \mathrm{g} / \mathrm{g}$-Bereich in anorganischen und organischen Matrices nach Verdampfungsanalyse im dynamischen System durch AAS: Fresenius Zeitschrift für analytische Chemie, v. 305 , no. 1 , p. 1-10.

Mika, Josef, 1928, Theoretische Beiträge zur Probenahme: Fresenius Zeitschrift für analytische Chemie, v. 73, no. 7-8, p. 257-264.

Mikeshina, N.G., 1966, The occurrence and elimination of anomalous values (Review): Industrial Laboratory, v. 32, no. 3, p. 381-391.

Mitchell, J.W., Blitzer, L.D., Kometani, T.Y., Gills, T., and Clark, L., Jr., 1977, Homogeneously doped silica matrix for trace element standards in neutron activation analysis: Journal of Radioanalytical Chemistry, v. 39, no. 1-2, p. 335-342.

Mohler, F.L., 1955, Reference samples of isotopic abundance: Science, v. 122 , no. 3164 , p. 334-335. 
Montgomery, Arthur, 1950, Geochemistry of tantalum in the Harding pegmatite, Taos County, New Mexico: American Mineralogist, v. 35, no. 9-10, p. 853-866.

Moore, D.M., 1978, A sample of the Purington shale prepared as a geochemical standard: Journal of Sedimentary Petrology, $v$. 48, no. 3, p. 995-998.

Moore, F., 1979, Some statistical calculations concerning the determination of trace constitutents: Geostandards Newsletter, v. 3 , no. 2 , p. 105-108.

Mori, Takeshi, 1983, Standards for electron-probe analysis: Volcanological Society of Japan Bulletin, v. 28 , no. 3, p. 225 232 [in Japanese].

Müller, Georg, and Strauss, K.W., 1984, Tremolite from Nord Talgje, Boknfjord, South Norway: A microprobe standard: Neues Jahrbuch für Mineralogie Monatschefte, Jahrgang 1984 , no. 12 , p. $543-546$.

Myasoedova, G.V., Antokolskaya, I.I., Shvoeva, O.P., Bolshakova, L.I., and Savvin, S.B., 1976, A selective sorbent for concentrating noble metals: Talanta, v. 23, no. 11-12, p. 866-868.

Myers, A.T., Havens, R.G., Connor, J.J., Conklin, N.M., and Rose, H.J., Jr., 1976, Glass reference standards for the traceelement analysis of geological materials-Compilation of interlaboratory data: U.S. Geological Survey Professional Paper 1013, 29 p.

Myers, A.T., Havens, R.G., and Dunton, P.J., 1961, A spectrochemical method for the semiquantitative analysis of rocks, minerals, and ores: U.S. Geological Survey Bulletin 1084-I, p. 207-229.

Myers, A.T., Havens, R.G., and Niles, W.W., 1970, Glass reference standards for trace element analysis of geologic materials, in Grove, E.L., ed., Developments in applied spectroscopy, v. 8: New York, Plenum Press, p. 132-137.

Nakahara, H., Tsukada, M., Moriizumi, A., Horiuchi, K., and Murakami, Y., 1982, Matrix effects on epithermal neutron activation analysis of various kinds of reference materials: Journal of Radioanalytical Chemistry, v. 72, no. 1-2, p. 377-391.

Nalobin, D.P., Shafrinskii, Yu.S., and Sidorov, A.A., 1980, Dependence of interlaboratory deviations on the concentration of the components with a determination of the chemical composition of vegetable materials: Journal of Analytical Chemistry of the USSR, v. 35, no. 6, pt. 2, p. 812-814.

[National] Bureau of Standards, 1910, Standard Analyzed Samples-General Information: Circular 25, 13 p.

Natrella, M.G., 1969, Characterizing linear relationships between two variables, in Ku, H.H., ed., Precision measurement and calibration-Selected NBS papers on statistical concepts and procedures: U.S. National Bureau of Standards Special Publication 300, v. 1, p. 204-249.

Neider, J.A., 1975, National RM programs in Germany (FRG), in Seward, R.W., ed., Standard reference materials and meaningful measurements: U.S. National Bureau of Standards Special Publication 408, p. 167-188.

Neuman, Henrich, 1956, A pulverizer for micas and micaceous minerals: Norsk Geologisk Tidsskrift, v. 36, p. 52-54.

Nier, A.O., 1950, A redetermination of the relative abundances of the isotopes of carbon, nitrogen, oxygen, argon, and potassium: Physical Review, v. 77, no. 6, p. 789-793.
Nockolds, S.R., 1954, Average chemical compositions of some igneous rocks: Geological Society of America Bulletin, v. 65, no. 10 , p. $1007-1032$.

Odin, G.S., 1976, La glauconite GL-O, étalon inter-laboratoires pour l'analyse radiochronométrique: Analusis, v. 4, no. 6, p. 287-291.

Odin, G.S., and others, 1982, Interlaboratory standards for dating purposes, in Odin, G.S., ed., Numerical dating in stratigraphy: New York Wiley, p. 123-150.

Okamoto, Kensaku, Yamamoto, Yuko, and Fuwa, Keiichiro, 1978, Pepperbush powder, a new standard reference material: Analytical Chemistry, v. 50, no. 13, p. 1950-1951.

Olson, D.G., 1980, Synthesized standards in natural matrices: Environment International, v. 3, no. 3, p. 271-273.

Ostroumov, G.V., 1979, Cooperation of COMECOM [CMEA] member nations in the analysis of minerals: Industrial Laboratory, v. 45, no. 9, p. 963-966.

Palmer, Kenneth, Kennedy, P.C., and Rosen, Barry, 1983, X-ray fluorescence determination of trace elements in 6 B.C.S. and 5 P.R.E. reference materials: Geostandards Newsletter, v. 7 , no. 2, p. 301-303.

Parker, A., 1977, Is there a need for sedimentary rock reference samples?: Geostandards Newsletter, v. 1, no. 2, p. 147.

Pearson, E.S., and Hartley, H.O., 1956, Biometrika tables for statisticians, v. 1: Cambridge, The University Press, 238 p.

Pérez R., Jose, Pal, Surendra, Terrell, D.J., Urrutia F., Jaime, and Lopez M., Margarita, 1979, Preliminary report on the analysis of some "in-house" geochemical reference samples from Mexico: Geofisica Internacional, v. 18, no. 2, p. 197-209.

Perlman, I., and Asaro, F., 1969, Pottery analysis by neutron activation: Archaeometry, v. 11, no. 1, p. 21-52.

Pigeat, G., and Lahanier, C., 1974, Étude coopérative de cinq étalons de céramiques preparés au Centre de Recherches Archéologiques Mediévales de l'Université de Caen: Societe Française de Céramique Bulletin, no. 105, p. 47-63.

Pinta, M., 1977a, Echantillons de référence pour l'analyse végétale: 1. Azote, phosphore, potassium, calcium, magnésium, manganèse, zinc: Geostandards Newsletter, v. 1, no. 1, p. 25-30.

1977b, Echantillons de référence pour l'analyze végétale: 2. Sodium, chlore, soufre, bore, oligo-élements: Geostandards Newslettter, v. 1, no. 2, p. 115-121.

Pirsson, L.V., 1918, The rise of petrology as a science, in Dana, E.S., and others, A century of science in America, with special reference to the American Journal of Science, 18181918: New Haven, Yale University Press, 458 p.

Plebanksi, T., 1975, National SRM programs in Poland, in Seward, R.W., ed., Standard reference materials and meaningful measurements: National Bureau of Standards Special Publication 408, p. 201-223.

ed., 1979, Physicochemical Certified Reference Materials (WZORMAT's Guide Book): Warsaw, Wydawnictwa Normalizacyjne, 57 p. [title and discussion of standards in Polish and English].

Pohl, H. , and Oberhauser, R., 1978, German standards of iron ore: Geostandards Newsletter, v. 2, no. 1, p. 27-30.

Potts, P.J., 1983, Proposal for the adoption of a microgranite from Ailsa Craig, S.W. Scotland, as a trace element rock reference sample: Geostandards Newsletter, v. 7, no. 2, p. 345-346. 
Potts, P.J., Thorpe, O.W., and Watson, J.S., 1981, Determination of the rare-earth element abundances in 29 international rock standards by instrumental neutron activation analysis: A critical appraisal of calibration errors: Chemical Geology, v. 34, no. 1, p. 331-352.

Prescott, P., 1979, Critical values for a sequential test for many outliers: Applied Statistics, v. 28, no. 1, p. 36-39.

Rakovskii, E.E., Krylova, T.D., Kuligin, V.M., Bol'shakova, L.I., Myasoedova, G.V., and Savvin, S.B., 1980, Polymerbased reference standards for neutron-activation analysis: Journal of Analytical Chemistry of the USSR, v. 35, no. 12, pt. 2, p. 1553-1556.

Rasberry, Stanley, 1981, Reference materials from Brazil: American Laboratory, v. 13 , no. 4 , p. 89.

Raymond, R.W., 1895, Assays of copper and copper matte: American Institute of Mining Engineers Transactions, v. 25, p. 250-292; Discussion, p. 1000-1010.

Reay, A., 1981, The effect of disc mill grinding on some rockforming minerals: Mineralogical Magazine, v. 44, no. 334, p. 179-182.

Reddy, G.R., Pant, D.R., and Das, M.S., 1982, Uranium content of thirty-three rock reference samples determined by the delayed fission neutron counting method: Geostandards Newsletter, v. 6, no. 2, p. 217-219.

Reed, S.A., 1882, Ore sampling: School of Mines Quarterly, v. 3, no. 4 , p. $253-259$.

1885, More remarks on ore sampling: School of Mines Quarterly, v. 6, no. 4, p. 351-358.

Reiss, H., John, G.S., Calkins, V.P., and Larson, C.E., 1945, A mathematical criterion for the sampling of powdered materials: U.S. Atomic Energy Commission, Technical Information Service, Doc. C-O.360.4, 15 p.

Richards, R.H., 1903, Ore dressing: New York, The Engineering and Mining Journal, v. 2, p. 644-1236.

Richardson, Clifford, ed., 1886, Methods of analysis of commercial fertilizers-Proceedings of the Third Annual Convention of the Association of Official Agricultural Chemists, Washington, D.C., August 26-27, 1886: Washington, D.C., U.S. Department of Agriculture, Division of Chemistry, Bulletin $12,59 \mathrm{p}$.

1902, Report of the Sub-Committee on Uniformity in Analysis of Materials for the Portland Cement Industry: Society of Chemical Industry Journal, v. 21, no. 1, p. 12-30 (January $15,1902)$.

Ridsdale, C.H., and Ridsdale, N.D., 1919, Notes on chemical standards and their bearing on the unification of analysis: Society of Chemical Industry Transactions, v. 38, no. 3, p. $15 \mathrm{~T}-26 \mathrm{~T}$.

Ritchie, J.A., 1968, Effect of metallic iron from grinding on ferrous iron determinations: Geochimica et Cosmochimica Acta, v. 32 , no. 12 , p. $1363-1366$.

Roche, H. de la, and Govindaraju, Kuppusami, 1971, Rapport sur un minerai d'aluminum bauxite $\mathrm{BX}-\mathrm{N}$ et sur un réfractaire silico-aluminex disthène $\mathrm{DT}-\mathrm{N}$ proposés comme étalons analytiques: Société Française de Céramique Bulletin, v. 90, p. 3-19.

1973, Étude coopérative sur un verre synthétique VS-N proposé comme étalon analytique pour le dosage des éléments en traces dans les silicates: Analusis, v. 2 , no. 1, p. 59-70.
1976, Nouveaux étalons géochimiques: Granite GS-N et feldspath FK-N: Analusis, v. 4, no. 8, p. 347-372.

Roche, H. de la, Govindaraju, Kuppusami, and Odin, G.S., 1976, Préparation d'un étalon analytique de glauconite: Analusis, v. 4, no. 9, p. 385-397.

Roddick, J.C., 1983, High precision intercalibration of ${ }^{40} \mathrm{Ar}-{ }^{39} \mathrm{Ar}$ standards: Geochimica et Cosmochimica Acta, v. 47, no. 5, p. 887-898.

Rojas, F., 1984, Preparación y certificación de una muestra de referencia de roca cuarzo sulfurosa: Cuba, Centro de Investigaciones Geologicas, Serie Geologica 1984, no. 2, p. 2534.

Rojas Pimentel, Fabio, 1984, Preparación y certificación de tres muestras de referencias de bauxitas: Cuba, Centro de Investigaciones Geologicas, Serie Geologica 1984, no. 1, p. 3-11.

Rose, A.W., Hawkes, H.E., and Webb, J.S., 1979, Geochemistry in mineral exploration, 2nd ed.: New York, Academic Press, $657 \mathrm{p}$.

Rose H.J., Jr., Adler, Isidore, and Flanagan, F.J., 1963, X-ray fluorescence analysis of the light elements in rocks and minerals: Applied Spectroscopy, v. 17, no. 4, p. 81-85.

Rosholt, J.N., Prijana, and Noble, D.C., 1971, Mobility of uranium and thorium in glassy and crystallized silicic volcanic rocks: Economic Geology, v. 66, no. 7, p. 1061-1069.

Rosner, Bernard, 1975, On the detection of many outliers: Technometrics, v. 17 , no. 2 , p. 221-227.

Roubault, Marcel, Roche, H. de la, and Govindaraju, Kuppusami, 1966, Rapport sur quatre roches étalons géochimiques: Granites GR, GA, GH, et basalte BR: Sciences de la Terre, v. 11, no. 1, p. $105-121$.

Roy, Rustum, 1956, Aids in hydrothermal experimentation: II, Methods of making mixtures for both "dry" and "wet" phase equilibrium studies: American Ceramic Society Journal, v. 39 , no. 4 , p. $145-146$.

Russell, D.S., 1984, Available standards for use in the analysis of marine materials: National Research Council of Canada, Marine Analytical Chemistry Standards Program Report No. 8, NRCC No. 23025, 35 p.

Samter, V., 1908, Theorie und Praxis der Probenahme körniger Materialien (Erze): Chemiker-Zeitung, v. 32, p. 1209-1210.

Savinova, E.N., Korobova, E.M., and Shumskaya, T.V., 1981, Direct simultaneous spectrographic determination of copper, cobalt, and molybdenum in soils and plants: Journal of Analytical Chemistry of the USSR, v. 36 , no. 7 , pt. 1, p. $883-$ 886.

Scheaffer, R.L., 1971, A test for the homogeneity of a mixture: Techometrics, v. 13 , no. 2 , p. 325-331.

Schindler, Rolf, 1972, Die Standardgesteinsproben des ZGI: 5. Mitteilung: Stand der Spurenelementanalyse der Gesteine GM, TB, BM, und KH: Zeitschrift für angewandte Geologie, v. 18 , no. 5 , p. $221-228$.

Schindler, Rolf, and Scheutzow, Rudi, 1975, Entwicklung und Anwendung von Standardproben für die Spurenelementanalyse mineralischer Rohstoffe: Zeitschrifte für angewandte Geologie, v. 21, no. 3, p. 130-136.

Schlesinger, M.D., Nazuruk, S., and Reggel, Leslie, 1963, Laboratory cylinder-mill for small samples: Journal of Chemical Education, v. 40 , no. 10 , p. 546.

Schmitt, B.F., Segebade, Chr., and Fusban, H.-U., 1980, Waste incineration ash-A versatile environmental reference mate- 
rial: Journal of Radioanalytical Chemistry, v. 60, no. 1, p. 99-109.

Schorin, Hasso, and LaBrecque, J.J., 1983, A laterite standard reference material: Venezuelan laterite, VL-1: Geostandards Newsletter, v. 7, no. 1, p. 233-242.

Schramel, P., and Xu, L.O., 1982, Determination of beryllium in the parts-per-billion range in three standard reference materials by inductively coupled plasma atomic emission spectrometry: Analytical Chemistry, v. 54, no. 8, p. 1333-1336.

Schroll, Erich, 1975, Analytische Geochemie. Band I: Methodik: Stuttgart, Ferdinand Enke Verlag, 292 p.

-1977, Working Group-Eastern Alps [Announcement]: Geostandards Newsletter, v. 1, no. 1, p. 101

Schrön, Werner, Rösler, H.-J., and others, 1975, Drei neue geochemisch-mineralogische Komplexstandards, Galen GF-1, Sphalerit SF-1 und Pyrit PS-1: Zeitschrift für angewandte Geologie, v. 21, no. 1, p. 17-25.

Schulz, R.K., Tompkins, G.A., and Babcock, K.L., 1976, Uptake of plutonium and americium by plants from soils: Uptake by wheat from various soils and effect of oxidation state of plutonium added to soil, in Proceedings of the Symposium on Transuranium Nuclides in the Environment: International Atomic Energy Agency, Vienna, Austria, p. 303-310.

Scilla, G.J., and Morrison, G.H., 1977, Sampling error in ion microprobe analysis: Analytical Chemistry, v. 49, no. 11, p. 1529-1536.

Senftle, F.E., Thorpe, A.N., Alexander, C.C., and Finkelman, R.B., 1982, Ferromagnetic and superparamagnetic contamination in pulverized coal: Fuel, v. 61, p. 81-86.

Serrini, G., 1981, Moroccan phosphate rock as a BCR reference material: Geostandards Newsletter, v. 5, no. 1, p. 83-85.

Shafrinskii, Yu.S., 1977, Development of standard samples for plant materials: Journal of Analytical Chemistry of the USSR, v. 32 , no. 7 , pt. 2 , p. 1169-1170.

Shimp, N.F., Connor, Jane, Prince, A.L., and Bear, F.E., 1957, Spectrochemical analysis of soils and biological materials: Soil Science, v. 83, no. 1, p. 51-64.

Sill, C.W., and Hindman, F.D., 1974, Preparation and testing of standard soils containing known quantities of radionuclides: Analytical Chemistry, v. 46, no. 1, p. 113-118.

Sine, N.M., Taylor, W.O., Webber, G.R., and Lewis, C.L., 1969, Third report of analytical data for CAAS sulfide ore and syenite rock standards: Geochimica et Cosochimica Acta, v. 33, no. 1, p. 121-131.

Smellie, J.A.T., 1972, Preparation of glass standards for use in X-ray microanalysis: Mineralogical Magazine, v. 38, no. 297, p. 614-617.

Smellie, J.A.T., Cogger, N., and Herrington, J., 1978, Standards for quantitative microprobe determination of uranium and thorium with additional information on the chemical formulae of davidite and euxenite-polycrase: Chemical Geology, v. 22, no. 1 , p. 1-10.

Smith, Thorn, 1903, Report on a co-operative chemical analysis of a copper slag: Engineering and Mining Journal, v. 75, no. 8, p. 295-297.

Snow, R.H., Kaye, B.H., Capes, C.E., Conley, R.F., Sheehan, Joseph, Schwarzkopf, Florian, and Pietsch, W.B., 1973, Size reduction and size enlargement, Section 8 in Perry, R.H., and Chilton, C.H., eds., Chemical Engineers' Handbook, 5th ed., New York, McGraw-Hill, variously paginated.
Sobornov, O.P., 1977, Radioelements in the standard rock samples: Geochemistry International, v. 14, no. 6, p. 71-81.

1983, Uranium, thorium and potassium in reference samples of rocks: Geokhimiya, no. 3, p. 429-437 [in Russian].

Society of Glass Technology, 1980, Standard samples of glasses and sands: Geostandards Newsletter, v. 4, no. 1, p. 142.

Stanger, W.H., and Blount, Bertram, 1902, The proposed standardisation of cement analysis: Society of Chemical Industry Journal, v. 21, no. 19, p. 1216-1223.

Steele, T.W., 1978, A guide to the reporting of analytical results relating to the certification of geological reference materials: Geostandards Newsletter, v. 2, no. 1, p. 31-33.

Steele, T.W., and Hansen, R.G., 1979, Major element data (1966-1978) for the six "Nimroc" reference samples: Geostandards Newsletter, v. 3, no. 2, p. 135-172.

Steele, T.W., Levin, J., and Copelowitz, I., 1975, The preparation and certification of a reference sample of a preciousmetal ore: National Institute for Metallurgy, Randburg 2125, South Africa, Report No. 1696, 50 p.

Steele, T.W., Wilson, A., Goudvis, R., Ellis, P.J., and Radford, A.J., 1978, Trace element data (1966-1977) for the six "Nimroc" reference samples: Geostandards Newsletter, v. 2, no. 1, p. 71-106.

Steger, H.F., 1980, Certified reference materials: Canada Centre for Mineral and Energy Technology, CANMET Report 80$6 \mathrm{E}, 30 \mathrm{p}$.

1981, The new certification procedure of the Canadian Certified Reference Materials Project: Geostandards Newsletter, v. 5, no. 2, p. 189-193.

1982, The rejection of RU-1 due to ambient oxidation: Geostandards Newsletter, v. 6, no. 2, p. 249-255.

1983, Certified reference materials: Canada Centre for Mineral and Energy Technology, CANMET Report 83-3E, $35 \mathrm{p}$.

Steger, H.F., and Bowman, W.S., 1984, KC-1a: A certified reference ore: Canada Centre for Mineral and Energy Technology, CANMET Report 84-6E, 16 p.

Steger, H.F., Bowman, W.S., McDonnell, B.D., and Pupp, C., 1981, PD-1: A certified non-ferrous reference dust: Canada Centre for Mineral and Energy Technology, CANMET Report 81-7E, 9 p., 2 app.

Steger, H.F., Bowman, W.S., Sutarno, R., and Faye, G.H., compilers, 1975, Iron ore SCH-1: Its characterization and preparation for use as a certified reference material: Canada Centre for Mineral and Energy Technology, CANMET Report MRP/ MSL 75-168 (TR), 17 p.

Steger, H.F., and Smith, C.W., 1984, Uranium tailings samples UTS-1 to UTS-4 of CCRMP: Geostandards Newsletter, v. 8, no. 1, p. 57-59.

Steinnes, E., 1981, Reference materials for trace analysis by radioanalytical methods: U.S. Geological Survey rock standards: Pure and Applied Chemistry, v. 53, no. 4, p. 903-908.

Stern, W.B., 1969, On the chemical composition of anorthoclase from Mt. Kibo/Kilimanjaro (Tanzania): Contributions to Mineralogy and Petrology, v. 20, no. 2, p. 198-202.

Stevens, R.E., and Niles, W.W., 1960, Chemical analyses of the granite and the diabase: Pt. 1 in Stevens, R.E. and others, Second report on a cooperative investigation of the composition of two silicate rocks: U.S. Geological Survey Bulletin 1113. 
Stillman, T.B., 1893, The chemical and physical examination of Portland cement: American Chemical Society Journal, v. 15, no. 4 , p. $181-190$.

1894, The chemical and physical examination of Portland cement: American Chemical Society Journal, v. 16, no. 3, p. 161-173; no. 4 , p. $283-286$; no. 5 , p. $323-332$; no. 6 , p. 374-385.

Stoch, Harry, 1974a, The establishment of preferred values for a series of fluorspar samples: National Institute for Metallurgy, Randburg 2125, South Africa Report no. 1649, 29 p.

1974b, An interlaboratory analysis of two ferrochromium slags: National Institute for Metallurgy, Randburg 2125, South Africa Report no. 1609, 31 p.

1978a, The preparation and certification of a reference sample of hematite ore: National Institute for Metallurgy, Randburg 2125, South Africa Report no. 1977, 43 p.

$-1978 \mathrm{~b}$, The preparation and certification of a reference sample of magnetite ore: National Institute for Metallurgy, Randburg 2125, South Africa Report no. 1978, 44 p.

Stoch, Harry, and Steele, T.W., 1978, Analyses, by several laboratories, of three ferromanganese slags: National Institute for Metallurgy, Randburg 2125, South Africa Report no. 1965, $34 \mathrm{p}$.

Stoch, Harry, Steele, T.W., and Copelowitz, I., 1976, The establishment of preferred values for a series of rare-earth samples: National Institute for Metallurgy, Randburg 2125, South Africa Report no. 1807, 35 p.

Stoch, Harry, Steele, T.W., and Rankin, R.S., 1979, The preparation and certification of two samples of chromium ore: Geostandards Newsletter, v. 3, no. 1, p. 25-45.

Stone, G.C., and Waring, W.G., 1907, Report of the subcommittee on zinc ore analysis (Contribution from the Committee on Uniformity in Technical Analysis): American Chemical Society Journal, v. 29, no. 3, p. 262-269.

Su, H.Y., and Zhang, S.X., 1984, China's first batch of environmental standard reference materials-River sediment, coal [fly ash], and peach leaves analysed by INAA: Ho Chi Shu [Nuclear Techniques], no. 3, June 1984, p. 51-53 [in Chinese].

Sun, F.T., Cao, R.S., and Gu, Qi Zhen, 1982, Determination of implantation profiles of phosphorus in silicon with neutron activation analysis: Ho Chi Shu [Nuclear Techniques], no. 4, August 1982, p. 76-78 [in Chinese].

Sun, J.X., Chen, B.R., Wang, Y.Q., and Zhang, Y.J., 1984, Instrumental neutron activation analysis of Chinese environmental standard reference materials - peach leaves, coal fly ash, and sediment: Ho Chi Shu [Nuclear Techniques], no. 3, June 1984, p. 53-54 [in Chinese].

Suschny, Otto, and Richman, D.M., 1975, The analytical quality control programme of the International Atomic Energy Agency, in Seward, R.W., ed., Standard reference materials and meaningful measurements: U.S. National Bureau of Standards Special Publication 408, p. 74-102.

Sutarno, R., Charette, D.J., Bowman, W.S., and Faye, G.H., 1978, Certification of reference iron ore $\mathrm{SCH}-1$ for sodium and potassium: Canada Centre for Mineral and Energy Technology, CANMET Report No. 78-5, 8 p.

Sutarno, R., and Faye, G.H., 1975, A measure for assessing certified reference ores and related materials: Talanta, v. 22, no. 8 , p. $675-681$.
Taggart, A.F., 1927, Handbook of ore dressing: New York, Wiley, $1679 \mathrm{p}$.

1945, Handbook of mineral dressing: Ores and industrial minerals: New York, Wiley, variously paged.

Tauson, L.V., Lontsikh, S.V., Shafrinskii, Yu.S., Kozlov, V.D., and Kochetkova, L.F., 1976, Geochemical standards of magmatic rocks: Academy of Sciences of the USSR, Siberian Branch, Institute of Geochemistry, Yearbook 1974, p. 370375 [in Russian].

Taylor, S.R., and Kolbe, P., 1964, Geochemical standards: Geochimica et Cosmochimica Acta, v. 28, no. 4, p. 447454.

Terashima, Shigeru, 1979, Determination of total carbon and sulfur in forty-two geochemical reference samples by combustion and infrared spectrometry: Geostandards Newsletter, v. 3, no. 2, p. 195-198.

Terashima, Shigeru, Yamashige, Takashi, and Ando, Atsushi, 1984, Determination of major and minor elements on the six GSJ rock reference samples: Geological Survey of Japan Bulletin, v. 35, no. 4, p. 171-177.

Thomas, W.K.L., and Kempe, D.R.C., 1963, Standard geochemical sample T-1, Msusule Tonalite, Supplement No. 1; Part 1, Chemical analysis of T-1, by W.K.L. Thomas, p. 1-4; Part 2, Modal analysis of T-1, by D.R.C. Kempe, p. 5-6: Dar es Salaam, Government Printer.

Thompson, Geoffrey, and Bankston, D.C., 1970, Sample contamination from grinding and sieving determined by emission spectrometry: Applied Spectroscopy, v. 24, no. 2, p. 210219.

Tietjen, G.J., and Moore, R.H., 1972, Some Grubbs-type statistics for the detection of several outliers: Technometrics, v. 14, no. 3, p. 583-597.

Tong, C.H., Zhou, R.S., You, Jun, Guan, H.G., Wang, Y.L., and Schmitt, R.A., 1984, The preparation of the sub-standard [secondary?] reference sample, S-CRB: Ho Chi Shu [Nuclear Techniques], no. 3, June 1984, p. 58-59 [in Chinese].

Troll, G., and Farzaneh, A., 1978, Determination of fluorine and total water in thirty-three international geochemical reference samples: Geostandards Newsletter, v. 2, no. 1, p. 43-47.

1980, Fluorine in some CII biological reference samples and fluorine losses during ashing: Geostandards Newsletter, v. 4 , no. 1 , p. $39-41$.

Tu, Shu De, and Lieser, K.H., 1984a, Homogeneity test of Chinese biological standard reference material by means of instrument neutron activation analaysis: Journal of Radioanalytical and Nuclear Chemistry, v. 84, no. 2, p. 301-306.

1984b, Homogeneity test of Chinese standard reference material (peach leaves) by means of instrumental neutron activation analysis: Ho Chi Shu [Nuclear Techniques], no. 3 (June 1984), p. 49-51, [in Chinese].

Turekian, K.K., and Carr, M.H., 1961, Chromium, cobalt and strontium in some Bureau of Standards rock reference samples: Geochimica et Cosmochimica Acta, v. 24, no. 1-2, p. 1-9.

Uchida, Hiroshi, Uchida, Tetsuo, and Iida, Chuzo, 1979, Determination of major and minor elements in silicates by inductively coupled plasma emission spectrometry: Analytica Chimica Acta, v. 108, p. 87-92.

U.S. Geological Survey, 1970, Mercury in the environment: U.S. Geological Survey Professional Paper 713, 67 p. 
Valcha, Zdeněk, 1977, Information on geochemical standard reference materials of the CMEA countries: Geostandards Newsletter, v. 1, no. 2, p. 111-113.

1979, Czechoslovak analytical standards of rocks and mineral raw materials; Reference standard material of magnesite (Kŏsice): Sborník Geologických Věd; Technologie, Geochemie, v. 16, p. 85-98.

van der Sloot, H.A., and Zonderhuis, J., 1979, Instrumental neutron activation analysis of 37 geochemical reference samples: Geostandards Newsletter, v. 3, no. 2, p. 185-193.

Van Olphen, H., and Fripiat, J.J., 1979, Data handbook for clay materials and other non-metallic minerals: New York, Pergamon Press, $346 \mathrm{p}$.

Victor, A.H., 1983, Accurate determination of copper in South African primary and secondary reference samples by cation exchange chromatography and atomic absorption spectrometry: Geostandards Newsletter, v. 7, no. 1, p. 227-232.

Visman, J., 1962, Towards a common basis for the sampling of materials: Canada Department of Mines and Technical Surveys, Mines Branch Research Report R93, 39 p. 1969, A general sampling theory: Materials Research and Standards, November 1969 , p. 8-13, 51-56, 62, 64, 66.

Volchok, H.L., and Feiner, Melvin, 1979, A radioanalytical laboratory intercomparison exercise: U.S. Department of Energy, Environmental Measurements Laboratory [Report] EML$366,43 \mathrm{p}$

Volchok, H.L., Feiner, Melvin, Inn, K.L.G.W., and McInroy, J.F., 1980, Development of some natural matrix standardsProgress report: Environment International, v. 3, no. 5, p. 395-398.

Volchok, H.L., and Matuszek, J.M., 1980, Comments: Synthesized standards in natural matrices: Environment International, v. 3, no. 3, p. 272-273.

Wainerdi, R.E., 1979, Reference material for trace analysis by radioanalytical methods: Bowen's kale: Pure and Applied Chemistry, v. 51, no. 5, p. 1183-1193.

Wang, S.S., 1983, [Age determinations by ${ }^{40} \mathrm{Ar}-{ }^{40} \mathrm{~K}$ and ${ }^{40} \mathrm{Ar}-$ ${ }^{39} \mathrm{Ar}$, and radiogenic ${ }^{40} \mathrm{Ar}$ release characteristics on potassium-argon geostandards of China]: Dizhi Kexue [Scientia Geologica Sinica] no. 4, p. 315-323 [in Chinese with English abstract].
Washington, H.S., 1903, Chemical analyses of igenous rocks published from 1884 to 1900 , with a critical discussion of the character and use of analyses: U.S. Geological Survey Professional Paper 14, 495 p.

Webber, G.R., 1965, Second report of analytical data for CAAS syenite and sulfide standards: Geochimica et Cosmochimica Acta, v. 29 , no. 4 , p. 229-248.

Wickman, F.E., 1963, The amount of material necessary for a trace element analysis: Arkiv för Mineralogi och Geologi, v. 3 , no. 2, p. 131-139.

Wilson, A.D., 1964, The sampling of silicate rock powders for chemical analysis: Analyst, v. 89, no. 1054, p. 18-30.

Wit, J.C. de, Straaten, C.M. van der, and Mook, W.G., 1980, Determination of the absolute hydrogen isotopic ratio of $\mathrm{V}-$ SMOW and SLAP: Geostandards Newsletter, v. 4, no. 1, p. 33-36.

Wu, Y.G., Wang, X.F., and Deng, Z.W., 1982, Measurement by neutron-activation analysis of the dose and concentration distribution of As ion-implanted in silicon: Ho Chi Shu [Nuclear Techniques], no. 4, August 1982, p. 68-69 [in Chinese].

Yang, Z.Z., and Liu, X.C., 1983, Seven standard ore samples of uranium, thorium, and radium prepared by the Bureau of Uranium Geology (China): Geostandards Newsletter, v. 7, no. 2, p. 251-260.

Yuan, Ling, and Chen, B.G., 1982, Instrumental neutron activation analysis of eight geological standard reference samples: Ho Chi Shu [Nuclear Techniques], no. 4, August 1982, p. 32-34 [in Chinese].

Zhang, Y.J., Zhao, M.Z., Jing, Tao, and Yan, Z.H., 1982, Primary ITNA [instrumental thermal neutron activation] results of the first release of geochemical standards in China: Ho Chi Shu [Nuclear Techniques], no. 4 (August 1982), p. 30-32 [in Chinese].

Zhao, M.Z., 1984, The analysis of the second grade [secondary ?] standard samples of geochemical stream sediments in province Gilin by INAA: Ho Chi Shu [Nuclear Techniques], no. 3 (June 1984), p. 56-58 [in Chinese].

Zvyagintsev, A.M., 1983, Standard samples for the quality control of forage and plant analysis: Journal of Analytical Chemistry of the USSR, v. 37 , no. 10 , pt. 2 , p. 1482-1484. 

